\title{
Zweiter Beratungsgegenstand: \\ Staatsaufgabe Umweltschutz
}

1. Bericht von Professor Dr. Dietrich Rauschning, Göttingen

Inhalt

Seite

I. Aufgabe Umweltschutz . . . . . . . . . . . . . . 168

II. Erwägungen der allgemeinen Staatslehre zum staatlichen Umweltschutz . . . . . . . . . . . . . . . . . 170

III. Völkerrechtliche Pflicht zum Umweltschutz . . . . . . 172

IV. Verfassungspflicht zum Umweltschutz . . . . . . . . 177

1. Fehlen einer allgemeinen Umweltschutzbestimmung . . 177

2. Umweltschutzrechtliche Teilgewährleistungen in Grundrechten . . . . . . . . . . . . . . . . . . . 179

a) Schutzbereich der umweltrelevanten Grundrechte . . 179

b) Wirkrichtung der Umweltgrundrechte . . . . . . 181

3. Umweltschutzaufgabe aus der Sozialstaatsklausel? . . 185

V. Umweltschutzbemühungen in der Bundesrepublik

Deutschland . . . . . . . . . . . 186

VI. Entscheidungskompetenzen über Intensität von Umweltschutzanforderungen . . . . . . . . . . . . . . 188

1. Bindung und Entscheidungskompetenz des Gesetzgebers 189

a) Grenzen der Bindung durch das grundrechtliche Schutzgebot . . . . . . . . . . . . . . 189

b) Bindungen durch das Verhältnismäßigkeitsgebot und den Gleichheitssatz . . . . . . . . . . . . . 194

2. Entscheidungsbereich der Exekutive . . . . . . . . 199

3. Entscheidungen über die Intensität des Umweltschutzes durch die Verwaltungsgerichtsbarkeit . . . . . . . 201

4. Aufgabenverteilung nach Gefahrenabwehr und Risikovorsorge . . . . . . . . . . . . . . . 
„Seid fruchtbar und mehret euch und füllet die Erde und machet sie euch untertan..."

Von dieser Legitimation oder in öffentlich rechtlicher Terminologie so zu bezeichnenden Ermächtigung aus der Schöpfungsgeschichte hat der Mensch einen nahezu erschöpfenden Gebrauch gemacht; er hat die Gefahr heraufbeschworen, die Erde zu erschöpfen. So wird der Menschheit zunehmend bewußt die Aufgabe, die in der Genesis deutlicher für das Paradies genannt ist, die - in unserem Denken wenigstens analog - für die Erde gilt:

„Und der Herr nahm den Menschen und setzte ihn in den Garten Eden, daß er ihn baute und bewahrte."

Hiermit mögen die Grundprobleme von Umweltbelastung und Umweltschutz umschrieben sein.

\section{Aufgabe Umweltschutz}

Der Mensch nutzt seine ökologische Umwelt ${ }^{1}$

- als Rohstoffquelle für Produktion und Konsum

- als Aufnahmemedium für Abfallstoffe und -energien, die bei seinen Aktivitäten in Produktion und Konsum anfallen, und

- als Regenerationspotential.

Die anthropogenen Belastungen der Umwelt stellen sich dar als die Kehrseite der Umweltnutzung; - sie sind bestimmt von deren Art und Intensität ${ }^{2}$. Ist aber auch die uns historisch überkommene Umwelt weitgehend menschengeprägt ${ }^{3}$, dann ist nicht jede Veränderung dieser gestalteten Umwelt eine Umweltschädigung. Maßstab für das Vorliegen einer Umweltschädigung ist zunächst und vordringlich das Auswirken der

1 So Umweltgutachten 1978 des Rates von Sachverständigen für Umweltfragen, BT-Drucksache 8/1938 vom 19. 9. 1978, Nr. 1763.

2 In einer groben Einteilung werden vier Okosysteme als funktionelle Einheiten unbelebter und belebter Natur unterschieden: die urbanindustriellen, die agrarischen (zu denen z. B. auch Fichtenforste zählen), die naturnahen (mit den Gewässern und einem Dauerbestand von Laub- und Mischwald) und die natürlichen, die in Deutschland nur noch in einigen kleinen Gewässern und Mooren anzutreffen sind. Nach dem Umweltgutachten 1978, Nr. 28 ff., 1257.

s So Umweltgutachten 1978, Nr. 1763. 
Veränderung auf die mögliche nachhaltige Umweltnutzung durch den Menschen. Nutzen in den oben beschriebenen Arten soll sehr umfassend verstanden werden: So rechnet zum Nutzungspotential z. B. auch die Artenvielfalt: ${ }^{4}$

- sie ist in manchen Okosystemen zur Erhaltung des funktionellen Gleichgewichts erforderlich;

- sie stellt vor allem als genetische Vielfalt ein erhebliches Potential als Genreserve z. B. für die Resistenzzüchtung im Pflanzenbereich oder für Zwecke biologischer Schädlingsbekämpfung dar;

- schließlich ist sie unter dem Gesichtspunkt der Erholungsund Bildungsfunktion zum Regenerationspotential zu zählen.

Allerdings muß bewußt bleiben, daß das Ziel der Nutzungserhaltung und -optimierung nicht alle Beweggründe für den Umweltschutz abdeckt: Bei der Erhaltung der Artenvielfalt und der Vorsorge für sehr lange Zeiträume kommen eine Ehrfurcht vor der Natur oder der Schöpfung und eine Verantwortung über eine ganze Generationenreihe hin und damit unmittelbar ethische Wertungen zum Tragen.

Die Gesamtheit der Maßnahmen, in diesem Sinne umweltschädliche Nutzungen der Umwelt zu vermindern oder doch der Art nach $z u$ einer geringeren Umweltschädlichkeit hin zu verändern, ist als Umweltschutz zu bezeichnen. Geht man zunächst von archaischen Kategorien aus, so erscheint eingeordnet in den Umweltschutz die Sorge für die klassischen Elemente der griechischen Naturphilosophie: Wasser, Luft und Erde als Träger der Biosphäre wie auch die Sorge für das Feuer, das für den Energiefluß steht. Damit sind zugleich die großen Bereiche der Umweltpolitik bezeichnet, nämlich die Wasserwirtschaft, die Luftreinhaltung, Landschaftspflege und Naturschutz sowie die Kontrolle störender Energien in Form von Lärm, Abwärme und Strahlungen und schließlich elementeübergreifend die Kontrolle von Schadstoffen und von Fremdstoffen in Lebensmitteln wie auch die Abfallwirtschaft ${ }^{5}$.

Bevölkerungsdichte und steiles Wachsen von Produktion und Konsum haben, gepaart mit einer gewissen Achtlosigkeit, die Umweltbelastungen in unserer Jahrhunderthälfte in bisher nicht gekannte Dimensionen gesteigert. Ein Fortsetzen des

\footnotetext{
4 So z. B. Umweltgutachten 1978, Nr. 34.

5 Entsprechend die Gliederungspunkte im Umweltgutachten 1978, S. 5.
} 
Trends hätte die Nutzbarkeit der Umwelt beendet und damit zur Katastrophe für das menschliche Leben geführt. Der Grad der Gefahr wird zwar unterschiedlich beurteilt, es herrscht aber Konsens darüber, daß die Intensität und Art der Umweltnutzung insgesamt und der Einzelnutzungen gerade zur Erhaltung jener Nutzung und zu ihrer Optimierung im Interesse der Menschheit jetzt und in Zukunft und auch im Einzelinteresse vermindert und verändert werden muß.

\section{Erwägungen der allgemeinen Staatslehre zum staatlichen Umweltschutz}

Von Staatsaufgaben handelt die allgemeine Staatslehre. Der moderne Staat - gerade auch in Deutschland - hat stets Aufgaben wahrgenommen, die jetzt Umweltschutz heißen'. Erwägungen, die ihm solche Aufgaben bestritten, verkennten den Staat als historisches Gebilde. Herbert Krüger ${ }^{7}$ hat zudem entgegen allen Staatszwecklehren gezeigt, daß a priori keine Aufgabe, die dem Gemeinwohl dient, ausgeschlossen sein kann. Der Staat wählt seine Aufgaben aus. Seine Legitimation, Umweltschutzaufgaben auf sich zu nehmen, ist unbestreitbar.

Die Staatslehre bietet für die staatliche Willensbildung Erwägungen - nach Roman Herzog Regeln politischer Klugheit ${ }^{8}$. Ergebnisse des Nachsinnens zur Übernahme des Umweltschutzes als Staatsaufgabe seien hier aufgezählt:

1. Das ständige Wachsen des Staatssektors zeigt die Tendenz zum Überhandnehmen des Staates ${ }^{9}$. Zurückhaltung beim Erweitern von Staatsaufgaben ist geboten!

${ }^{6}$ So geht die bis zum Erlaß des Bundes-Immissionsschutzgesetzes 1974 geltende Fassung der Gewerbeordnung für den Norddeutschen Bund vom 21. 6. 1869 (BGBl. 1869, S. 245) im §16 wörtlich auf $\S 26$ der preußischen Allgemeinen Gewerbeordnung vom 17. Januar 1845 (Gesetz-Sammlung 1845, S. 41) zurück. - In den Stadtrechten lassen sich vielfach Vorschriften zur Abfallbeseitigung und zum Gewässerschutz finden; als Beispiel sei auf den Nachweis für Lübeck verwiesen bei Johann C. H. Dreyer: Einleitung zur Kenntnis der in GeistBürgerlichen-Gerichts-Handlungs-Policey- und Kammer-Sachen von E. Hochw. Rath der Reichsstadt Lübeck von Zeit zu Zeit ergangenen allgemeinen Verordnungen ..., Lübeck 1769, S. $551 \mathrm{ff}$.

7 Herbert Krüger: Allgemeine Staatslehre, Stuttgart 1964, S. 759 ff.

8 Es handelt sich um Fragen ,zur Okonomie staatlicher Aufgabenwahl", so Roman Herzog: Algemeine Staatslehre, Frankfurt a. M. 1971, S. 151.

- So hat sich das Verhältnis der Ausgaben der öffentlichen Hand zum Bruttosozialprodukt (Staatsquote) von 1960-69 um 5,4\% (von 
2. Wer könnte aber die Aufgaben so erfüllen, daß der Staat sich zurückhalten kann?

- Viele die Umwelt nutzende Produzenten und Konsumenten mögen Einsicht in die Notwendigkeit des Umweltschutzes haben, doch führt das nicht spontan zu allgemein umweltbewahrendem Verhalten.

- Im gesellschaftlichen System eines Marktes gibt es Kräfte, die auf eine optimale Gesamtnutzung der Umweltgüter hinwirken ${ }^{10}$. Wenn ein Produzent ein Umweltgut so nutzt, daß anderen die Nutzung gemindert wird, muß er je nach dem Rechtssystem einen Schadensersatz zahlen, oder aber die anderen Nutzer bieten ihm ein Abstandsgeld. Dieser theoretische gesellschaftliche Modellmechanismus, der unter der Bezeichnung Coase-Theorem diskutiert wird, leistet in Wirklichkeit nicht den ihm zugedachten Erfolg - und macht staatliche Regelungen nicht überflüssig. Die Utberlegung verdeutlicht aber das positive ökonomische Interesse der Industrie-Gesellschaft am Umweltschutz. Ein Gegensatz zum Allgemeininteresse in der Weise, wie Forsthoff ${ }^{11}$ ihn angenommen hat, besteht nicht.

- Internationale Organisationen werden zum Umweltschutz tätig, da Umweltbelastung ein globales Problem ist und Welthandel und die internationale Arbeitsteilung betroffen $\operatorname{sind}^{12}$. Doch koordinieren die Staaten in diesen Organisationen ihre Umwelttätigkeit, regen einander an und unterstützen sich gegenseitig. Die internationalen Organisationen

32,5 auf $37,9 \%$ ) erhöht, bis 1977 aber um weitere $9,4 \%$ auf $47,3 \%$. Quelle: Antwort der Bundesregierung in BT-Drucksache 8/1761 vom 27. 4. 1978, S. 2 ff. Siehe auch Frido Wagener: Der öffentliche Dienst im Staat der Gegenwart, VVDStRL Bd. 37 (für 1978) 1979, S. 212 ff., S. 219 und Walter Rudolf, ebenda, S. 187 f. Umfassender: Dieter Duwendag (Hrsg.): Der Staatssektor in der sozialen Marktwirtschaft, Vorträge, Hochschule Speyer 1975, Berlin 1976. Vgl. auch Klaus Stern: Das Staatsrecht der Bundesrepublik Deutschland, Bd. I, München 1977, S. 717.

10 Umweltgutachten 1978 (Anm. 1), Nr. 1770; R. H. Coase: The Problem of Social Cost, Journal of Law and Economics, Bd. 3 (1960), S. $1 \mathrm{ff}$; umfassend Horst Siebert: Okonomische Theorie der Umwelt, Tübingen 1978.

11 Ernst Forsthoff: Der Staat der Industrie-Gesellschaft, München 1971, S. 25 ff.

12 Siehe dazu D. Rauschning: Umweltschutz als Problem des Völkerrechts, Europa-Archiv 1972, S. 567-580; M. Bothe: Umweltschutz 
machen Staatstätigkeit zum Umweltschutz gleichfalls nicht überflüssig.

3. Ganz überwiegend dient der Umweltschutz dem Allgemeininteresse ${ }^{13}$ : so der Schutz von Boden, Natur und Landschaft, von Luft und Wasser, der Lufthülle und der Meere und der Umweltschutz für die nächste und die folgenden Generationen. Der geborene Wahrer des Allgemeininteresses ist der Staat ${ }^{14}$.

4. Die Dimension der Aufgabe, die Notwendigkeit von Anordnung und Durchsetzung gegenüber vielen und auch mächtigen Nutzern erfordern schließlich Mittel und Macht, über die nur der Staat verfügt.

Umweltschutz als unausweichliche Menschheitsaufgabe ist gegenwärtig nur unter Einsatz des Staates zu bewältigen. Der Art nach werden die staatlichen Aufgaben sich vor allem auf die Regelung der konkurrierenden Umweltnutzung durch Produzenten und Konsumenten richten. Konkrete Materien und Intensität werden im staatlichen Willensbildungsproze $B$ bestimmt.

\section{Völkerrechtliche Pflicht zum Umweltschutz}

Umweltbelastung ist ein globales, Umweltschutz so notwendig ein internationales Problem ${ }^{15}$. Völkergewohnheitsrecht verpflichtet gegenwärtig zur Verhütung grenzüberschreitender

als Aufgabe der Rechtswissenschaft, Völkerrecht und Rechtsvergleichung, ZaöRV 32 (1972), S. 483; L. F. E. Goldie: A General View of International Environmental Law - A Survey of Capabilities, Trends and Limits, Colloque La Haye 1973, S. 26-33; A. Ch. Kiss: Survey of Current Developments in International Environmental Law, IUCN Environmental Policy and Law Paper Nr. 10, Morges 1976, S. 12 f.; Eb. Klein: Umweltschutz im völkerrechtlichen Nachbarrecht, Berlin 1976, S. 15; I. v. Münch: Umweltschutz im Völkerrecht, Archiv des Völkerrechts 15 (1971/72), S. 385. Kurz gefaßte Ubersicht über die Tätigkeit internationaler Organisationen in D. Rauschning (Rapporteur): Preliminary Report on Questions of International Law Concerning the Protection of the Environment, International Law Association, Manila Conference (1978), S. 8-14.

13 Umweltgutachten 1978 (Anm. 1), Nr. 1945.

14 Hier kann wieder an die Betrachtungen von Forsthoff (Anm. 11), S. $46,121,168$ angeknüpft werden.

15 Siehe Anm. 12. 
Umweltverschmutzung ${ }^{16}$. In der berühmten Trail-Smelter-Entscheidung ${ }^{17} \mathrm{zu}$ grenzüberschreitenden Rauchemissionen hat ein amerikanisch-kanadisches Schiedsgericht 1941 festgestellt, daß kein Staat das Recht hat, sein Gebiet in solcher Weise zu nutzen oder die Nutzung zuzulassen, daß Schäden in dem oder an dem Gebiet eines anderen Staates entstehen, wenn erhebliche Folgen auftreten und Schäden klar nachweisbar sind. Im Anschluß an diese Entscheidung wird der darin ausgedrückte Rechtssatz heute als allgemeines Völkergewohnheitsrecht angesehen. Für neue und zusätzliche Umweltbelastungen mag die Pflicht zur Verhütung grenzüberschreitender Schäden schon vor der Gefahr eines schweren Schadens einsetzen ${ }^{18}$. Bei der Nutzung gemeinsamer Medien wie der eines internationalen Wasserlaufes dürfte das weithin anerkannte Prinzip der fairen Nutzungsaufteilung ${ }^{19}$ auch für die Nutzung zum Abtransport von Abfallstoffen gelten. - Im Seerecht findet sich zudem der Rechtssatz, daß die Ausübung der Meeresfreiheiten auch das Interesse anderer an den Meeresfreiheiten berücksichtigen müsse ${ }^{20}$. Diese Verhaltens- und Utberwachungspflichten des

16 Zusammenfassend D. Rauschning, in ILA 1978 (Anm. 12), S. 14 bis 23 ; $L$. Wildhaber, Die Oldestillerieanlage Sennwald und das Völkerrecht der grenzüberschreitenden Luftverschmutzung, Schweizerisches Jahrbuch für internationales Recht 1975, S. 102-106; Randelzhofer/Simma: Das Kernkraftwerk an der Grenze, Festschrift für F. Berber, München 1973, S. 397-410.

17 Vom 11. 3. 1941, United Nations Reports of International Arbitral Awards, vol. 3, S. 1911 und 1938 ff. (1965).

18 Dazu Rauschning in ILA 1978 (Anm. 12), S. 18-21. So auch J. Kelson: State Responsibility and the Abnormally Dangerous Activity, Harvard International Law Journal 13 (1972), S. 242; L. Wildhaber (Anm. 16), S. 119.

19 Der Grundsatz (equitable apportionment oder equitable utilization) ist am deutlichsten formuliert in den „Helsinki Rules on the uses of waters of international rivers" International Law Association, Report on the 52nd Conference, Helsinki 1966, S. 477-532. Ausführlich dazu Eb. Klein (Anm. 12), S. $187 \mathrm{ff}$. Er wird als geltender Völkerrechtssatz bezeichnet z. B. von Ch. Bourne: International Law and Pollution of International Rivers and Lakes, U. B. C. L. R. 6 (1971), S. 195; W. Griffin: The Use of Waters of International Drainage Basins under Customary International Law, AJIL 53 (1959), S. $77 \mathrm{ff} . ; A$. Utton: International Water Quality Law, in: Teclaff/Utton: Intennational Environmental Law, N. Y. 1974, S. 296. Zur Ubertragbarkeit dieses Grundsatzes von internationalen Flüssen auf andere Medien siehe Rauschning, ILA 1978 (Anm. 12), S. 21 f.

20 Diese Gemeinverträglichkeitsklausel hat ihren Niederschlag in Art. 2 der Genfer Konvention über die Hohe See von 1958 gefunden (450 UNTS 82). 
Völkergewohnheitsrechts gelten gegenständlich und räumlich begrenzt.

Vertraglich haben sich viele Staaten gegenseitig zum Umweltschutz in internationalen Materien verpflichtet. In mehreren Konventionen haben sie Maßnahmen zur Verhütung der Meeresverschmutzung vereinbart, in einigen Anstrengungen zum Gewässerschutz ${ }^{21}$. Nutzungsbegrenzungen in den Fischereikonventionen gehören im weiteren Sinne hierher, zunehmend gewinnen Naturschutzkonventionen an Bedeutung ${ }^{22}$. Interna-

21 Unter den Verträgen zum Schutz der Meeresumwelt mit universellem Geltungsbereich sind $\mathrm{zu}$ erwähnen: Das Internationale Ubereinkommen zur Verhütung von Verschmutzung der See durch Ol von 1954 (327 UNTS 3), mit den Änderungen von 1962 (600 UNTS 332), 1969 (ILM 1970, S. 1 ff.) und 1971 (ILM 1972, S. 267 ff.); das Übereinkommen über die Verhütung der Meeresverschmutzung durch das Einbringen von Abfällen und anderen Stoffen von 1972 (ILM 1972, S. 1291); das Internationale Übereinkommen betreffend die Verschmutzung von Schiffen aus (in: Rüster/Simma, International Protection of the Environment, Bd. II, S. 552), das das Abkommen von 1954 ablösen wird und eine Verschärfung der bisherigen Bestimmungen vorsieht.

Die jüngsten und wichtigsten regionalen Abkommen auf dem Gebiet sind:Das Übereinkommen zur Verhütung der Meeresverschmutzung infolge der Verklappung durch Schiffe und Flugzeuge, Oslo 15. 2. 1972 (ILM 1972, S. 262); die Konvention über den Schutz der Meeresumwelt des Ostseegebiets, Helsinki 22. 3. 1974 (ILM 1974, S. 544); das Ubereinkommen zur Verhütung von Meeresverschmutzung vom Lande aus, Paris 4. 6. 1974 (ILM 1974, S. 352); das Ubereinkommen zum Schutz des Mittelmeeres vor Verschmutzung, Barcelona 16. 2. 1976 (ILM 1976, S. 290). Die multilateralen Verträge zum Schutz der Meeresumwelt sind abgedruckt in: Internationales Umweltrecht - Multilaterale Verträge, Hrsg. W. E. Burhenne, Berlin 1974 ff., Bd. 1-4.

Zum Schutz internationaler Wasserläufe seien als jüngste Beispiele genannt: Das Ubereinkommen zum Schutz des Rheins gegen chemische Verunreinigung vom 3. 12. 1976, ABl. der EG Nr. L 240 v. 19. 9. 1977, S. 76, und das Ubereinkommen zum Schutz des Rheins gegen Verunreinigung durch Chloride vom 3. 12. 1976 (Burhenne, Int. Umw.R Bd. 4). Uberragende Bedeutung kommt dem Entwurf einer europäischen Gewässerschutzkonvention zu, der im Rahmen des Europarats erarbeitet wurde, Doc. EXP/Eau (74) 6, Addendum I. Für eine detaillierte Auflistung der auf dem Gebiet existierenden Verträge siehe Eb. Klein (Anm. 12), S. 125 ff. und die FAO-Studie „Systematic Index of International Water Resources Treaties, Declarations, Acts and Cases by Basin", Rom 1978.

22 Das Ubereinkommen über das Verhalten beim Fischfang im Nordatlantik vom 1. 6. 1967, BGBl. 1976 II 1910; das Utbereinkommen über die Erhaltung der lebenden Schätze des Südostatlantiks vom 23. 10. 1969, BGB1. 1976, II 1545; die Konvention über die Fischerei 
tionale Luftreinhalteabkommen, z. B. zur Begrenzung der Abgabe von $\mathrm{SO}_{2}$ oder zur Beschränkung des Gebrauchs von Fluorkohlenwasserstoffen, fehlen noch. Die Anreicherung des $\mathrm{CO}_{2}-$ Gehalts der Lufthülle durch Verfeuern fossiler Brennstoffe wird noch nicht einmal national behandelt, so daß auch internationale Regelungen fehlen müssen. Lediglich das Teststoppabkommen ${ }^{23}$ dient auch dem Schutz der Luft.

Internationale Organisationen, insbesondere im Kreis der Industrie-Staaten mit Marktwirtschaft die OECD ${ }^{24}$, haben in einer Reihe von Empfehlungen den Staaten materiell die Wahrnehmung von Umweltschutzaufgaben nahegelegt, verfahrensmäßig sowohl Informationspflichten wie Beteiligungsrechte in nationalen Genehmigungsverfahren empfohlen; die OECD hat mit den Beschlüssen über die Anwendung des Verursacherprinzips versucht, im Kreis der Industrie-Staaten das System der Ko-

und den Schutz der lebenden Ressourcen in der Ostsee und den Belten vom 13. 9. 1973, BGBl. 1976 II 1564. Für elne erschöpfende Auflistung der multilateralen und bilateralen Verträge auf dem Fischereigebiet vgl. Rüster/Simma, International Protection of the Environment, N. Y. 1977, Bd. VI, VII, VIII.

Als Beispiele von Naturschutzabkommen seien erwähnt: African Convention on the Conservation of Nature and Natural Resources v. 15. 9. 1968, abgedruckt in: Internationales Umweltrecht (Anm. 21), Bd. 3; Convention on International Trade in Endangered Species of Wild Fauna and Flora v. 3. 3. 1973, BGBl. 1975 II 773, Vgl. auch die Auflistung der Naturschutzabkommen bei Rüster/Simma, ibid., Bd. IV und V.

23 Vertrag über ein Verbot der Kernwaffenversuche in der Atmosphäre, im Weltraum und unter Wasser vom 5. 8. 1963, 480 UNTS 43, BGBl. 1964 II 906.

${ }^{24}$ Die wichtigsten OECD-Empfehlungen auf dem Gebiet des Umweltschutzes sind: Recommendation on Principles concerning Transfrontier Pollution vom 14. 11. 1974, OECD Doc. C (74) 224, abgedruckt in ILM 1975, S. 242; Recommendation on Equal Right of Access in relation to Transfrontier Pollution vom 11. 5. 1975, OECD Doc. C (76) 55 (Final), abgedruckt in ILM 1976, S. 1218; Recommendation on the Implementation of a Regime of Equal Right of Access and Non-Discrimination in relation to Transfrontier PolIution, OECD Doc. C (77) 28 (Final), abgedruckt in ILM 1977, S. 977. Recommendation for Strengthening International Cooperation on Environmental Protection in Frontier Regions vom 27. 9. 1978, OECD Doc. C (78) 77 (Final), abgedruckt in ILM 1978, S. 1530; Recommendation on Guiding Principles concerning International Economic Aspects of Environmental Policies, abgedruckt in ILM 1972, S. 1172. Zu den Empfehlungen der OECD siehe insbesondere: Legal aspects of transfrontier pollution, OECD (Hrsg.), Paris 1977. 
stenaufbringung $\mathrm{zu}$ vereinheitlichen. Die Europäischen Gemeinschaften verpflichten ihre Mitgliedstaaten im Wege der hinsichtlich des Zieles verbindlichen Richtlinien zu Umweltschutzmaßnahmen ${ }^{25}$. Als die wichtigsten Richtlinien seien die zum Gewässerschutz und zur Begrenzung der Luftverunreinigung genannt.

Anders als die allerdings nur beschränkt anwendbaren Gewohnheitsrechtsregeln werden die völkerrechtlichen Verträge jeweils nur mit Zustimmung des gebundenen Staates verbindlich. Das gleiche gilt gegenwärtig noch für die einschlägigen Akte der internationalen Organisationen, nach der bisherigen Praxis auch für die Richtlinienbeschlüsse der Europäischen Gemeinschaften. So sind die Verträge und Organisationsakte als Bemühen der Staaten um eine Vereinheitlichung und Effektuierung des staatlichen Umweltschutzes anzusehen. Die Staaten begründen diese internationalen Verpflichtungen zum Umweltschutz, um auf diese Weise die Staatsaufgabe Umweltschutz besser zu erfüllen; die Verträge sind nicht Grund der Aufgabenübernahme.

25 Hingewiesen sei nur auf folgende Richtlinien:

Gewässerschutz: Richtlinie des Rates betreffend die Verschmutzung infolge der Ableitung bestimmter gefährlicher Stoffe in die Gewässer der Gemeinschaft, ABl. Nr. L 129 v. 18. 5. 1976, S. 23; Richtlinie des Rates über die Qualitätsanforderungen an Oberflächenwasser für die Trinkwassergewinnung in den Mitgliedstaaten, ABl. Nr. L 194 v. 25. 7. 1975, S. 34; Richtlinie über den Schutz des Grundwassers gegen Verschmutzung durch bestimmte gefährliche Stoffe, ABl. Nr. C 37 v. 14. 2. 1978, S. 3.

Luftreinhaltung: Richtlinie des Rates zur Angleichung der Rechtsvorschriften der Mitgliedstaaten über den Schwefelgehalt bestimmter flüssiger Brennstoffe, ABl. Nr. L 307 v. 27. 11. 1975, S. 22; Richtlinie der Kommission zur Anpassung der Richtlinie des Rates 70/220/ EWG vom 20. März 1970 zur Angleichung der Rechtsvorschriften der Mitgliedstaaten über Maßnahmen gegen die Verunreinigung der Luft durch Abgase von Kraftfahrzeugmotoren mit Fremdzündung an den technischen Fortschritt, ABl. Nr. 32 v. 3. 2. 1977, S. 32.

Lärmschutz: Im April 1978 hat die Kommission dem Rat einen Vorschlag für eine Richtlinie betreffend den zulässigen Schallemissionspegel von Motorkompressoren vorgelegt, ABl. C 94 v. 19.4. 1978. Einen Uberblick über die Ziele der Umweltschutzpolitik der EG und über die schon ergriffenen Maßnahmen enthalten das 1. und das 2. Umweltschutzprogramm der EG, ABl. Nr. C 112 v. 20. 12. 1973, S. 1 und $A B 1$. Nr. C 139 v. 13. 6. 1977, S. 1. 


\section{Verfassungspflicht zum Umweltschutz}

\section{Fehlen einer allgemeinen Umweltschutzbestimmung}

Abgesehen von den wenigen Regeln des Völkergewohnheitsrechts werden dem Staat die Umweltschutzaufgaben nicht von übergeordneten Normen auferlegt, er nimmt sie aufgrund eines Willensbildungsprozesses auf sich. Die höchste Stufe des vom und für den Staat gebildeten Willens ist die Verfassung ${ }^{26}$, für uns das Grundgesetz.

Das Grundgesetz stellt eine Umweltschutzverpflichtung des Staates in seiner Gliederung vom Bund über die Länder bis zu den Gemeinden und Körperschaften nicht ausdrücklich fest ${ }^{27}$, weder im Grundrechtsteil noch bei den Staatszielbestimmungen. Weite Bereiche des Umweltschutzes sind in den Zuständigkeitskatalogen der Art. 74 und 75 genannt. Dort wird die Gesetzgebungszuständigkeit z.B. über friedliche Nutzung der Kernenergie und zum Schutz gegen Gefahren, die bei Freiwerden von Kernenergie entstehen (Art. $74 \mathrm{Nr} .11$ a) oder zur Abfallbeseitigung, zur Luftreinhaltung und zur Lärmbekämpfung (Art. 74 Nr. 24) und schließlich die Rahmenzuständigkeit zum Naturschutz, zur Landschaftspflege und zum Wasserhaushalt (Art. 75 Nr. 3, 4) dem Bund zuerteilt. Damit wird zwar gleichzeitig von Verfassungs wegen ausgesprochen, daß in jenen Materien Regelungen ergehen können ${ }^{28}$. Die Aufnahme in die nur aus bundesstaatlichen Gründen notwendigen Kataloge der Gesetzgebungsmaterien verpflichtet aber keine der staatlichen Ebenen, in diesem Bereich regelnd tätig zu werden ${ }^{29}$.

26 Für das Gesetz als vorrangige Stufe des gebildeten Staatswillens BVerfGE 8, 155 (169). Allgemein dazu Rauschning: Die Sicherung der Beachtung von Verfassungsrecht, Bad Homburg 1969, S. 58 ff. (67).

27 Für den Grundrechtsbereich u. a. H. Steiger: Mensch und Umwelt, Zur Frage der Einführung eines Umweltgrundrechtes, Berlin 1975, S. 33; $M$. Kloepfer: Zum Grundrecht auf Umweltschutz, Berlin 1978, S. 27; R. Scholz: Verfassungsfragen zum Schutz des Nichtrauchers, Beilage 10/79 zu Der Betrieb, S. 13 rechts. Für die gegenteilige Auffassung wird zuweilen $H$. H. Rupp: Die verfassungsrechtliche Seite des Umweltschutzes, JZ 1971, S. 401 ff. (402), zitiert; doch spricht Rupp dort im Zusammenhang mit Art. 1 und 2 GG über Rechtswirkungen einer Art, die bisher nicht als Grundrechtswirkungen angesehen werden.

${ }^{28}$ Siehe dazu BVerfGE 48, 127 (159 f.) - Wehrpflichtänderungsgesetz.

20 Eine Umweltschutzpflicht aus den Kompetenzbestimmungen nehmen aber an: W. Weber: Umweltschutz im Verfassungs- und 
Es ist von politischer wie von wissenschaftlicher Seite versucht worden, eine allgemeine Verpflichtung des Staates zum Umweltschutz in das Grundgesetz einzufügen, und zwar in Gestalt eines Grundrechts ${ }^{30}$. Die Diskussion dieser Pläne hat überzeugende Gründe gegen die Aufnahme eines solchen Umweltschutzgrundrechtes in die Verfassung ergeben. Die Pläne und Bemühungen dürften inzwischen aufgegeben $\operatorname{sein}^{31}$.

Verwaltungsrecht, DVBl. 1971, S. 806; H. Steiger (Anm. 27), S. 68, 70; mit der Kommentierung von Maunz in: Maunz/Dürig/Herzog/ Scholz: Grundgesetz, Kommentar, München 1958 ff., Art. 73, Rndnr. 5 , ist aber $\mathrm{zu}$ betonen, daß mit der Kompetenzzuweisung keine Verpflichtung verbunden ist. So verpflichtet z. B. auch Art. 87 a i. V. m. Art. 12 a GG den Bund nicht zur Einführung der allgemeinen Wehrpflicht - BVerfGE 48, 127 (160), Art. 74 Nr. 11 a GG nicht zum Bau von Kernkraftwerken.

so Berichte über die Bemühungen und Erörterungen dazu u. a.: Hans H. Klein: Ein Grundrecht auf saubere Umwelt? Festschrift Werner Weber, Berlin 1974, S. $643 \mathrm{ff}$. mit ablehnendem Ergebnis S. 660; H. Steiger (Anm. 27), befürwortend S. 73 ff., mit weiteren Nachweisen S. 76-84; M. Kloepfer: Zum Grundrecht auf Umweltschutz (Anm. 12), passim. Diskussion, auch zu einem entsprechenden internationalen Menschenrecht, in: Individualrecht oder Verpflichtung des Staates - Internationales Kolloquium über das Recht auf menschenwürdige Umwelt ( = Beiträge zur Umweltgestaltung Heft A 41); zum internationalen Aspekt Rauschning: Ein internationales Menschenrecht auf Schutz der Umwelt? Festschrift W. Weber 1974, S. 719-734.

s1 Die Argumente gegen die Aufnahme eines Umweltschutzgrundrechts in das Grundgesetz sind - zusammengefaßt - folgende:

1. Das Schutzgut einer "menschenwürdigen Umwelt" ist nicht hinreichend bestimmbar.

2. Ein Umweltgrundrecht hätte nicht den Charakter eines gegen den Staat gerichteten Abwehrrechtes und würde so das Grundrechtsverständnis der gegenwärtigen Grundrechte relativieren.

3. Da nicht jede Umweltnutzung, die eine Belastung oder Schädigung mit sich bringt, verboten werden kann, muß eine rechtliche Regelung des Umweltschutzes stets eine Abwägung und Entscheidung in Zielkonflikten zum Inhalt haben. Dafür sind die dem einzelnen Interessenten zuerteilten grundrechtlichen Positionen nicht geeignet oder hilfreich.

4. Die Schutzgüter Luft und Wasser, Landschaft und Artenvielfalt sind keine Individualgüter. Die Aufgabe des Umweltschutzes wird verfehlt, wenn man sie durch Einräumen von subjektiven Individualrechten $\mathrm{zu}$ lösen versucht.

5. Ein Umweltgrundrecht mit einem $z u$ hohen Standard brandmarkt die gegenwärtige Situation als verfassungswidrig; eine Formulierung, die den gegenwärtigen Zustand noch als verfas- 
2. Umweltschutzrechtliche Teilgewährleistungen in Grundrechten

Aus dem Grundgesetz lassen sich jedoch umweltrechtliche Teilgewährleistungen ableiten ${ }^{32}$. Als Grundlage solcher Gewährleistungen ${ }^{33}$ stehen das Recht auf Leben und körperliche Unversehrtheit (Art. 2 II GG) und das Eigentumsrecht (Art. 14 I GG) im Vordergrund. Erwogen wird weiterhin die Herleitung aus dem allgemeinen Persönlichkeitsrecht (Art. 2 I GG) und dem Gebot zur Achtung der Menschenwürde (Art. 1 I 2 GG).

a) Schutzbereich der umweltrelevanten Grundrechte. Das Grundrechtsgut Leben ist zweifellos berührt, wenn eine geschädigte Umwelt auf den Grundrechtsträger derart einwirkt, daß eine Lebensgefährdung entsteht. Allerdings ist das Leben als solches Schutzgut von Art. 2 II GG, nicht ein besonders erfülltes oder erfreuliches. Das Leben ist selbstverständlich Basis der Menschenwürde; daß sich das Leben der Menschenwürde entsprechend vollziehen kann, ist ein gesondertes Problem von Art. 1 I 2 GG.

Das Recht auf körperliche Unversehrtheit kann betroffen sein in den Teilrechten der Freiheit von Verletzung der körperlichen Gesundheit und der Freiheit von Schmerzen. Der weite Gesundheitsbegriff aus der Satzung der Weltgesundheitsorganisation, der positiv ein Wohlbefinden einschließt, ist Art. 2 II GG nicht zugrundegelegt ${ }^{34}$.

Grundlage für den Schutz von Sachen - von Liegenschaften wie von Fahrnis - bildet verfassungsrechtlich Art. 14 I GG. Nach dem verfassungsrechtlichen Eigentumsbegriff ist der Besitz in den Schutz eingeschlossen.

Der Schutzbereich von Gesundheit oder Eigentum ist nur betroffen, wenn die Kausalität einer Umweltbeeinträchtigung für

sungsgemä $B$ erscheinen läßt, kann das Bemühen um eine Umweltverbesserung dämpfen.

6. Die Gewährung eines Umweltgrundrechtes an die Bürger würde zunächst beruhigen, dann aber Erwartungen auf eine schnelle Verbesserung der Umwelt wecken, die nicht erfüllt werden können.

Vgl. dazu auch $H$. Steiger: Individualrecht oder Verpflichtung des Staates? (Anm. 30), S. 20, und zum Grundrecht inzwischen gleichfalls ablehnend Umweltgutachten 1978 (Anm. 1), Nr. 1945.

32 So R. Scholz (Anm. 27), S. 13 rechts.

s3 Vgl. dazu BVerwGE 54, 211 (219 ff.).

34 So G. Dürig, in: Maunz/Dürig/Herzog/Scholz (Anm. 29), Art. 2 II, Rndnr. 30. Ihm folgend z. B. R. Scholz (Anm. 27), S. 16; H. Steiger (Anm. 27), S. 34. 
den Schaden oder die erwartete Schädigung vorliegt. Auch muß die Einwirkung eine gewisse Schwelle überschreiten ${ }^{35}$ : Unannehmlichkeiten oder Belästigungen sind noch keine Gesundheitsverletzung, eine ortsübliche Immission keine Eigentumsverletzung.

Um gerade auch Belästigungen in den grundrechtlichen Umweltschutz einzubeziehen, wird von einigen Autoren Art. 2 I GG) herangezogen ${ }^{36}$. Eine Beschränkung der allgemeinen Handlungsfreiheit dürfte aber über Einwirkungen auf dem Weg durch die Umweltmedien, wenn sie nicht die Schadensgrenze erreichen, kaum zu konstruieren sein. Ein Schutz vor Belästigungen kann auch aus der Kasuistik der Entscheidungen des Bundesverfassungsgerichts nicht hergeleitet werden. Zwar wird insbesondere in den Urteilen zum Mikrozensus, zum LebachFall und zur politischen Betätigung von Soldaten in der $\mathrm{Ka}-$ serne $^{37}$ im Bereich des allgemeinen Persönlichkeitsrechts der Anspruch, „in Ruhe gelassen zu werden“, konkretisiert. Dieser so abgeleitete Rechtssatz bezieht sich in der Rechtsprechung aber jeweils auf den geistig-kommunikativen Bereich. Demgegenüber soll Emissionsschutz Beeinträchtigungen durch Stoffe und Energie abwehren. Damit ist der Bereich des Gesundheitsund Eigentumsschutzes angesprochen. Er kann über seine Grenzen hinaus nicht durch Anwendung des allgemeinen Persönlichkeitsrechts erweitert werden. Allgemein hat sich das Bundesverwaltungsgericht dezidiert gegen eine solche Anwendung von Art. 2 I GG ausgesprochen ${ }^{38}$, z. B. auch gegen die Herleitung eines Rechts auf die Erhaltung eines NaherholungsGebietes.

Aus der Verpflichtung des Staates zur Achtung der Menschenwürde (Art. 1 I 2 GG) soll sich schließlich ebenfalls eine Grundrechtsposition im Umweltschutz, entweder allein oder in

ss So J. Lücke: Das Grundrecht des einzelnen gegenüber dem Staat auf Umweltschutz, DOVV 1976, S. 289 ff., 291 rechts; J. Baltes: Immissionsgrenzwerte und Art. 2 Abs. 2 GG, BB 1978, S. 130 ff., 133 links; M. Kloepfer (Anm. 27), S. 20 und grundsätzlicher mit Nachweisen aus der Rspr.: Grundrechtstatbestand und Grundrechtsschranken in der Rechtsprechung des Bundesverfassungsgerichts, in: Festschrift Bundesverfassungsgericht, Bd. 2, Tübingen 1976, S. 405 ff., 409.

36 Allgemein $H$. Steiger (Anm. 27), S. 17; Chr. Sening: Zum Umweltgrundrecht des Bürgers, BayVBl. 1978, S. 205 ff.; R. Scholz (Anm. 27), S. 17.

37 BVerfGE 27, 1 (6 ff.) (Mikrozensus); BVerfGE 35, 202 (233) (Lehbach); BVerfGE 44, 197 (203) (Soldaten).

s8 BVerwGE 54, 211 (219 ff.). 
Verbindung mit dem allgemeinen Persönlichkeitsrecht oder dem Schutz von Leben und Gesundheit, herleiten. Wenn diese Grundrechte zusammen, gegebenenfalls unter Hinzuziehung der Sozialstaatsklausel, ein Recht auf Gewährleistung eines ökonomischen Existenzminimums gewährleisten, dann kann ihnen gleichermaßen ein Recht auf Gewährleistung eines ökologischen Existenzminimums entnommen werden ${ }^{39}$. Das soll auch deshalb nicht weiter vertieft werden, weil nach übereinstimmender Ansicht in der Literatur ein solches ökologisches Existenzminimum durch staatliche Maßnahmen gegenwärtig gesichert ist. Zudem hat Scholz darauf hingewiesen, daß dieses Schutzgut sich maßgebend mit dem Schutz der Gesundheit vor Umweltbeeinträchtigungen von existenziellem Ausmaß gleichsetzen läßt40; Menschenwürde und allgemeines Persönlichkeitsrecht brauchen dafür nicht herangezogen zu werden. Einwirkungen über Umweltmedien unterhalb des Schutzbereichs des Gesundheitsschutzes berühren dagegen nicht die Pfiicht zur Achtung der Menschenwürde. Einerseits ist die Menschenwürde ein $z u$ erhabener Wert, um gegen Belästigungen sozusagen in kleiner Münze eingesetzt zu werden ${ }^{41}$, zum anderen ist sie ein derart abstrakter Wert, da $B$ in die Konkretisierung zur Abwehr von Belästigungen viele andere Abwägungsgesichtspunkte einflössen und so die Anwendung nicht mehr praktikabel sein könnte.

b) Wirkrichtung der Umweltgrundrechte. Schon vom Schutzbereich her decken also die Grundrechte das Gebiet des Umweltschutzes zwar zu einem wichtigen, doch aber nur geringen Teil. Ihre Schutzwirkung ist zusätzlich zu differenzieren. Sie gelten vor allem als Abwehrrechte gegenüber der öffentlichen Gewalt. Da Umweltbeeinträchtigungen sich in tatsächlichen Einwirkungen vollziehen, richten sie sich zunächst in den Grenzen ihres Schutzbereiches gegen umweltbelastende Realakte

39 Zum Recht aus Art. 2 II GG auf Gewährleistung des Existenzminimums siehe G. Dürig in: Maunz/Dürig/Herzog/Scholz (Anm. 29), Art. 2 II, Rndnr. 27. Zur Ubertragung auf den Umweltbereich: H. H. Klein, Festschrift für W. Weber (Anm. 30), S. 647; H. Steiger (Anm. 27), S. 42, 54; J. Dellmann: Zur Problematik eines „Grundrechts auf menschenwürdige Umwelt", DOV 1975, S. 588; R. Scholz (Anm. 27), S. $13 \mathrm{f}$.

40 R. Scholz (Anm. 27), S. 14 links. Zur Feststellung, daß das „ökologische Existenzminimum" durch die gegenwärtige Gesetzgebung gesichert ist, siehe $M$. Kloepfer (Anm. 27), S. 22 und dort Fußnote 51.

41 So G. Dürig in: Maunz/Dürig/Herzog/Scholz (Anm. 29), Art. 1 I, Rndnr. 16 und 29; ihm folgend H. Steiger (Anm. 27), S. 36. 
des Staates selbst42. Das Abwehrrecht kommt auch als gegen einen Eingriff gerichtet zum Tragen, wenn der Staat eine benutzbare Einrichtung schafft, deren bestimmungsgemäße Nutzung durch Dritte die Gesundheit oder das Eigentum verletzt. So ist der Staat im Grundrechtsbereich für die Lärm- und Immissionsbelastung durch die Verkehrsteilnehmer auf einer Straße dann verantwortlich, wenn von Dauer und Intensität her Gesundheitsschäden dadurch verursacht werden. Die unmittelbare Verantwortlichkeit ergibt sich aus der entsprechenden Anwendung der Zurechnungsfigur des Zweckveranlassers ${ }^{43}$. Eine unmittelbare Verantwortlichkeit träfe den Staat auch für Umweltbelastungen, die aus einem durch Verwaltungsakt oder Rechtsnorm gebotenen Handeln durch Dritte entstehen. Hier stellt das Gebot zu einem das Grundrechtsschutzgut verletzenden Handeln den Eingriff dar. Als Beispiel wäre an eine ordnungsrechtliche Handlungsanweisung an den Störer zu denken, wenn die gefahrenbeseitigende Handlung die Umwelt belastet.

Auch soweit der Schutzbereich von Art. 2 II und 14 I GG durch Umweltbeeinträchtigungen betroffen wird, können diese Einwirkungen demnach nur zum kleinen Teil dem Staat sozusagen als Eingriff zugerechnet werden. Als eigentliches Problem der Grundrechtsargumentation im Umweltschutz wird deshalb das Zur-Wirkung-Bringen von Grundrechten gegenüber Umweltbelastungen bezeichnet, die von Bürgern ausgehen. Da die einzelnen Grundrechte nicht unmittelbar im Verhältnis zwischen den Bürgern gelten, wird diese Problematik unter der wohl nicht ganz treffenden Bezeichnung der Drittwirkung diskutiert ${ }^{44}$. Wie die Grundrechte allgemein, so sind

42 Als Beispiel sei auf den Sachverhalt im Fall des Hannoverschen Paketpostamts hingewiesen (OVG Lüneburg, OVGE 12, 340; dazu auch V. Götz: Allgemeines Polizei- und Ordnungsrecht, 5. Auflage, Göttingen 1978, S. 107); dort störte das nächtliche Verladen der Pakete durch Lärmbelästigung die Nachtruhe.

43 Vgl. dazu V. Götz (Anm. 42), S. 100 ff.; W. Martens in: Drews/ Wacke/Vogel/Martens: Gefahrenabwehr, Bd. II, 8. Aufl., Köln 1977, S. $194 \mathrm{ff}$. Zur konkreten Verantwortlichkeit des StraBenherrn für Verkehrslärm siehe $\mathrm{BGHZ} 64,220$; einschränkend $\mathrm{BGH}$, Urteil v. 13. 1. 1977, - III ZR 6/75 -, DVBl. 1977, S. 523.

4 So von H. Dellmann (Anm. 39), S. 590; J. Lücke (Anm. 34), S. 290 f.; $H$. Steiger (Anm. 27), S. 64 f.; M. Kloepfer (Anm. 27), S. 19; R. Scholz (Anm. 27), S. 14 rechts.

Unter Drittwirkung der Grundrechte wird im engeren Sinne deren Geltung für die Rechtsbeziehungen zwischen den Bürgern, z. B. im Zivilrecht, verstanden. Im öffentlich-rechtlichen Umweltschutzrecht wirken die Grundrechte selbstverständlich nicht zwischen den Bür- 
auch Art. 2 II und Art. 14 I GG maßgeblich dafür, ob und wie der Staat das Verhältnis zwischen den Bürgern regelt. Ausgangspunkt einer solchen Wirkung ist das Verständnis der Grundrechte über ihre Funktion als Abwehrrechte hinaus dahingehend, daß sie zugleich „objektivrechtliche Wertentscheidungen der Verfassung dar(-stellen), die für alle Bereiche der Rechtsordnung gelten und Richtlinien für Gesetzgebung, Verwaltung und Rechtsprechung geben"445. Aus diesem Richtliniencharakter der Wertentscheidung können sich in Verbindung mit der Pflicht aus Art. 1 I 2 GG zur Achtung und zum Schutz der Menschenwürde verfassungsrechtliche Schutzpflichten ergeben. Utber das Verbot unmittelbarer staatlicher Eingriffe hinaus kann das vor allem bedeuten, daß das Schutzgut vor rechtswidrigen Eingriffen von seiten anderer zu bewahren ist. Entsprechend dem Rang, der dem menschlichen Leben in der Wertordnung des Grundgesetzes zukommt, hat so mit jenem Grundrecht der Staat verfassungsrechtlich die Verpflichtung auf sich genommen, das Leben mit äußersten Kräften zu schützen ${ }^{46}$. Entsprechendes dürfte für einen Schutz gegen schwere Eingriffe in die körperliche Unversehrtheit gelten.

Wie der Staat allerdings diese seine Schutzpflichten erfüllt, ist von den jeweils kompetenten Organen, also von dem Gesetzgeber oder im Einzelfall von der Exekutive zu entscheiden ${ }^{4}$. Lediglich in besonders gelagerten Fällen kann sich die Freiheit der Wahl zwischen verschiedenen Wegen und Mitteln zur Anwendung eines bestimmten Mittels verengen. Nur in einem solchen, selten anzunehmenden Fall kann aus dieser Schutzpflicht eine Pflicht zu einer bestimmten staatlichen Maßnahme abgeleitet werden. Die Herleitung aus objektivem Recht bedeutet zudem, daß ein Individualrecht, das auch noch gerichtlich verfolgbar wäre, auf einen solchen Schutz nur in besondeden Lagen hergeleitet werden könnte.

gern; es geht aber darum, welchen Einfluß die Grundrechte des Belasteten auf die staatlichen Maßnahmen gegenüber dem Verursacher der Belastung haben.

43 Kalkar-Beschluß, BVerfGE 49, 89 (142), dort Nachweise der ständigen Rechtsprechung.

40 BVerfGE 39, 1 (42) - Urteil zum Schwangerschaftsabbruch und Urteil zur terroristischen Erpressung (Schleyer), E 46, 160 (164). Zur Schutzpflicht aus Art. 2, II GG vgl. auch BVerfGE 49, 304 (320), wonach der in Einklang mit Art. 2 II GG gesetzlich gewährte Anspruch aus $\$ 823$ I BGB nicht im Wege der richterlichen Rechtsfortbildung verkürzt werden darf.

47 BVerfGE 39, 1 (44); BVerfGE 46, 160 (164 f.). 
Wenn der Staat das Verhalten der Bürger zueinander oder das Verhalten der Bürger insoweit, als es Auswirkungen auf andere Bürger haben kann, derart regelt, daß die Umweltbelastung vermindert wird, so übernimmt der Staat nicht positiv die Verantwortung für die von den Bürgern verursachten Umweltbeeinträchtigungen. Die in solchen Gesetzen oder in Einzelmaßnahmen nicht verbotenen Belastungen würden durch ein solches Begrenzen der Beeinträchtigungen nicht zu Eingriffen des Staates ${ }^{48}$. Gleichfalls handelt es sich um die Anwendung einer solchen objektivrechtlichen Richtlinie, wenn der Staat als Aufsichtsmittel über möglicherweise umweltgefährdende Tätigkeiten die Figur des Verbots mit Genehmigungsvorbehalt einsetzt. Mit der Genehmigung einer Anlage oder eines Tuns regelt der Staat im Einzelfall die Beziehungen des Betreibers $\mathrm{zu}$ anderen Bürgern und zur Allgemeinheit. Auch in diesem Fall bedeutet die Immission aus der genehmigten Anlage nicht einen staatlichen Eingriff in die Gesundheit des Anwohners ${ }^{49}$,

48 So stellt die Begrenzung radioaktiver Belastung durch das Festsetzen von Dosisgrenzwerten in der Strahlenschutzverordnung keinen Eingriff in Grundrechte dar: So V. Götz: Zur VerfassungsmäBigkeit der Dosisgrenzwerte, Viertes Deutsches Atomrechtssymposium 1975 in Göttingen, Köln 1976, S. 177 ff., 181, 185; VGH Baden-Württemberg, Beschluß v. 8. 10. $1975-\mathrm{X} 351 / 75-$, DVB1. 1976, S. 538 (543). Der Beschluß des OVG Lüneburg vom 22. 11. 1976 - VII OVG B 76/74. DVBl. 1977. S. 340 (342) spricht auch von keinem Eingriff durch Festsetzen der Dosiswerte in der VO, sieht aber einen Konflikt mit dem Gebot, daß der Gesetzgeber die Entscheidung selbst treffen müsse, als möglich an. Eindeutig wird der Eingriffscharakter verneint in den Urteilen des VG Oldenburg zum Kernkraftwerk Unterweser vom 27. 7. 1978 und vom 15. 9. $1978-$ z. B. im Verfahren I A 443/73, S. 45 der Urteilsgründe.

49 Dem kann nicht entgegengehalten werden, es könne kein entscheidender Unterschied sein, ob der Staat die Immissionen selbst verursache oder ob er unterlasse, gegen sie zu schützen; so aber J. Baltes: Immissionsgrenzwerte und Art. 2 Abs. 2 GG, BetriebsBerater 1978, S. $131 \mathrm{ff}$. (132). Von seiner besonderen Sicht der Wirkrichtung der Grundrechte her kommt J. Schwabe: Probleme der Grundrechtsdogmatik, Darmstadt 1977, S. $213 \mathrm{ff}$., über die staatliche Achtungspflicht bei allen genehmigten Immissionen, die den Schutzbereich von Art. 2 II GG verletzen, zu einer Grundrechtsverletzung durch den Staat. Verursache der Staat die Immission nicht selbst, so lege er dem Betroffenen, indem er ihm kein Abwehrrecht zuordne, eine Duldungspflicht auf, womit er sich die Belastung zurechnen lassen müsse. Mit dieser Konstruktion möchte er bewußt die Drittwirkungsbegrenzung relativieren. Dagegen steht die allgemeine Auffassung von der Funktion der Grundrechte, im Bereich des Umweltschutzes, u. a. die der in Anm. 44 Genannten. 
sondern eine Beschränkung der Handlungsfreiheit des Betreibers dieser Anlage, bei der die Genehmigungsbehörde die objektivrechtliche Wertentscheidung für die Erhaltung der körperlichen Unversehrtheit der Bürger aus Art. 2 II GG zu berücksichtigen hat.

Diese Beurteilung ergibt sich aus der Art jener aus den Grundrechten hergeleiteten Schutzpflicht. Daß der Staat in der jeweiligen gesetzlichen Ausgestaltung jener Beschränkung den möglicherweise Betroffenen subjektive Rechtspositionen einräumt ${ }^{50}$, steht dazu nicht im Widerspruch.

\section{Umweltschutzaufgabe aus der Sozialstaatsklausel?}

Außerhalb der Grundrechte wird auf die Sozialstaatsklausel als Grundlage einer verfassungsrechtlichen Verpflichtung des Staates zu Umweltschutzmaßnahmen verwiesen, regelmäßig ohne nähere Begründung ${ }^{51}$. In der Aufzählung der aus dem Sozialstaatsprinzip herzuleitenden materiellen staatlichen Handlungspflichten berichtet Stern in seinem Staatsrecht ${ }^{52}$ über diese dem Sozialstaatsprinzip neu zugedachte Folge erst unter „i“. Diese Aufgabe träte also selbst im Rahmen der Sozialstaatsklausel in Konkurrenz zu einer Reihe anderer Aufgaben.

Auch steht die Zulassung einer Nachbarklage in dem obiter dictum des BVerwG (E 32, 173 (178) und danach) aus Art. 14 GG der hier vertretenen Auffassung nicht entgegen, wird doch dort als Ausnahme die besondere Situationsgebundenheit des Grundstückes betont, das in seinem Wert durch die behördliche Entscheidung über ein Nachbargrundstück mit bestimmt wird, dann, wenn die Grundstückssituation nachhaltig verändert und dadurch der Nachbar „,schwer und unerträglich" getroffen wird. - Die entsprechende Rechtsprechung des BVerwG zum Wasserrecht betrifft nicht die Verschmutzung oder den Umweltschutz, sondern die Entnahme von Wasser derart, daß es den Klägern nicht mehr wie bisher zur Verfügung steht: BVerwGE 36, 248 (251 f.) und Urteil vom 20. 10. 1972 - IV C 107. 67 -, ZfW 1973, S. 99 (104).

so So werden z. B. $\$ 7$ II Nr. 2 und 4 AtomG (a. F., jetzt II Nr. 3 und 5) ebenso wie $\$ 5 \mathrm{Nr} .1 \mathrm{BImSchG}$ als nachbarschützend angesehen: siehe statt vieler Entscheidungen VGH Baden-Württemberg, Beschl. 8. 10. 1975 - X 351/75 -, DVBl. 1976, S. 538 (541).

51 Lediglich Hinweise finden sich bei J. Kölble: Staat und Umwelt, DOV 1977, S. 1 (3) und Fußnote 19; skeptisch $H$. Steiger (Anm. 27), S. 69 f.; K. Stern (Anm. 9), S. 708. Bull sagt sogar ausdrücklich, außer dieses Hinweises bedürfe die verfassungsrechtliche Pflicht keiner Begründung: $H$. P. Bull: Die Staatsaufgaben nach dem Grundgesetz, Frankfurt 1973, S. 224.

s2 K. Stern (Anm. 9), S. $708 \mathrm{f}$. 
Ohne nähere Konturen und deutlich deduzierbare Konkretisierung müßte die Intensität und der Weg zur Erfüllung einer solchen Aufgabe dem Gesetzgeber überlassen bleiben. Dafür aber, daß sich der Staat überhaupt des Umweltschutzes annimmt, bedarf es einer solchen Begründung nicht. Entsprechend der Warnung von Stern $^{53}$, daß die verfassungsrechtliche Herleitung von Staatsaufgaben aus der Sozialstaatsklausel mit der Entscheidungsfreiheit des Gesetzgebers und damit mit dem Demokratieprinzip in Kollision gerät, wird man auf eine Deduktion der Staatsaufgabe Umweltschutz aus der Sozialstaatsklausel verzichten müssen und auch können.

Das Durchmustern des Grundgesetzes auf eine Willensbildung des Staates auf höchster Ebene zur Ubernahme der Umweltschutzaufgaben hin erbringt ein bescheidenes Ergebnis. Lediglich erhebliche Gefährdungen von Leben, körperlicher Unversehrtheit und Sachbesitz durch die Umweltmedien fallen in den Schutzbereich von Grundrechten. Gegenüber Schädigungen durch Umweltbelastungen von seiten des Staates hat der Bürger ein Abwehrrecht; objektivrechtlich besteht, gestaffelt nach Intensität der Gefährdung, eine Schutzpflicht des Staates, die nach Entscheidung der zuständigen Organe auszuführen ist. Eine weiterreichende Aufgabenübernahme läßt sich aus dem Grundgesetz selbst nicht herleiten ${ }^{54}$.

Dieses Ergebnis darf weder enttäuschen noch erschrecken. Die von der Staatslehre her unbedingt staatliche Aufgabe, nach der jeweiligen Lage zur Auseinandersetzung mit ihr die Staatsaufgabe $\mathrm{zu}$ wählen, wäre unangemessen beschränkt, wollte man alle Staatstätigkeit nur als Verfassungsvollzug verstehen $^{55}$ oder eine verfassungsrechtliche materielle Legitimierung verlangen. Ein solcher Legitimierungszwang würde auch lediglich dazu führen, eine Generalklausel über „good government" aufzubauen, die zu einer Schein-Legitimation und zu der Gefahr führte, daß der Interpret dieser Klausel den demokratisch legitimierten Organen die Aufgaben vorschreiben und absprechen könnte.

\section{Umweltschutzbemühungen in der Bundesrepublik Deutschland}

Der Staat hat im Willensbildungsprozeß unterhalb der Verfassung in breitem Umfang Aufgaben des Umweltschutzes auf

ss K. Stern (Anm. 9), S. 710.

54 So auch J. Köble (Anm. 51), S. 3.

ss Krüger (Anm. 7), S. 696, 707. 
sich genommen und dabei erhebliche Erfolge erzielt. Allein auf der Ebene des Bundes sind Regelungen zu den Bereichen der Wasserwirtschaft, der Luftreinhaltung, der Landschaftspflege und des Naturschutzes sowie zur Kontrolle störender Energien in Form von Lärm, Abwärme und Strahlung und schließlich elementeübergreifend zur Begrenzung von Schadstoffen und Fremdstoffen in Lebensmitteln und im Bereich der Abfallbeseitigung ergangen. Die zweibändige Sammlung der Vorschriften von Kloepfer ${ }^{58}$ ist nicht einmal erschöpfend, und aus dem internationalen Regelungsbereich lassen sich viele Vorschriftenbände daneben stellen.

Die Tätigkeit der öffentlichen Hand selbst und die Eingriffe und Regelungen gegenüber den Umweltbenutzern in den letzten Jahren haben eine beachtliche Wirkung gezeigt. Wie das Umweltgutachten 1978 des Rates von Sachverständigen für Umweltfragen ausweist, konnte die Tendenz zur steigenden Belastung der Umweltmedien in einer Anzahl von Bereichen aufgehalten und auch in Richtung auf eine Besserung hin gewendet werden. Im Abwasserwesen dürfte die Gewässerbelastung mit abbaubaren, im biochemischen Sauerstoffbedarf (BSB5) erfaßbaren Stoffen ihren Höhepunkt überschreiten. Der Anschlußgrad an Sammelkanalisationen hat $90 \%$ der Einwohner erreicht. Im Grundstoff- und Produktionsgütergewerbe nehmen die Umweltschutzinvestitionen eines Jahres mit 1,7 Mrd DM 9,5\% des gesamten Investitionsvolumens ein. Die Gesamt-Staubemissionen gingen von 2,5 Mrd Tonnen 1965 auf 1,2 Mrd Tonnen 1974 zurück. Gleichfalls ist die Blei- und Zinkbelastung wesentlich reduziert. Die Verminderung des Ausstoßes anderer Belastungen wie $\mathrm{SO}_{2}$ in die Luft ist allerdings nur gering vermindert, $\mathrm{CO}_{2}$ wird mit der zunehmenden Verfeuerung fossiler Brennstoffe vermehrt abgegeben. Eine deutliche Umweltverbesserung hat sich auch im Bereich der Abfallbeseitigung nach Anwendung des Abfallbeseitigungsgesetzes, das den Ablieferungszwang und die Abfallbeseitigung vorschrieb, ergeben ${ }^{57}$.

Mit diesen wenigen Beispielen sei dokumentiert, daß die Umweltschutzmaßnahmen der letzten Jahre einen deutlichen

\footnotetext{
36 M. Kloepfer (Hrsg.): Deutsches Umweltschutzrecht, Loseblattslg.

${ }_{57}$ Umweltgutachten 1978 (Anm. 1), Nr. 354, 358, 500, 533. Zum Investitionsvolumen im Grundstoff- und Produktionsgütergewerbe mit Schwerpunkten in der Mineralölverarbeitung, dem Bereich Steine und Erden, der eisenschaffenden, der chemischen und der Zellstoff- und Papierindustrie im Jahre 1976, siehe Statistisches Jahrbuch 1979, S. 541.
} 
Erfolg zeigen. Bei notwendigen weiteren Anstrengungen erscheint die Hoffnung begründet, der weiteren Umweltbelastung Einhalt gebieten und die Umweltbedingungen wirklich bessern zu können. Anstrengungen lohnen sich, für Resignation besteht kein Anlaß.

\section{Entscheidungskompetenzen über Intensität von Umwelt- schutzanforderungen}

Die staatlichen Umweltschutzanstrengungen werden seit Mitte der 60er Jahre verstärkt. Angesichts der weit fortgeschrittenen Umweltbelastung in der Bundesrepublik Deutschland und des Trends zu weiterer Verschlechterung erschienen die Maßnahmen insgesamt und je einzeln gerechtfertigt. Mit der Praxis und auch mit dem Engerwerden des Maßnahmennetzes zeigen sich jedoch schwerwiegende Probleme, die die Bevölkerung, die Wirtschaft und den Staat mit Gesetzgeber, Exekutive und Gerichtsbarkeit in den Bann ziehen. Davon soll hier ein Ausschnitt behandelt werden.

Die Gesamtnutzung der Umwelt zu einem hohen und doch verträglichen Grade dürfte dadurch ermöglicht werden, daß man einander störende Nutzungen hinreichend räumlich trennt. Dies ist der Umweltschutzansatz der Planung, der im Mitbericht abgehandelt wird. Erörterungswürdig sind auch die Rechtsfragen, die durch die gesetzliche Utbernahme von Umweltschutzaufgaben, besonders bei der Abfallbeseitigung, durch die Körperschaften erwachsen. Hingewiesen sei nur auf die Lage im Bereich der nuklearen Entsorgung: Gesetzlich sind die Besitzer radioaktiver Abfallstoffe zur Ablieferung an staatliche Stellen, Länder und Bund zur Errichtung von Sammel- und Endlagern verpflichtet ${ }^{58}$. Während der Staat einerseits der gesetzlichen Errichtungspflicht nicht nachkommt, macht er andererseits die Entsorgungsvorsorge zur Genehmigungsvoraussetzung ${ }^{59}$. Zeitgründe erlauben die Behandlung dieses Komplexes nicht.

58 Die Ablieferungspflicht ergibt sich aus $\$ 9$ a II AtG und $\S 47$ StrlSchV, die Errichtungspflicht für Sammel- und Endlager aus § 9 a III AtG.

59 So in den "Grundsätzen zur Entsorgungsvorsorge für Kernkraftwerke" des Bundesinnenministers vom 14. 6. 1977, abgedruckt als Anlage 1 zu BT-Drucks. 8/1281 v. 30. 11. 1977. - Das VG Schleswig, Beschl. v. 9. 2. 1977 - 10 D 176/76 -, DVB1. 1977, 358 (359 f.) und das OVG Lüneburg, Beschl. v. 17. 10. 1977 - VII OVG B 22/77 - DVBl. 1978, 67 (73) halten in Sachen Brokdorf die Ent- 
Erörtert werden sollen die Probleme der Intensität von hoheitlichen Umweltanforderungen und die Verteilung der Entscheidungen auf Gesetzgeber, Exekutive und Verwaltungsgerichtsbarkeit; die Beispiele sollen aus den Auseinandersetzungen über Großanlagen entnommen werden.

\section{Bindung und Entscheidungskompetenz des Gesetzgebers}

Der Gesetzgeber muß die wesentlichen Entscheidungen zur Regelung der Umweltnutzung durch Konsumenten und Produzenten und zur umweltschützenden Beschränkung dieser Nutzung nach der Wesentlichkeitslehre des Bundesverfassungsgerichts selbst treffen ${ }^{80}$. Es handelt sich beim Umweltschutz nämlich um grundlegend normative Bereiche, die auf der Seite des am Schutz Interessierten die Ausübung der Grundrechte nach Art. 2 II und Art. 14 I GG berühren können; auf der Seite der Ge- und Verbotsadressaten sind die Berufsfreiheit, die Nutzung des Eigentums und die allgemeine Handlungsfreiheit betroffen ${ }^{\theta 1}$, für Eingriffe ist also stets ein Gesetz erforderlich.

a) Grenzen der Bindung durch das grundrechtliche Schutzgebot Die Entscheidungskompetenz des Gesetzgebers ist begrenzt durch die aus Art. 2 II in Verbindung mit Art. 1 I GG hergeleiteten Schutzpflichten. Wie das Abwehrrecht aus Art. 2 II GG aber unter Gesetzesvorbehalt steht, so kann der Gesetzgeber unter entsprechenden materiellen Voraussetzungen die Grenzen der Schutzpflicht bestimmen; d.h. er kann bei der Konkretisierung der Schutzpflicht zum Ausdruck bringen, der Einsatz welcher Mittel dem Schutzauftrag des Staates genügen sollte. Angesichts des Ranges der Grundrechtsgüter Leben und Gesundheit läge es nahe, ein Zurückbleiben des staatlichen Schutzes nur dann hinzunehmen, wenn auch die Schutzmaß-

sorgungsvorsorge nach $\S 9$ a AtG für eine Genehmigungsvoraussetzung im Rahmen von $\$ 7$ II AtG. - Die Entsorgungsvorsorge nach $\$ 9$ a halten demgegenüber nicht für eine Genehmigungsvoraussetzung für die Errichtung von Kernkraftwerken: VG Freiburg, Urt. v. 14. 3. 1977 - VS II $27 / 75-$, Energiewirtschaftliche Tagesfragen (= ET) 1977, 626 (635); VG Würzburg, Urt. v. 25. 3. $1977-$ Nr. W 115 II $74-$, ET 1977, $444(463,464$ f.); VG Karlsruhe, Beschl. v. 18. 8. 1978 - IV $19 / 78-$, DVBl. 1978,856 (859) und dazu bestätigend VGH Baden-Württemberg, Beschl. v. 26. 2. $1979-\mathrm{X}$ 3908/78 -, ET 1979, 211 (213 f.).

o BVerfGE 49, 89 (126 f.) (Kalkar) mit weiteren Nachweisen.

o1 Vgl. BVerfGE 49, 89 (127). 
nahme mit den Grundrechten auf Leben und Gesundheit anderer kollidierte. Die Eingriffe in die körperliche Unversehrtheit z. B. nach $\S 81$ a StPO werden aber nicht aus der Grundrechtskollision gerechtfertigt, sondern mit Erfordernissen der Strafrechtspflege als wichtigem Gemeinschaftsgut ${ }^{62}$. Nach dem Verfassungsgerichtsurteil, das gerade die Schutzpflicht aus Art. 2 II GG besonders betont, kann die Schutzverpflichtung für das Leben des Nasciturus auch aus Rücksicht auf das Freiheitsrecht aus Art. 2 I GG eingeschränkt werden ${ }^{63}$. Auf dieser Grundlage sind 1978 in über 49000 Fällen lebensvernichtende Schwangerschaftsabbrüche nicht aus medizinischen Gründen, sondern - wie es heißt - zur Abwendung einer sonstigen schweren Notlage vorgenommen worden ${ }^{64}$.

Wirtschaftliche Gründe und das Hinnehmen eines Bedürfnisses an Lebensfreude haben den Gesetzgeber bewogen, es bei den Straßenverkehrsvorschriften bewenden zu lassen, obwohl wir weiterhin rund 15000 Verkehrsunfalltote jährlich zählen ${ }^{65}$.

Diese jeweilige Begrenzung in der Schutzintensität auf die gesetzlich ausgestalteten Mittel stellt keinen „Eingriff“ in das Recht auf Leben und körperliche Unversehrtheit dar; weder das Straßenverkehrsgesetz noch $\S 218$ a StGB müßten entsprechend der Zitierklausel auf eine Einschränkung des Lebensrechts hinweisen ${ }^{66}$.

Die vom Gesetzgeber auszuübende und zu konkretisierende Schutzpflicht aus Art. 2 II und 1 I GG ist zudem von sich aus nicht unbegrenzt. Wie das Bundesverfassungsgericht im Kalkar-Beschluß selbst zu den streng formulierten Anforderungen des Atomgesetzes betont hat, müssen Grundrechtsgefährdungen nicht mit absoluter Sicherheit ausgeschlossen werden ${ }^{67}$. Entsprechend dem sich entwickelnden Sprachgebrauch gilt die Schutzpflicht gegenüber der Gefahr für Leben und Gesundheit.

\footnotetext{
62 Siehe BVerfGE 16, $194 \quad(200-202)$ zur Liquorentnahme; BVerfGE, 17, 108 (117 ff.).

os BVerfGE 39, $1(43,50)$.

64 Angaben im Statistischen Jahrbuch 1979, S. 372. - Es ist hier nicht der Ort zu untersuchen, ob das Bundesverfassungsgericht dieses Ergebnis wirklich für verfassungsrechtlich hinnehmbar erklären wollte.

65 Statistisches Jahrbuch 1979, S. 298.

60 Insofern ist der Hinweis auf die Zitierklausel im Kalkar-Beschluß - BVerfGE 49, 89 (141) zumindest überflüssig: Während es sich bei den in $\$ 12$ I Nr. 4 AtG vorgesehenen ärztlichen Untersuchungen vielleicht um Eingriffe in die körperliche Unversehrtheit handelt, fehlt bei einem Zurückbleiben der Schutzausübung schon die Grundrechteinschränkung.

${ }^{67}$ BVerfGE 49, 89 (143 ff.).
} 
Die Abgrenzung der Gefahr von dem fernerliegenden Risiko ist zu einem zentralen Streitpunkt des Umweltschutzrechts geworden ${ }^{68}$. Polizeirechtlich liegt eine Gefahr vor, wenn eine Sachlage bei objektiv zu erwartendem, ungehindertem Geschehensablauf hinreichend wahrscheinlich zu einem Schaden führt $^{69}$. Die Anforderungen an die Wahrscheinlichkeit werden zum Teil durch Gesetzesformulierungen differenziert. Allgemein wird die Formel verwendet, daß, je schwerwiegender der potentielle Schaden sei, um so geringere Anforderungen an die Eintrittswahrscheinlichkeit zu stellen seien. Zum Schutz des einzelnen Bürgers reicht ein wenig wahrscheinlicher Schadenseintritt schon für die Annahme einer Gefahr, wenn Grundrechtsgüter höchsten Ranges wie das Leben auf dem Spiel stehen ${ }^{70}$. Da es kein höheres individuelles Rechtsgut als das Leben gibt, ist hiermit für den Gefahrenbegriff im Rahmen des grundrechtlich herzuleitenden Schutzgebotes der höchste potentielle Schaden gekennzeichnet. Die Möglichkeit gleichzeitiger Tötung oder Schädigung mehrerer oder vieler bis hin zur nationalen Katastrophe kann nur noch den Allgemeinschaden erweitern und die Gefahrenschwelle zum Zweck der Eingriffslegitimation gegenüber dem potentiellen Verursacher ermäßigen.

$\mathrm{DaB}$ der Schutzanspruch des Einzelnen durch das kumulierte Risiko einer Bevölkerung in ihrer Gesamtheit - das gegebenenfalls den Staat zu höheren Anforderungen legitimiert nicht verschärft wird, hat das OVG Münster schon im zweiten Würgassen-Urteil 1975 betont ${ }^{71}$. Die zum gegensätzlichen Er-

${ }_{6}^{6}$ Vgl. A. Hanning und K. Schmieder, Gefahrenabwehr und Risikovorsorge im Atom- und Immissionsschutzrecht, Der Betrieb, Beilage Nr. 14/77, S. 1 ff.; $R$. Breuer, Gefahrenabwehr und Risikovorsorge im Atomrecht, DVBl. 1978, S. 829 ff.; B. Bender Gefahrenabwehr und Risikovorsorge als Gegenstand nukleartechnischen Sicherheitsrechts, NJW 1979, S. 1425 ff.

${ }^{60}$ Siehe V. Götz, Polizeirecht (Anm. 42), S. 56 und ders., Verfassungsmäßigkeit der Dosisgrenzwerte (Anm. 48), S. 181 f.; $K$. $H$. Friauf: Polizei- und Ordnungsrecht in: v. Münch, Bes. VerwR, 5. Aufl. Berlin 1979, S. 163 (187 ff.).

${ }^{70}$ Siehe die in Anm. 69 Genannten und W. Martens in: Drews/ Wacke/Vogel/Martens, Gefahrenabwehr, 8. Aufl. 2. Bd., Köln 1977, S. 108 ff. - BVerwG, Urt. v. 26. 6. 1970 - IV C $99.67-$, DOV 1970, 713 (715); BVerwGE 47, 31 (40). Siehe auch Kalkar-Beschluß des BVerfG, E 49, 89 (138).

${ }^{71}$ Urteil vom 20. 2. 1975 - VII A 911/69 -, ET 75, S. $220(223$, 227). Vgl. auch VG Karlsruhe, Beschl. v. 18. 8. 1978 - IV 19/78 -, DVBl. 1978, 856 (858) und jüngst Bay. VGH, Urt. v. 9. $4.1979-\mathrm{Nr}$. 167 VI $77-$, DVBl. 1979, 673 (675 rechts). 
gebnis führende Annahme, daß eine größere Bevölkerungsdichte die Wahrscheinlichkeit für den Eintritt eines Einzelschadens erhöht ${ }^{72}$, verkennt die statistische Wahrscheinlichkeitsaussage: Wenn zusätzlich zum allgemeinen Risiko ein Ereignis mit einer Wahrscheinlichkeit von 1:1000 000 zum Tode führt, bedeutet das nicht, daß bei einer Million Betroffenen einer stirbt, sondern daß für alle gleichermaßen Betroffenen gleichermaßen ein Risiko von 1:1000 000 besteht.

Die Abgrenzung der Gefahr vom verbleibenden Restrisiko nach dem Grad der Wahrscheinlichkeit wird mit dem Argument bekämpft, die Unterscheidung müsse notwendig unscharf bleiben ${ }^{73}$, es könne nur an einem qualitativen Sprung abgegrenzt werden. Abgrenzungen nach dem Intensitätsgrad sind dem Rechtswesen aber geläufig und werden auch geleistet. Wenn sich die Grenzen auch nicht ohne autoritative Setzung genau bestimmen lassen, so ist ein Urteil, eine bestimmte Intensität läge gewiß unter einer Grenze, sicher zu fällen. Eine Situation stellt dann mit Sicherheit keine Individualgefahr im Rahmen grundrechtlicher Schutzpflicht für Leben und Gesundheit dar, wenn sie zu dem allgemeinen Lebensrisiko der konkreten Person nichts Wesentliches hinzufügt ${ }^{74}$. Derartige Bewertungen setzen, in manchen Bereichen gewi $B$ angreifbare, probabilistische Abschätzungen der Schadenseintrittswahrscheinlichkeit voraus ${ }^{75}$. Eine Gefahr liegt auch dann mit Gewißheit nicht vor, wenn nach deterministischer Analyse nach den Erkenntnissen fachkundiger Naturwissenschaftler und Techniker nach menschlichem Ermessen mit einem Schaden nicht zu rechnen ist, er also praktisch ausgeschlossen erscheint ${ }^{76}$.

${ }^{22}$ So offensichtlich OVG Lüneburg, Beschl. v. 22. 11. 1976 - VII OVG B 76/74 -, DVBI. 1977, 340 (344); zuletzt Urt. v. 22. $12.1978-$ VII A $61 / 74-$, DVBl. 1979, 686 (692).

73 So $H$. Albers: Atomgesetz und Berstsicherung für Druckwasserreaktoren, DVBl. 1978. $22(23,26)$; B. Bender (Anm. 68), S. 1428.

Ein absoluter Ausschluß einer jeden Schadensmöglichkeit kann aber rechtlich nicht verlangt werden: BVerfGE 49, 89 (143). In der Rspr. zu Kernkraftwerken schon OVG Münster, Urt. v. 20. 2. 1975 - VII A 911/69 一, ET 1975, $220(229)=2$. Würgassenurteil.

${ }^{74}$ Entsprechend VG Oldenburg, Urt. v. 15. 9. 1978 - I A 443/73, S. 51.

${ }^{75}$ Siehe dazu $R$. Lukes: Die Verwendung von Risikoanalysen in der Rechtsordnung unter besonderer Berücksichtigung des Kernenergierechts, BB 1978, 317 ff. und R. Breuer (Anm. 68), S. 835. Zur Beurteilung in der Rspr. siehe schon OVG Münster, 2. Würgassenurteil (Anm. 73), S. 229 rechts.

${ }^{76}$ So VG Oldenburg im Schlußurteil zum Kernkraftwerk Unterweser vom 15. 9. 1978 - I A 443/73 -, S. 51; R. Breuer (Anm. 68), S. 835 mit Nachweisen. 
Der nach dieser Abgrenzung zu unwahrscheinliche, aber nicht unmögliche Schadenseintritt gehört zum Bereich des Restrisikos ${ }^{77}$. Ebenfalls sind ihm zuzurechnen die Situationen, die nicht unmittelbar erkennbar oder auch nur sicher nach statistischer Beurteilung zu einem Schaden führen, für die aber ein kausaler Schaden nicht ausgeschlossen werden kann. Ein Beispiel ist die vorsorgliche Annahme von Spätschäden bei kleinen Dosen radioaktiver Strahlung, für deren Schädlichkeit selbst statistisch keine Belege gefunden sind ${ }^{78}$. Es handelt sich nicht um eine Gefahr, die eine grundrechtliche Schutzpflicht auslösen könnte, sondern um einen Gefahrenverdacht ${ }^{79}$.

In dem verhältnismäßig kleinen Ausschnitt aus dem Umweltschutz, in dem es um den grundrechtlichen Schutz gegen Gefahren für Leben und Gesundheit geht, steht es beim Gesetzgeber, im Rahmen des Gesetzesvorbehalts von Art. 2 II 2 GG die Grenzen der Schutzpflicht $\mathrm{zu}$ bestimmen. Wegen des kategorischen Schutzgebots im Kernbereich und aus Achtung vor der Menschenwürde kann die für die Grenzbestimmung des Schutzes notwendige Abwägung nicht den Weg der Kosten/

77 So OVG Münster, 2. Würgassen-Urteil (Anm. 73), S. 229 links. Danach hat sich dieser Sprachgebrauch durchgesetzt: Siehe am umfassendsten $R$. Breuer (Anm. 68), S. $829 \mathrm{ff}$.

${ }^{78}$ Die aus Gründen der Vorsorge auch für kleine Strahlendosen angenommene Wahrscheinlichkeit somatischer Schäden (Krebserregung) mit 1:10000 je rad beruht auf Beobachtungen bei absorbierten Strahlendosen von über $100 \mathrm{rad}$ (So Report of the United Nations Scientific Committee on the Effects of Atomic Radiation, Gen. Ass., Off. Records, 32nd Session, Suppl. 40 (A 32/40) New York 1977, Nr. 27). Um die Wirkung von Strahlendosen im Bereich von $10 \mathrm{~m}$ rem abzuschätzen, werden so z. B. die beobachteten Beziehungen auf den Bereich von einem Zehntausendstel der Belastung projiziert. - Weil es keinen konkret in Einzelfällen beobachteten oder auch nur statistisch belegbaren Ursachenzusammenhang zwischen der Absorbtion geringer Dosen und Krebserkrankungen gibt, verneint das VG Oldenburg im Schlußurteil zum Kernkraftwerk Unterweser (Anm. 74), S. 42 ff., insoweit die Annahme einer Gefahr und spricht mit Hanning/Schmieder: Gefahrenabwehr und Risikovorsorge im Atom- und Immissionsschutzrecht, Beilage 14/77 zum Betriebsberater von einem bloßen Verdacht einer Gefahr. - Demgegenüber hält das OVG Lüneburg im Beschl. v. 22. 11. $1976-$ VII OVG B 76/74 -, DVB1. 1977, $340(342,344)$ die mangelnde Beweisbarkeit eines Ursachenzusammenhanges für unerheblich: „Das gilt jedenfalls für die vom Verursacherprinzip beherrschten Rechtsbereiche. in denen es nicht darum geht, konkrete Kausalzusammenhänge aufzudecken, ..." (S. 344).

79 So VG Oldenburg (Anm. 78). 
Nutzen-Analyse beschreiten. Abwägung und legislative Dezision kennzeichnen das Verfahren.

b) Bindungen durch das Verhältnismäßigkeitsgebot und den Gleichheitssatz. Bei der Verminderung des Restrisikos im Bevölkerungsinteresse, bei der Eindämmung von Belästigungen, beim Sachgüterschutz und beim Schutz individueller Güter wird eine rationale Entscheidung über die Intensität des Umweltschutzes unter Berücksichtigung von Ziel und Nutzen erwartet ${ }^{80}$. Verfassungsrechtlich zwingt $\mathrm{zu}$ rationaler Abwägung das Verhältnismäßigkeitsprinzip. Nach der ständigen Rechtsprechung des Bundesverfassungsgerichts steht jeder staatliche Eingriff in den grundrechtlich geschützten Bereich - hier der Adressaten der Umweltschutzregelungen - unter dem rechtsstaatlichen Gebot der Verhältnismäßigkeit des Mittels ${ }^{81}$. Nach der herkömmlichen Formulierung des Prinzips der Verhältnismäßigkeit im engeren Sinne darf die Anordnung nicht zu einem Nachteil führen, der zu dem erstrebten Erfolg erkennbar außer Verhältnis steht ${ }^{82}$. Verglichen wird, wie Dürig in der Kommentierung zu Art. 2 I GG deutlich sagt, zwischen dem Nachteil des Betroffenen und dem angestrebten Gemeinwohlzweck $^{83}$. Im Polizeirecht ist der Verfügungsadressat jeweils der Störer, dessen Position bei dieser Abwägung entsprechend schwach ist. Bei der Abwägung gegenüber dem Grundrechtsträger hat deshalb die Rechtsprechung des Bundesverfassungsgerichts nicht an das krasse Mißverhältnis angeknüpft, sondern formuliert, das gewählte Mittel müsse in einem vernünftigen Verhältnis zu dem angestrebten Erfolg stehen $^{84}$.

Der insgesamt angestrebte Erfolg, das Ziel des Umweltschutzes, ist eingangs bestimmt als die Erhaltung und Verbesserung der nachhaltigen Nutzungsmöglichkeiten im weitesten Sinne. Sektoral erklären die Grundsatzbestimmungen der jüngeren Umweltschutzgesetze die Nutzbarkeit zum Ziel, so

80 Umweltgutachten 1978 (Anm. 1), S. 534 ff., insbes. Nr. 1776, $1778,1792$.

${ }^{81}$ BVerfGE 49, 24 (58) - Kontaktsperre - mit Hinweis auf E 24, 367 (404) und 25, 269 (292).

82 Siehe V. Götz, Polizeirecht (Anm. 42), S. 76 mit Nachweisen über die Formulierungen in der Gesetzgebung.

${ }^{83}$ Dürig in Maunz/Dürig/Herzog/Scholz (Anm. 29), Art. 2 I Rdnr. 63.

84 BVerfGE 35, 382 (401) mit Verweisungen auf frühere Rechtsprechung. Jetzt auch E 49, 24 (58). 
$\S 1$ des Bundeswaldgesetzes ${ }^{85}$ von 1975 , $\$ 1$ des Naturschutzgesetzes von 1976 und der 1976 eingefügte $\S 1$ a des Wasserhaushaltsgesetzes. Als erstrebter Erfolg kann somit nicht die Minimierung oder das Verbot der Umweltnutzung deduziert werden.

Die ökonomische Theorie der Umwelt hat einen wohlfahrtsökonomischen Ansatz: Umweltschutz soll solange gesteigert werden, wie umweltschützende Maßnahmen einen größeren Nutzen für die Gesellschaft stiften, als sie Kosten verursachen ${ }^{86}$. $\mathrm{Da}$ trotz vielfältig entwickelter Methoden insbesondere die social costs der zu vermeidenden Umweltbelastung nicht sicher in Geldwert ausgedrückt werden können, ergeben Einzeluntersuchungen und Gesamtrechnungen zwar Einsichten und Tendenzen, aber keinen Vergleich meßbarer Nutzen und Kosten ${ }^{87}$. Wie im Gutachten 1978 des Rats für Umweltfragen festgestellt wird, ist die Umwelttheorie nicht oder nur in seltenen Grenzfällen in der Lage, vor dem Hintergrund $\mathrm{zu}$ vermeidender Schäden einen bestimmten Umweltqualitätsstandard wissenschaftlich exakt ökologisch zwingend zu begründen ${ }^{88}$.

Wenn auch die social costs der Umweltbelastung sicher zu bestimmen wären und der verursachende Produzent und Konsument damit entsprechend belastet würde, könnten theoretisch die Bewertungs-, Regulierungs- und Entscheidungsvorgänge dem Markt oder den Beteiligten überlassen werden ${ }^{8 \theta}$. Dieses unter dem Verursacherprinzip diskutierte Modell liefert Einsichten für die Anwendung des Verhältnismäßigkeitsprinzips, die Einführung einer Abwasserabgabe von 1981 an ist ein sektoraler Versuch.

85 Vom 2. 5. 1975, BGB1. I 1037. Für die folgend genannten Gesetze siehe die Sammlung Sartorius.

${ }^{80}$ H. Siebert (Anm. 10), S. 66, 67 f.; Umweltgutachten 1978 (Anm. 1), S. $537 \mathrm{ff}$.

87 So schon $H$. Soell: Rechtsfragen des Umweltschutzes, WiR 1973, S. $72 \mathrm{ff}$. (79); Umweltgutachten 1978 (Anm. 1), S. 540. - Über die Art der Entscheidungshilfe im Einzelfall, die Tendenzen, aber keine gemeinsamen Meßgrößen geben kann, informiert anschaulich der Bericht: F. Arnold/A. Winkelbrandt: Untersuchung der Umweltverträglichkeit am Beispiel der Autobahn Kiel-Rendsburg, in: $G$. Olschowy (Hrsg.): Natur- und Umweltschutz in der Bundesrepublik Deutschland, Hamburg 1978, S. $374-380$.

88 Umweltgutachten 1978 (Anm. 1), Nr. 1774.

69 Umweltgutachten 1978 (Anm. 1) Nr. 1769, 1765 f. - „Die Bundesregierung versteht das Verursacherprinzip im Umweltschutz als Kostenzurechnungsprinzip; Schadensersatz oder Haftungspflichten werden damit nicht begründet" - so Umweltbericht '76 der BReg., (Vlg. Kohlhammer/Stuttgart) 1976, Nr. 006. 
Nach Abwägung zwischen Gesamtnutzen und Gesamtschaden kann der Gesetzgeber eine Produktion ganz verbieten. Ein Beispiel ist das gesetzliche Verbot der Herstellung und Anwendung von DDT ${ }^{90}$. Der Grad der Erforderlichkeit des Produktes für die Allgemeinheit ist einer der Bewertungsgesichtspunkte. Er konnte für DDT nach einer Utbergangsfrist geringer eingeschätzt werden, weil dieser Wirkstoff durch andere, unschädliche Stoffe substituiert werden kann.

Eine derart eindeutige Entscheidung durch Gesetz findet sich selten. Ganz überwiegend wird unter Verwendung dynamischer unbestimmter Rechtsbegriffe eine Grundpflicht mit hohem Anspruch normiert"1, dem die Konkretisierung nicht standhalten kann.

So heißt es in $\S 1$ a WHG, daß jede vermeidbare Beeinträchtigung des Wassers unterbleiben müsse. Die Grenze des Vermeidbaren verschiebt sich mit der Fortentwicklung der Technik zu immer höheren Schutz- und Reinigungsgraden. Die Untersuchungen über die Grenzkostenkurven für die Vermeidung einer Schadeinheit im Abwasser machen sehr deutlich, daB der Effekt des Umweltschutzaufwandes abnimmt, je näher man sich der vollständigen Abwasserreinigung nähert. So erbringt in der Papierindustrie die Erhöhung des Reinigungsaufwandes von 5,- DM auf 20,- DM je Schadenseinheit eine Reinigungssteigerung von 60 auf $94 \%$; die Erhöhung des Aufwandes von 20,- DM auf 60,- DM steigert die Wirkung nur noch um ca. $3 \% 0^{92}$. Technisch vermeidbar ist jede Schadstoffabgabe in das Wasser, wenn man nur das gesamte Abwasser destilliert und lediglich das Destillat ableitet. Vom Aufwand und Erfolg her wäre ein dahingehendes Verlangen unverhältnismäßig. Zudem würden Errichtung und Betrieb derartiger Reinigungsanlagen die Umwelt weit mehr belasten als die Restabgabe an das Gewässer, so daß auch in einer integrierten Umweltschutzbewertung die Totalreinigung des Abwassers zielwidrig wäre.

Dem gegenwärtig geltenden Wortlaut nach dürften auch die Genehmigungsvoraussetzungen nach den $\S \S 5$ und 6 des BImSchG das Verhältnismäßigkeitsgebot verletzen. Wenn es in $\S 5$ Ziffer 1 heißt, Anlagen seien so zu errichten und zu betreiben, „daß schädliche Umwelteinwirkungen und sonstige

90 Gesetz über den Verkehr mit DDT vom 7. 8. 1972, BGB1. I 1385.

01 Vgl. R. Breuer: Die Entwicklung des Umweltschutzrechtes seit 1977, NJW 1979, S. 1862 (1865). K. Dienes: Die Entwürfe zur Novellierung des Immissionsschutzrechts 1979 - Ein Beitrag zu mehr Rechtssicherheit? Recht der Elektrizitätswirtschaft 1979, S. 98 ff. (99). 92 Umweltgutachten 1978 (Anm. 1), S. 115, Abb. 8. 
Gefahren, erhebliche Nachteile und erhebliche Belästigungen für die Allgemeinheit und die Nachbarschaft nicht hervorgerufen werden können" und nach $\S 6$ eine Genehmigung nur erteilt werden darf, wenn dieses "sichergestellt" ist, dann ist vom Wortlaut her die Genehmigung einer Großanlage nicht möglich. Die Konsequenz hat das Oberverwaltungsgericht Münster im Voerde-Urteil gezogen ${ }^{93}$, als es diesen Maßstab unmittelbar anwandte und darauf hinwies, daß das Gesetz keine Abwägungsklausel enthalte. Nach Ergehen des ersten VoerdeUrteils des VG Düsseldorf ${ }^{94}$ hat der Gesetzgeber dann - in einer legislatorischen Fehlleistung ${ }^{55}$ - die Úbergangsvorschrift des $\S 67$ BImSchG geändert. Erst das Bundesverwaltungsgericht ${ }^{96}$ hat den Wortlaut des $\S 5$ im Sinne der Verhältnismäßigkeit interpretiert und damit entschärft. Der Regierungsentwurf zur Änderung des BImSchG sieht vor, jene überzeichnete Formulierung des $\S 5$ aufzugeben ${ }^{97}$.

Daß diese dynamischen Grundsatzklauseln jedoch die normativ festgesetzten Grenzwerte außer Funktion setzen und verselbständigt in Konflikt mit dem Verhältnismäßigkeitsgrundsatz geraten, ist am Beispiel des Atomenergierechts zu zeigen. $\$ 45$ der Strahlenschutzverordnung ${ }^{98}$ schreibt vor, daß die technische Auslegung und der Betrieb einer Kernanlage so zu planen ist, daß eine Strahlenexposition des Menschen so gering wie möglich gehalten wird und über die Belastungspfade Luft und Wasser nicht mehr als je $30 \mathrm{~m}$ rem/a erreichen darf. In der Rechtsprechung und der ihr notwendigerweise folgenden Genehmigungspraxis ist der wirkliche Maßstab nur noch das Minimierungsgebot ${ }^{99}$. Nach rechtlich nicht verbindlichen Berechnungsmodellen wird mit äußerst pessimistischen Annahmen die mögliche Strahlenexposition theoretisch errechnet. Diese Werte liegen um ein Vielfaches über den wirklich auftretenden oder $\mathrm{zu}$ erwartenden Werten, müssen aber

\footnotetext{
93 Urteil vom 7. 7. 1976 - VII A 1804/75 -, DVB1. 1976, S. 790.

94 VG Düsseldorf, Urt. v. 15. 9. 1975, ET 1975, 500 (Bericht).

05 R. Breuer: Die Entwicklung des Immissionsschutzrechts 19741976, NJW 1977, S. 1025 ff. (1026).

${ }^{96}$ Urteil vom 17. 2. 1978 - IC 102. 76 -, DVBl. 1978, 591.

97 BRat-Drs. 403/78, BT-Drs. 8/2751 v. 11. 4. 1979. Siehe dazu: K. Dienes (Anm. 91), S. $98 \mathrm{ff}$.

${ }^{98}$ Vom 13. 10. 1976, BGBI. I 2905 geändert durch VO vom 12. 12. 1977, BGBl. I 2537.

${ }^{9 \theta}$ V. Götz, Verfassungsmäßigkeit der Dosisgrenzwerte (Anm. 48), S. 181.
} 
dennoch, je nach OVG-Bezirk verschieden, die normativen Grenzwerte weit unterschreiten ${ }^{\mathbf{1 0 0}}$.

An dem Beispiel läßt sich auch zeigen, daß staatliche Anforderungen an den Betreiber in Konflikt mit dem Gleichheitssatz geraten können. Angesichts der weiten Gestaltungsfreiheit des Gesetzgebers führt der Gleichheitssatz zwar nicht allgemein zu der Forderung gleichmäßiger Emissions- oder Immissionsbegrenzung. Von Großfeuerungsanlagen über $4 \mathrm{TJ} / \mathrm{h}$ Leistung kann so entsprechend der TA Luft ${ }^{101}$ eine höhere Entschwefelung verlangt werden als von kleineren Anlagen, schon weil der Belastungsbeitrag absolut höher ist, eine Reduzierung für die Gesamtumweltlage mehr zu Buche schlägt, der technische Aufwand effektiver ist. Doch zurück zu dem Beispiel: Die Physikalisch Technische Bundesanstalt hat im Februar 1978 festgestellt, daß die errechnete Strahlenbelastung durch den Normalbetrieb des Kernkraftwerkes Stade nach den Angaben von $1975100 \mathrm{mal}$ geringer ist als die der radioaktiven Belastung aus Flugasche und Rauch eines Kohlekraftwerkes gleicher Leistung ${ }^{102}$. Die Bundesregierung hat das auf eine Anfrage hin im Bundestag bestätigt und erklärt ${ }^{103}$, es werde angenommen, daß die Strahlenbelastung durch ein Kohlekraftwerk wenigstens das Zehnfache betrage; aber auch diese Belastung sei gesundheitlich unbedenklich. Bei dieser engen Vergleichbarkeit dürften dann aber die Anforderungen an die Kernkraftwerke zur weiteren Minimierung der Abgaben im Minimalbereich außer gegen das Verhältnismäßigkeitsprinzip auch gegen den Gleichheitssatz verstoßen. Das OVG Lüneburg hat aber gerade im Fall Stade im Verfahren zum vorläufigen Rechtsschutz Ende 1976 die Genehmigungswerte weiter herabgesetzt ${ }^{104}$.

100 Siehe jetzt: Allgemeine Berechnungsgrundlage für die Strahlenexposition bei radioaktiven Ableitungen mit der Abluft oder in Oberflächengewässer - Richtlinie des BMI zu §45 StrlSchV v. 6. Februar/15. August 1979, GMB1. 1979, 371. Zur Uberschätzung der Belastung bei den Abschätzungen mit jenem Rechenverfahren siehe insbesondere VG Karlsruhe, Beschl. v. 18. 8. 1978 - IV 19/78 -, ET 1978, 606 (608 f.).

101 Vom 28. 8. 1974, GMBl. 1974, 426, ber. S. 525, Nr. 3. 1. 1.4 und

3. 1.2. 4 .

102 Siehe W. Kolb: Die Emission radioaktiver Stoffe und der Abluft aus Kern- und Steinkohlekraftwerken - ein Vergleich der Strahlenbelastung, Bericht PTB-Ra-8. Feb. 1978.

${ }^{103}$ BT, Sten. Berichte, 8. Wahlperiode, 86. Sitzung, 20. 4. 1978, S. 6845 .

${ }^{104}$ OVG Lüneburg, Beschl. v. 22. 11. 1976 - VII OVG B 76/74 -, DVB1. 1977, 340. 


\section{Entscheidungsbereich der Exekutive}

Mit der Verwendung dyamischer unbestimmter Rechtsbegriffe, die im technischen Sicherheitsrecht wohl unvermeidbar ist $^{105}$, überträgt der Gesetzgeber die Entscheidung über die Intensität der Umweltschutzanforderungen der Exekutive. Zur Vereinheitlichung und auch zur Festlegung von Grenzwerten wird die Exekutive zuweilen besonders ermächtigt. Nach $\S 12$ I Nr. 1, 2 AtG ist die Bundesregierung ermächtigt, die erforderliche Vorsorge gegen Schäden und auch Grenzwerte für Strahlendosen in einer Verordnung zu konkretisieren. Die Strahlenschutzverordnung gibt aber insbesondere mit dem Minimierungsgebot in $\S 45 \mathrm{AnlaB}$, die Grenzwerte wieder gegenstandslos werden zu lassen. Die Ermächtigung zur Festlegung von Immissions- und Emissionsgrenzwerten in $\S 48$ BImSchG richtet sich auf Verwaltungsvorschriften, z. B. die TA Luft. Außerhalb solcher Regelungen muß die Verwaltung, wenn ihr die Rechtsvorschriften dazu Raum lassen, unter Berücksichtigung auch einer Gesamtschau nach der Aufwand/ Nutzen-Betrachtung die Entscheidung fällen. Wenn, wie in den meisten Bereichen, in den Gesetzen Abwägungsklauseln fehlen, dann muß sie dafür auf das Verhältnismäßigkeitsprinzip zurückgreifen.

Soweit die Kontrollfigur des Verbots mit Genehmigungsvorbehalt angeordnet ist, muß bei Vorliegen der gesetzlich zu bestimmenden Voraussetzungen die Genehmigung erteilt wer$\mathrm{de}^{106}$. Zwar räumt $\S 7 \mathrm{AtG}$ ausnahmsweise für Atomanlagen ein Versagensermessen ein. Im Kalkar-Beschluß hat das Bundesverfassungsgericht das für diesen Sonderfall als zulässig erklärt; es hat aber zugleich die Versagensmöglichkeit darauf beschränkt, ,falls besondere und unvorhergesehene Umstände es einmal notwendig machen" "107. Ein Ermessen außerhalb dieser besonders zu begründenden Ausnahmesituation kann auch wegen der Folgen nicht angenommen werden: Zum einen wäre der Bestand von Genehmigungen äußerst prekär, weil eine unterschiedliche Tatsachenannahme durch ein Gericht oder eine vom Gericht für notwendig gehaltene unterlassene Erwägung die materiell rechtmäßige Genehmigung wegen eines Ermes-

${ }^{105}$ Vgl. auch BVerfGE 49, 89 (133 ff.) (Kalkar).

${ }^{108}$ St. Rspr. des BVerfG: BVerfGE 8, 71 (76) bis E 46, 120 (157) und Kalkar-Beschluß E 49, 89 (145).

107 BVerfGE 49, 89 (147) - Kalkar-Beschluß. 
sensfehlers zu Fall bringt ${ }^{108}$. Zum anderen schließt das angenommene Versagensermessen ein Rechtsmittel des Antragstellers in der Praxis aus.

Ebenfalls nach der Kosten/Nutzen-Abwägung hat die Exekutive über die Kontrolldichte zu entscheiden. Der Wert des vollständigen Gesetzesvollzuges steht auf der einen, die Kosten an Finanzmitteln und an Freiheitsverlust bei umfassenden laufenden Kontrollen stehen auf der anderen Seite. Bei abgesonderter Betrachtung des Verwaltungsbereichs Umweltschutz wird verschiedentlich ein "Vollzugsdefizit" für die Umweltrechtsvorschriften festgestellt ${ }^{109}$. Gewiß ist der Vollzug und seine Utberwachung verbesserungsfähig, doch sollte nicht übersehen werden, daß in kaum einem Verwaltungsbereich ein vollständiger Vollzug von Vorschriften $\mathrm{zu}$ beobachten ist ${ }^{110}$ und auch zweifelhaft ist, ob der Aufwand für einen vollständigen Vollzug durch den Nutzen gerechtfertigt würde. Die Diskussion um den „Dienst nach Vorschrift" hat ins Bewußtsein gebracht, daß die vollständige Durchführung aller Vorschriften die Verwaltung lähmte und ihrer Effizienz entgegenstünde ${ }^{111}$; auch der Zweckerreichung im Umweltschutz ist mit einem langen Atem der Verwaltung zuweilen nachhaltig mehr gedient. Das Vollzugsdefizit ist zudem dann nur ein scheinbares, wenn überzeichnete Grundsätze in Gesetzen postuliert werden in dem Verständnis des Gesetzgebers, die Verwaltung werde diesen Grundsatz nach dem Verhältnismäßigkeitsgebot praktisch relativieren.

108 So VGH Baden-Württemberg, Beschl. v. 8. 10. 1975 - X 351/ 75 -, DVBl. 1976, 539 (545 links).

${ }_{100}$ Zum Problem des Vollzugsdefizits im Umweltschutz siehe Umweltgutachten 1978 (Anm. 1), Nr. 1640 und R. Mayntz, J. Hucke: Gesetzesvollzug im Umweltschutz, Wirksamkeit und Probleme, ZfU 1978, S. $217 \mathrm{ff}$; R. Mayntz und Mitarbeiter: Vollzugsprobleme der Umweltpolitik (Materialien zur Umweltforschung, Bd. 4), Stuttgart 1978.

${ }^{110}$ Siehe dazu das Referat von Frido Wagener auf der Tagung der Vereinigung 1978: Der öffentliche Dienst im Staat der Gegenwart, VVDStRL 37 (für 1978) 1979, S. 212 ff. (246 ff.).

111 Siehe insbesondere J. Isensee: Beamtenstreik - Zur rechtlichen Zulässigkeit des Dienstkampfes, Bad Godesberg 1971, S. 148 ff.; Zum Verhältnis von Vorschriften und Dienstaufgaben auch BVerwG, Beschl. v. 19. 9. 1977 - I DB 12/77 -, DVBl. 1978, 410 (412) - Fluglotsendisziplinarfall; Erwägungen zum Verhältnis von Vorschriftenerfüllung und Effizienz auch im Umweltgutachten 1978 (Anm. 1), Nr. 1641. 
3. Entscheidungen über die Intensität des Umweltschutzes durch die Verwaltungsgerichtsbarkeit

Für die Verwaltungsgerichtsbarkeit soll im Gegensatz zu kritischen Stimmen in der Literatur ${ }^{112}$ nicht die Kompetenz zur Beurteilung von Verwaltungsakten auch über hochkomplizierte technische Fragen in Zweifel gezogen werden - fraglich bleibt lediglich, ob in Einzelfällen die Versuche selbständiger technischer Erwägungen stets geglückt erscheinen ${ }^{113}$. Politisch haben Verfahren mit ausführlicher gerichtlich-öffentlicher Beweisaufnahme zudem eine erhebliche Bedeutung, tragen sie und die darauf beruhenden Entscheidungen doch zur vertrauensvollen Ubernahme von Beurteilungen durch dem Rechtsstaat zugetane Bürger bei.

Die gesetzlichen Umweltnutzungsbegrenzungen mit Hilfe unbestimmter Rechtsbegriffe eröffnen der Verwaltungsgerichtsbarkeit ein weites Feld. Sie werden vielfach von den Gerichten als „drittschützend“ qualifiziert ${ }^{114}$, womit die Klagbefugnis von Interessenten begründet wird. Die gesetzlichen Nutzungsbeschränkungsklauseln differenzieren allgemein nicht zwischen Gefahrenabwehr oder Risikovorsorge für den einzelnen und der weiteren Herabsetzung der Nutzung im Allgemeininteresse;

112 W. Schmitt Glaeser: Planende Behörden, protestierende Bürger und überforderte Richter, Rechtliche Aspekte zur Genehmigung von Kernkraftwerken in: Der Landkreis 1976, S. $442 \mathrm{ff}$. (446 ff.); F. Ossenbühl: Die gerichtliche Uberprüfung der Beurteilung technischer und wirtschaftlicher Fragen in Genehmigungen des Baus von Kraftwerken, DVBl. 1978, S. 1 (2 ff.).

11 So z. B. OVG Lüneburg, Beschluß v. 2. 2. 1979 - VII OVG B 80/75 -, ET 1979, 178 (180-181); Im Tenor wird u. a. aufgegeben „,verbindlich zu regeln, daß die Sicherheitsventile notfalls durch Handeingriff von der Warte aus geöffnet werden können..... In den Gründen heißt es dann, es werde mit Verzicht auf die Handeingriffsmöglichkeit die Sicherheit allein vom Funktionieren einer Apparatur abhängig gemacht. „Die dafür gegebene Begründung (Gefahr von Fehlbedienung) überzeugt nicht." Dem Gericht war vom Beklagten dargelegt, daß bei der angenommenen Kombination von Versagen mehrfacher Sicherheitsstufen ein Handeingriff nur in einem Zeitraum von ca. 20 Sekunden sinnvoll sein könne.

114 Für $\S 5 \mathrm{Nr} .1$ und 2 BImSchG z. B. OVG Münster, Urt. v. 7. 7. 76 - VII 1804/75 -, DVBI. 1976, 790; für $\$ 7$ II Nr. 3 und 5 AtG (n. F.) z. B. VGH Baden-Württemberg, Beschl. v. 8. 10. $1975-\mathrm{X}$ $351 / 75-$, DVBl. $1976,538 \mathrm{ff}$. Für das Minimierungsgebot in $\S 21$ der früheren StrahlenschutzVO (jetzt \$ 45 StrlSchV) OVG Münster, Urt. v. 20. 2. 1975 - VII A 911/69 - ET 1975, 220 (224 links) und OVG Lüneburg, Beschl. v. 17. 10. 1977 - VII OVG B 22/77 -, DVB1. 1978, 67 (69 rechts). 
entsprechend grenzen die meisten Gerichte innerhalb der einzelnen Vorschriften nicht zwischen Individualanspruch und objektivrechtlicher Beschränkung $\mathrm{ab}^{115}$.

Bei einigen Gerichten besteht die Tendenz, den Bereich der Kontrolle dadurch auszudehnen, daß sie sowohl bei der $\mathrm{Zu}$ lässigkeitsfrage wie bei der Frage der Verletzung von Rechten über den Individualschutz hinausgehen. Zwei Beispiele aus vielen: Das Voerde-Urteil des OVG Münster zielt deutlich auf Allgemeinschutz und Erziehung mit Tadel und Sanktion, während es einräumt, daß die Immissionen am Klägerstandort hinreichend begrenzbar sein mögen ${ }^{116}$. Das $O V G$ Lüneburg beschränkte in einem Eilverfahren zum Kernkraftwerk Stade die Abgabe von Krypton 85, um dessen langfristige Anreicherung in der Erdatmosphäre zu bekämpfen ${ }^{117}$. Gerichte erliegen $z u-$ weilen der Versuchung, die Position von Obergenehmigungsbehörden einzunehmen.

Die Gerichte haben zusätzlich zu der formellen Entscheidungsgewalt einen zwingenden Einfuß auf den Genehmigungsinhalt: Erkennbare Erwartungen eines Gerichts in Anfechtungssachen gegen Großanlagengenehmigungen führen, auch wenn sie die Genehmigungsbehörde für unbegründet hält, eilfertig zu einer von dem Betreiber beantragten Genehmigungsänderung. In Beschlüssen zum einstweiligen Rechtsschutz finden sich Bemerkungen wie: „Bis zur Entscheidung in der Hauptsache ist zu erwarten, daß die Beklagte die Genehmigung... ergänzt ${ }^{118}$." Vergleichsvorschläge oder auch prozeßleitende Anordnungen lassen entsprechende Vorstellungen des Berichterstatters erkennen. Der Stillstand einer Großanlage wie eines Kernkraftwerks bedeutet einen Ausfall von 1-2 Millionen DM/ $\mathrm{d}^{119}$, so daß der Bewerber und auch Genehmigungsbehörden kein Risiko dadurch eingehen können, daß sie angesichts solcher Zeichen auch nur zögerten. Auf der Grund-

115 Individualschutz und weitergehenden Bevölkerungsschutz im Rahmen derselben Norm unterscheiden aber zutreffend z. B. OVG Münster, Urt. 20. 2. 1975 (Anm. 114), S. 227 rechts; VG Karlsruhe, Beschl. v. 18. 8. 1978 - IV 19/78 -, DVBl. 1978, 856 (858 rechts) und jüngstens Bay VGH, Urt. v. 9. 4. 1979 - Nr. 167 VI 77 -, DVBl. 1979,673 (675 f.).

116 OVG Münster, Urt. v. 7. 7. 1976 - VII A 1804/75, DVBl. 1976, 790 (797).

117 OVG Lüneburg, Beschl. v. 22. 11. 1976 - VII OVG B 76/74 -, DVB1. 1976, 340 (343).

118 Z. B. OVG Lüneburg, Beschl. v. 2. 2. 1979 - VII OVG B 80/ 75, ET 1979, 178 (182).

${ }^{119} \mathrm{Zu}$ den Verzögerungskosten siehe $H$. Trenkler: Kosten der Bauzeitverlängerungen bei Kraftwerken, atw 1976, S. 246 ff. 
lage der dynamischen unbestimmten Rechtsbegriffe in den Rechtsvorschriften zur Genehmigung bestimmen gegenwärtig in weiten Bereichen die Gerichte die Schutzintensität. In den Verfahren wird jedoch um Grenzwerte und Anforderungen gestritten, die nicht mehr der Abwehr einer Gefahr für den jeweiligen Kläger dienen, sondern der weiteren Verminderung des unter der Gefahrenschwelle verbleibenden Risikos ${ }^{120}$. Nach allgemeiner fachkundiger Auffassung tritt eine Gesundheitsgefahr unterhalb der Immissionsgrenzwerte der TA Luft oder der Strahlenschutzverordnung bzw. bei Einhaltung der Sicherheitskriterien des BMI und der Leitlinien der Reaktorsicherheitskommission nicht ein ${ }^{121}$ - und die angefochtenen Genehmigungen bleiben hinter diesen Anforderungen nicht zurück. Die Gerichtsentscheidungen konkretisieren den von den Klägern geltend gemachten Anspruch auf Verminderung des Risikos unterhalb der Gefahrengrenze, und die Konkretisierung im Einzelfall ist verschieden und unvorhersehbar. Zudem stehen manche konkreten Entscheidungen in Konflikt mit dem Verhältnismäßigkeitsgrundsatz und dem Gleichheitssatz.

Die aufwendigen Beweisaufnahmen wie auch das oben dargestellte Überschreiten der Grenzen des Individualrechtsschutzes führen zu Mammutprozessen, die die Gerichte überlasten. Damit verlängert sich die Prozeßdauer auf unvertretbar lange Zeiten. Auf das Urteil des Europäischen Gerichtshofs für Menschenrechte vom 28. Juni 1978 sei in diesem Zusammenhang nur hingewiesen ${ }^{122}$. Die Situation verschärft sich dadurch, daß gegenwärtig über alle Großanlagen auf Drittklagen hin zunächst im vorläufigen Rechtsschutzverfahren gestritten wird. Wenn die Suspensivwirkung von einem OVG unanfechtbar wiederhergestellt wird, muß nun erst das Urteil des Verwaltungsgerichts und das Berufungsurteil dazu in der Hauptsache herbeigeführt werden, um die Rechtsauffassung des Oberverwaltungsgerichts vom Bundesverwaltungsgericht überprüfen zu lassen. Dieser Weg erfordert viele Jahre.

\section{Aufgabenverteilung nach Gefahrenabwehr und Risikovor- sorge}

Die mehr praxisbezogene Erörterung des letzten Teiles über die Intensität hoheitlicher Umweltanforderungen und die Ent-

120 Vgl. die in Anm. 116, 117 genannten Entscheidungen.

121 Siehe BMI: Medizinische, biologische und ökologische Grundlagen zur Bewertung schädlicher Luftverunreinigungen, Sachverständigenanhörung 20. - 24. 2. 1978 (Umweltbundesamt) 1978 .

122 Europ. Gerichtshof für Menschenrechte, Urt. v. 28. 6. 1978 (Fall König), EuGRZ 1978, 406. 
scheidungskompetenz dafür zeigt ein unbefriedigendes Ergebnis: Die Entscheidung über die Schutzintensität auch deutlich unterhalb der Gefahrenschwelle ist von Gesetzgeber und Exekutive in weiten Bereichen auf die Verwaltungsgerichtsbarkeit übergegangen. Die hier erforderliche Dezision ist jedoch Aufgabe der politisch verantwortlichen Organe von Legislative und Exekutive ${ }^{123}$. Gerichtliche Konkretisierungen in diesem Bereich sind kaum vorhersehbar, so $\mathrm{da} B$ die Rechtssicherheit beeinträchtigt ist. Als Bestandteil der Staatswillensbildung um Umweltschutz dauert der Entscheidungsweg über die Verwaltungsgerichtsbarkeit unzulässig lange.

Zur Abhilfe ist zunächst die Änderung des Verwaltungsprozeßrechts erörtert worden mit den Stichworten Beschränkung der Kontrolldichte, Verkürzung des Instanzenzuges, Fachgerichte und Ausschluß der Suspensivwirkung bei Drittanfechtungsklagen. Die verfahrensrechtliche Abteilung des Deutschen Juristentages 1978 hat sich gegen diese Vorschläge ausgesprochen ${ }^{124}$. Richtiger erscheint auch mir der Ansatz über die materielle Rechtsgestaltung: Unterhalb der Schwelle der Gefahr für Leben und Gesundheit besteht von der Verfassung her keine Notwendigkeit, die Beschränkung der Umweltnutzung eines Produzenten oder Konsumenten zur Rechtsposition eines anderen Bürgers auszugestalten ${ }^{125}$. Auch bei den gegenwärtig vorliegenden Gesetzesformulierungen ist die drittschüt-

123 Vgl. z. B. F. Ossenbühl (Anm. 112), S. $8 \mathrm{f}$.

${ }_{124}$ Zur Kontrolldichte insbes. F. Ossenbühl (Anm. 112), S. $3 \mathrm{ff}$. Zum Ausschluß der Suspensivwirkung von Nachbarklagen siehe $\S 152$ des Entwurfs einer Verwaltungsprozeßordnung, als Kommissionsentwurf veröffentlicht vom BM Justiz, Köln 1978 und dazu $P$. Stelkens: $\mathrm{Zu}$ einigen neuen Verfahrensvorschriften für die Verwaltungsgerichtsbarkeit im Entwurf einer Verwaltungsprozeßordnung, DVBl. 1979, S. 544 ff. (548) und H. J. Becker: Einheitliche Verwaltungsprozeßordnung in Sicht, Recht im Amt 1978, S. 149 ff. (153). Die verfahrensrechtlichen Abhilfen sind von der verfahrensrechtlichen Abteilung des Deutschen Juristentages 1978 behandelt und abgelehnt; siehe den Bericht von $K$. Schmaltz: 52. Deutscher Juristentag, DVB1. 1979, S. 109 ff. (110 f.).

125 Die Unterscheidung nachbarschützender Rechtsnormen von solchen, die jenseits der Grenze der Gesundheitsgefährdung ausschließlich im Allgemeininteresse weitergehend schützen, wird ausdrücklich von J. Salzwedel: Bericht zur Festsetzung von Immissionsgrenzwerten..., Anlage 2 zu: Umweltrecht mildern? Anhörung des Arbeitskreises für Umweltrecht (= Beiträge zur Umweltgestaltung, Heft A 64), Berlin 1978, S. 146, gefordert. Dort auch einführend Salzwedel, S. 34; Zustimmung der Beteiligten laut $\mathrm{Zu}$ sammenfassung, S. 9. 
zende Wirkung solcher Beschränkungen von den Gerichten auf den Individualschutz zu begrenzen, selbst wenn aus derselben Vorschrift weitergehende Anforderungen zur Verminderung des Bevölkerungsrisikos hergeleitet werden ${ }^{126}$.

Zur Abhilfe sind aber vorrangig die normsetzenden Organe berufen. Entweder ist in rechtlich verbindlichen Normen die Grenze, unterhalb derer eine Gefahr gewiß nicht mehr anzunehmen ist, selbst festzulegen, oder es ist bei unbestimmten Rechtsbegriffen deutlich auszudrücken, daß damit der Schutz vor Gefahren im Rechtssinne gefordert werde. Weitergehende Beschränkungen der Umweltnutzung sind dann als im ausschlieBlichen Interesse der Allgemeinheit angeordnet deutlich nicht als Individualrechtsposition auszugestalten. Der Rechtsschutz des Drittbetroffenen entfaltet sich unbeschränkt zum Schutz vor einer ihm drohenden Gefahr - und es wird nicht wie gegenwärtig verbreitet um den Anspruch auf Verminderung des weiteren Risikos gestritten. Über dieses weitere Herabsetzen des Risikos wie über die weitere Verbesserung der Umweltsituation entscheiden die politisch verantwortlichen Gewalten, und dem Adressaten der Begrenzung im Allgemeininteresse steht dagegen selbstverständlich Rechtsschutz zu.

Vorausgesetzt wird für diesen Weg der Abhilfe, daß Regierung und Parlament die Entscheidung über die Umweltschutzintensität sich selbst zuordnen und diese Aufgabe erfüllen. Für den Bereich der genehmigungsbedürftigen Anlagen sind gegenwärtig Zweifel an der Entscheidungsfähigkeit angebracht. Vielleicht wird es einmal als Vorteil empfunden werden, wenn die Verwaltungsgerichtsbarkeit selbst unter erheblichem Zeitlauf und Aufwand nach fortschreitender Klärung der Grundsatzprobleme und mehrmaligem Durchgang von Musterprozessen durch die Instanzen unter Mithilfe des Bundesverfassungsgerichts die Staatswillensbildung mit einem vielseitig befriedigenden Ergebnis vollzieht.

128 So die in Anm. 115 genannten Entscheidungen. 


\section{Staatsaufgabe Umweltschutz}

\section{Aufgabe Umweltschutz}

1. Der Mensch nutzt die Umweltgüter dieser Erde, die er füllt und die er sich untertan gemacht hat. Die Kehrseite der Nutzung ist die Umweltbelastung, die als Verminderung der potentiellen Nutzung zu umschreiben ist. Umweltschutz soll durch Veränderungen von Art und Intensität der Nutzung die Nutzbarkeit der Umwelt erhalten und erhöhen.

2. Umweltschutz kann nicht nur aus Nutzungserwägungen hergeleitet werden; einige Teilziele lassen sich nur mit ethischen Wertungen begründen.

3. Ein Fortsetzen der Entwicklung der Umweltlage hätte die Nutzbarkeit der Erde beendet und damit zur Katastrophe für das menschliche Leben geführt. Es besteht Konsens darüber, daß Umweltschutz eine unausweichliche Aufgabe darstellt.

II. Erwägungen der allgemeinen Staatslehre zum staatlichen Umweltschutz

4. Der moderne Staat als historische Erscheinung hat stets Umweltschutzaufgaben wahrgenommen. Da keine dem Gemeinwohl dienende Aufgabe a priori von den staatlichen Aufgaben ausgeschlossen werden kann, ist die Legitimation des Staates, Umweltschutzaufgaben auf sich zu nehmen, unbestreitbar.

5. Die Gefahr des Utberhandnehmens des Staates gebietet Zurückhaltung beim Erweitern von Staatsaufgaben. Jedoch können weder die einzelnen Nutzer spontan noch gesellschaftliche Ordnungssysteme wie der Markt knapper Güter die Umweltbelastungen hinreichend effektiv mindern; internationale Organisationen nehmen dem Staat die Umweltschutzaufgabe ebenfalls nicht $a b$. Der Staat ist als Wahrer des Allgemeininteresses zum Umweltschutz berufen, und nur er verfügt über die erforderliche Macht und die Mittel.

III. Völkerrechtliche Pflicht zum Umweltschutz

6. Das allgemeine Völkergewohnheitsrecht verpflichtet den Staat zur Abwehr erheblicher grenzüberschreitender Umwelt- 
schäden. Die Nutzung gemeinsamer Medien wie die der Grenzgewässer unterliegt dem Prinzip der fairen Nutzungsaufteilung auch für die Ableitung von Abfallprodukten. Uber diese engen nachbarrechtlichen Pfichten hinaus findet sich im Völkergewohnheitsrecht zum Umweltschutz nur noch das Gemeinverträglichkeitsprinzip des Meeresnutzungsrechts.

7. Die Staaten sind in völkerrechtlichen Verträgen vielfältige Verpflichtungen zu Umweltschutzmaßnahmen wie auch zur Zusammenarbeit eingegangen oder haben entsprechende internationale Organisationen errichtet. Damit erfüllen sie angesichts der notwendig internationalen Umweltschutzproblematik ihre Aufgaben effektiver, die Verträge oder Akte internationaler Organisationen begründen die Umweltschutzaufgaben aber nicht heteronom.

IV. Verfassungspficht zum Umweltschutz

8. Im Grundgesetz als dem ranghöchsten Akt staatlicher Willensbildung hat der Staat die Umweltschutzaufgaben nicht ausdrücklich übernommen. Auch aus den bundesstaatlich bedingten Kompetenzzuweisungen über einzelne Umweltschutzmaterialien ist kein Verfassungsauftrag zum Tätigwerden auf diesen Sachgebieten abzuleiten.

9. Umweltbelastungen berühren den Schutzbereich der Grundrechte auf Leben und körperliche Unversehrtheit (Art. 2 II) und auf Eigentum (Art. 14 I GG). Diese Grundrechtsgüter sind betroffen bei Tötung, Schädigung der körperlichen Gesundheit und bei Sachgüterschädigung sowie bei einer entsprechenden Gefährdung.

10. Belästigungen und Beeinträchtigungen geringerer Intensität betreffen nicht den Schutzbereich von Grundrechten. Insbesondere ist die allgemeine Handlungsfreiheit im Rahmen von Art. 2 I GG nicht durch Umweltbelästigungen berührt; das vom Bundesverfassungsgericht aus Art. 2 I GG abgeleitete Recht, „in Ruhe gelassen zu werden", gilt nur zum Schutz des engsten Persönlichkeitsbereichs gegen geistig-kommunikative Störungen. Auch begründet das Gebot der Achtung der Menschenwürde keinen Schutzbereich gegen Umweltbelästigungen.

11. In der Abwehrfunktion schützen die Artikel 2 II, 14 I GG nur gegen über die Umweltmedien schädigende Realakte des Staates selbst und gegen solche tatsächlichen Beeinträchtigungen durch Dritte, die dem Staat als staatlich veranlaßt oder staatlich geboten zuzurechnen sind.

12. In den Grundrechten auf Leben und körperliche Unversehrtheit und auf Eigentum kommt eine objektivrechtliche 
Wertentscheidung mit Richtliniencharakter zum Ausdruck. In Verbindung mit dem Gebot zur Achtung der Menschenwürde hat der Staat dadurch die Pflicht zum Schutz des Lebens und gegen erhebliche Beschädigungen der körperlichen Gesundheit übernommen. Die zuständigen Organe wählen die Mittel zum Schutz der Grundrechtsgüter aus.

13. Wenn der Staat die umweltbelastende Nutzung eines Produzenten oder Konsumenten auf eine bestimmte Intensität begrenzt, dann kann der durch die Nutzung unterhalb jener Begrenzung Dritten entstehende Nachteil nicht dem Staat sozusagen als „Eingriff“ zugerechnet werden; das gilt für normative Grenzwertfestsetzungen wie auch für Uberwachungsmaßnahmen, auch in Gestalt des Verbots mit Erlaubnisvorbehalt.

14. Aus der Sozialstaatklausel kann, ohne das Demokratiegebot zu verletzen, keine Umweltschutzpflicht des Staates hergeleitet werden.

V. Umweltschutzbemühungen der Bundesrepublik Deutschland

15. Der Staat hat im Willensbildungsproze $\beta$ unterhalb der Verfassung in breitem Umfang Aufgaben des Umweltschutzes auf sich genommen und dabei erhebliche Erfolge erzielt. Bei notwendigen weiteren Anstrengungen erscheint die Hoffnung begründet, der weiteren Umweltbelastung Einhalt gebieten und die Umweltbedingungen wirklich bessern zu können.

VI. Entscheidungskompetenz über Intensität von Umweltschutzanforderungen

16. Der Gesetzgeber muß die wesentlichen Entscheidungen zur Regelung der Umweltnutzung durch Produzenten und Konsumenten selbst treffen, auch, weil auf der Seite der Geund Verbotsadressaten Berufsfreiheit, Eigentum und Handlungsfreiheit betroffen sind.

17. Der Gesetzgeber kann in Ausübung der Schutzpflicht aus Art. 2 II i. V.m. 1 I GG im Rahmen des Gesetzesvorbehalts in Art. 2 II 3 GG bestimmen, beim Einsatz welcher Mittel es sein Bewenden haben soll. Die Schutzpflicht richtet sich auf die Abwehr von Gefahren, die vom verbleibenden Risiko nach Eintrittswahrscheinlichkeit oder praktischer Vernunft abzugrenzen sind. Es unterliegt der Entscheidung des Gesetzgebers, ob er noch Schritte zur Verminderung jenes Risikos anordnet. 
18. Umweltschutzregelungen müssen dem Verhältnismäßigkeitsgebot entsprechen. Außerhalb der Gefährdnung von Leben und Gesundheit ist nach Nutzen-/Aufwands-Abschätzungen abzuwägen. Die ökonomische Umwelttheorie und das Verursacherprinzip liefern nur bedingt Maßstäbe. Da die Erhaltung der Umweltnutzung Ziel ist, kann ein Verbieten der Nutzung oder eine Minimalisierung nicht Ziel sein.

19. Die Umweltschutzgesetze begründen überwiegend Grundpflichten mit hohem Anspruch unter Verwendung dynamischer unbestimmter Rechtsbegriffe. Mit fortschreitenden technischen Möglichkeiten verstößt die verbale Anwendung dieser Formeln gegen das Verhältnismäßigkeitsgebot und gegen den Gleichheitssatz.

20. Die dynamischen unbestimmten Rechtsbegriffe und ausdrückliche Ermächtigungen überweisen das Bestimmen der Nutzungs- und Belastungsgrenzen normativ oder im Einzelfall an die Exekutive. Im Rahmen der Kontrollfigur Verbot mit Erlaubnisvorbehalt steht der Exekutive kein Versagensermessen zu; das nominelle Ermessen nach dem Atomgesetz ist auf „besondere und unvorhergesehene Umstände“ beschränkt. Auch über die Kontroll- oder Vollzugsdichte ist nach Kosten-l Nutzen-Abwägungen zu entscheiden. Ein „Vollzugsdefizit" besteht nicht in größerem Maße als in anderen Verwaltungsbereichen.

21. Die Verwaltungsgerichtsbarkeit bestimmt wegen der als drittschützend qualifizierten dynamischen unbestimmten Rechtsbegriffe in weiten Bereichen die Schutzintensität. Innerhalb der gleichen Vorschrift wird regelmäßig nicht zwischen Individualanspruch und objektivrechtlicher Beschränkung unterschieden; allgemein besteht eine Tendenz, bei Klagen Dritter prozessual wie materiell über die Grenzen des Individualrechtsschutzes hinauszugehen. Gestritten wird dabei regelmäßig nicht um den Anspruch des Klägers auf Schutz vor Gefahren im Rechtssinne, sondern um das Begehren, die Verminderung des verbleibenden Risikos weiter zu vervollkommnen. Als Bestandteil der Staatswillensbildung zu Großprojekten ist der Entscheidungsgang in zwei Instanzen um die sofortige Vollziehbarkeit und in weiteren drei Instanzen in der Hauptsache zu lang.

22. Die Dezision über die Schutzintensität im Bereich der Risikovorsorge muß von der Gerichtsbarkeit auf die politisch verantwortlichen Gewalten zurückverlagert werden. Vorschlägen zur Änderung des Prozeßrechts dürfte der Ansatz über die materielle Rechtsgestaltung vorzuziehen sein. In rechtlich ver- 
bindlichen Normen sind Grenzwerte festzulegen, unterhalb derer eine Gefahr im Rechtssinne gewiß nicht mehr besteht; bei Verwendung unbestimmter Rechtsbegriffe ist klarzustellen, daß damit der Schutz vor Gefahren im Rechtssinne gefordert werde. Auf die Einhaltung dieser Grenzen ist dem Bürger ein Rechtsanspruch ausdrücklich einzuräumen, weitergehende Beschränkungen der Umweltnutzung sind dann als ausschließlich im Allgemeininteresse angeordnet nicht als Individualrechtspositionen auszugestalten.

Vorausgesetzt wird für diesen Weg der Abhilfe, daß Parlamente und Regierungen die Kraft haben, die Entscheidung über die Umweltschutzintensität sich selbst zuzuordnen und diese Aufgaben auch zu erfüllen. 
2. Mitbericht von Professor Dr. Werner Hoppe, Münster

\section{Staatsaufgabe Umweltschutz}

\section{Inhalt}

Seite

Vorbemerkung . . . . . . . . . . . . . . . . . 214

I. Vollzug des Umweltschutzes in der Krise . . . . . . 216

1. Entwicklung und Tendenzen . . . . . . . . . . 218

2. Frage nach den Ursachen mangelnden Umweltschutzes 222

II. Planung als Teil der Staatsaufgabe Umweltschutz durch Vorsorge . . . . . . . . . . . . . . . . . . 228

1. Planung als Ausdruck des Vorsorgeprinzips . . . . 228

2. Das unterschiedliche Verständnis von Umweltschutz als Staatsaufgabe . . . . . . . . . . . . . . 230

3. Umweltschutz als Planungsaufgabe des Staates . . . 231

4. Die Einfügung der Umweltschutzplanung in eine ökologische Gesamtbetrachtung . . . . . . . . . 236

III. Die Situation des Umweltschutzes und seiner Planung . . 241

1. Die Situation des Umweltschutzes . . . . . . . . 241

2. Die Situation der Planungsinstrumente . . . . . . 245

2.1 Mängel in den einzelnen Planungsarten . . . . . 245

2.2 Tendenzen zur „Entfeinerung“, „Durchforstung“ und "Verfahrens-Ausdünnung" . . . . . . . 248

3. Die Situation der Okologie . . . . . . . . . . . . . 249

IV. Modelle der Umweltschutzplanung . . . . . . . . . 252

1. Die Arten der Umweltschutzplanung . . . . . . . 253

2. Modelle der Globalsteuerung . . . . . . . . . . 254

3. Integrierte statt isolierter Umweltschutzplanung . . 259

V. Die Strukturen der Planung und die Strukturen des Umweltschutzes . . . . . . . . . . . . . . . . 262

1. Die Struktur des Planungsvorgangs . . . . . . . 262

2. Die Wirkungszusammenhänge im Umweltschutz . . . 265

VI. Die Verbesserung des Vorgangs der Ermittlung von Umweltschutzdaten . . . . . . . . . . . . . . . . 267

1. Die Bedeutung der Ermittlung von Umweltschutzdaten 267 
Seite

2. Die Ermittlung als zieldirigierter Informationsgewinnungs- und InformationsverarbeitungsprozeB . . . . 272

3. Die Verbesserung der Ermittlung durch das Filtern und Aufarbeiten von Umweltschutzdaten

VII. Verbesserung der Zielsetzung, der Gewichtung und der Abwägung von Umweltschutzbelangen . . . . . . . 279

1. Die Gleichrangigkeit aller planerischen Ziele . . . . 279

2. Die Verbesserung der Umweltschutzziele und deren Gewichtung . . . . . . . . . . . . . . . 281

3. Die bessere Vernetzung der Planungen . . . . . . 289

4. Abkoppelung von Einzelgenehmigungen und Umweltschutzplanung . . . . . . . . . . . . . . . 295

VIII. Die Verbesserung des Umweltschutzes in den Planungsleitbildern . . . . . . . . . . . . . . . . . . 299

1. Wachstumsbegrenzung als Staatsaufgabe? . . . . . 299

2. Leitbilder der Verkehrspolitik, der Stadtstruktur und der Raumordnung und Landesplanung . . . . . . 300

IX. Verfassungsrechtliche Grenzen des vorsorgenden Umweltschutzes . . . . . . . . . . . . . . . . . 304

1. Sicherheitsfaktoren bei dem gesamtökologischen Umweltschutz . . . . . . . . . . . . . . 304

2. Vorsorge durch Kooperation anstelle von Planung . . 308 
Für die Unterstützung bei der Vorbereitung des Mitberichts schulde ich vielfältigen Dank: Sehr hilfreich waren Gespräche im Umweltbundesamt in Berlin am 18. Mai 1979, die ich unter der Leitung von Herrn Direktor beim Umweltbundesamt Dr. Uppenbrink, Leiter des Fachbereichs I (Umweltplanung, Okologie), mit den Herren Wissenschaftlicher Direktor Dr. Storm, Leiter der Gruppe rechts-, wirtschafts- und sozialwissenschaftliche Umweltfragen innerhalb des Fachbereichs I, Regierungsdirektor Treuner, Leiter des Fachgebiets Umweltforschung und -entwicklung innerhalb des Fachbereichs I, Regierungsrat z. A. Procksch, Juristischer Mitarbeiter im Fachbereich I, Regierungsdirektor Szelinski, Leiter des Fachgebiets Grundsatzangelegenheiten, Recht, Planung der Abfall- und Wasserwirtschaft innerhalb des Fachbereichs III (Abfallwirtschaft, Wasserwirtschaft), und unter der Leitung von Herrn Wissenschaftlicher Direktor Dr. Hassemer, Leiter der Gruppe Umweltplanung, Umweltverträglichkeitsprüfungen innerhalb des Fachbereichs I 2 mit Frau Locher und den Herren Augustin und Dr. Summerer geführt habe.

Herr Ministerialdirektor Menke-Glückert, Leiter der Abteilung Umwelt im Bundesministerium des Inneren, und Herr Ministerialrat Goerke, Leiter des Referats Okologie und Umwelthygiene im Bundesministerium des Innern, haben mich am 6. Juni 1979 eingehend über Auffassungen des für den Umweltschutz federführenden Bundesinnenministeriums zu Umweltschutzfragen unterrichtet.

Mehrere Diskussionen im Zentralinstitut für Raumplanung an der Westfälischen Wilhelms-Universität in Münster im Rahmen der Vorbereitung eines Forschungsprojekts zur Umweltschutzplanung unter der Leitung von Herrn Staatssekretär a. D. Professor Dr. Ernst mit den Herren Professor Dr. Erbguth, Diplom-Volkswirt Timmer und Assessor Schlarmann haben mir weiterführende Erkenntnisse vermittelt. Die frühzeitige Uberlassung von $z$. T. im Druck befindlichen einschlägigen Veröffentlichungen durch die Herren Kollegen Kloepfer, Soell und Steiger sowie durch die Herren Ministerialdirigent $D r$. Feldhaus (Bundesministerium des Innern), Leitender Ministerialrat Dr. Fickert (Ministerium für Wirtschaft, Mittelstand und Verkehr des Landes NRW) und Herrn Ministerialdirektor a. D. Kölble hat mir ihre Verwertung im Mitbericht ermöglicht.

Die an meinem Lehrstuhl tätigen wissenschaftlichen und studentischen Hilfskräfte, und zwar die Herren Referendare Flocke, Hoene und Kayser sowie die Herren stud. jur. Bülow und Paßlick, haben mir vor allem bei der Beschaffung der vielfach nicht leicht erreichbaren Literatur, der Bearbeitung der Verweisungen innerhalb der Anmerkungen, der Durchsicht aller Zitatstellen sowie der Korrektur des Textes, aber auch mit ergänzenden Gedanken sehr geholfen.

Ganz besonderer Dank gilt meiner Sekretärin, Frau Inge Bodem, die mit unermüdlicher Geduld und verläßlicher Präzision unter kritischem Mitdenken den Text geschrieben hat. 


\section{Vorbemerkung}

Der Sachverständigenrat für Umweltfragen bei dem Bundesminister des Innern ${ }^{1}$ hat in seinem Umweltgutachten 1978 darauf hingewiesen, daß er die traditionellen Gefahren, die der Umwelt aus dem ökonomisch-industriellen System erwachsen, noch nicht als bewältigt ansehe ${ }^{2}$. Uber die bereits heute im Mittelpunkt der Umweltpolitik stehenden "traditionellen" Problemfelder und Lösungen hinaus bezeichnet der Rat alle diejenigen Entwicklungen für besorgniserregend, die zukünftige Entwicklungsmöglichkeiten einengen ${ }^{3}$.

Als solche besorgniserregenden Entwicklungen sind dabei anzusehen:

- Der Landverbrauch für Verkehrswegebau, Siedlung, Industrie, Landwirtschaft und Erholung am falschen Platz und die ökologisch schädliche Landnutzung4.

- Die weitere Belastung der Naturgüter Wasser, Boden, Luft, Klima, Tier- und Pflanzenwelt und damit die Schädigung von Ökosystemen ${ }^{5}$.

- Eine gesteigerte Naturausbeutung, die eine selbständige Wiedergesundung lebensnotwendiger Ressourcen in Frage stellt.

1 Der aus 12 Mitgliedern bestehende Rat von Sachverständigen für Umweltfragen ist gebildet aufgrund des „Erlasses über die Einrichtung eines Rates von Sachverständigen für Umweltfragen bei dem Bundesminister des Innern" vom 28. Dezember 1971 (GMBl. 1972, Nr. 3, S. 27) und hat die Aufgabe der periodischen Begutachtung der Umweltsituation und der Umweltbedingungen in der Bundesrepublik Deutschland, die die Urteilsbildung bei allen umweltpolitisch verantwortlichen Instanzen sowie in der Offentlichkeit erleichtern soll (§ 1 des Einrichtungserlasses). Er soll die jeweilige Situation der Umwelt und deren Entwicklungstendenzen darstellen sowie Fehlentwicklungen und Möglichkeiten zu deren Vermeidung und deren Beseitigung aufzeigen ( $\S 2$ des Einrichtungserlasses). Er hat zwei Hauptgutachten: „Umweltgutachten 1974“ (BT-Drucks. 7/2802) und „Umweltgutachten 1978" (BT-Drucks. 8/1938) sowie drei Sondergutachten: "Auto und Umwelt", Mainz 1973, "Die Abwasserabgabe", Mainz 1974, und „Umweltprobleme des Rheins" (BT-Drucks. 7/5014) erstattet.

2 Umweltgutachten 1978 (FN 1) Tz 1878.

3 Umweltgutachten 1978 (FN 1) Tz 1880.

4 Umweltgutachten 1978 (FN 1) Tz 1880, 1898.

5 Siehe hierzu z. B. die Antwort der Landesregierung des Landes Baden-Württemberg auf die Große Anfrage der Fraktion der CDU vom 17. 11. 1978 (LT-Drucks. 7/4820), S. 3. 
- Die Zunahme des gewerblich-industriellen sowie des Verkehrslärms.

Im Umweltschutz tritt wegen dieser Entwicklungen der Aspekt der planenden Umweltpflege immer deutlicher zutage, wird das Bewußtsein stärker, daß die Zukunft - deren Wurzeln in der Gegenwart liegen - weitgehend von dem abhängt, was wir von jetzt an mit unseren Informationen, Kenntnissen, wissenschaftlichen Fertigkeiten und technischen Errungenschaften vorsorgend tun werden ${ }^{6}$.

Diesen Tendenzen entspricht es, daß auch in der Umweltpolitik der Bundesregierung der Gedanke einer langfristig vorsorgenden Umweltpolitik, die auf alle Teilbereiche übergreift, stark an Boden gewinnt, um so eine dauerhafte Sicherung unserer Lebensgrundlagen $\mathrm{zu}$ erreichen. Er äußert sich in der Besorgnis, daß es an einer einheitlichen übergreifenden Gesamtplanung fehle: Die notwendige Periode des reagierenden Umweltschutzes müsse sobald wie möglich durch eine Politik der Umweltvorsorge abgelöst werden ${ }^{7}$.

Diese Umweltvorsorge durch Umweltschutzplanung stellt der Mitbericht in den Mittelpunkt. Gerechtfertigt ist eine solche seit jeher dem Mitberichterstatter eingeräumte $\mathrm{Be}$ schränkung aufgrund der tberlegung, daß damit ein zentraler Bereich des Umweltschutzes, für den der Staat schon wegen der zeitlichen Dimensionen existenzsichernder Zukunftsvorsorge - auch für kommende Generationen - eine besondere Verantwortung trägt ${ }^{8}$, behandelt wird.

- Siehe dazu Peccei, Optionen für die Zukunft (hektogr. Vortragsmanuskript), „Lebenswerte Zukunft“, Wissenschaftliche Fachtagung zu Umwelt und Wachstum (1979), 9 f.; Picht, Umweltschutz und Politik, ZRP 1971, 152 ff.

7 So z. B. Bundesminister des Innern Baum, Erklärung zum "Tag der Umwelt 1979“, Umwelt Nr. 70 (1979), 1; Umweltgutachten 1978 (FN 1) Tz 1935; Kölble, Staatsaufgabe Umweltschutz, Rechtsformen und Umrisse eines neuen Politikbereichs, DOV 1979, $470 \mathrm{ff} ., 470$; Hartkopf, Es ist Zeit für die ökologische Wende, Umwelt Nr. 69 (1979), $1 \mathrm{ff} ., 3$.

${ }^{8}$ Kloepfer, Staatsaufgabe Umweltschutz, DVBl. 1979, 639 ff., 642. Begriffliche Abgrenzungen sollen demgegenüber zurücktreten, so oszillierend der Begriff Umwelt sein mag (Weber, Umweltschutz im Verfassungs- und Verwaltungsrecht, DVBl. 1971, $806 \mathrm{ff} ., 806$ ) und so sehr sich das Wort Umweltschutz - neuerdings zu "Lebensschutz" gesteigert - durch besondere Unbestimmtheit, Relativität und Subjektivität auszeichnet (Engler, Welche Möglichkeiten des Schutzes vor schädlichen Umwelteinflüssen bietet das Zivilrecht?, AgrarR 1972, 371 ff., 371). Umweltschutz kann mit Kloepfer, Systematisierung 


\section{Vollzug des Umweltschutzes in der Krise}

Wendet man sich der langfristig vorsorgenden Umweltpolitik und einer Umweltschutzplanung, möglicherweise in Form einer übergreifenden Gesamtplanung zu, geschieht dies einerseits auf dem Hintergrund des ständig beschworenen und viel

des Umweltrechts (1978), Umweltbundesamt Bericht 8/78 (1979), der eine erschöpfende Darstellung der Abgrenzungsmöglichkeiten für das Umweltschutzrecht gibt ( $71 \mathrm{ff}$.), verstanden werden ,als die Gesamtheit von Maßnahmen, welche die natürliche (und menschlich gestaltete) Umwelt vor schädlichen Auswirkungen der Zivilisation gestaltend, planend, eingreifend und fördernd schützen. Dazu gehört auch die Regeneration der Umwelt" (70); siehe auch Kloepfer, Umweltschutz, Evangelisches Staatslexikon, 2. Aufl. 1975, Sp. $2651 \mathrm{ff}$., Sp. 2652. Rauschning, Umweltschutz als Problem des Völkerrechts, Europa-Archiv 1972, 567 ff., 567, versteht unter Umweltschutz das Bewahren der Biosphäre vor physischen und damit auch physikalischen, chemischen und biologischen Einflüssen oder Veränderungen, die Leben oder Wohlbefinden der Menschen unmittelbar oder mittelbar beeinträchtigen. Eingeschlossen sind Bemühungen, schädigende Nebenfolgen von als nützlich angesehenen menschlichen Aktivitäten wieder auszugleichen. Soell, Rechtsfragen des Umweltschutzes, WiR 1973, $72 \mathrm{ff}$., $82 \mathrm{f}$., warnt vor einer zu weiten Auslegung, die unter dem Begriff der Umwelt schlechthin alles erfassen will, was die „Qualität des Lebens" irgendwie berührt. Er will den Begriff im Anschluß an das Umweltprogramm der Bundesregierung vom 29. 4. 1971, BTDrucks. VI/2710, S. 6, den Bericht der niedersächsischen Landesregierung vom 29. 1. 1971 „Stand des Umweltschutzes und der Umweltpflege Niedersachsens", LT-Drucks. 7/595; Rehbinder, Grundfragen des Umweltrechts, ZRP 1970, 250 ff., 251; Steiger, Umweltschutz durch planende Gestaltung, ZRP 1971, 133 ff.; Weber, a. a. O., auf den Schutz der natürlichen Lebensgrundlagen des Menschen beschränken: Im Ergebnis läßt sich nach Soell Umweltschutz als die Summe all jener Maßnahmen begreifen, die zur Beseitigung bereits eingetretener Schäden oder zur Vorsorge vor weiteren Schädigungen unserer natürlichen Umwelt (mit ihren Hauptfaktoren Luft, Boden, Wasser, Pflanzen, Tiere) erforderlich sind, wobei das rechtliche Instrumentarium dem Zivilrecht (Nachbarschutz, Haftung), dem Strafrecht (Inkriminierung umweltschädigenden Verhaltens), dem öffentlichen Uberwachungs-, Eingriffs-, Leistungs- und Planungsrecht, also einem mehrdimensionalen Handlungssystem (Steiger, a. a. O., 139) angehört. (Soell, a. a. O., 83 f., mit weiteren zahlreichen Nachweisen.) Auf den Schutz des Menschen hebt besonders ab Kimminich, Das Recht des Umweltschutzes, 2. Aufl. 1972, 15; Moll, Taschenbuch für Umweltschutz II: Biologische Informationen, 2. Aufl. 1979, 1, spricht im Anschluß an Schwab, Bruns und Grzimek von "Lebensschutz" als Oberbegriff von technologischem Umweltschutz, biologisch orientiertem Naturschutz und Gesundheitsschutz. Er verweist auch auf den Gebrauch des Terminus "Menschenschutz“. 
beklagten "Vollzugsdefizits“ im Umweltschutz", andererseits angesichts einer - trotz spektakulärer Vorfälle und Aktionen - möglicherweise abnehmenden „Umweltsensibilität" der öffentlichen Meinung, nicht zuletzt infolge der wirtschaftlichen Rezession, der Arbeitsmarktprobleme und einer sich abzeichnenden Energiekrise ${ }^{10}$.

${ }^{\theta}$ Als Vollzugsdefizit ist die Diskrepanz zwischen dem normativ festgelegten Soll einerseits und dem Ist an Umweltschutz andererseits zu verstehen, so Ule-Laubinger, Empfehlen sich unter dem Gesichtspunkt der Gewährleistung notwendigen Umweltschutzes ergänzende Regelungen im Verwaltungsverfahrens- und Verwaltungsprozeßrecht? Gutachten B zum 52. Deutschen Juristentag (1978), B 13 ff.; siehe Umweltgutachten 1974 (FN 1) Tz 660 ff.; Umweltgutachten 1978 (FN 1) Tz 1640; siehe auch Rehbinder-Burgbacher-Knieper, Bürgerklage im Umweltrecht 1972, 15 ff.; von Lersner, Der Stand der Umweltpolitik in der Bundesrepublik Deutschland, TUB, Zeitschrift der Technischen Universität, Berlin 1974, 295 f.; Stich, Normative Anforderungen des demokratischen Rechtsstaats an die städtebauliche Entwicklungsplanung, NJW 1974, $1673 \mathrm{ff} ., 1674 \mathrm{~m}$. w. N.; Ders., Personale Probleme des Vollzugsdefizits in der Umweltschutzverwaltung, Festschrift für C. H. Ule (1977), $217 \mathrm{ff}$.; Rehbinder, Argumente für die Verbandsklage im Umweltrecht, ZRP 1976, $157 \mathrm{ff}$; Weyreuther, Verwaltungskontrolle durch Verbände? (1975), 20, 22. Ernst, Zur staatlichen Verantwortung für umweltbelastende Entscheidungen, BauR 1978, 8, bezieht auch das nicht volle Ausschöpfen des umweltschützenden Gehalts von Normen, also die „stiefmütterliche" Behandlung des Umweltschutzes, mit ein. Die erste gründliche empirische Untersuchung, die im Auftrag des Rates von Sachverständigen für Umweltfragen (FN 1) erstattet worden ist, liegt jetzt vor: Mayntz u. a., Vollzugsprobleme der Umweltpolitik, Empirische Untersuchung der Implementation von Gesetzen im Bereich der Luftreinhaltung und des Gewässerschutzes, Materialien zur Umweltforschung, hrsg. vom Rat von Sachverständigen für Umweltfragen (1978). Ule bemerkt zutreffend in seiner Besprechung (DVBl. 1979, 437 f., 438), daß defizitärer Umweltschutz nicht notwendigerweise auf einem Vollzugsdefizit beruhe, er könne auch bei den Rechts- und Verwaltungsvorschriften liegen. Der Rat werde zu prüfen haben, welches Gewicht dem in der Untersuchung in verschiedener Hinsicht festgestellten Vollzugsdefizit gegenüber dem Regelungsdefizit zukomme. Wagener, Der öffentliche Dienst im Staat der Gegenwart, VVDStRL 37 (1979), $212 \mathrm{ff} ., 246$, behandelt die Frage des Vollzugsdefizits auch unter dem Gesichtspunkt der Selbstbestimmung des Beamtenkörpers durch Regelungsüberlastung.

10 Oppermann, Gesetzte Normen des Völkerrechts zum Umweltschutz und die Grundlagen und Verfahren ihres Erlasses, in: Umweltschutz und internationale Wirtschaft (1975), $5 \mathrm{ff} ., 20$, stellte bereits 1975 diese Frage. Sie ist angesichts der sich abzeichnenden Energiekrise und der möglicherweise negativen Beschäftigungseffekte des Umweltschutzes nicht weniger akut als damals. 


\section{Entwicklung und Tendenzen}

Tatsächlich ist die kurze Geschichte des Umweltschutzes wechselhaft: Als Ausgangspunkt für das Erwachen des Umweltschutzes wird das 1962 erschienene Buch "The silent Spring" der amerikanischen Biologin Rachel Carson angesehen ${ }^{11}$. Seither hat sich ein - teilweise übersteigertes Umweltbewußtsein in breiten Kreisen der Bevölkerung entwickelt ${ }^{12}$. Diese Bewußtsein war verbunden mit einer manch-

11 Das Umweltbewußtsein findet seinen Ausdruck in einer Reihe von Untersuchungen, die von etwa 1970 an erschienen sind und von denen der Bericht des Club of Rome besonders hervorgetreten ist, siehe dazu vor allem Picht, Umweltschutz und Politik (FN 6); Taylor, Das Selbstmordprogramm, Zukunft oder Untergang der Menschheit (1971); Meadows, Die Grenzen des Wachstums, Bericht des Club of Rome zur Lage der Menschheit (1972); H. Schultze (Hrsg.), UmweltReport, Unser verschmutzter Planet (1972); Wellmann (Hrsg.), Die Umwelt-Revolte, Von der Ökonomie zur Ökologie (1972); Maddox, Unsere Zukunft hat Zukunft, Der Jüngste Tag findet nicht statt (1973); H. E. Richter (Hrsg.), Wachstum bis zur Katastrophe? Pro und Contra zum Weltmodell (1974); Mesarovich/Pestel, Menschheit am Wendepunkt, Zweiter Bericht an den Club of Rome zur Weltlage (1974); Hans Schaefer (Hrsg.), Folgen der Zivilisation, Therapie oder Untergang; Bericht der Studiengruppe "Zivilisationsfolgen" in der Vereinigung Deutscher Wissenschaftler (1974); Gruhl, Ein Planet wird geplündert, Die Schreckensbilanz unserer Politik (1975); Bussauer, Manifest zur umweltpolitischen Situation, in: Scheidewege, Heft 4 (1975), 1 ff.; Gabor-Colombo-King-Galli, Das Ende der Verschwendung, Zur materiellen Lage der Menschheit, Ein Tatsachenbericht an den Club of Rome (1976); eingehend zu dieser Literatur Storm, Umweltrecht (hektographiert, o. J.) 4, FN 2; Kimminich, Verwaltung und Verwaltungsrecht im Dienst des Umweltschutzes, BayVBl. 1979, 523 ff., 526, FN 23. Siehe auch die Angaben bei Kölble, Staatsaufgabe Umweltschutz (FN 7) 2, FN9. - Das Umweltprogramm der Bundesregierung (BT-Drucks. VI/2710) stammt auch aus dem Jahre 1971, fortgeschrieben im Umweltbericht '76 (1976) (BTDrucks. 7/5684).

12 Bereits 1972 verbanden $92 \%$ der Bevölkerung der Bundesrepublik Vorstellungen mit dem Thema Umweltschutz, Hartkopf, Das Umweltprogramm der Bundesregierung, structur 1972, 123 ff., 127. Allerdings haben "apokalyptische Visionen" (siehe dazu Soell, Rechtsfragen [FN 8] 72 mit Literatur FN 2), die von einer „gigantischen Demontage unserer natürlichen Umwelt" sprechen (Picht, Umweltschutz und Politik [FN 6] 153), die zu einem „Kollaps des Zivilisationssystems" (siehe dazu Saladin, Wachstumsbegrenzung als Staatsaufgabe, Festschrift für Ulrich Scheuner [1973], 541 ff., 542), zu einem "gigantischen ,ökologischen Bankrott“" (Rehbinder, Grundfragen [FN 8] führen sollen, eine teilweise hysterische Diskussion, wie Blümel (Die Standortvorsorgeplanung für Kernkraftwerke und 
mal euphorischen Utberschätzung der Möglichkeiten des Umweltschutzes ${ }^{13}$.

Diese Euphorie ist inzwischen allerdings nüchterner Einschätzung, ja Skepsis gewichen. So wird die Ankündigung des Uthergangs von einer medialen - auf einzelne Umweltmedien wie Boden, Wasser, Luft ausgerichteten - zu einer gesamtökologischen Betrachtungs- und Verfahrensweise des Umweltschutzes, der Einbettung der industriellen Entwicklung in ökologische Gesamtzusammenhänge und der Einführung von Instrumenten der übergreifenden Gesamtplanung und weitreichender Umweltverträglichkeitsprüfungen - zumindest von der Industrie, aber auch von der Landwirtschaft - als unnötige „neue Irritation" angesehen und vor einem Umbruch der Umweltpolitik im Sinne einer „ökologischen Wende" — wie Staatssekretär Hartkopf sie kennzeichnet - gewarnt, einer Wende also, die ihren Ausdruck in einer übergreifenden ganzheitlichen Umweltgestaltung und einem umfassenden Umweltgestaltungsinstrumentarium finden soll ${ }^{14}$.

andere umweltrelevante Großvorhaben in der Bundesrepublik Deutschland, DVBl. 1977, $301 \mathrm{ff}$., 305) sie gegeißelt hat, verursacht. Bothe, Umweltschutz als Aufgabe der Rechtswissenschaft, ZaöRV 1972, $483 \mathrm{ff}$., 483, hat darauf hingewiesen, daß es Probleme des Umweltschutzes bereits in der Antike gegeben habe, daß allerdings die Dimensionen neu seien, die der Gesamtkomplex dieser Probleme heute angenommen habe.

13 Bundesverband der Deutschen Industrie (BDI), Jahresbericht 1978/79, 157.

14 Bundesverband der Deutschen Industrie (BDI), Jahresbericht 1978/79, $156 \mathrm{ff}$.; Bundesverband der Deutschen Industrie (BDI), Umweltschutz und industrielle Entwicklung in der Bundesrepublik Deutschland (1979), 7, $12 \mathrm{f}$. Die Bedenken der Landwirtschaft hat Lillotte, Landwirtschaft und Landschaftsgestaltung, Beilage I/1978 in AgrarR (H. 10) 1978, $9 \mathrm{ff}$., $14 \mathrm{ff}$., formuliert. Von der „ökologischen Wende" hat Staatssekretär Dr. Günter Hartkopf, Es ist Zeit für die ökologische Wende (FN 7), 1 ff., 4; Ders., Ressourcenpolitik und Marktwirtschaft, Umwelt Nr. 69 (1979), 4 ff., 5, gesprochen. Der Bundesverband der Deutschen Industrie (BDI), Umweltschutz, 38, tritt auch der Aussage entgegen, Umweltschutz führe generell zu eindeutig positiven Beschäftigungseffekten. Er hegt die Befürchtung, daß durch eine konjunkturpolitisch motivierte Forcierung von Umweltschutzinvestitionen in einzelnen Industriebereichen weitaus häufiger als bisher die Grenze der Belastbarkeit überschritten werde, wodurch die Arbeitsmarktprobleme in der Bundesrepublik Deutschland verschärft würden; siehe dazu Hartkopf, Umwelt Nr. 69 (1979), 4. Siehe auch das Gutachten des IFO-Instituts zu Umweltschutz und Arbeitsplätzen. Zahlenangaben zu positiven Beschäftigungseffekten aus den bisher vorliegenden Gutachten und Untersuchungen, siehe 
Die bisherige Entwicklung des Umweltschutzes und des Umweltbewußtseins zeigt zweierlei deutlich an:

- Angesichts der Dimensionen der Umweltschutzprobleme die Notwendigkeit, zu ihrer Bewältigung sowohl das Arsenal staatlicher wie auch privater Instrumente einzusetzen ${ }^{15}$.

- Die Gefahr, daß bestimmte Lösungswege der zweifellos vorhandenen Jahrhundertaufgabe des Umweltschutzes einseitig diskutiert werden.

Man muß doch fragen, ob die zeitweise geradezu überbordende Diskussion von Grundsatzperspektiven, die dem soviel berufenen Vollzugsdefizit entgegenwirken soll, nicht nur den Blick für eine auf praktische Bedürfnisse abgestellte Verbesserung der vorhandenen Instrumente des Umweltschutzes verstellt, sondern auch die Ursachen mangelnden oder unzureichenden Umweltschutzes eher verdeckt als sichtbar gemacht hat. Das gilt auch für die intensive Behandlung der „Verankerung" eines Grundrechts auf Umweltschutz in der Verfassung ${ }^{16}$, die allerdings in letzter Zeit stark zurückgetreten ist ${ }^{17}$,

in: Bundesverband der Deutschen Industrie (BDI), Umweltschutz, $28 \mathrm{ff}$.

15 Bullinger, Haftungsprobleme des Umweltschutzes aus der Sicht des Verwaltungsrechts, VersR 1972, $599 \mathrm{ff} ., 601,608,610$ : Nur von einer Summierung aller denkbaren Mittel des Umweltschutzes, die jeweils für sich allein zu schwach sind, wird das Minimum an Umweltschutz zu erwarten sein; Rehbinder, Umweltrecht, Rechtsvergleichendes Generalreferat, RabelsZ 40 (1976), 363 ff., 287: Hartkopf, Industrie und Umweltschutz - ein Gegensatz?, Umwelt Nr. 71 (1979), $1 \mathrm{ff} ., 4 \mathrm{f}$.

16 Gegen den Terminus „Verankerung“ Klein, Ein Grundrecht auf saubere Umwelt?, Festschrift für Werner Weber (1974), $643 \mathrm{ff.}$., 661; Forsthoff, Einiges über die Geltung und Wirkung der Verfassung; Festschrift für Ernst Rudolf Huber (1973), $3 \mathrm{ff.,} 7 \mathrm{f}$.

17 Siehe dazu grundlegend Steiger, Mensch und Umwelt - Zur Frage der Einführung eines Umweltgrundrechts (1975), $11 \mathrm{ff}$. In der sehr gründlichen Untersuchung von Kloepfer, Zum Grundrecht auf Umweltschutz (1978) mit eingehenden und erschöpfenden Literaturnachweisen, sind alle Beđenken überzeugend aufgeführt, die gegen eine solche Aufnahme eines Grundrechts auf Umweltschutz sprechen; siehe jetzt auch Scholz, Verfassungsfragen zum Schutz des Nichtrauchers, DB Beilage Nr. 10/79, $13 \mathrm{f}$. Kloepfer untersucht ein Umweltgrundrecht als Voraussetzungsgewährleistung für die Umwelt in Form grundrechtlicher Garantien unter den fünf denkbaren Konzeptionen abwehrrechtlicher, institutioneller, sozialgrundrechtlicher, leistungsrechtlicher und aktiv-teilhaberechtlicher Art. Kloepfer rät von der Neueinführung eines Grundrechts in Ubereinstimmung mit einer sich mehr und mehr durchsetzenden Meinung ab, weil insgesamt die Nachteile die Vorteile überwögen (zusammen- 
die Erörterung der Einführung einer verfassungsrechtlichen Staatszielbestimmung oder wertentscheidenden Grundsatznorm $^{18}$ ) und die intensive Behandlung der Verbandsklage ${ }^{\mathbf{1 0}}$.

fassend 39). Zu den im Gespräch befindlichen Formulierungsvorschlägen siehe Kloepfer, $31 \mathrm{f}$.

Während das Umweltgutachten 1974 (FN 1) Tz 634 ff. sich noch für die Einführung eines Grundrechts auf menschenwürdige Umwelt in das Grundgesetz einsetzte, hat der Rat im Umweltgutachten 1978 (FN 1) $\mathrm{Tz} 1945$ hervorgehoben, die verfassungs- und verwaltungsrechtliche Diskussion habe ihn inzwischen - wie fast alle Beteiligten - zu der Erkenntnis gebracht, daß ein einklagbares Grundrecht auf Umweltschutz weder praktikabel noch für die angestrebte Verankerung der Umweltpolitik zweckmäßig sei. Er hat die Nachteile überzeugend dargetan: Zum einen würde durch diese Judifizierung die Umweltqualität scheinbar juristisch bestimmbar, obwohl es sich bei den langwierigen Erörterungen umweltpolitischer Fragen herausgestellt habe, daß es bei der Umweltpolitik immer um die $\mathrm{Ab}$ wägung zwischen widersprüchlichen und kaum quantifizierbar vergleichbaren Zielen gehe. Zum zweiten würde die falsche Erwartung bestätigt, Umweltqualität sei ein Anspruch und Gut des einzelnen, obwohl es sich hierbei fast immer um kollektive Güter handle. Insgesamt könnte eine solche Grundrechtsbestimmung den politischen Charakter der Umweltfragen eher verdrängen. Darüber hinaus sieht der Rat die Gefahr, daß bei dem hohen Umweltbewußtsein der Bevölkerung die Einführung eines Grundrechts den Hoffnungen und Erwartungen der Bevölkerung einen Maßstab geben würde, der unrealistisch und unerfüllbar wäre und zu Enttäuschungen und schließlich zu Rückschlägen für die Umweltpolitik führen könnte.

18 Dellmann, Zur Problematik eines Grundrechts auf menschenwürdige Umwelt, DOVV 1975, 588 ff., 588; Storm, Umweltrecht, AgrarR 1974, $181 \mathrm{ff}$., $185 \mathrm{f}$., spricht von der Aufnahme einer wertentscheidenden Grundsatznorm für den Schutz der Erhaltung der natürlichen Lebensgrundlagen, die eindeutige Maßstäbe der Auslegung und Abwägung für das geltende und der Ausgestaltung für das künftige Umweltrecht setze; Ders., Bodeneigentum, land- und forstwirtschaftliche Bewirtschaftung und Umweltschutz, Festschrift für Franz Schad (1978), 451 ff.; Umweltbericht '76 (FN 11) Tz 110; Umweltgutachten 1978 (FN 1) Tz 1946 spricht sich für die Aufnahme des Umweltschutzes als Staatsaufgabe aus. Eine solche Bestimmung soll als Verfassungsauftrag für die Legislative (Umweltbericht '76, a. a. O., $\mathrm{Tz}$ 110), Exekutive und Judikative (Umweltgutachten 1978 [FN 1] Tz 1946) die Verpflichtung enthalten, einen wirksamen und möglichst umfassenden Umweltschutz zu schaffen. Das Umweltgutachten 1978 (FN 1) Tz 1947 sieht folgende positive Wirkungen mit der Aufnahme in die Verfassung verbunden: Der Rang der Umweltpolitik könnte durch eine solche Deklaration erhöht werden; die neue Staatsaufgabe würde stärker als bisher in der verfassungspolitischen Diskussion berücksichtigt werden; eine Verfassungsbestimmung dürfte auch eine Ausstrahlung auf die Rechtsprechung haben, und zwar 


\section{Frage nach den Ursachen mangelnden Umweltschutzes}

Sieht man einmal davon $a b$, daß die Herausbildung von Extrempositionen im Umweltschutz selbst eine Umweltpolitik

nicht nur im Verwaltungsrecht, sondern auch im Zivilrecht; durch eine grundsätzliche Erklärung des Umweltschutzes als Staatsaufgabe würde klargestellt, daß es sich um eine Querschnittsaufgabe handle, die nicht nur in den Aufgabenbereich eines Ressorts fällt; eine grundgesetzliche Verankerung könnte auch die Berücksichtigung des Umweltschutzes in der politischen Bildung verstärken.

Von den Auswirkungen einer solchen verfassungsrechtlichen Regelung auf die Gewichtung von Umweltbelangen bei Planungsentscheidungen ist allerdings nirgends die Rede, siehe dazu unten VII, 2.

Ganz dezidiert gegen eine solche Bestimmung Kloepfer, Zum Grundrecht auf Umweltschutz (FN 17), 38, mit der Begründung, es gehe dabei letztlich um die verfassungspolitische Aufwertung des von der Bundesregierung verfolgten politischen Staatsziels Umweltschutz. Die Abkehr vom Grundrechtsgedanken gebe der Regierung dann faktisch die Möglichkeit, nach eigenem Gutdünken von dem neuen verfassungsrechtlichen Titel Gebrauch zu machen. Hiergegen auch Meyer-Tasch, Umweltrecht im Wandel (1978), 17, FN 16: Als Staatszielbestimmung sei sie schon im Sozialstaatsprinzip (mit) enthalten. Ihre Einführung wäre daher auch vor allem von propagandistischer Bedeutung und würde von den eigentlichen Problemen eher ablenken als zu ihrer Wirkung beitragen; ebenso: Senning, Systemdynamische und energetische Uberlegungen zur Klagebefugnis im Naturschutzrecht, Natur + Recht 1979, 9 ff., 12.

10 Schrifttum hierzu siehe bei Ule-Laubinger (FN 9), B $63 \mathrm{f}$., FN 101; B 99 ff., FN 179-192, die der Verbandsklage ablehnend gegenüberstehen. Ein Bedürfnis für eine egoistische Verbandsklage bestehe nicht, da jedes Mitglied, wenn es in seinen Rechten verletzt sei, selbständig klagen könne (B 99). Die altruistische oder ideelle Verbandsklage durchbreche das System des individuellen Rechtsschutzes an einer entscheidenden Stelle, sie sei nicht geeignet, um die „richtige“ und „effektive“ Anwendung der Umweltgesetze zu sichern, und entspreche - als öffentliche, weil dem öffentlichen Interesse dienende Aufgabe - nicht den Aufgaben, die private Verbände, die lediglich von ihnen selbst gesetzte Ziele verfolgten, zu übernehmen hätten. Ebenso Ossenbühl, Aktuelle Probleme des Umweltschutzrechts, Verwaltungsrundschau 1979, 1 ff., 7.

Die Klagebefugnis Dritter im Naturschutzrecht wird von Senning schon nicht mehr als "Kategorie des Rechts“ gewertet, er sieht ihr vielmehr im Umweltrecht „systemdynamische" Bedeutung zukommen; sie führe zu einer negativen Rückkoppelung des bisher positiv rückgekoppelten Systems (Senning [FN 18], 12). Zu dem ganzen Problem jetzt eingehend Skouris, Verletztenklage und Interessentenklage im Verwaltungsprozeß (1979). 
„der kleinen Schritte" behindert"20 und daß die „Eigengesetzlichkeit unseres politischen Systems" einschließlich der politischen Schwäche der vollziehenden Verwaltung den Verwaltungsvollzug erschwert ${ }^{21}$, erscheinen mir vor allem die eingesetzten Instrumente - auch und insbesondere die der Planung - an mangelnder Eignung zu kranken. Offensichtlich sind sie dort überperfekt, - wie vielfach beklagt -, wo die Perfektion ineffektiv ist und dort defizitär, wo der Umweltschutz auf effektivere Regelungen angewiesen ist ${ }^{22}$.

${ }_{20}$ Siehe dazu Umweltgutachten 1978 (FN 1) Tz 1924, in dem der Rat darauf hinweist, daß sowohl die Beurteilungen der Umweltgefährdung als auch die Bewertung des Technologiebeitrages zur Lösung des Umweltproblems sowie der notwendigen Anpassung wirtschaftlicher Strukturen so kontrovers geworden sind, daß Rolle und Bedeutung der Umweltpolitik im Verhältnis zu anderen Teilbereichen der Wirtschafts- und Gesellschaftspolitik kaum noch konsensfähig zu sein scheinen: Die Diskussion um "Lebensqualität" und „qualitatives Wachstum" und um die wirtschaftlich-sozialen Inhalte und Auswirkungen dieser Konzeptionen habe zur Ausprägung zweier Extrempositionen geführt, zwischen denen eine rationale Vermittlung immer schwieriger werde. Das ökonomisch-technologische Modell, das im Grundsatz die Dominanz wirtschaftlicher Werte beibehalte, erkenne zwar die Umwelt als begrenzenden Faktor wirtschaftlicher Entwicklung an, es unterstelle jedoch, daß die technologische Entwicklung das Umweltproblem weitgehend beherrschbar mache. Ihm seien innerhalb der Okologiebewegung lebensreformerische Modelle gegenübergetreten, die eine absolute Priorität von Umweltzielen verlangten und daher folgerichtig eine grundlegende Reform der ökonomisch-sozialen Strukturen im Sinne einer Anpassung an die natürliche Umweltgegebenheit forderten. Beide extremen Betrachtungsweisen fänden sich in allen im Deutschen Bundestag vertretenen politischen Parteien.

21 Salzwedel, Anhörung zum Thema „Wasserhaushalt“, Teil II, Protokoll Nr. 42 (Nr. 30) über die 3. Informationssitzung des Innenausschusses und des Ausschusses für Jugend, Familie und Gesundheit zu Fragen des Umweltschutzes am 8. Mai 1971; Soell, Rechtsfragen (FN 8), 75; siehe auch Forsthoff, Der Staat der Industriegesellschaft (1971), 107 ff.; Bullinger, Haftungsprobleme (FN 15), 600.

22 Bender, Das Selbstregulierungstheorem als die zentrale $\mathrm{Me}-$ thode einer allgemeinen Gesetzgebungslehre, Festschrift für Helmut Schelsky (1978), 31 ff., 36, glaubt sogar die Feststellung treffen zu können, daß angesichts des Standes unserer Gesetzgebungstheorie nach wie vor jedes Gesetz „ein Schuß ins Dunkle“ sei. Für Gesetzestests setzen sich ein Fricke und Hugger, Sollten Gesetze vor Erlaß getestet werden, DOV 1979, (550) ff.; siehe Umweltgutachten 1978 (FN 1) Tz 1644; Stich, Personale Probleme (FN 9), 237. Storm, Diskussionsbeitrag bei dem 52. DJT, K 179, weist darauf hin, daß der Abbau des sogenannten Vollzugs- und Implementationsdefizits nicht nur als 
Macht es nicht nachdenklich, daß der Entwurf des Umweltchemikaliengesetzes noch vor wenigen Tagen vom Sachverständigenrat und dessen Vorsitzenden Bick als „schlechter Ansatz" und untauglich abqualifiziert und das vorgesehene Prüfverfahren als „fossil“ bezeichnet worden ist ${ }^{23}$ ?

Hinzu kommt, daß die Umweltschutzregelungen in einer selbst für Experten kaum noch überschaubaren Vielzahl erlassen und permanent geändert werden. Dies kann man feststellen, ohne einen "latenten Gesetzesgroll“ zu hegen ${ }^{24}$.

Hinzu tritt die besondere Struktur des Umweltschutzrechts ${ }^{25}$, die sich durch abstrakt-generelle Formulierungen von Zielvorgaben auszeichnet, die Hand in Hand mit mangelnder Operationalisierbarkeit, d.h. Auflösbarkeit in meßbare Merkmale, gehen $^{26}$. Mangelnde Festlegung der Rangfolge kollidierender Interessen führt dahin, daß die Vollzugsbehörden überfordert sind, insbesondere überfordert, den unterschiedlich starken Pressionen, mit denen die kollidierenden Interessen vorgetragen werden, standzuhalten ${ }^{27}$. Das gilt auch, wenn Ziele vieldeutig geworden oder eindeutige Ziele zwar formuliert sind, die zu ihrer Erreichung notwendigen Instrumente aber nicht mitgeliefert sind ${ }^{28}$.

Es ist allgemein anerkannt und wird vom Umweltgutachten 1978 bestätigt, daß sich z. B. mehr als zwei Drittel der Kom-

Problem auf der Seite der Normanwendung, sondern auch auf seiten der Normerzeugung liege.

23 FAZ Nr. 218 vom 19. 9. 1979: „Bauern für mehr Schutz vor den Gefahren der Chemie, Der Sachverständigenrat kritisiert den Entwurf zum Chemikaliengesetz"; siehe auch die Kritik von Breuer, Die Entwicklung des Umweltschutzrechts seit 1977, NJW 1979, $1862 \mathrm{ff}$., 1864.

24 Siehe Kloepfer, Umweltschutz und Recht, BB 1978, 1729 ff., 1732; siehe dazu die Gesetzessammlung von Kloepfer, Deutsches Umweltschutzrecht (Loseblatt), 2 Bände, und die Zusammenstellung des geltenden Rechts bei Kloepfer, Systematisierung (FN 8) FN 13-63, (FN 7) FN 13-300. Auch der Bundesverband der Deutschen Industrie (BDI), Umweltschutz (FN 14), 28, verlangt Ubersichtlichkeit und technische Anwendbarkeit der Umweltschutzgesetzgebung auch für kleinere und mittlere Unternehmen.

25 Siehe dazu vor allem Rehbinder, Umweltrecht (FN 15), 405; Ernst, Zur staatlichen Verantwortung (FN 9), 1.

${ }^{28}$ Roth, Effektivitätsprobleme im Umweltschutzrecht, Festschrift für Friedrich August Freiherr von der Heydte (1977), 1144 ff., 1148.

${ }^{27}$ Roth, Effektivitätsprobleme (FN 26), 1159; siehe auch Umweltgutachten 1978 (FN 1) Tz 1644; Papier, Die Stellung der Verwaltungsgerichtsbarkeit im demokratischen Rechtsstaat, Schriftenreihe der Juristischen Gesellschaft e.V. Berlin, H. 58 (1979), 30.

${ }^{28}$ Umweltgutachten 1978 (FN 1) Tz 1642. 
munen durch die umweltpolitische Aufgabenstellung als überfordert ansehen ${ }^{29}$. Charakteristisch dafür ist, daß „fast der gesamten Eisen- und Stahlindustrie eine verbindliche Bauleitplanung" fehlt. Dabei besteht bei 56 von 68 untersuchten Standorten unmittelbare Nachbarschaft zu Wohnbebauung ${ }^{30}$.

${ }^{29}$ Umweltgutachten 1978 (FN 1) Tz 1041, unter Hinweis auf Otto, Umweltschutz überfordert Städte, Umwelt (VDI: Zeitschrift des Vereins Deutscher Ingenieure für Immissionsschutz - Abfall - Gewässerschutz) 1975, H. 5, 13 ff.; Stich, Personale Probleme (FN 9), 232.

30 Die Ergebnisse gehen zurück auf eine Umfrage der Wirtschaftsvereinigung Eisen- und Stahlindustrie (Düsseldorf) aus dem Jahr 1978 bei den Mitgliedern der Vereinigung (Anlage zu Rundschreiben Nr. 14 an die Mitglieder im Fachausschuß „Wasser- und Immissionsrecht"). Es heißt hier: „Die Umfrage hat eine unerwartet hohe Resonanz gefunden. Legt man als Maßstab die Beschäftigtenzahl zugrunde, so haben sich $\mathbf{8 7} \%$ der der Wirtschaftsvereinigung angeschlossenen Industrie beteiligt. Untersucht wurden 68 Standorte mit insgesamt 217000 Arbeitsplätzen und einer Gesamtfläche von 71,1 Mio. qm, davon 56,7 Mio. qm betrieblich genutzte Fläche und 14,4 Mio. qm Erweiterungsgelände. Im Vergleich dazu: In der Stadt Leverkusen leben auf 78 Mio. qm 165000 Menschen. Als Ergebnis der Umfrage läßt sich festhalten, daß fast der gesamten Eisen- und Stahlindustrie eine verbindliche Bauleitplanung und damit eine Voraussetzung für ihre Investitionsentscheidungen fehlt. Die Stahlindustrie ist in ihrer Erweiterung und Entwicklung nicht abgesichert. Die Ergebnisse im einzelnen: Für 93\% des bebauten Betriebsgeländes mit 199000 Arbeitsplätzen und 81\% des Erweiterungsgeländes bestehen keine Bebauungspläne im Sinne von $\S 30$ Bundesbaugesetz. Nur für 1,6\% des bebauten Betriebsgeländes ist ein Verfahren zur Schaffung eines verbindlichen Bauleitplans eingeleitet. Selbst in diesen nur sehr wenigen Fällen wird die Aussicht für eine planungsrechtliche Absicherung des Betriebsstandortes durch Bebauungsplan überwiegend schlecht beurteilt. Die eingeleiteten Verfahren ziehen sich teilweise bereits über mehrere Jahre hin, ohne daß sich erkennbare Lösungen aufzeigen. Bei 56 von 68 untersuchten Standorten besteht unmittelbare Nachbarschaft zur Wohnbebauung. Für 15 von 68 Standorten mit einem Anteil von $40 \%$ an der bebauten Betriebsfläche sind im Flächennutzungsplan zeichnerische bzw. textliche Beschränkungen enthalten. Bei weiteren 28 Standorten mit einem Anteil von $17 \%$ an der betrieblich genutzten Fläche zeichnen sich für die Zukunft aufgrund der fehlenden Darstellung als Industriegebiet Schwierigkeiten ab. In nur 7 der Antworten wurden Beschränkungen für die Wohnbebauung erwähnt. Während für die Produktionsanlagen in der Eisen- und Stahlindustrie eine Darstellung im Flächennutzungsplan als Industriegebiet (GI) erforderlich ist, sind nur $79 \%$ der betrieblich genutzten Fläche als Industriegebiet (GI), $17 \%$ als gewerbliche Baufläche (G) und $4 \%$ als Gewerbegebiet (GE) dargestellt. Die Erweiterungsflächen sind sogar nur zu 
$66 \%$ als Industriegebiet (GI) dargestellt. Bei 46 von 68 Standorten mit $42 \%$ der betrieblich genutzten Fläche zeigen Flächennutzungspläne bei bestehender Gemengelage keine Möglichkeit der Entzerrung zwischen Industrie- und Wohnbereichen auf. Bei nur 7 Standorten erscheint an einzelnen Stellen eine Entzerrung aufgrund der Kennzeichnung von Wohnbereichen als Sanierungsgebiet im Flächennutzungsplan möglich. In nur 4 Fällen sind in angrenzenden Wohngebieten geringfügige Sanierungen nach Städtebauförderungsgesetz eingeleitet.

Obwohl das Bundesbaugesetz vor fast 20 Jahren in Kraft getreten ist, sind die Schwierigkeiten bei dessen Verwirklichung noch nicht überbrückt worden, weil bei den im Gesetz verankerten städtebaulichen Grundsätzen die Interessen von Umweltschutz und Wirtschaft hart aufeinandertreffen. Zwar sind in der unverbindlichen Planung (Flächennutzungsplan) die Flächen bestehender Betriebe weitgehend als Industriegebiet dargestellt, das gleiche gilt aber auch für die benachbarte Wohnbebauung, die als Wohnflächen dargestellt ist. Die Entzerrung der Verflechtung von Industrie und Wohnen ist also nicht erfolgt, und damit sind die Probleme des Umweltschutzes auf die Ebene des verbindlichen Bauleitplans (Bebauungsplan) bzw. auf die Ebene der Antragsverfahren nach dem Bundes-ImmissionsschutzGesetz verlagert.“

Siehe hierzu von Holleben, Die Sicherung bestehender gewerblicher Standorte bei der Utberplanung dicht bebauter Bereiche, GewArch. 1978, 41 ff.; Das Umweltgespräch, Aktuell: Lösungsvorschläge für Standortkonflikte, Möglichkeiten und Grenzen der Standortvorsorge, Schriftenreihe der Arbeitsgemeinschaft für Umweltfragen e.V., H. 12 (1978); Hoppe, Planungsrechtliche Grundsätze für die Uberplanung gewachsener Strukturen und zur Lösung von Standortkonflikten, in: Festschrift für Werner Ernst (1980, $215 \mathrm{ff}$. Diese Untersuchungen zeigen, wie außerordentlich schwer die Probleme mit vorhandenen Instrumenten, so z. B. dem Gebot der Rücksichtnahme (siehe dazu Weyreuther, Das bebauungsrechtliche Gebot der Rücksichtnahme und seine Bedeutung für den Nachbarschutz, BauR 1975, $1 \mathrm{ff}$.; siehe auch Sendler, Industrieansiedlung, Umweltschutz, Planungs- und Nachbarrecht, WiR 1972, $453 \mathrm{ff.;}$. Breuer, Die Bodennutzung im Konflikt zwischen Städtebau und Eigentumsgarantie [1976], 265 ff. [letzterer vor allem unter eigentumsrechtlichen Gesichtspunkten]), zu lösen sind.

Der Deutsche Bundestag hat aus Anlaß der letzten Novellierung des BBauG am 31. Mai 1979 durch Beschluß festgestellt, er sei sich bewuBt, „daß in Gebieten mit engem Nebeneinander von gewerblichen Anlagen und Wohnnutzungen Probleme bestehen, die sich auf die notwendigen Modernisierungs- und Erweiterungsmaßnahmen an den gewerblichen Anlagen nachteilig auswirken". Er hat die Bundesregierung beauftragt, zu prüfen, „worauf diese Probleme beruhen, insbesondere ob sie städtebaurechtlicher oder immissionsschutzrechtlicher Natur sind“, und gegebenenfalls Vorschläge für gesetzliche Regelungen vorzulegen (Entschließungsantrag des Deutschen Bundestages, BT-Drucks. 8/2885 vom 31. Mai 1979). 
Gerade bei den größten Firmen in der Bundesrepublik - wie Hoesch, Ford, BASF - gibt es für die Standorte keine rechtsbeständigen Bebauungspläne ${ }^{31}$. Es fehlt an Regelungen im BBauG für solche umweltschutzempfindlichen historisch gewachsenen Gemengelagen und deren Entmischung. Inzwischen bleiben aber die Gemeinden alleingelassen, und das Wort vom "Vollzugsdefizit im Umweltschutz" dient weiter dazu, Forderungen nach Grundgesetzänderungen, auf Erweiterung der Klagebefugnis und der Partizipation zu unterstützen ${ }^{32}$.

Den Ursachen mangelnden oder unzureichenden Umweltschutzes kann nur mit kleinen Schritten möglicherweise auf der Grundlage eines langfristigen Orientierungsrahmens entgegengewirkt werden ${ }^{33}$. Man kann dem Rat von Sachverständigen nur beipflichten, daß „eine modische Globalbetrachtung der Umweltprobleme auf hohem Abstraktionsniveau" kaum Entscheidungshilfen bietet, daß es vielmehr darum gehe, „konkrete umweltpolitische Probleme aufzugreifen, Lösungsansätze vorzulegen und auf ihre ökonomische Tragfähigkeit zu überprüfen"s4.

${ }^{31}$ Pielow, Sicherung von Industriestandorten, Lösungsmodelle für Standortkonflikte, Möglichkeiten und Grenzen der Standortvorsorge, Schriftenreihe der Arbeitsgemeinschaft für Umweltfragen $\mathrm{Nr} .12$ (1978), 18.

32 Die Schwierigkeiten der Entmischung unverträglicher Nutzung werden auch im Umweltgutachten 1978 (FN 1) $\mathrm{Tz} 1062,1063$ angesprochen, die Frage aber einerseits nur als finanzielles Problem, andererseits als eine Frage des Bundes-Immissionsschutzgesetzes und verstärkter Auflagen bei industriellen Anlagen angesehen. Es fehlt aber ein adäquates planungsrechtliches Instrumentarium. Es wird andererseits nicht verkannt, daß diese Gemengelagen vielfach durch gemeindliche Fehlplanungen entstanden sind und da $B$ oft technische Möglichkeiten des Umweltschutzes bei der gemeindlichen Planung infolge des Fehlens von Basiswissen nicht ausgeschöpft werden. Speer, Das Planungsinstrumentarium zur Bewältigung des Imissionsschutzes bei der Aufstellung von Flächennutzungs- und Bebauungsplänen, Kurzfassung eines Vortrages im Rahmen der wissenschaftlichen Arbeitstagung der Universität Kaiserslautern vom 11./12. 10. 1978 (hektographiert), 2.

33 Umweltgutachten 1978 (FN 1) Tz 1930, das zusätzlich betont, die dem Umweltprogramm der Bundesregierung zugrunde liegenden Prinzipien (Vorsorge-, Verursacher- und Kooperationsprinzip) reichten dazu in der bisherigen allgemeinen Form nicht aus, da aus ihnen direkt keine konkreten Folgerungen für Ziele und Instrumente abgeleitet werden könnten.

34 Rheingutachten (FN 1) Vorwort, 1; Umweltgutachten 1978 (FN 1) $\mathrm{Tz}$ 6. Die Zielverwirklichungstechnik in der Gesetzgebungslehre kennt das „Kleine-Schrittchen-Theorem“ (Bender, Das Selbstregu- 
Bevor die "ökologische Wende" eingeläutet wird, sollten die bestehenden Instrumentarien auf ihre Effektivität, Praktikabilität, Flexibilität und Bestimmtheit untersucht und soweit notwendig - vervollständigt und verbessert werden.

\section{Planung als Teil der Staatsaufgabe Umweltschutz durch Vorsorge}

\section{Planung als Ausdruck des Vorsorgeprinzips}

Eines der zentralen Instrumente im mehrdimensionalen System des sich als staatliche Aufgabe darstellenden Umweltschutzes ${ }^{35}$, nämlich die Umweltschutzplanung, steht im Dienste des Vorsorgeprinzips. Dieses Prinzip - im Umweltprogramm der Bundesregierung von 1971 noch nicht expressis verbis aufgeführt, aber implizit enthalten ${ }^{36}$ - hat bisher noch keine festen Konturen gewonnen ${ }^{37}$. Dennoch wird es inzwischen in jedem Umweltbericht und Umweltprogramm neben dem Verursacher- und Koordinationsprinzip des Umweltschutzes vorgestellt.

Diese Prinzipien des Umweltschutzes geben Leitbilder, Grundkonzeptionen und politische Handlungsanweisungen für

lierungstheorem [FN 22], 47; Dellmann, Grundrecht auf menschenwürdige Umwelt [FN 18], 590; in der Tendenz ebenso Soell, Rechtsfragen [FN 8], 73; Rupp, Die verfassungsrechtliche Seite des Umweltschutzes, JZ 1971, 401).

35 Steiger, Umweltschutz durch planende Gestaltung (FN 8), 139.

s6 Das Umweltprogramm 71 (FN 8) führt neben dem Verursacherprinzip (9, $10 \mathrm{ff}$.), das durchzusetzen sei, die Umweltplanung als Ziel der Umweltpolitik an (9 f.); ebenso das Umweltgutachten 1974 (FN 1) Tz 23. Das Vorsorgeprinzip ist im Umweltbericht '76 (FN 11) Tz 004 sehr allgemein umrissen: „Umweltpolitik erschöpft sich nicht in der Abwehr drohender Gefahren und der Beseitigung eingetretener Schäden. Vorsorgende Umweltpolitik verlangt aber darüber hinaus, daß die Naturgrundlagen geschützt und schonend in Anspruch genommen werden."

s7 Das Umweltgutachten 1978 (FN 1) Tz 1936 bezeichnet es zutreffend als inhaltlich und instrumentell unbestimmt: Ohne weitere Operationalisierung könne es allenfalls eine allgemeine konsensbildende Wirkung erzeugen, nicht jedoch die umweltpolitische Entscheidungsfindung erleichtern, da es keine konkrete Entscheidungsalternative ausschlösse. Das Vorsorgeprinzip bedürfe noch der begrifflichen Klärung. Es bedarf überđies der Klärung der verfassungsrechtlichen Grenzen des Vorsorgeprinzips, vor allem, wenn es dazu dient, vorsorgende Umweltgestaltung mit sehr hohen Sicherheitsfaktoren auszustatten, siehe dazu unten unter IX. 
eine rationale Umweltpolitik $a b^{38}$, so $d a B$ sich zunächst die Frage stellt, ob Umweltschutzplanung vom Leitbild des vorsorgenden Umweltschutzes gefordert ist ${ }^{39}$. Nach der Definition, die das Vorsorgeprinzip im Umweltbericht '76 gefunden hat, spricht es den prospektiv-planerischen Aspekt an, und zwar mit dem Hinweis, daß bei allen Entscheidungen ökologische Gesichtspunkte berücksichtigt werden müssen, und zwar gerade zur Verhinderung von Entwicklungen, die künftig $\mathrm{zu}$ Umweltbelastungen führen ${ }^{40}$. Umweltschutzplanung ist. zwar nicht identisch mit dem Vorsorgeprinzip, das auch den repressiven Umweltschutz mitbestimmt ${ }^{41}$, es trägt und legiti-

s8 So Rehbinder, Politische und rechtliche Probleme des Verursacherprinzips (1973), 9, der von einer Grundkonzeption rationaler Umweltpolitik im Hinblick auf das Verursacherprinzip spricht.

39 Das Verursacherprinzip ist auf dem Gebiet der Umweltplanung nahezu unergiebig, siehe dazu Soell, Rechtsfragen (FN 8), 80; Rehbinder, Mensch und Umwelt (FN 17), 196.

40 Zum Aspekt der Bemühungen um die Vermeidung der Entstehung von Gefahren siehe auch Umweltgutachten 1978 (FN 1) Tz 13.

41 Das Vorsorgeprinzip erfüllt nämlich auch Funktionen im Rahmen des repressiven Umweltschutzes, siehe dazu vor allem Feldhaus, Konturen eines modernen Umweltschutzrechts, DƠV 1974, 613 ff., 615 m. w. N. Eine präzise Analyse des Vorsorgegrundsatzes in $\S 1, \S 5$ Nr. 1 und Nr. 2, $\$ 6$ des Gesetzes zum Schutz vor schädlichen Umwelteinwirkungen durch Luftverunreinigungen, Geräusche, Erschütterungen und ähnliche Vorgänge (Bundes-Immissionsschutzgesetz BImSchG) vom 15. März 1974 (BGBl. I S. 721) gibt Feldhaus, Der Vorsorgegrundsatz des Bundes-Immissionsschutzgesetzes, DVBI. 1980, 133 ff. Feldhaus, a. a. O., 137, spricht die interessante Frage an, ob die Genehmigungsentscheidung nach $\$ 6$ BImSchG nicht durch Einbindung des Vorsorgegrundsatzes - durch Verweis auf $\S 5 \mathrm{Nr}$. 2 und $\S 7 \mathrm{BImSchG}-\mathrm{zu}$ einer partiellen Planungsentscheidung geworden sei.

Den Aspekt der Planung betont auch der damalige Vorsitzende des Innenausschusses, Professor Schäfer, bei der 3. Lesung des BImSchG: "Umweltschutz heißt..., alle Vorgänge unseres Wirtschafts- und Verwaltungslebens so zu planen und zu gestalten, daß der Gemeinschaft bestmögliche Umweltbedingungen erhalten bleiben können oder wieder verschafft werden", in: BT, 7. Wahlperiode. 74. Sitzung vom 18. 1. 1974, Sten. Ber. S. 4677 ff.: Zweite und dritte Beratung des von der Bundesregierung eingebrachten Entwurfs eines Gesetzes zum Schutz vor schädlichen Umwelteinwirkungen durch Luftverunreinigung, Geräusche, Erschütterungen und ähnliche Vorgänge (Bundes-Immissionsschutzgesetz), S. 4688. Zu den einzelnen Ausprägungen des Vorsorgeprinzips siehe Rehbinder, Umweltrecht (FN 15), $372 \mathrm{ff}$. 
miert aber als Leitbild rationaler Umweltpolitik, als eine vernünftige Handlungsanweisung die Umweltschutzplanung ${ }^{42}$.

Es begründet damit aber noch nicht diese Planung als staatliche Aufgabe, vor allem noch nicht als eine einheitliche, übergreifende Gesamtplanung im Sinne eines „umfassenden Umweltgestaltungsinstrumentariums". Die Inanspruchnahme des Vorsorgeprinzips als Handlungsanweisung für die Umweltschutzplanung muß überdies die - vor allem in den Grundrechten gegebenen - verfassungsrechtlichen Grenzen wahren.

Kein Zweifel kann hingegen bestehen, daß Planung ein geeignetes Handlungsinstrument des vorbeugenden Umweltschutzes ist, geeignet, das Vorsorgeprinzip mit zu verwirklichen ${ }^{43}$. Das Umweltgutachten 1978 versteht die zentrale Frage nach der Durchsetzbarkeit von Umweltzielen geradezu als Suche nach einer „richtigen" Umweltplanung".

\section{Das unterschiedliche Verständnis von Umweltschutz als Staatsaufgabe}

Umweltschutzplanung als staatliche Vorsorgeaufgabe im Umweltschutzbereich ist auf dem Hintergrund des unterschiedlichen Verständnisses zu sehen, das man dem Umweltschutz als Staatsaufgabe allgemein entgegenbringt. Folgt man der These von Hans Peter Bull: „Wenn der Staat überhaupt Aufgaben hat, dann gehört dazu, daß er die natürlichen (,bio-

42 So auch Staatssekretär Günther Hartkopf, Industrie und Umweltschutz - ein Gegensatz? (FN 15), 3, der es als konsequente Anwendung des Vorsorgeprinzips betrachtet, Umweltschutz stärker als bisher im Planungsstadium zu berücksichtigen und dabei ein umfassendes Umweltgestaltungsinstrumentarium, das alle Medien und sonstigen Schutzobjekte (nämlich Mensch, Tier, Pflanze, Landschaft usw.) einschließt, zu entwickeln.

43 Soell, Der Grundsatz der wirtschaftlichen Vertretbarkeit im Bundes-Immissionsschutzgesetz, Dokumentation des Symposiums der Alexander-von-Humboldt-Stiftung in Ludwigsburg, Oktober 1978 (hektographiert), 10 (zum planenden Vorsorgeaspekt des $\S 5$ Nr. 2 BImSchG); siehe auch Kutscheidt, in: Landmann-Rohmer, Gewerbeordnung, Kommentar Bd. III, (Loseblatt, Stand 1977), Einleitung B Rdn. 7, Stichwort „Vorsorge“. Planung - insbesondere Raumplanung - stellt nach Rehbinder, Umweltrecht (FN 15), 372, die „Vorsorgetechnik" dar, ohne die privater Umweltschutz nicht geleistet werden kann (Schmidt-Aßmann, Umweltschutz in der Raumplanung, DOV 1979, 1 ff., 7).

${ }_{44}$ Umweltgutachten 1978 (FN 1) Tz 14, das sich gegen die heute verbreitete Distanz zur Planung ausspricht. 
logischen') Grundlagen menschlichen Lebens schützt" 4 , kann man sich einer weit verbreiteten, wenn nicht gar herrschenden Meinung sicher sein ${ }^{46}$.

Man setzt sich aber dem Vorwurf aus, angesichts der vielfältigen denkbaren Umweltschutzaktivitäten des Staates mit dieser globalen Feststellung nicht hinreichend nach Tätigkeitsfeldern zu differenzieren, notwendige Grenzziehungen zu unterlassen $^{47}$ und zu verkennen, da $\beta$ diese Aufgabe - auch als öffentliche, der Allgemeinheit dienende Angelegenheit des öffentlichen Interesses - grundsätzlich ebenfalls durch Private, wenigstens in weiten Teilbereichen, erfüllbar sei, worauf die viel diskutierte Forderung nach der Privatisierung öffentlicher Einrichtungen des Umweltschutzes abzielt. Umweltschutz ist eben nicht allein Staatsaufgabe, sondern auch Aufgabe der Gesellschaft und Privater, Gemeinschaftsaufgabe ${ }^{49}$.

\section{Umweltschutz als Planungsaufgabe des Staates}

Folgt man dieser nach Tätigkeitsbereichen differenzierenden Methode, sprechen eine Reihe von Momenten für die staat-

45 Bull, Die Staatsaufgaben nach dem Grundgesetz, um einen Anhang erweiterte Studienausgabe, Taschenbuchausgabe der 2. Auflage (1977), 224. Dazu bedarf es nach Bull keiner weiteren verfassungsrechtlichen Begründung als des Hinweises auf die Grundrechte, insbesondere Art. 2 GG (beide Absätze) und das Sozialstaatsprinzip.

46 Weber, Umweltschutz im Verfassungs- und Verwaltungsrecht (FN 8), 806. Dazu, daß das Umweltprogramm 71 (FN 8) davon ausgeht, daß die Umweltsicherung Staatsaufgabe ist, siehe Kölble, Staat und Umwelt: Zur Grundstruktur des rechtlichen Instrumentariums der Umweltsicherung, DOV 1977, 1 ff.; Ders., Staatsaufgabe Umweltschutz (FN 7), $492 \mathrm{~m}$. FN 15, qualifiziert den Umweltschutz als Staatsaufgabe unter Berufung auf Bull; Storm, Festschrift Schad (FN 18), 451; er bezieht sich auf die fundamentale Staatszielbestimmung des Sozialstaatsprinzips im Grundgesetz und verschiedene Garantie- und Kompetenzformen; Ders., Umweltrecht (FN 11), 29: Umweltpflege habe sich im Laufe des letzten Jahrzehnts zu einer eigenständigen, über Querschnitts- und Koordinationsfunktionen hinausgehenden Staats- und Verwaltungsaufgabe entwickelt; Ders., Umweltrecht, AgnarR 1974 (FN 18), 184.

${ }^{47}$ Für dieses differenzierende Vorgehen Kloepfer, Staatsaufgabe Umweltschutz (FN 8) 639 ff.; skeptisch auch Bundesverband der Deutschen Industrie (BDI), Umweltschutz (FN 14), $43 \mathrm{f}$.

${ }^{48}$ Siehe dazu Storm, Umweltrecht, AgrarR 1974 (FN 18), 184; Kloepfer, Gewerbemüllbeseitigung durch Private, VerwArch. 1979, 195 ff.; siehe auch Kloepfer, Umweltschutz, Evangelisches Staatslexikon (FN 8), Sp. 2652. 
liche Aufgabenwahrnehmung der Umweltschutzplanung wenigstens in weiten Bereichen -, und zwar ergibt sich dies - aus der Bedeutung und dem Charakter der prospektive Interessen koordinierenden und zukünftige Konflikte vermeidenden Funktion einer Umweltschutzplanung, die also auf eine weitergreifende zeitliche Perspektive angelegt ist,

- aus der existenzsichernden, freiheitserhaltenden und grundrechtsstärkenden Bedeutung der vorsorgenden Umweltschutzplanung, also aus ihrer Funktion der Grundrechtsverwirklichung,

- aus der räumlich, gegenständlich und zeitlich begrenzten Planungsfähigkeit Privater und von gewerblich-industriellen Unternehmen, auch angesichts der Intensität und Tragweite der die Umweltgüter bedrohenden Aktivitäten von z. B. Siedlung, Verkehr, Produktion etc.,

- aus der längerfristigen Verbindlichkeit staatlicher Planung im Unterschied zur Unverbindlichkeit privater Planung.

Vor allem Raumordnung und Stadtentwicklung, aber nicht minder Fachplanung und Umweltschutzfachplanung haben eine zentrale Position in einer aktiven Politik zur langfristigen Sicherung der natürlichen Ressourcen und zur Verbesserung der Umweltqualität. Ein erheblicher Teil der gegenwärtigen Umweltschäden geht auf die Raum- und Siedlungsentwicklung und die Verkehrsplanung zurück, in denen über lange Jahre die Umweltqualität nur eine nachgeordnete Rolle spielte. Das Wachstum von Wirtschaft und Bevölkerung führte zu hohen Umweltbelastungen gerade in den Gebieten, in denen der gröRere Teil der Bevölkerung lebt.

Heute wird aber außerdem sichtbar, daß nicht nur in den Verdichtungsräumen, sondern auch in den ländlichen Gebieten durch eine rasche und ökologisch wenig kontrollierte Siedlungsausweitung, durch hohe agrarische Nutzungsintensitäten, durch vielfältige Inanspruchnahme für Erholungszwecke ${ }^{48}$, durch den Verkehrswegebau und durch eine weiträumige Verteilung der Emissionen nachteilige Auswirkungen auf die Umwelt auftreten ${ }^{50} 51$.

49 Siehe Umweltgutachten 1978 (FN 1) Tz 1898, 1899, das zu Recht darauf hinweist, daß das bisher verfolgte Ziel einer allgemeinen Offnung der Wälder für jedermann problematisch erscheint.

50 Aus diesen und ähnlichen Gründen werten Umweltplanung als Staatsaufgabe: Umweltprogramm 71 (FN 8), $7 \mathrm{f}$., $10 \mathrm{f}$.; Umweltbericht '76 (FN 11) Tz 102. Beirat für Raumordnung, Sicherung der natürlichen Lebensgrundlagen, in: Beirat für Raumordnung, Emp- 
fehlungen vom 16. Juni 1976: Die Gültigkeit der Ziele des Raumordnungsgesetzes und des Bundesraumordnungsprogramms unter sich ändernden Entwicklungsbedingungen; Gesellschaftliche Indikatoren für die Raumordnung; Berücksichtigung europäischer Aspekte bei der Fortentwicklung der Raumordnungspolitik der Bundesregierung; Sicherung der natürlichen Lebensgrundlagen, hrsg. vom Bundesminister für Raumordnung, Bauwesen und Städtebau (1976), $71 \mathrm{ff} ., 73$ : „Der Begriff ,Umweltplanung“ ist im Umweltprogramm nicht genau definiert, sondern als Maßnahmenbündel ... beschrieben. Auch der Sachverständigenrat für Umweltfragen beschreibt Umweltplanung als die Aufstellung von raum- und flächenbezogenen Plänen und als ,Uberlegungen zur künftigen Gestaltung der Umweltschutzpolitik, der Umweltschutzgesetzgebung sowie der wirtschaftlich-technischen Entwicklungsplanung‘. Die Sicherung und die Entwicklung der natürlichen Faktoren als Basis einer ,Umweltplanung*, die eigentlich nicht mehr als Planung, sondern als allgemeine Staatstätigkeit umschrieben werden kann, sind bisher noch nicht realisiert." - Nach Weber, Umweltschutz im Verfassungs- und Verwaltungsrecht (FN 8), 812, sind durchgreifende Erfolge nur zu erwarten, wenn der Umweltschutz zugleich und insgesamt als gestaltende Aufgabe begriffen wird; siehe auch Steiger, Umweltschutz durch planende Gestaltung (FN 8), 137 ff.; Ders., Probleme des Umweltrechts, in: Gießener Universitätsblätter, H. 1 (1978), 61 ff.; Ders., Zur Entscheidung kollidierender öffentlicher Interessen bei der politischen Planung als rechtlichem Problem, Festschrift für Hans J. Wolff (1973), 385 ff., 387 , weist auf den auch bewahrenden Charakter der Planung hin. - Schmidt-Aßmann, Umweltschutz in der Raumplanung (FN 43), $1 \mathrm{ff}$., 7; Bullinger, Haftungsprobleme (FN 15), $608 \mathrm{f}$.; Ders., Umweltrechtliches Verursacherprinzip und Raumordnung, Festschrift für Werner Weber (1974), $663 \mathrm{ff}$.; Bothe, Umweltschutz als Aufgabe der Rechtswissenschaft (FN 12), 484 f., 487; Rehbinder, Umweltrecht (FN 15), 400 ff.; Ders., Grundfragen (FN 8), 253; Kuhl, Umweltschutz im materiellen Raumordnungsrecht, Beiträge zum Siedlungs- und Wohnungswesen und zur Raumplanung, Bd. 39 (1977), 1 f., 12 ff., mit zahlreichen Nachweisen; Henneke, Raumplanerische Verfahren und Umweltschutz unter besonderer Berücksichtigung der planerischen Umweltverträglichkeitsprüfung, Beiträge zum Siedlungs- und Wohnungswesen und zur Raumplanung, Bd. 40 (1977), 1 ff. Das Umweltgutachten 1978 (FN 1) Tz 14, hat sich zur Umweltplanung zwar "mit Bedacht" nicht in allgemeiner und zusammenfassender Form geäußert, wohl aber in sehr eingehenden Aussagen zur Stadt-, Verkehrs- und Landschaftsplanung. Der Rat geht davon aus, daß weiter geplant werde und weiter geplant werden müsse.

Kloepfer, Staatsaufgabe Umweltschutz (FN 8), 642, hält unter dem Aspekt des Umweltschutzes schon heute die Abstimmungen und Integrationen der verschiedenen staatlichen Politiken und Planungen als Mittel innerstaatlicher Konfliktlösung für unverzichtbar. Er spricht sich (a. a. O., 642) für staatliche Zuständigkeiten im Bereich der weit vorausschauenden Umweltvorsorge, der Vorsorge für die "weitergehende Zukunft" aus. Ob das nur so weit reicht, als die 
Macht die Komplexität der prospektiven Koordination von Umweltbelangen staatliche Planung einerseits, die künftige Bedrohung der Umwelt durch unkoordinierte Entwicklung sie andererseits erforderlich, wird staatliche Aufgabenwahrnehmung also nach den Erfordernissen der Lage aktualisiert, um „die Entstehung von kritischen Situationen zu verhindern, statt sich mit ihnen nach ihrer Entstehung auseinandersetzen

"Zukunft keine Lobby" hat - wie Kloepfer meint -, erscheint mir zweifelhaft, vor allem, ob die Lobby überhaupt für die nähere und nächste Zukunft ausreicht, um Umweltschutzbelange hinreichend zu schützen.

Steiger, Zur Entscheidung kollidierender Interessen, a. a. O., 397, betont zu Recht, daß die öffentlichen Interessen der Zukunft der Gegenwart aufgegeben seien. Saladin, Wachstumsbegrenzung als Staatsaufgabe (FN 12), 557, 560; Rupp, Die verfassungsrechtliche Seite des Umweltschutzes (FN 34), 404, sprechen sich auch für die Umweltschutzplanung als Staatsaufgabe aus.

51 Um sich eine Vorstellung allein vom Landverbrauch zu machen, muß man sich folgende Zahlen vergegenwärtigen: Nach einer Berechnung der Bundesforschungsanstalt für Landeskunde und Raumordnung nimmt die landwirtschaftliche Nutzfläche im Bundesgebiet täglich um 140 ha ab, die Waldfläche um 11 ha, Gartenland um 13 ha; die Wasserfläche nimmt täglich um 9 ha zu, die Gebäudefläche um 68 ha und die Verkehrsfläche um 31 ha; nach Hillebrecht, Forum Zukunft der SPD, 22./23. 3. 1979, Arbeitskreis II, Einführungsreferat: "Landschaftsverbrauch - Notwendigkeiten und Grenzen“ (hektographiert), 1. Nach anderen Angaben werden für Wohnungsbau, Industrie, Verkehr und andere Einrichtungen bis 1980 jährlich 45000 ha benötigt. Pro Jahr fallen 7000 bis 8000 ha Wald in der Nähe der Großstädte der Besiedlung zum Opfer, Angaben nach Umweltprogramm des Deutschen Gewerkschaftsbundes (DGB) vom 6. 3. 1974, 10. - Große Areale naturnaher Lebensräume, die als Zufluchtsorte und Regenerationsgebiete für bedrohte Pflanzen- und Tierarten dienen könnten, gehen ständig verloren. So betrug der jährliche Verlust an Moorfläche in Finnland in den vergangenen. Jahren 2000000 ha, im südlichen Schweden 30000 ha. In Irland sind nur mehr 20 Prozent der früheren Hochmoore im naturnahen Zustand geblieben, in Liechtenstein wurden die Niedermoore des Rheintalraumes auf 18 Prozent des Bestandes des Jahres 1900 reduziert. Von den weiten Heidegebieten, die Belgien noch um 1770 bedeckten, nämlich bis zu 40 Prozent des ganzen Landes, waren zweihundert Jahre später nur mehr 100 ha oder 0,15 Prozent im ursprünglichen Zustand erhalten; in Schweden ging der Anteil der Heideflächen in der Provinz Halland auf 2 Prozent zurück. Angaben nach FAZ Nr. 218 vom 19. 9. 1979, S. 7: Flad-Schnorrenberg, Läßt sich das eine mit dem anderen noch vereinbaren? Landwirtschaft, Forstwirtschaft und der Schutz der Umwelt. Umweltminister tagen in Bern. 
zu müssen"52, so heißt das zugleich, daß Planlosigkeit oder Fehlplanung von umweltbelastenden oder -zerstörenden Nutzungen zu Freiheitsbeschränkungen großen Ausmaßes führen können ${ }^{53}$.

Daraus ergibt sich, daß Umweltschutzplanung - wie Planung überhaupt - nicht nur ein Gebot der Sozialstaatlichkeit ist ${ }^{54}$, diese Einsicht läßt vielmehr die freiheitserhaltende und grundrechtsverwirklichende Bedeutung der staatlichen Umweltvorsorge deutlich zutage treten ${ }^{55}$ : Mangelnde Vorsorge durch Umweltschutzplanung und planlose Vergeudung von Ressourcen führt in Zukunft unweigerlich zu Defiziten im Schutz und in der Sicherung der natürlichen Lebensgrundlagen, die Voraussetzung für ein menschenwürdiges Dasein $\operatorname{sind}^{56}$.

$52 \mathrm{Zu}$ diesem Aspekt siehe Krüger, Allgemeine Staatslehre, 2. Aufl. 1966, $759 \mathrm{ff}$., 763, $768 \mathrm{ff}$.

5s Hierzu Würtenberger, Staatsrechtliche Probleme politischer Planung (1979), $380 \mathrm{ff}$., 382 .

${ }_{54}$ Häberle, Grundrechte im Leistungsstaat, VVDSTRL 30 (1972), $43 \mathrm{ff}$., $117 \mathrm{ff}$; Herzog, in: Maunz-Dürig-Herzog-Scholz, Grundgesetz, Kommentar (Loseblatt, Stand Mai 1978), Art. 20 GG, Rdn. 164; Ossenbühl, Welche normativen Anforderungen stellt der Verfassungsgrundsatz des demokratischen Rechtsstaates an die planende staatliche Tätigkeit, dargestellt am Beispiel der Entwicklungsplanung?, Gutachten B zum 50. Deutschen Juristentag (1974), B 30 ff.; Redeker, Staatliche Planung im Rechtsstaat, JZ 1967, 537; Schmidt-Aßmann, Planung unter dem Grundgesetz, DOV 1974, $541 \mathrm{ff}$.; Würtenberger, Staatsrechtliche Probleme politischer Planung (FN 53), $383 \mathrm{ff}$.

55 Eingehend zu diesen Zusammenhängen neuestens Würtenberger, Staatsrechtliche Probleme politischer Planung (FN 53), $383 \mathrm{ff}$., mit weiteren zahlreichen Nachweisen.

56 Würtenberger, Staatsrechtliche Probleme politischer Planung (FN 53), 411; Rupp, Die verfassungsrechtliche Seite des Umweltschutzes (FN 34), 401 ff., 402; Rehbinder, Grundfragen (FN 8), 250 ff.; Scholz, Verfassungsfragen zum Schutz des Nichtrauchers (FN 17), 14; Soell, Rechtsfragen (FN 8), 85; Wahl, Notwendigkeit und Grenzen langfristiger Aufgabenplanung, Der Staat 11 (1972), 459 ff., 474; Bökkenförde, Planung zwischen Regierung und Parlament, Der Staat 11 (1972), 429 ff., 432, weist darauf hin, daß Ausdehnung und Steigerung staatlicher Planung eine notwendige Folge des Ungenügens bzw. Nichtvorhandenseins gesellschaftlicher und wirtschaftlicher Selbstregulierungsmechanismen sei; Rehbinder, Grundfragen (FN 8), 251. Daß Umweltplanung zugleich einen eminent wichtigen Beitrag zur Verwirklichung des Rechtsstaates liefert, zeigt überzeugend Würtenberger, a. a. O., $337 \mathrm{ff}$.: Solche Planungen strukturieren künftiges staatliches Handeln und führen zur Rechtssicherheit durch Konsequenz im Planungsrecht. 
Soweit Umweltschutzplanung Staatsaufgabe ist, ist der Staat auch gehalten, ein für diese Planung ausreichend geeignetes Instrumentarium zu schaffen und bereitzuhalten.

Alle diese Ubberlegungen zur Planung von Umweltschutz als Staatsaufgabe stellen selbstverständlich keinen Freibrief für staatliche Umweltschutzplanung jedweder Art dar. Diese banale und überflüssig erscheinende Feststellung ist angezeigt angesichts der Tendenz, der Umweltschutzplanung ein langfristig angelegtes Konzept zugrundezulegen, das zur Verwirklichung eines umfassenden ökologischen Umweltgestaltungsprinzips in den 80er Jahren führen soll ${ }^{57}$.

Darauf ist noch einzugehen.

Wenn sich wirtschaftslenkende Momente mit der gesamtökologischen Sicht der Umweltschutzplanung und einem scharf gefaßten Risikobegriff und einer weitreichenden Gefahrenvorsorge verbinden, gedeiht nämlich vorbeugender Umweltschutz leicht zu ökologisch bedingter Investitionslenkung ${ }^{58}$.

\section{Die Einfügung der Umweltschutzplanung in eine ökologische Gesamtbetrachtung}

Auf diese Gefahren der Umweltschutzplanung hinzuweisen und auf die Notwendigkeit aufmerksam zu machen, die recht-

57 So Staatssekretär Günter Hartkopf, Es ist Zeit für die ökologische Wende (FN 7), 1 und 3.

${ }^{58}$ Darauf weist sehr deutlich Kloepfer, Staatsaufgabe Umweltschutz (FN 8), 640, hin, der es für unverkennbar hält, daß der umweltschützende Staat in weite Bereiche des gesellschaftlichen Lebens hineinwirken und - mit einem ökologischen Titel versehen - das gesamte Wirtschaftsgefüge grundlegend verändern kann. Die ökologisch bedingte Investitionslenkung sei partiell längst verwirklicht. Siehe hierzu das Umweltprogramm DGB (FN 51), 17, 28 f., 35, 37, das sich für eine verstärkte Einbeziehung der Umweltplanung in ein System von gesamtwirtschaftlicher Rahmenplanung mit daraus abgeleiteten Maßnahmen der Investitionslenkung einsetzt. Bundesverband der Deutschen Industrie (BDI), Umweltschutz (FN 14), 7, der davor warnt, daß die Umweltpolitik in die Nähe eines Globalanspruchs gerät, der alle anderen gesellschaftspolitischen Ziele überdeckt. Besonders deutlich werde dies bei jüngsten Forderungen nach einer übergreifenden gesamtökologischen Betrachtung; Bundesverband der Deutschen Industrie (BDI), Jahresbericht 1978/79 (FN 13), $156 \mathrm{ff}$.: Es sei zu befürchten, daß im Zuge solcher Überlegungen der Spielraum für weitere industrielle Fortentwicklungen zumindest in den bereits belasteten Regionen der Bundesrepublik Deutschland zusehends enger würde und zusätzlich strukturpolitische Probleme entstehen könnten. 
lichen, insbesondere verfassungsrechtlichen Grenzen sorgsam im Auge zu behalten oder solche Grenzen erst zu entwickeln, bedeutet nicht, eine Umweltschutzplanung aus ökologischer Gesamtsicht abzulehnen, im Gegenteil: Die ökologische Gesamtbetrachtung ist im kommenden Umweltschutzrecht und in der Umweltschutzplanung der Zukunft unvermeidlich ${ }^{59}$. Sie zeichnet sich in neueren Gesetzesvorhaben, wie dem Umweltchemikaliengesetz, auch bereits $\mathbf{a b}^{60}$.

${ }^{50}$ Das Umweltprogramm 71 (FN 8), 61, definiert Okologie als die „Lehre von den Wechselbeziehungen der Organismen (Pflanzen, Tiere, Menschen) untereinander und mit allen Faktoren ihrer belebten und unbelebten Umwelt. Kurzformel: Wissenschaft von der Struktur und Funktion der Natur, biologisches Gleichgewicht, ökologisches System". "Okologisches System oder Okosystem ist die grundlegende Funktionseinheit unterschiedlicher Größenordnung, in der die Organismen und ihre Gemeinschaften in wechselseitiger naturgesetzlicher Beziehung zu allen Faktoren ihrer unbelebten Umwelt stehen." Bei der Sicherung der natürlichen Lebensgrundlagen kommen als zu sichernde Bereiche in Betracht (nach Kölble, Staat und Umwelt [FN 46], 1 FN 6) die Umweltmedien Boden, Wasser, Luft, die Umweltfaktoren, und zwar sowohl die „unbelebten“, insbesondere die klimatischen wie z. B. Temperatur oder Feuchtigkeit, als auch die biotischen wie Tiere, Pflanzen und sonstige Lebewesen, sowie das Okosystem in seinen zahlreichen verschiedenartigen, zum Teil sehr komplexen Subsystemen ebenso wie in seiner Gesamtheit mit seinen verschiedenen Stoffkreisläufen sowie dem Energiehaushalt. Siehe hierzu Czihak u. a., Biologie (1976), $673 \mathrm{ff}$.; Odum, Okologie (1973); Ellenberg, Ziele und Stand der Okosystemforschung, in: Ellenberg (Hrsg.), Okosystemforschung, (1973), 1 ff. Zur Sicherung der natürlichen Lebensgrundlagen des Menschen gehört auch der Schutz vor Lärm; siehe auch Natur- und Umweltschutz in der Bundesrepublik Deutschland, unter Mitwirkung von 78 Autoren hrsg. von Olschowy (1978), vor allem 25-85 (ökologische Grundlagen des Natur- und Umweltschutzes). Kloepfer, Systematisierung des Umweltrechts (FN 8), 104, umreißt den Umweltschutz in vier Komponenten, er versteht darunter den Schutz der natürlichen Umwelt, die Sanierung bzw. Regenerierung der natürlichen (und gestalteten) Umwelt und die Gestaltung der natürlichen (und bebauten) Umwelt mit dem Ziel einer ausgewogenen, nachhaltigen Nutzung. Mit nachhaltiger Nutzung ist eine zeitlich andauernde und maßhaltende Nutzung gemeint, FN 447.

60 Das wird deutlich an dem gesetzgeberischen Bemühen, das Recht der Umweltchemikalien umfassend zu regeln. Siehe den noch nicht veröffentlichten Entwurf eines Gesetzes zum Schutz vor gefährlichen Stoffen (Chemikaliengesetz), den jüngst die Bundesregierung vorgelegt hat. Nach der amtlichen Begründung soll es das Ziel des Chemikaliengesetzes sein, „in Verfolgung des Vorsorgeprinzips den Menschen und die Umwelt besser als bisher vor den Wirkungen 
Dieser Ansatz geht davon aus, daß die ökologische Fachwissenschaft in den letzten Jahren soviel Einsicht in die ökosystemaren Verhältnisse gewonnen hat, daß diese Kenntnisse in die Umweltpolitik eingehen können ${ }^{61}$.

Die ökologische Gesamtsicht wird durch folgende Faktoren bestimmt:

- Abkehr von dem sektoralen Schutz einzelner Umweltmedien (Boden, Wasser, Luft), einzelner Umweltfaktoren (Tiere, Pflanzen, Temperatur), einzelner Anwendungsgebiete von Stoffen (Nahrungsmittel, Pestizide) und einzeln erfaßbarer Immissionen ${ }^{62}$.

- Hinwendung zum Schutz der mehr oder weniger komplexen Systeme, in denen sich die Wechselwirkungen zwischen den Organismen und ihrer Umwelt abspielen. Dabei ist Umwelt die Gesamtheit aller wirkenden Faktoren, mögen sie von unbelebten oder belebten Umweltfaktoren ausgehen. Diese Definition schließt den Menschen ein, von dem starke Wirkungen auf die Mit- und Umwelt ausgehen, der aber seinerseits zahlreichen Wirkungen aus der Umwelt ausgesetzt ist. Der Komplexheit dieser Wechselbeziehungen entspricht es, daß sich kein Organismus, sei es ein Mikroorganismus, eine Pflanze, ein Tier oder ein Mensch, ihnen entziehen kann. Die moderne Ókologie denkt folglich in „ökologischen

gefährlicher Stoffe und Zubereitungen zu schützen“. In $\S 1$ wird der Gesetzeszweck dahin umschrieben, $\mathrm{da} B$ "durch Verpflichtung zur Prüfung und Anmeldung chemischer Stoffe und zur Einstufung, Kennzeichnung und Verpackung gefährlicher Stoffe und Zubereitungen, durch Verbote und Beschränkungen sowie durch besondere giftrechtliche und arbeitsschutzrechtliche Regelungen" der Mensch und die Umwelt vor schädlichen Einwirkungen gefährlicher Stoffe geschützt werden sollen. Als „Speerspitze" in diese Richtung wird auch der Entwurf eines 16. Strafrechtsänderungsgesetzes (Gesetz zur Bekämpfung der Umweltkriminalität [BT-Drucks. 8/2382 vom 13.12. 1978]) angesehen (verkündet als 16. StrÄndG v. 16. 7. 1979 [BGBl. I, 1046]), der die Umweltstraftaten aus den wichtigsten Umweltschutzgesetzen herauslöst, harmoniert und unter einem eigenen Abschnitt "Straftaten gegen die Umwelt" in das StGB einbringt, siehe Storm, Umweltrecht (FN 11), 12.

61 So Bick, Okonomie - Okologie - Umweltpolitik, Grundsatzreferat Forum Zukunft der SPD, 22./23. März 1979 (hektographiert), 2. Bick ist Vorsitzender des Sachverständigenrates für Umweltfragen; siehe dazu auch Kölble, Staatsaufgabe Umweltschutz (FN 7), 482.

${ }^{62}$ Siehe Kölble, Staatsaufgabe Umweltschutz (FN 7), 482. 
Systemen" und nennt die komplexen Wechselbeziehungen „ökologische Vernetzung"63.

Die ökologische Gesamtsicht fordert schließlich:

- Erfassung und Berücksichtigung der - weitgehend langfristigen - Interaktionen von Schadstoffen sowie ihrer Anreicherung in Nahrungsketten und der Kombinationswirkungen der verschiedensten umweltbelastenden Faktoren, also Beachtung der synergetischen und langfristigen Zusammenhänge, Abhängigkeiten und Querverbindungen ${ }^{64}$.

Diese ökologische Gesamtkonzeption wird ganz herrschend als Grundlage der künftigen Umweltschutzpolitik eingeschätzt ${ }^{65}$.

B3 Siehe dazu Bick (FN 61), 2. Nach Bick haben Orkosysteme einen kennzeichnenden Stoff- und Energiehaushalt. Sie besitzen ein gewisses Regulationsvermögen und zeigen entsprechend ein dynamisches „ökologisches Gleichgewicht". Okosysteme verfügen über eine gewisșe Stabilität, d. h. eine Fähigkeit zum Ausgleich von Störungen. Diese Stabilität ist allerdings typmäßig sehr unterschiedlich; z. B. gibt es sehr empfindliche, störungsanfällige Okosysteme, die folglich wenig belastbar sind, und andererseits weniger empfindliche Typen.

Wesentlich ist der Hinweis, daß zwischen einzelnen Okosystemen Querverbindungen im Sinne von Vernetzungen höheren Grades bestehen. Beispielsweise gibt es Stofftransport über Wind oder Gewässerströmungen zwischen unter Umständen weit auseinanderliegenden Arealen; Klimabeeinflussungen können weltweite Auswirkungen haben. So ist es verständlich, daß man von einem globalen Groß-Okosystem, der „Okosphäre“, sprechen kann; daneben gibt es kleinere Einheiten, etwa die Nordsee, den Bodensee oder ein geschlossenes Waldgebiet. Letztlich geht es um die Funktionsfähigkeit des Naturhaushaltes.

${ }^{64}$ Bick (FN 61), 6. Nach Bick bezieht sich langfristiges Denken insoweit auf den Ressourcenschutz (Wasser, Boden, fossile Energieträger usw.), den Schutz des Klimas und den Schutz der Okosysteme auf nationaler wie auf internationaler Ebene. Verläßlichen Schutz brauche schließlich der Mensch selbst vor den schleichenden Gefahren durch Schadstoffe, wobei an die Schlagworte Mutagenität, Teratogenität und Carcinogenese zu denken sei.

${ }^{65}$ Umweltgutachten 1974 (FN 1) $\mathrm{Tz} 144$; Tz 535, 536 (in bezug auf die Stadtentwicklungsplanung); Umweltgutachten 1978 (FN 1) Tz 8; Tz 1313 (in bezug auf Landschaftsplanung); Umweltbericht '76 (FN 11) Tz $021 \mathrm{ff}$; ; Antwort der Landesregierung des Landes Baden-Württemberg vom 17. 11. 1978 (FN 5), 3 ff.; Beirat für Raumordnung, Sicherung der natürlichen Lebensgrundlagen (FN 50), $71 \mathrm{f}$., $73 \mathrm{ff}$., $87 \mathrm{ff}$.; Bundesverband der Deutschen Industrie (BDI), Umweltschutz (FN 14), 12, der ein Abgehen von der bisherigen Praxis des isolierten Vorgehens in den einzelnen Umweltmedien im Prinzip begrüßt, es allerdings nur als konsequente Abrundung und Verknüpfung der 
Es liegt auf der Hand, daß der Umweltschutz aus einer solchen gesamtökologischen Sicht vor allem durch vorsorgende und vorbeugende Planung zu realisieren is ${ }^{68}$ und daß diese Art von Umweltschutzplanung eine völlig neue Dimension erhält, die nicht ohne Rückwirkung auf deren Struktur bleiben kann. Zu Problemen, die bisher schon allgemein bei der planerischen Zielsetzung und Abwägung bestanden, ohne daß sie gelöst wären, treten neue spezifische Probleme hinzu. Sie rühren vor allem aus dem vieldimensionalen Informationsprozeß, der

bisherigen Bemühungen zum Schutz der einzelnen Umweltmedien gewertet wissen will; Deutscher Gewerkschaftsbund (DGB), Umweltprogramm (FN 51), 26 ff.; Boese-Eckstein-Schier, Diskussion der Voraussetzungen und Nutzen integrierender Umweltschutzpläne (1978) (maschinenschriftlich; Dornier-System GmbH), Umweltforschungsplan des Bundesministers des Innern Querschnittsfragen, $\mathrm{F}+\mathrm{E}$ Vorhaben 10101013 , $18 \mathrm{f}$.; Hartkopf, Verbindlichkeit und Schranken des Umweltschutzes; Grußwort des Staatssekretärs im Bundesministerium des Innern, Dr. Günter Hartkopf, zur Umweltrechtlichen Fachtagung der Gesellschaft für Umweltrecht e.V. am Freitag, dem 3. November 1978, in Berlin, in: Der Bundesminister des Innern teilt mit (vom 3. 11. 1978), 10 f.; Ders., Industrie und Umweltschutz - ein Gegensatz? (FN 15), 1; Kloepfer, Staatsaufgabe Umweltschutz (FN 8), 644; Kölble, Staat und Umwelt (FN 46), 1; Ders., Staatsaufgabe Umweltschutz (FN 7), 482; Müller-Stahel, Environmental Law: Umweltschutzrecht - Eine neue Disziplin im Recht der USA, SJZ 1972, 49 ff., 56 f.; von Münch, Umweltschutz im Völkerrecht, ArchVR 1972, 385 f., 386; Ellenberg-Fränzle-Müller, Oekosystemforschung im Hinblick auf Umweltpolitik und Entwicklungsplanung, Bundesminister des Innern, Forschung im Bereich Umweltgrundsatzangelegenheiten, Abschnitt Oekologie, MAB (1978) (maschinenschriftlich), $18 \mathrm{f}$;; Olschowy, Landschaftsökologische Kriterien der Planung, Landk. 1979, $291 \mathrm{ff}$.; Ders., Natur- und Umweltschutz in der Bundesrepublik Deutschland (FN 59), VII; Picht, Umweltschutz und Politik (FN 6), $153 \mathrm{f}$; Rehbinder, Grundlagen des Umweltrechts (FN 87), 25 (unter dem Aspekt der Langzeitwirkung); Ders., Umweltrecht (FN 15), 369 f.; Steiger, Probleme des Umweltrechts (FN 50), 57; Weidner, Von der Schadstoffbeseitigung zur Risikoverhinderung, Aus Politik und Zeitgeschichte (1977), 34 ff., 37.

${ }^{60}$ So Beirat für Raumordnung, Sicherung der natürlichen Lebensgrundlagen (FN 50), 75 f.; Peccei, Optionen für die Zukunft (FN 6), 11, verlangt ein Mindestma $B$ an Globalplanung; Umweltgutachten 1978 (FN 1) Tz 1313 sieht das Entscheidende an der neuen Landschaftsplanung in dem Versuch, menschliche Umwelt als ökologisch-strukturelles Wirkungsgefüge zu erfassen und im Hinblick auf nachhaltige und ökologisch optimale Nutzung zu sichern und neu zu gestalten; Storm, Umweltrecht (FN 11), 13. 
ablaufen muß, bevor das "Abwägungsmaterial"67, seinen ökosystemaren Querverbindungen und synergetischen Zusammenhängen entsprechend aufbereitet, in den planerischen $\mathrm{Ab}$ wägungsprozeß eingehen kann - gleichgültig, um welche Art von Planung es sich handelt.

Es ist $\mathrm{zu}$ fragen, ob bestehende Planungen dies leisten können oder aber - wie bereits vorgeschlagen wird - neue Planungsinstrumente der Umweltschutzplanung notwendig werden.

\section{Die Situation des Umweltschutzes und seiner Planung}

Ob sich neue Instrumente der Umweltschutzplanung als notwendig erweisen oder ob die - als unzureichend empfundene - Berücksichtigung von Belangen des Umweltschutzes in vorhandenen Planungsarten durch "Nachbesserungen" im materiellen Umweltschutzplanungsrecht oder im Verfahrensrecht erreicht werden kann, ist besser $\mathrm{zu}$ beurteilen, wenn man die Situation des Umweltschutzes, der Planungsinstrumente und - im Blick auf gesamtökologische Ansätze - der Ökologie kennt.

\section{Die Situation des Umweltschutzes}

Umweltschutz und Umweltschutzplanung haben sich in den letzten Jahren in anderen Planungen und in Genehmigungsverfahren nicht hinreichend durchsetzen und nicht das Ziel erreichen können, eine Zunahme der Umweltbelastung zu verhindern. Der Grund ist nicht zuletzt in der fachübergreifenden Qualität dieser Planung und in ihrem Charakter als Querschnittsaufgabe zu suchen, die mit gesteigertem Koordinationsund Kostenbedarf bei stark divergierenden Interessen und dem Ziel der prospektiven Vermeidung von Zielkonflikten zwischen diesen Interessen einhergeht $t^{68}$ und die insoweit mit den Aufgaben von Planung allgemein konvergiert ${ }^{69}$. Die Klage

${ }^{67}$ Hoppe, Die „Zusammenstellung des Abwägungsmaterials" und „Einstellung der Belange“ in die Abwägung "nach Lage der Dinge“ bei der Planung, DVBl. 1977, $136 \mathrm{ff}$.

${ }_{68} \mathrm{Kuhl}$, Umweltschutz im materiellen Raumordnungsrecht (FN 50), 17 ff. m. w. N.; Rehbinder, Umweltrecht (FN 15), 400.

${ }^{69}$ Umweltgutachten 1974 (FN 1) $\mathrm{Tz}$ 664: "Umweltschutz ist... keine selbständige, fachlich begrenzbare Aufgabe oder Aufgabengruppe, sondern eine fachübergreifende Querschnittsaufgabe. Umweltschutzplanung kann deswegen nicht Fachplanung, sondern muß 
über das Fortschreiten der Umweltzerstörung jedenfalls ist allgemein ${ }^{70}$.

Bereichsplanung sein, die zwischenfachliche Zusammenhänge erfaßt. Sie ist deswegen vor allem koordinierte Planung, da sie nicht nur bei der Zielfindung, sondern auch bei der Plandurchführung widerstreitende Interessen und Kompetenzen aufeinander abstimmen und dabei den übergeordneten Zielvorstellungen Geltung verschaffen muß." Nach dem Umweltschutzgutachten 1978 (FN 1) Tz 14 genügt für die Umweltschutzplanung die zuletzt im Rheingutachten (FN 1) erhobene Forderung nach einer Querschnittsplanung nicht. Siehe im übrigen dazu Schmidt-Aßmann, Umweltschutz in der Raumplanung (FN 43), 2; Kimminich, Das Recht des Umweltschutzes (FN 8), 12; Wahl, Rechtsfragen der Landesplanung und Landesentwicklung (1978), Bd. 1, 5: Ebenso wie die Raumordnung bringt der Umweltschutz Ziele und Interessen zur Geltung, die von den anderen Ressorts fast immer auch berührt, aber allenfalls als Nebenfolgen ihrer Aktivitäten beachtet werden: „Die spezifische Schwierigkeit dieser Politikbereiche besteht... darin, gegenüber anderen sektoral ausgerichteten, auf organisierte Interessen bezogenen Politiken übergeordnete, aber nicht organisierte und nur schwer organisierbare Interessen und Belange geltend machen zu müssen."; siehe auch Rehbinder, Umweltrecht (FN 15), 370, zu dem Aspekt, daß die Verwirklichung von Umweltschutz Zielverzicht und Prioritätsentscheidungen voraussetze; hierzu auch Storm, Umweltschutzrecht, AgrarR (FN 18), 182; Kölble, Staatsaufgabe Umweltschutz (FN 7), $478 \mathrm{ff}$; Kuhl, Umweltschutz im materiellen Raumordnungsrecht (FN 50), 14 ff. m. w. N.; Scharpf-Schnabel, Durchsetzungsprobleme der Raumordnung im öffentlichen Sektor, Informationen zur Raumentwicklung 1978, $29 \mathrm{ff}$., 39 (zu Konsensbildungsproblemen bei der Raumplanung); BoeseEckstein-Schier, Voraussetzungen und Nutzen integrierender Umweltschutzpläne (FN 65), 56, gehen davon aus, daß durch die Gegebenheiten der institutionellen und instrumentellen Dimensionen unseres Gesamtsystems ein „unübersehbares Konfliktpotential“ geradezu vorprogrammiert sei. Diese Konflikte ergäben sich horizontal (zwischen Umweltsachgebieten und zu anderen Ressorts), vertikal (innerhalb der Zuständigkeiten der Verwaltungsebenen) und im $\mathrm{Zu}-$ sammenhang mit der Unverträglichkeit der Mittel in Planung, Vollzug und Kontrolle.

70 Umweltgutachten 1978 (FN 1) Tz 1202 spricht davon, daß - ungeachtet der in vielen Bereichen verbesserten Immissionssituation und trotz verlangsamten Wirtschaftswachstums und Rückgangs der Bevölkerung - die Belastungen der natürlichen, naturnahen und Agrarökosysteme in ländlichen und städtischen Räumen durch Uberlagerungen und nebeneinander sich beeinträchtigender oder sogar ausschließender Nutzungen wesentlich erhöht worden seien. Der Rat von Sachverständigen für Umweltfragen (Umweltgutachten 1978, $\mathrm{Tz}$ 1898) beklagt, daß die gegenwärtige starke Belastung naturnaher Okosysteme in der Bundesrepublik Deutschland durch Nutzungsänderungen, die als eine entscheidende Ursache für den fortschrei- 
Der Umweltschutz leidet zudem an den bekannten Schwächen des technischen Rechts. Man hat davon gesprochen, das technisch-ingenieurmäßige Denken sei eine Koalition mit juristischem Normdenken eingegangen ${ }^{71}$, wobei diese Verbindung offensichtlich als Mesalliance gewertet wird ${ }^{72}$.

Der Umweltschutz wird bestimmt durch innere und äußere Úbernormierung und Überinstrumentierung. Man hat diese

tenden Artenschwund bei Pflanzen und Tieren gelten müssen, auch mittelfristig erhalten bleiben werde, da sich trotz einiger Verbesserungen keine entscheidende Tendenzwende in der Raumplanung und Verkehrswegeplanung erkennen lasse. Immer wieder, und da sei auch trotz zugestandener positiver Entwicklungen kein genereller Tendenzwandel zu erkennen, würden Verkehrswege in wertvolle Landschaftsgebiete, durch Naturschutzgebiete oder in unmittelbare Nähe dieser Gebiete gelegt. Immer noch laufe - wenn auch mit verringerter Intensität - die Melioration von kleinen Feuchtgebieten ab, oder es würden durch Flurbereinigung außerhalb landwirtschaftlicher Kerngebiete Biotope mit wertvollem Arteninventar vernichtet. Siehe auch Umweltbericht'76 (FN 11) Tz 010, 011, $467 \mathrm{ff}$.; Beirat für Raumordnung, Sicherung der natürlichen Lebensgrundlagen (FN 50), 87; Henneke, Raumplanerische Verfahren (FN 50), 37, spricht von der häufig stiefmütterlichen Behandlung der Umweltschutzbelange in den flächenbezogenen Planungen; $K u h l$, Umweltschutz im materiellen Raumordnungsrecht (FN 50), 3 ff.; Soell, Rechtsfragen (FN 8), 87; Ders., Schutz gegen Fluglärm, in: Schutz gegen Verkehrslärm, Arbeiten zur Rechtsvergleichung (H. 39) (1978), 45 ff., 45 (zur Verschlechterung des „akustischen Profils").

${ }^{71}$ Bundesverband der Deutschen Industrie (BDI), Umweltschutz (FN 14), 41.

72 Zur rechtlichen Qualifizierung technischer Regeln siehe Hanning, Umweltschutz und überbetriebliche technische Normung (1976), $35 \mathrm{ff}$., $59 \mathrm{ff}$.; Berg, Allgemein anerkannte Regeln der Technik im Verwaltungsprozeß, GewArch. 1978, 281 ff. - Denninger, Die Herausforderung der Technik an das Recht in der technologischen Gesellschaft, Universitas Bd. 25 (1970), 2. Bd., 1135 ff., 1149 ff., fragt, ob die Rechtsnorm in einer von technologischer Rationalität durchzogenen Gesellschaft wirklich zum Anhängsel technischer Gebrauchsanweisungen degradiert werde (1150). Er setzt sich ein für ein technologisches Plan-Gesetz, wobei das Gesetz als Regelkreis-Normensystem mit flexiblen Orientierungsdaten erscheine; Hanning-Schmieder, Gefahrenabwehr und Risikovorsorge im Atom- und Immissionsschutzrecht, Beilage Nr. 14/77 zu DB Heft 46, 2, m. w. N. in FN 13, 14; Lukes, Das Atomrecht im Spannungsfeld zwischen Technik und Recht, NJW 1978, $241 \mathrm{ff}$; Ossenbühl, Aktuelle Probleme des Umweltrechts (FN 19), $1 \mathrm{ff}$., 5, der auf ein Grundproblem des technischen Sicherheitsrechts, die Inadäquanz der überkommenen Regelungsinstrumente und der modernen Aufgaben des Parlaments hinweist. 
Situation zutreffend als "Normenwirrwarr" gegeißelt ${ }^{73}$. Dieses Normenübermaß geht einher mit einem inhaltlichen Regelungsdefizit, weil Umweltschutzrecht in weitmaschigen unbestimmten Gesetzesbegriffen vielfach der Konfliktentscheidung ausweicht. Damit weist Umweltschutz und Umweltschutzrecht ein erhebliches Defizit an Übersichtlichkeit, Eindeutigkeit und somit an Rechtssicherheit auf ${ }^{74}$.

Der Umweltschutz und seine Planung sind also durch mangelnde Effektivität gekennzeichnet.

73 So Storm, Umweltrecht, AgrarR (FN 18), 186; Kloepfer, Umweltschutz und Recht (FN 24), 1731 f., der gravierende Mängel des Umweltschutzrechts in der unüberschaubaren Vielzahl der geltenden Rechtsnormen (äußere Ubernormierung), dem Hang zum Perfektionismus und zur Detailbesessenheit (innere U'bernormierung) sieht; Ders., Staatsaufgabe Umweltschutz (FN 8), 644; Der Bundesverband der Deutschen Industrie (BDI), Umweltschutz (FN 14), 41, spricht von "Datensetzungs-Interventionismus". Lange, Eindämmung der "Vorschriftenflut" im Verwaltungsrecht?, DVBl. 1979, 533 ff., 536, weist darauf hin, daß Normenfülle jedenfalls im Verwaltungsrecht nicht pauschal negativ beurteilt werden könne. Wo versucht werde, Freiheit, sozialen Ausgleich und Integration zu verbinden, müßten diese Steuerungsmittel vergleichsweise differenziert und kompliziert sein.

74 Dienes, Die Entwürfe zur Novellierung des Immissionsschutzrechtes 1979 - Ein Beitrag zu mehr Rechtssicherheit?, Recht der Elektrizitätswirtschaft, 1979 (Heft 7), Sonderdruck, 3; Bickel, StraBenplanung, Umweltbelastung und verwaltungsgerichtlicher Rechtsschutz, in: Straße und Umwelt, Schriftenreihe der Hochschule Speyer, Bd. 77 (1979), 117 ff., spricht von den stets weitmaschigeren Regelungen und unbestimmten Gesetzesbegriffen: Nach der gesetzgeberischen "Grobpeilung" bleibe im Bereich der Planung und des Umweltschutzes die „Feinabstimmung“ als Aufgabe der Gerichte, also der Ausgleich eines Regelungsdefizits des Gesetzgebers durch Richterrecht; Ernst, Zur staatlichen Verantwortung (FN 9), 1 f.; Kloepfer, Umweltschutz und Recht (FN 24), 1730; Lange, Eindämmung der „Vorschriftenflut“ (FN 73), 533 f., macht zu Recht darauf aufmerksam, daß es auf absehbare Zeit völlig ausgeschlossen sei, die Rechtsordnung durch eine Verringerung von Normen für den Bürger so überschaubar zu machen, daß er sich durch eigene Kenntnis von der Gerechtigkeit sämtlicher Vorschriften überzeugen könne. Lambrecht, Vollzugseignung des Bundes-Immissionsschutzgesetzes in der Eisenund Stahlindustrie, Diss. jur. Hamburg 1977, $230 \mathrm{f}$., kommt allerdings zu dem Ergebnis, daß weder die Verwendung zahlreicher unbestimmter Gesetzesbegriffe noch die Aufnahme von Generalklauseln in das BImSchG dem Vollzug entgegenständen. Er hält die These für widerlegt, nach der unbestimmte Rechtsbegriffe und Generalklauseln des BImSchG als Ursache für das Vollzugsdefizit anzusehen seien. 


\section{Die Situation der Planungsinstrumente}

Die Situation der Planungsinstrumente ist nicht minder desolat. Das gilt ganz allgemein und im Hinblick auf den Umweltschutz, soweit er durch Planung verwirklicht werden soll, in ganz besonderer Weise.

\subsection{Mängel in den einzelnen Planungsarten.}

In der Praxis zeigt sich, daß die bisherige Planung die Belange des Umweltschutzes aus verschiedenen Gründen nur unzureichend berücksichtigt:

Zum einen, weil sie - insbesondere die räumliche Planung selbst Mängel aufweist, die ihre Wirksamkeit ganz allgemein in Frage stellen. So heißt es bei Schulz zur Wiesch lapidar: „Die Raumordnungspolitik aller administrativen Ebenen hat sich mit dem Vorwurf ihrer Wirkungslosigkeit auseinanderzusetzen"75 und Frido Wagener konstatiert: „Die neueren Arten der öffentlichen Planung sind erfolglos geblieben... Die einzig funktionierende ... Planungsart ist die kurzfristige Finanzplanung, der Haushaltsplan ${ }^{\text {"78 }}$. Das wirklich Streitige und Allerwichtigste werde ausgelassen ${ }^{77}$.

Zum anderen, weil in diesen Planungsarten Umweltschutzbelange nicht immer hinreichend wirksam in die Abwägung eingestellt, geschweige denn in dem Planungsprodukt - nach

${ }^{75}$ Schulz zur Wiesch, Regionalplanung ohne Wirkung?, Uberlegungen zur Situation der übergemeindlichen Planung, ArchfKommWiss. 1978, $21 \mathrm{f}$. Als Grund gibt Schulz zur Wiesch an: „Der kritische Engpaß einer, gemessen an ihrem Koordinationsanspruch und -aufwand, ineffizienten regionalen Raumordnung liegt weniger in methodischen Defiziten, z. B. der Richtwertplanung, als vielmehr in ihrer Unterversorgung mit Durchsetzungsinstrumenten. Die Schwächen der Regionalplanung werden dort am deutlichsten, wo die interkommunale Konkurrenz um regionale Ressourcen am schärfsten, das Konfliktniveau am höchsten ist."

${ }^{76}$ Wagener, Mehr horizontale Koordinierung bei Bund und Ländern, Informationen zur Raumentwicklung 1978, $11 \mathrm{f}$.; siehe auch Scharpf-Schnabel, Durchsetzungsprobleme der Raumordnung im öffentlichen Sektor (FN 69), 29 ff., die auch die geringe politische Durchsetzungsfähigkeit als den eigentlichen Engpaßfaktor bezeichnen; zusammenfassend zu den Konsensbildungs- und Durchsetzungsnachteilen, 42; $K u h l$, Umweltschutz im materiellen Raumordnungsrecht (FN 50), 35 ff. Eine genaue Analyse der Kritik liefert jetzt Joachim Jens Hesse, Zum Bedeutungsverlust der Raumordnungspolitik und Raumplanung in der Bundesrepublik, Festschrift für Werner Ernst (1980) 201 ff.

77 Wagener, Mehr horizontale Koordinierung (FN 76), 13. 
dem Grade ihrer Beachtlichkeit - durchgesetzt werden können $^{78}$.

Hebt man auf die räumliche Planung und hier auf die spezifische Umweltfachplanung (z. B. Abfallbeseitigungspläne, Landschaftsprogramme und -pläne, Luftreinhaltepläne ${ }^{79}$, die Fachplanung (Anlagenplanung) ${ }^{80}$ und Gesamtplanung (Bauleitplanung, Regionalplanung, Landesplanung und Bundesraumordnung) ${ }^{81}$ ab, zeigt sich folgendes Bild: Die spezifische Umweltfachplanung hat zwar eine hervorgehobene Stellung. Trotz dieser scheinbar starken Stellung dürfte die Durchsetzungsfähigkeit der Umweltbelange in der Praxis kritisch zu beurteilen sein. Denn der gegenwärtige Rechtszustand ist durch eine schädliche Konkurrenz zu den Fachzuständigkeiten und eine Uberlappung mit ihnen gekennzeichnet ${ }^{82}$.

In den beiden Hauptbereichen staatlicher Planungstätigkeit, der Fachplanung und der Gesamtplanung, kommt dem Umweltschutz in verfahrensrechtlicher Hinsicht lediglich eine Beteiligtenstellung, in materiell-inhaltlicher Hinsicht die Bedeutung

${ }^{78}$ Das liegt an dem Fehlen von ausreichend wirksamen und erprobten Verfahren, mit deren Hilfe es möglich wird, integrative Planungsverfahren für den Interaktionsbereich der einzelnen Planungsfelder in feste Regeln zu fassen, Rhein-Gutachten (FN 1) Tz 355, 356, 364, 365. Die Koppelung von Raumplanung und Umweltschutz, die Schmidt-Aßmann, Umweltschutz in der Raumplanung (FN 43), 2, für sinnvoll hält, ist noch nicht gelungen. Zum Planungssystem als Organisationsprinzip für Aufgabenverflechtungen zwischen selbständigen Aufgabenträgern siehe Wahl, Rechtsfragen der Landesplanung und Landesentwicklung, Bd. 1 (FN 69), $114 \mathrm{ff}$.; siehe vor allem die Konstruktionselemente und Grundsätze von Planungssystemen, a. a. O., $156 \mathrm{ff}$.; $K u h l$, Umweltschutz im materiellen Raumordnungsrecht (FN 50), $31 \mathrm{ff}$.

79 Siehe dazu die Aufzählung im Umweltbericht'76 (FN 1) Tz 47.

80 Siehe dazu die Ubersicht bei Hoppe, Rechtsschutz bei der Planung von Straßen und anderen Verkehrsanlagen, NJW-Schriftenreihe H. 8 (1971), Rdn. 15 ff., $236 \mathrm{ff}$.

81 Siehe hierzu Hoppe, Rechtsschutz (FN 80), Rdn. 10; ForsthoffBlümel, Raumordnungsbericht und Fachplanungsrecht, Ein Rechtsgutachten (1970) $18 \mathrm{f}$.

82 Die Zuweisung einzelner Planungskompetenzen vermag dem Umweltschutz noch keine den herkömmlichen institutionalisierten und mit wesentlich umfangreicheren Eigenmitteln ausgestatteten Fachministerien vergleichbare Positionen zu verschaffen. Siehe hierzu und zu folgendem Ernst-Erbguth-Hoppe-Schlarmann, in: Rechtliche und verwaltungsmäßige Möglichkeiten zur Durchsetzung von Umweltbelangen im Bereich der räumlichen Planung, FE-Vorhaben, Antrag Zentralinstitut für Raumplanung der Universität zu Münster (maschinenschriftlich) (1979), 16 ff. 
eines Belangs neben den übrigen bei der Erarbeitung des Planungsproduktes $\mathrm{zu}$ berücksichtigenden öffentlichen und privaten Belangen zu. Diese schon vom Ansatz her schwache Stellung der Umweltschutzbelange und damit ihrer Vertretung wird besonders deutlich im Rahmen fachplanerischer Zuständigkeiten. Hier stehen die ressortspezifischen Interessen typischerweise im Vordergrund ${ }^{83}$.

Die Aufgabe, alle Teilaspekte des Umweltschutzes aus ihrer sektoralen Isolierung $\mathrm{zu}$ lösen und $\mathrm{zu}$ einem Gesamtkonzept zusammenzufügen, das den Zielen der Raumordnung und des Umweltschutzes gerecht wird, ist nicht gelöst.

83 Dabei kommen dem sektoralen, fachplanungsspezifischen Verständnis der Fachplaner Unterscheidungen der Rechtsprechung des BVerwG entgegen, die zwischen dem eigentlichen Leitziel der Fachplanung, der möglichst optimalen Erfüllung der Planungsaufgabe des Fachplanungsbereichs und anderen Belangen - z. B. solchen des Umweltschutzes, die „nur“ ein abwägungserheblicher Belang sind unterscheiden, siehe BVerwG vom 14. Februar 1975 - IV C 21.74 BVerwGE 48, 56 ff., 62 f.: „Der Immissionsschutz macht zwar . . für die fernstraßenrechtliche Planung einen gewichtigen abwägungserheblichen Belang aus...; ; er bestimmt aber nicht als planerischer Leitsatz das eigentliche Ziel der fernstraßenrechtlichen Planung, die als Fachplanung ganz ebenso wie etwa diejenige des Luftverkehrsgesetzes oder des Wasserhaushaltsgesetzes auf die - möglichst optimale - Erfüllung der spezifischen Aufgaben gerade ihres Fachplanungsbereichs ausgerichtet ist“; Wahl (FN 69), 160 FN 12, bemerkt hierzu zu Recht, daß gesetzgebungspolitisch diese Regelungstechnik, die die Fachplanungsgesetze inhaltlich unvollständig, aber sektoral homogen sein läßt, problematisch sei, weil sie der sowieso gegebenen selektiven Aufmerksamkeit der jeweiligen Fachleute entgegenkomme und sie verstärke. Siehe dazu auch Hoppe, Verfahren und gerichtliche Kontrolle bei der straßenrechtlichen Planfeststellung, in: Ein Vierteljahrhundert Straßenrechtsgesetzgebung (hrsg. von Bartlsperger, Blümel, Schroeter - im Erscheinen begriffen); Ders., Stellungnahme im Rahmen der Befragung von Sachverständigen $\mathrm{zu}$ dem Entwurf eines Verkehrslärmschutzgesetzes (VLärmSchGE) (BTDrucks. 8/1671) aufgrund des Beschlusses des Ausschusses für Verkehr und für das Post- und Fernmeldewesen (1979), 22 ff. (zu immanenten und externen Planungsleitlinien im Fachplanungsrecht); siehe auch Korbmacher, Straßenplanung und verwaltungsgerichtliche Planungskontrolle unter der Geltung des Bundes-Immissionsschutzgesetzes und des 2. Fernstraßenänderungsgesetzes, DƠV 1976, $1 \mathrm{ff} ., 3 \mathrm{ff} . ; \mathrm{Kuhl}$, Umweltschutz im materiellen Raumordnungsrecht (FN 50), 24; Rheingutachten (FN 1) Tz 367; Scharpf-Schnabel, Durchsetzungsprobleme (FN 69), 39 ff. (zur besseren Durchsetzungsfähigkeit von Zielen der Fachplanung); Schmidt-A $\beta$ mann, Umweltschutz in der Raumplanung (FN 43), 2 ff.; Umweltgutachten 1978 (FN 1) 


\subsection{Tendenzen zur „Entfeinerung“, „Durchforstung" und „Verfahrens-Ausdünnung“.}

Führt man sich nun vor Augen, welche Heilmittel der räumlichen Planung anempfohlen werden und vergleicht sie mit dem, was ihr durch das Ziel eines effektiveren Umweltschutzes vor allem aus gesamtökologischer Sicht nahegebracht werden muß, erkennt man bald, wie gegenläufig diese Tendenzen sind und sein müssen.

Gegenüber einer angeblich wegen ihres Perfektionsgrades und einer Regelungsüberlastung ineffektiven Planung soll das gebotene Mittel die „Entfeinerung" der Regelungen sein, d. h. ein Abwerfen von Ballast an Regelungsüberfluß und ein Verzicht auf Feinstruktur bei Neuregelungen, z. B. eine Durchforstung des "Wildwuchses" an Umweltschutzfachplanungen ${ }^{84}$. In die gleiche Richtung zielen Vorschläge für eine „Verfahrensausdünnung "85 bei der Planung und das hohe Lied auf die „unvollständige Planung"88, das neuerdings immer häufiger angestimmt wird.

Tz $1094 \mathrm{ff}$. (zur Verkehrsplanung und Verkehrstechnik).

${ }^{84}$ Siehe dazu Wagener, Der öffentliche Dienst im Staat der Gegenwart (FN 9), 250 ff., 254; Ders., Mehr horizontale Koordinierung (FN 76), 14, der auf eine Parallele im technischen Bereich (Schiffe, Lokomotiven, Autos) in Krisenzeiten hinweist, in der beispielsweise in Kriegszeiten auf Polster, Lack und Rundungen verzichtet worden sei. Dieser Vergleich ist irreführend: Diese „entfeinerten“ technischen Modelle waren in der Funktion nicht schlechter als die vorherigen. Wenn allerdings versucht wird, Freiheitsrechten und dem Sozialstaatsgebot Rechnung zu tragen und sie zum Ausgleich zu bringen und dabei dem höchst komplexen und komplizierten Regelungsgegenstand des Umweltschutzes vorbeugend Rechnung zu tragen, müssen die Steuerungsmittel differenziert sein, so zu Recht (allgemein) Lange, Eindämmung der „Vorschriftenflut" (FN 73), 536.

${ }_{85}$ Umweltgutachten 1978 (FN 1) Tz 624 hat sich allerdings im Hinblick auf die lange Dauer von Planfeststellungsverfahren bei der Planung der Abfallbeseitigung (Tz 617 ff.) gegen eine Verfahrensausdünnung ausgesprochen ( $\mathrm{Tz}$ 624). Damit habe der Gesetzgeber den Querschnittscharakter des Umweltproblems Abfallbeseitigung anerkannt. Die Beteiligungspflichtigen müßten sich mehr als bisher auf längere Verfahrensdauer, frühzeitige Gespräche mit den Betroffenen und die Risiken des vorzeitigen Beginns einstellen. Das Gutachten betont zu Recht: Mit der Regelung eines Planfeststellungsverfahrens sei dem Umstand Rechnung getragen, daß die Entscheidung über Standort, Verfahren und Schutzvorrichtungen moderner Beseitigungsanlagen die Beurteilung verschiedenartigster Faktoren erfordere und in der Regel Interessen eines größeren Personenkreises beeinträchtigt oder auch begünstigt seien. Dabei seien unter Umweltgesichtspunkten vielfältige Fragen zu klären und auch wirtschaftliche, strukturpolitische und verkehrspolitische Belange zu beachten. 
Gleichwie man zu Entfeinerung und Durchforstung, Verfahrensausdünnung und Planungslückenhaftigkeit steht, vielfach wird nur eine detaillierte Regelung dem komplexen Regelungsgegenstand des Umweltschutzes und dem zu leistenden Ausgleich von Interessen und den zu bewältigenden Koordinationsproblemen von Belangen gerecht.

Soll der gesamtökologischen Sicht bei der Umweltschutzplanung Rechnung getragen werden, können diese Tendenzen allerdings nicht unberücksichtigt bleiben.

\section{Die Situation der Ökologie}

Die Tendenz zu zurückhaltender Regelung in der Umweltschutzplanung wird allerdings unterstützt durch einen Blick auf den Stand der ökologischen Kenntnisse. In weiten Bereichen fehlen nämlich noch hinreichende ökologische Ergebnisse und Daten, die es überhaupt erlauben würden, zu einem übergreifenden und umfassenden Umweltgestaltungsinstrumentarium aus gesamtökologischer Sicht zu kommen. Klagen doch heute schon die OKologen, der Gesetzgeber sei bereits mit geltendem Recht der Entwicklung vorausgeeilt und verlange Leistungen, für die bislang weder ausreichende ökologische Erkenntnisse noch praktische Erfahrungen vorlägen ${ }^{87}$.

${ }^{86}$ Wagener, Mehr horizontale Koordinierung (FN 76), 14; Schmidt$A \beta m a n n$, Planung unter dem Grundgesetz (FN 54), 542, der sich gegen eine planerische Effektivitätsmaximierung ausspricht; Ders., Umweltschutz in der Raumplanung (FN 43), 2, der in den Lücken des Planungssystems eine Garantie für Freiräume sieht.

${ }^{87}$ Das Umweltgutachten 1978 (FN 1) Tz 4 beklagt, daß die Beschaffung zuverlässiger Daten aus allen Umweltbereichen immer noch schwierig sei. Zwar nehme die Zahl der Meßstellen und Meßreihen ständig zu, doch könne von einer bundesweiten Koordinierung und Standardisierung erst in wenigen Teilbereichen die Rede sein. Umweltgutachten 1978 (FN 1) Tz 1606 im Hinblick auf Datenprobleme auf der gemeindlichen Ebene. Im Umweltbericht '76 (FN 11) Tz 021 heißt es: „Die Kenntnisse über die Wirkung einzelner Schadfaktoren und über ihr Zusammenwirken reichen in vielen Fällen noch nicht aus, um die Gefahren und die zu ihrer Abwehr erforderlichen Maßnahmen genügend exakt zu bestimmen. Es bestehen Lücken auf den verschiedenen Gebieten der Wirkungsforschung, insbesondere in den Bereichen Toxikologie, Epidemiologie und Okologie. Es ist vordringliche Aufgabe der Forschungsförderung, zur Schließung dieser Lükken beizutragen." Nach Tz 025 hält die Bundesregierung zur Erweiterung der wissenschaftlichen Grundlagen im Bereich der Okologie und Umwelthygiene die Durchführung folgender Forschungsarbeiten für besonders vordringlich: Verstärkung toxikologischer und epidemiologischer Untersuchungen zur Bewertung der Wirkung von 
Schadstoffen, Erarbeitung von Stoffbilanzen, Aufdeckung von Wirkungsketten und biologischen Regelkreisen, Erprobung ökologischer Modelle unter Berücksichtigung von Wirtschafts- und Sozialfaktoren, Entwicklung von Umweltindikatoren und Modellen für die katastermäßige Erfassung von Wirkungen, Entwicklung von Verfahren zur Prüfung der Umweltverträglichkeit von chemischen Stoffen. Im Vorbericht über das Handbuch zur ökologischen Planung: Vorstellung eines Instrumentariums zur umweltgerechten Standortrahmenplanung, bearb. von Boese-Hanke-Ophoff-Rauschelbach-Seiler, hrsg. vom Bundesministerium des Innern (1976), $1 \mathrm{f}$., heißt es zur Planung gemäß den Zielen einer gesamtökologischen Umweltpolitik: „Eine strikte Beachtung der genannten Ziele der Umweltpolitik durch den Planer setzt voraus, daß ihm in geeigneter Form ausreichende Informationen über Zustand und Leistungsfähigkeit der Umwelt im Planungsraum zur Verfügung stehen sowie die sich aus den gegenwärtigen Nutzungen und den Zielsetzungen der Umweltpolitik ergebenden Ansprüche an die Umwelt bekannt sind. Diese Voraussetzungen sind heute in der Regel in keiner Weise erfüllt. Die Ursachen liegen hierfür u. a. in der oftmals sehr unbefriedigenden Informationsbasis, der mangelnden Konkretisierung umweltbezogener Ansprüche und Zielsetzungen für die Planer, dem Fehlen geeigneter Methoden und Instrumente, die es erlauben, die verfügbaren Informationen im Hinblick auf die angestrebten Ziele auszuwerten und auf eine für planerische Entscheidungen verwertbare Form zu verdichten. Die Erfassung aller erforderlichen Informationen für einen größeren Planungsraum ist eine Aufgabe, die gerade in den problematischen Umweltbereichen bestenfalls auf mittlere bis lange Sicht befriedigend gelöst werden kann. Der Planer ist daher bei seinen meist relativ kurzfristig zu treffenden Entscheidungen im wesentlichen auf das heute verfügbare Datenmaterial angewiesen." Das Projekt ist inzwischen vorangetrieben worden, siehe hierzu die Kurzinformationen über das Handbuch zur ökologischen Planung: Ein Instrumentarium zur umweltgerechten Standortrahmenplanung, bearb. von BoeseBrogli-Hanke-Ophoff-Rauschelbach-Seiler, hrsg. vom Bundesministerium des Innern (1977). Ein Defizit an ökologischen Kenntnissen konstatieren: Beirat für Raumordnung, Sicherung der natürlichen Lebensgrundlagen (FN 50), 73, 80 (in bezug auf Klima); siehe auch Beirat für Raumordnung, Gesellschaftliche Indikatoren für die Raumordnung (FN 50), 37, Ziff. 8: Appell an den Gesetzgeber und die Statistischen Ämter von Bund und Ländern, die Voraussetzungen zu schaffen, damit für künftige Programme möglichst frühzeitig die regional-statistischen Angaben über die Ist-Situation hergestellt werden können; Boese-Eckstein-Schier, Voraussetzungen und Nutzen integrierender Umweltschutzpläne (FN 65), 19 f., stellen fest, daB auch der Stand der Forschung zum Synergismen-Problem noch rudimentär sei. Sie erwägen, ob nicht bereits heute im planerischen Bereich die Gesamtbelastungssituation durch verschiedene Komponenten in einem Raum (d. h. "Vitalsituation“) im Hinblick auf den Menschen und die Natur entweder aufgrund der rudimentären Kenntnisse abgeschätzt oder per gesellschaftlichen Konsens durch 
Normensetzung berücksichtigt werden müsse. Heintze, Die Umweltverträglichkeitsprüfung (UVP) der Bauleitplanung in Hessen, Vortrag vom 21. 3. 1979 (Institut für Städtebau Berlin der Deutschen Akademie für Städtebau und Landesplanung) (maschinenschriftlich), 6, weist darauf hin, daß sich in fachlicher Hinsicht die fehlenden oder lückenhaften Grundlagen z. B. hinsichtlich der Pflanzensoziologie oder des Kleinklimas negativ bei der Anwendung von Planungsrechtsnormen bemerkbar machen. Siehe auch Kloepfer, Umweltschutz, Ev. Staatslexikon (FN 8), Sp. 2654; Kölble, Staatsaufgabe Umweltschutz (FN 7), 482: „Im Hinblick auf die immer noch bestehende Kluft zwischen dem verfügbaren und dem notwendigen ökologischen Steuerungswissen bedürfte es allerđings bis auf weiteres zunächst einer erheblichen Intensivierung der Okosystemforschung, bevor die ökologische Gesamtkonzeption in einen Ausbau des umweltrechtlichen Instrumentariums im einzelnen umgesetzt werden kann." Müller-Stahel, Environmental Law (FN 65), 57; bei Ellenberg-Fränzle-Müller, Oekosystemforschung im Hinblick auf Umweltpolitik und Entwicklungsplanung (Forschungsbericht) (FN 65) heißt es (18ff.): "Wie einige Landesgesetze (u. a. das Gesetz zur Sicherung des Naturhaushaltes und zur Entwicklung der Landschaft NRW vom 18. 2. 1975) bereits deutlich machen, kann nur eine ökologisch orientierte Betrachtungsweise verhindern, da $\beta$ heute ergriffene Maßnahmen später nicht ungewollte und unter Umständen irreparable Folgen haben. Solche Gesetze zeigen jedoch zugleich an, daß die Erwartungen, die heute von Politikern und Entscheidungsträgern in die Okologie gesetzt werden, im Augenblick nur teilweise erfüllt werden können. Das liegt vornehmlich daran, daß flächendeckende ökologische Informationen, die als Grundlage für eine gleichwertige Behandlung aller Teilräume der Bundesrepublik Deutschland verwandt werden können, nur lückenhaft vorliegen, ,ökologische' Beweissicherung nur punktuell (und meist ohne ,Probendeponie' für spätere Untersuchungen) durchgeführt wird, Sukzessionskontrollen zur Kenntnis der Entwicklungstendenzen und -möglichkeiten bestimmter Räume bzw. Okosysteme fehlen oder weitgehend von einzelnen Wissenschaftlern abhängen (deren Weggang meist zum Erlöschen der Kontrollfläche führt), die Gründe für das Existieren und Reagieren von bestimmten Lebewesen, insbesondere von Indikatororganismen, sowie der Lebensgemeinschaften in den meisten Teilräumen der Bundesrepublik Deutschland immer noch unzulänglich bekannt sind, die Wirkungsforschung (z. B. Toxikologie, Resistenzuntersuchung, Epidemiologie) noch erhebliche Lücken und/oder methodische Schwierigkeiten aufweist, nicht einmal in den wichtigsten Okosystemen die funktionalen Zusammenhänge (Nahrungsketten, Energie- und Stoffumsetzungen) und die Regulationsmechanismen ausreichend untersucht sind, der Grad der Belastung lebendiger Systeme, ihre Belastbarkeit und ihre Entlastungsfunktion nicht zufriedenstellend aufgeklärt sind. Diese fehlenden Informationen erschweren naturgemäß die Quantifizierung ökologischer Kriterien für die Erstellung ökologischer - ökonomischer Nutzungsmodelle (z.B. für die Standort-Optimierung sowie die Verbesserung von Techno- 


\section{Modelle der Umweltschutzplanung}

Begrenzt man die staatliche Umweltschutzplanung auf diejenigen Aufgaben, die der Staat wegen der zu berücksichtigenden Lagen im Gemeinwohlinteresse für erforderlich halten $\mathrm{kann}^{88}$, und vergegenwärtigt man sich den derzeitigen Stand von Umweltschutz, Planung und Ókologie ${ }^{89}$, so laufen die Uberlegungen zu Modellen von Umweltschutzplanung, die auf eine effektivere Durchsetzung von Umweltschutzbelangen in der Planung unter Berücksichtigung einer ökologischen Gesamtkonzeption ausgerichtet sind, eher auf zurückhaltende Vorschläge hinaus. Die Realisierung eines der sich anbietenden Modelle einer Umweltschutzplanung - in Ubersicht grob skizziert - als

- Modelle der globalsteuernden Umweltschutzplanung

- Modelle der isolierten, eigenständigen Umweltschutzplanung und

logien und Produkten). Solche Modelle aber wären die Voraussetzung für eine gemeinsame Sprache zwischen Okologen, Technologen und Okonomen. Die Situation wird außerdem dadurch verschärft, daß die ökologische Fachausbildung bisher keineswegs ausreichend gesichert ist und daß in weiten Bereichen des öffentlichen Lebens Einsichten in bereits bekannte ökologische Zusammenhänge fehlen. Um die angedeuteten Lücken zu schließen und die Erwartungen zu erfüllen, die der Gesetzgeber bereits an die Okologie formuliert hat, sollte deshalb möglichst bald und konsequent ein ,ökologisches Informations- und Bewertungssystem für die Bundesrepublik Deutschland' erstellt und die ,OKologenausbildung und Öffentlichkeitsarbeit in Ookologie intensiviert werden. Vorrangig ist für die beiden letztgenannten Aufgaben, eine tragfähige Förderungsgrundlage zu schaffen, weil es sich um ein Kernproblem der Umweltplanung und um ausgesprochene Langfristaufgaben handelt." Siehe auch Olschowy, Landschaftsökologische Kriterien (FN 65), 291; Picht, Umweltschutz und Politik (FN 6), 154; Rehbinder, Grundlagen des Umweltrechts, in: Umweltschutz - aber wie? Rechtliche Hindernisse, rechtliche Möglichkeiten (1972), Schriften der Evangelischen Akademie in Hessen und Nassau, H. 95, 24: Es gibt im Grunde auch noch keine echten Ansatzpunkte für eine Verarbeitung ökologischer Gesichtspunkte in der industriellen Standort-, Verfahrens- und Produktplanung; Steiger, Probleme des Umweltrechts (FN 50), 58; Czajka, Rechtsprobleme bei der Festsetzung von Immissionsgrenzwerten aus der Sicht der Verwaltungsgerichtsbarkeit, in: Umweltschutz und Umweltforschung, Okologie-Forum 1978 (Hamburg), 12 ff., 17 f.; Umweltprogramm des DGB (FN 51), 26 ff.; Bundesverband der Deutschen Industrie (BDI), Umweltschutz (FN 14), 13.

${ }^{88}$ Siehe oben II, 4 und Krüger, Allgemeine Staatslehre (FN 52), $760 \mathrm{ff}$.

89 Siehe oben III, 1-3. 
- Modelle der in anderen Planungen integrierten Umweltschutzplanung -

muß sich an diesen Gegebenheiten orientieren.

\section{Die Arten der Umweltschutzplanung ${ }^{90}$}

Dabei kann sich die Umweltschutzplanung auf verschiedene Fehler planender Aktivitäten erstrecken. Von den in Betracht kommenden Planungsarten: Raumplanung, technologische Planung, Wirtschaftsplanung und finanzielle Planung ${ }^{91}$ liegt aber die räumliche Planung - schon wegen des Raumbezuges des Umweltschutzes und wegen des Querschnittcharakters beider Aufgaben - im Schwerpunkt der Utberlegungen ${ }^{22}$, wobei ihre

${ }^{90}$ Es wird der Begriff der Umweltschutzplanung dem vielfach verwendeten Terminus Umweltplanung vorgezogen, einerseits, weil es nur um die Planung zum Schutz der Umwelt geht, zum anderen, weil mit dem Begriff der Umweltplanung die Vorstellung eines Anspruchs auf Globalsteuerung der Umwelt verbunden sein könnte, der hier gerade nicht vertreten wird. Das Umweltgutachten 1974 (FN 1) Tz 664 verwendet beide Termini nebeneinander.

${ }^{91}$ Rehbinder, Grundlagen des Umweltrechts (FN 87), 22; Steiger, Umweltschutz durch planende Gestaltung (FN 8), 137 ff. Zum Einsatz der Finanzplanung siehe Bullinger, Haftungsprobleme (FN 15), 601.

92 So auch gewertet vom Umweltprogramm 71 (FN 8), 9, 12 ff.; Umweltgutachten 1974 (FN 1) Tz 519 ff.; Umweltbericht '76 (FN 11) Tz 141. Nach Feldhaus, Konturen eines modernen Umweltschutzrechts (FN 41), 617, erfordert eine wirksame Umweltgestaltung eine gebietsbezogene Planung; Henneke, Raumplanerische Verfahren und Umweltschutz (FN 50), 5 m. w. N.; Müller, Umweltschutz und kommunale Bauleitplanung, Die rechtlichen Bindungen der Bauleitplanung im Umweltschutz nach dem Bundes-Baugesetz sowie den Raum- und Fachplanungsgesetzen (1975), $22 \mathrm{~m}$. w. N.; Picht, Umweltschutz und Politik (FN 6), 154, hält die Raumordnung für den Umweltschutz für konstitutiv, da sich keines der Probleme des Umweltschutzes ohne Zusammenhang mit der Raumordnung sachgemä $\beta$ bearbeiten lasse. - Rehbinder, Grundlagen des Umweltschutzrechts (FN 87), 24, 33; Ders., Umweltrecht (FN 15), 365, unterschätzt die Bedeutung der räumlichen Planung für den Umweltschutz, wenn er ihr nur die Funktion einer Verteilung wachsender Umweltbelastung zukommen läßt und sie in einer Randzone des Umweltschutzes angesiedelt sieht. Er hält deswegen eine wirtschaftlich-technische Zukunftsplanung für wichtiger. Er verkennt, daß auch und gerade räumliche Umweltschutzplanung der Vermeidung von Umweltbelastungen dient. Rehbinder, Grundfragen (FN 8), 254, erkennt zwar später an, daß räumliche Planung von vornherein Umweltgefahren ausschalten oder mildern könne, wertet aber mit dem Terminus "passiver" Umweltschutz die Raumordnung nach wie vor nur als 
Ausweitung zur Entwicklungsplanung immer im Auge behalten werden muß $\beta^{93}$. Das bedeutet nicht, daß - nach dem Vorbild des japanischen Rechts - der gesamte Umweltschutz als eine Funktion der Raumordnung behandelt wird ${ }^{94}$.

\section{Modelle der Globalsteuerung}

Geht man von diesen Ansätzen aus, so spricht wenig für globalsteuernde Instrumente des vorsorgenden Umweltschutzes. Es sei noch einmal an die Skepsis des Umweltgutachtens 1978 gegen "modische Globalbetrachtungen" erinnert, eine Skepsis, die begründet erschein ${ }^{95}$, ist doch bereits früher gegenüber Werkzeugen der Globalsteuerung, die auf den unmittelbaren Einzeleingriff gegenüber dem Bürger verzichten und statt dessen mittelbar auf ihn einwirken, geltend gemacht worden, sie seien für den Staat eine stete Versuchung, den Grundrechtsschutz zu unterlaufen ${ }^{96}$. So werden auch "holistische" Gesamtkonzeptionen in Form eines bestimmten Umweltplanungsmo-

ergänzende Komponente. Er hebt bei alledem zu einseitig auf wirtschaftlich-industrielle Umweltbelastungen ab und betont - im Gegensatz zu Steiger - besonders stark die überwachungsrechtliche Dimension des Umweltschutzes. So wie hier Schmidt-Aßmann, Umweltschutz in der Raumplanung (FN 43), 7.

93 Zur Entwicklungsplanung siehe Ossenbühl, Welche normativen Anforderungen stellt der Verfassungsgrundsatz des demokratischen Rechtsstaates an die planende staatliche Tätigkeit, dargestellt am Beispiel der Entwicklungsplanung? (FN 54), B $30 \mathrm{ff}$.; siehe auch den Entwurf eines Gesetzes über die Grundsätze der Entwicklungsplanung des Bundes, der Länder, Kreise und Gemeinden (Planungsgrundsätzegesetz) von Wagener, Anhang zu: Mehr horizontale Koordinierung bei Bund und Ländern, Informationen zur Raumentwicklung 1978, $17 \mathrm{f}$.

94 So der japanische „New Comprehensive National Development Plan" nach Picht, Umweltschutz und Politik (FN 6), 154; gegen diese Identifizierung auch Konow, Rechtliche Möglichkeiten und politische Probleme des Umweltschutzes, Beilage B 38/71 zur Wochenzeitung „Das Parlament" vom 18. September 1971, 3 ff., 13; Müller, Umweltschutz und kommunale Bauleitplanung (FN 92), 22; Rehbinder, Grundlagen des Umweltrechts (FN 87), 24.

${ }^{95}$ Umweltgutachten 1978 (FN 1) Tz 6 (S. 14) im Anschluß an das Rheingutachten (FN 1). Es mag Rupp zuzustimmen sein, daß man auf Dauer nicht umhinkomme, die gesamte Innen- und Wirtschaftspolitik unter dem Stichwort des Umweltschutzes neu zu durchdenken (Rupp, Die verfassungsrechtliche Seite des Umweltschutzes [FN 34], 401).

${ }^{96}$ Stern, Grundfragen der globalen Wirtschaftssteuerung (1969), 26, unter Hinweis auf Friauf, BB 1967, 1367. 
dells kontinuierlich vom Sachverständigenrat für Umweltfragen als nicht vollziehbar abgelehnt ${ }^{07}$.

Soweit neuere politische Tendenzen einer einheitlichen, übergreifenden Umweltgesamtplanung und einer ganzheitlichen Umweltgestaltung mit umfassenden Umweltgestaltungsinstrumentarien ${ }^{98}$ in diese Richtung zielen, ist ihnen nicht nur die kritische Sonde der Erforderlichkeit als Staatsaufgabe anzulegen, sondern auch nüchtern zu fragen, ob sie auf dem Prüfstand der Vollziehbarkeit und Effektivität und - angesichts des Standes der ökologischen Forschung - der Realisierbarkeit Bestand haben ${ }^{99}{ }^{100}$. Solche globalen Ansätze mindern - infolge

${ }^{97}$ Das Umweltgutachten 1974 (FN 1) Tz 20 konnte noch uneingeschränkt konstatieren, daß sich die Bundesregierung nicht für ein „holistisches“ Politikkonzept entschieden habe, d. h. für ein Konzept der Gesamtumweltplanung. Die Umweltpolitik werde sich damit auch im Rahmen einer längerfristig integrierten Planung letzten Endes „inkremental“, d. h. über eine Politik der kleinen Schritte, vollziehen. Ebenso Umweltgutachten 1978 (FN 1) $\mathrm{Tz} 1928,1930$, wo noch einmal festgehalten wird, daß es unter gesellschaftspolitischen Aspekten weniger darauf ankomme, ein bestimmtes Umweltplanungsmodell durchzusetzen, als die politische Funktion einer fachübergreifenden Aufgaben- und Programmplanung zu stärken.

${ }^{98}$ Baum, siehe oben FN 7, und Hartkopf, siehe oben FN 7.

99 Áhnlichen Bedenken begegnet Rehbinders (Grundlagen des Umweltrechts [FN 87], 26 ff., 27) Vorschlag eines Umweltpolitikgesetzes, das als Plangesetz sowohl strukturell wie prozeßpolitisch ausgerichtet sein soll. Nach seiner Vorstellung soll das Gesetz folgende Inhalte haben: Es soll erstens die Grobziele umweltrelevanter staatlicher Politik fixieren und, soweit möglich, bereits Prioritäten bei Zielkonflikten setzen oder jedenfalls ein rationales Verfahren zur $\mathrm{Ab}$ stimmung solcher Konflikte zur Verfügung stellen; zweitens den Rahmen für Regelungen setzen, die indikativ, notfalls auch imperativ auf umweltfreundliche Wirtschaftsstrukturen hinwirken und die notwendigen Anpassungsmaßnahmen vorsehen; drittens einen Rahmen dafür schaffen, das Ziel von Produktion und technischer Entwicklung, Prioritäten und die ungefähre Richtung der Entwicklung dem unpolitischen Marktmechanismus zu entziehen und politischer Entscheidung zu unterstellen. Das bedeute wiederum nur indikative Planung mit Reizschwellen, aber statt globaler dürten auch sektorale Eingriffe (Investitionseingriffe) erforderlich sein; viertens das Plangesetz müßte Rahmenbedingungen für die Ausgestaltung spezifischer Anforderungen an Anlagen, Verfahren und Produkte (ökologische Kosten-Nutzen-Analyse statt bisheriger eindimensionaler Genehmigungsverfahren) schaffen.

Soweit sich der Vorschlag auf die Setzung von umweltschutzrelevanten Prioritäten bei Zielkonflikten in der Planung und indikative Regelungen und Rahmenbedingungen für umweltfreundliche Wirtschaftsstrukturen beschränkt, mag er hingehen und in Ansätzen zu 
begrüßen sein; nicht hingegen, wenn dieses Umweltpolitikgesetz auf staatliche Investitionsentscheidungen im Konfliktfall hinausläuft und Ziele von Produktion und technologischer Entwicklung der politischen Entscheidung unterstellen will. Abgesehen davon ist die Durchsetzbarkeit und Effektivität eines solchen global steuernden Instruments keineswegs gesichert.

Rehbinders Vorstellungen finden ihren theoretischen Hintergrund in den Vorstellungen des tschechoslowakischen Wirtschaftstheoretikers Ota Sik, (Ota Sik, Marktwirtschaft ohne Kapitalismus, in: Fragen der Freiheit, 87/88 [1971], 3 ff.), auf den er sich ausdrücklich bezieht (a. a. O., 26). Šiks wirtschafts- und gesellschaftspolitische Theorie läuft auf einen sogenannten „Dritten Weg zwischen Kapitalismus und Sozialismus", allerdings auf der Basis des Sozialismus, hinaus. Sein Modell einer sozialistischen Marktwirtschaft beruht neben einigen anderen Faktoren im wesentlichen auf einer politischen oder, wie er es selbst nennt, einer „demokratischen“ Wirtschaftsplanung unter Beibehaltung eines "regulierten" Marktes (a. a. O., 13). Unter demokratischer Planung versteht Ota Šik staatliche Planung von sogenannten Planungskommissionen, zusammengesetzt aus Vertretern aller unterschiedlichen Interessengruppen der Gesellschaft, in denen volkswirtschaftliche, soziale und kulturelle Orientierungspläne auf mehrere Jahre hin aufgestellt werden. Die in diesen Plänen formulierten Ziele sollen durch wirtschaftspolitische Maßnahmen erreicht werden (a. a. O., 18). Die Schaffung eines „regulierten“ Marktes soll in Ergänzung dieser Planung dem Ausgleich zwischen Produktion und Bedarf sowie der optimalen Verteilung des Bruttosozialproduktes dienen (a. a. O., 20).

Für den Vorschlag Rehbinders spricht, daß der Gesetzgeber mit Hilfe einer gesetzlichen Festlegung staatlichen und privaten Handelns für die Ziele des Umweltschutzes eine klare programmatische Aussage über die Richtung seines Handelns treffen kann, die bei Zielkonflikten eine Entscheidung zugunsten des Umweltschutzes erleichtert. Auch bestehen insoweit keine Bedenken gegen ein Umweltpolitikgesetz, als es eine Art Grundsatzprogramm allen staatlichen Handelns, soweit es Umweltrelevanz besitzt, darstellt. Allerdings befreit eine derartige globale Zielbestimmung den Gesetzgeber nicht von der Notwendigkeit, die entsprechenden Grundentscheidungen mit ihren spezifischen Ausgestaltungen in all den Gesetzen, die den Staat zu umweltgerechter Planung ermächtigen, erneut zu treffen. Die globale Zielbestimmung in einem Umweltpolitikgesetz könnte dafür lediglich den Rahmen setzen. Die Effizienz staatlichen Handelns zur Lösung der Umweltschutzprobleme hängt eher davon ab, ob es dem Gesetzgeber gelingt, die erforderlichen Einzelentscheidungen in den konkreten Planungsermächtigungen für die Gesetzesanwendung wirksam zu gestalten und sie zu einem Gesamtkonzept Umweltschutz zu harmonisieren. Dies vermag eine globale Zielbestimmung in einem allgemeinen Umweltpolitikgesetz nicht zu leisten.

Soweit Rehbinder die Zielbestimmung privater Wirtschaftsplanung staatlicher Entscheidungsgewalt unterstellen will, stellt sich die 
Frage, ob das angestrebte Ziel, auch privates Handeln und Planen langfristig auf den Umweltschutz zu verpflichten, tatsächlich erreicht wird, wenn gleichzeitig die dem Gesetzgeber durch die Verfassung gezogenen Grenzen nicht überschritten werden sollen. Private Planungsentscheidungen, die aufgrund ihrer Bedeutung für die Umwelt einer Korrektur auf die Ziele des Umweltschutzes bedürften, sind in erster Linie Investitionsentscheidungen privater Wirtschaftsunternehmen. Betriebliche Investitionsentscheidungen werden bislang im wesentlichen unter Wachstums- und Rentabilitätsgesichtspunkten getroffen. Ihnen liegt regelmäßig eine detaillierte Kosten-NutzenAnalyse zugrunde. Volkswirtschaftliche oder gesellschaftspolitische Zielvorstellungen spielen dabei nur die Rolle von Rahmenbedingungen, soweit durch staatliche Anreize oder Erschwerungen versucht wird, die Investitionsentscheidung im Rahmen der Kosten-NutzenAnalyse zu beeinflussen.

Aufgrund der Erfahrungen während der Rezession Mitte der 60er Jahre und aufgrund der Erkenntnis, daß der Staat durch sein eigenes Verhalten auf dem Markt, insbesondere auf dem Geldmarkt mittels öffentlicher Investitionen, Einfluß auf die Investitionsentscheidungen der privaten Unternehmensträger nehmen kann, hat er sein eigenes Marktverhalten und darüber hinaus seine gesamte Wirtschaftspolitik durch das Stabilitätsgesetz bestimmten volkswirtschaftlichen Zielen unterstellt. Dies dient dem Zweck, dem Staat eine zur staatlichen Aufgabenerfüllung unerläßliche, funktionierende Marktwirtschaft zu erhalten, die durch zu hohe konjunkturelle Schwankungen gefährdet ist (Böckenförde, Die politische Funktion wirtschaftlich sozialer Verbände und Interessenträger in der sozialstaatlichen Demokratie, Der Staat 15 [1976], $457 \mathrm{ff}$.).

Dieses Instrumentarium indirekter Beeinflussung wirtschaftlicher Investitionen bleibt jedoch in seinen Auswirkungen auf die unternehmerische Freiheit weit hinter den Vorstellungen zurück, die Rehbinder mit dem Vorschlag eines Umweltpolitikgesetzes verfolgt. Da, wie bereits festgestellt, unternehmerische Investitionen bislang im Regelfall seitens des Entscheidungsträgers nicht irgendwelchen volkswirtschaftlichen Zielen untergeordnet sind, bedeutet der Vorschlag Rehbinders, die Ziele wirtschaftlicher Entwicklung der Bestimmung durch den Markt zu entziehen und politischer Entscheidung zu unterstellen (a. a. O., 27), nicht, privaten Investitionsentscheidungen eine um den Umweltschutz erweiterte Zielorientierung zu geben, sondern sie überhaupt erst einer über den betrieblichen Rahmen hinausgehenden Zielorientierung zu unterstellen.

Nun ist es nicht zu leugnen, daß den Zielen des Umweltschutzes mitunter bedeutende wachstumsorientierte Expansionsbestrebungen der Unternehmensträger gegenüberstehen oder in concreto die Kosten-Nutzen-Analyse zuungunsten einer umweltfreundlichen Investition ausfällt (Hartkopf, Umweltschutz gestern - heute - morgen, Bundesregierung und Industrie - Partner oder Gegner?, Umwelt Nr. 70 [1979], 2). Soll in diesem Konfliktfall den Zielen des Umweltschutzes zum Durchbruch verholfen werden, so wird der - nach Rehbinders Vorschlag - nun staatliche Entscheidungsträger direkt auf 
mangelnder Durchsetzbarkeit - den Umweltschutz in seiner Glaubwürdigkeit und Realitätsbezogenheit ${ }^{101}$.

diese Entscheidung im gewünschten Sinne Einfluß nehmen. Dies scheint auch Rehbinder erkannt zu haben, da er "notfalls" auch eine imperative Einwirkung auf umweltfreundliche Marktstrukturen für erforderlich hält (a.a.O., 27). „Notfalls“ kann hier letztendlich nur „im Konfliktfalle " bedeuten. Im Ergebnis führt dies dazu, daß im Konfliktfalle die betreffende Investitionsentscheidung nicht mehr vom Unternehmensträger, sondern vom Staat getroffen wird. Dies läßt den Wesensgehalt grundrechtlich geschützter unternehmerischer Freiheit nicht unangetastet; denn diese umfaßt auch die prinzipielle Zuweisung unternehmerischer Planungszuständigkeit an den Unternehmensträger (Papier, Unternehmen und Unternehmer in der verfassungsrechtlichen Ordnung der Wirtschaft, VVDStRL 35 [1977], 55 ff., 76/77; Ipsen, Rechtsfragen der Wirtschaftsplanung, in: Planung II, hrsg. von Kaiser [1966], 63 ff.).

Soweit sich das von Rehbinder vorgeschlagene Umweltpolitikgesetz ausschließlich auf eine indikative Einflußnahme auf private Entscheidungen und Planungen beschränkt, so fehlt es im Vergleich zum Stabilitätsgesetz an dem dort vorhandenen Instrumentarium, um in ähnlich globaler Weise einer Zielbestimmung Umweltschutz gerecht zu werden. Den eigenen umweltrelevanten Planungsentscheidungen fehlt es - sieht man einmai von den konkreten Einzelentscheidungen im Rahmen der Raumordnung ab, die unmittelbare Wirkung auf private Planungsentscheidungen entfalten - insgesamt gesehen an der notwendigen indikativen Wirkung für private Planungsentscheidungen. Im Vergleich zu der indikativen Wirtschaftsplanung nach dem Stabilitätsgesetz fehlt es zur Verfolgung von Zielen des Umweltschutzes an einem unmittelbar beeinflussenden Faktor, wie dies der vom Staat steuerbare Geldmarkt darstellt. Eine solche Wirkung kann vielmehr in besonderer Form von einer aktiven Raumordnungspolitik zugunsten des Umweltschutzes erzielt werden. Es kann aber nicht Sinn eines globalen Umweltpolitikgesetzes sein, sich insoweit auf die staatliche Raumordnung zu beschränken.

100 Eine gesamtwirtschaftliche Rahmenplanung, die die Umweltbeziehungen als wesentlichen Aspekt einbeziehen müßte und eine daraus abgeleitete Investitionslenkung strebt der Deutsche Gewerkschaftsbund (DGB), Umweltprogramm (FN 51), 17, 29, 35, an. Er setzt sich auch ein für eine Erweiterung des Gesetzes zur Förderung der Stabilität und des Wachstums der Wirtschaft (Stabilitätsgesetz) um das gesellschaftspolitische Ziel des ökologischen Gleichgewichts; ebenso Krüper als Vertreter der Gewerkschaften bei der Jahrestagung des BDI 1979, Thesen (maschinenschriftlich) 3.

101 Ein „Umweltpolitikgesetz" im Sinne von Rehbinder ist nicht gleichzusetzen mit einem „Umweltgesetz", das ein Grundgesetz der Umweltpflege sein soll, Storm, Umweltrecht, AgrarR (FN 18), 185. Siehe dazu die sehr gründlichen Vorarbeiten von Kloepfer, Systematisierung des Umweltrechts (FN 8); Ders., Kodifikation des deutschen Umweltschutzrechts, Zeitschrift für Umweltpolitik 1979, 145 ff. 
Eine Erhöhung der Effektivität des Umweltschutzes ist bei bescheideneren Ansätzen zu suchen.

\section{Integrierte statt isolierter Umweltschutzplanung ${ }^{102}$}

Es ist einerseits an Modelle der eigenständigen, isolierten und an Modelle der in andere Planungen integrierten Umweltschutzplanung andererseits zu denken ${ }^{103}$, die geeignet sein müßten, sowohl rivalisierende Umweltschutzbelange wie auch konfligierende sozio-ökonomische Interessen zu koordinieren und dabei gesamtökologische Erkenntnisse zu verarbeiten.

Eine eigenständige, isolierte und umfassende Umweltschutzplanung - eventuell regional ausgerichtet - würde auf ein eigenständiges Planwerk als Vorgabe für die anderen Planungen hinauslaufen ${ }^{104}$. Diese Vorgabe könnte auch durch eine

Nach der Vorstellung von Storm (a. a. O.) soll im Allgemeinen Teil eines solchen Gesetzes eine allgemeine Umweltberücksichtigungspflicht eingeführt werden.

${ }^{102} \mathrm{Zu}$ folgendem siehe vor allem Boese-Eckstein-Schier, Voraussetzungen und Nutzen integrierender Umweltschutzpläne (FN 65); Ernst-Erbguth-Hoppe-Schlarmann, Rechtliche und verwaltungsmäBige Möglichkeiten zur Durchsetzung von Umweltbelangen (FN 82). ${ }^{103}$ Die Terminologie ist nicht ganz einheitlich. Boese-EcksteinSchier, Voraussetzungen und Nutzen integrierender Umweltschutzpläne (FN 65), 20, bezeichnen die Pläne, die hier als eigenständige isolierte Umweltschutzpläne charakterisiert werden, als „integrierende" Umweltschutzpläne, wobei sie den Vorgang der Integration als Zusammenfügen der Vorstellungen der Fachgebiete zu einem eigenständigen Gesamtkonzept der umweltpolitischen Aktivitäten in einem Plan oder auf der Grundlage eines Plans verstehen (ebenso Rehbinder, Grundlagen des Umweltrechts [FN 87], 38), während die im Text verwendete Terminologie auf die Integration der Umweltschutzbelange in die einzelnen Planungen der Gesamtplanung, der Fachpläne und der Umweitschutzfachpläne abstellt. In diesem Sinne spricht Ernst, Zur staatlichen Verantwortung (FN 9), 9, von der Integration der Umweltverträglichkeitsprüfung in vorhandene Verwaltungs- und Planverfahren.

104 Boese-Eckstein-Schier, Voraussetzungen und Nutzen integrierender Umweltschutzpläne (FN 65), 48, unterscheiden noch den dominanten Umweltplan, dessen Inhalt und Zielsetzung von allen gleich- und nachrangigen Planungen strikt zu berücksichtigen ist, vom koordinierenden Umweltplan, der die Planungsziele aller umweltbezogenen Pläne zusammenfaßt und auf die Berührungspunkte mit anderen Fachplanungen abhebt. Seine koordinierende Wirkung würde auf der Verpflichtung zur gegenseitigen Abstimmung und zur Berücksichtigung seiner generellen Vorgaben (Leitliniencharakter), Inhalte und Vorgaben bei der Abwägung von Zielkonflikten sowie 
Weiterentwicklung der Landschaftsplanung geschaffen ${ }^{105}$ und eventuell über die Instrumente der Raumordnung und Landesplanung in die anderen Planungen eingebracht werden ${ }^{106}$.

Modellen der isolierten und eigenständigen Umweltplanung soll nicht weiter nachgegangen werden. Abgesehen davon, daß sie als selbständige Planung einen relativ hohen und schwer zu befriedigenden Koordinationsbedarf entfalten ${ }^{107}$, und abgesehen davon, daß sie bald auf die durch das Ressortprinzip gezogenen Grenzen stoßen ${ }^{108}$, setzen sie für die Berücksichti-

bei den anderen Fachplanungen beruhen. Der flankierende Umweltplan, der lediglich als Informationsangebot dienen und von anderen Fachplanungen quasi freiwillig berücksichtigt werden soll, kann nicht als isolierter, eigenständiger Umweltschutzplan gewertet werden.

105 Siehe Boese-Eckstein-Schier, Voraussetzungen und Nutzen integrierender Umweltschutzpläne (FN 65), 18, 46; Das Umweltgutachten 1978 (FN 1) Tz 1313 stellt zutreffend fest, daß sich die Landschaftsplanung von einer zunächst überwiegend gestalterisch-funktionalen Aufgabenstellung zu einer ökologisch ausgerichteten Planung entwickelt habe, die auch Querschnittsaufgaben übernehmen könne.

${ }^{106}$ Dieser Weg führt aber leicht dazu, daß die Belange des Umweltschutzes nur als sektorale Teilaspekte gewertet werden. Zum einen wären Träger einer solchen Planung nicht die maßgeblichen Umweltstellen, sondern die Landesplanungsbehörden. Zum anderen sind fachliche Teilpläne, die in der Praxis der Landesplanung durchaus anzutreffen sind, nicht unbesehen mit dem Anspruch der Raumordnung als eines alle raumbezogenen staatlichen Aktivitäten umfassenden Koordinationskonzepts vereinbar; siehe dazu Ernst-ErbguthHoppe-Schlarmann, Rechtliche und verwaltungsmäßige Möglichkeiten zur Durchsetzung von Umweltbelangen (FN 82), 23. Ähnlich wird z. Z. im Saarland verfahren, wo ein Landesentwicklungsteilplan "Umwelt", der in der Hauptsache mit der Technik der Festlegung von Vorranggebieten arbeitet, sich im Aufstellungsverfahren befindet und nach Auskunft des zuständigen Ministeriums für Umwelt, Raumordnung und Bauwesen voraussichtlich Ende 1979 bereits genehmigungsreif sein soll. In diesem Plan sind allerdings nur einzelne Umweltbelange enthalten; eine umfassende Einbeziehung sämtlicher Umweltplanungen ist nicht angestrebt.

${ }^{107}$ Ernst, Zur staatlichen Verantwortung (FN 9), 9; Kuhl, Umweltschutz im materiellen Raumordnungsrecht (FN 50), 26. Siehe zu der Notwendigkeit, organisatorische Maßnahmen in die Umweltschutzpläne einzubeziehen: Boese-Eckstein-Schier, Voraussetzungen und Nutzen integrierender Umweltschutzpläne (FN 65), 157 ff.

${ }_{108}$ Ernst-Erbguth-Hoppe-Schlarmann, Rechtliche und verwaltungsmäßige Möglichkeiten zur Durchsetzung von Umweltbelangen (FN 82), 21: Aufgrund des Ressortprinzips und nach der grundgesetzlichen Kompetenzverteilung stehen die einzelnen Sachzuständigkei- 
gung der ökologischen Gesamtsicht einen höheren Grad praktisch verwertbaren ökologischen Grundwissens voraus, als dieses derzeit vorhanden ist.

Die Integration von Umweltschutzbelangen in bestehende Planungsverfahren läßt sich erreichen.

- durch Ausbau und Verstärkung der Umweltschutzfachplanungen

- durch Verbesserung der Berücksichtigung von Umweltbelangen in der Gesamtplanung und in Fachplanung

- durch generelle Einführung einer Umweltverträglichkeitsprüfung oder Umweltverträglichkeitsstellungnahme in alle Planungsverfahren, eventuell durch eine organisatorisch selbständige Umweltstelle ${ }^{109} 110$

ten grundsätzlich gleichberechtigt nebeneinander. Lediglich die in Art. 75 Nr. 4 GG normierte Kompetenz zur Raumordnung legitimiert zur Aufstellung eines fachübergreifenden, querschnittsartigen Gesamtkonzepts mit Raumbezug, das den Fachbereichen gegenüber in seiner zielförmigen Ausgestaltung Bindungswirkung äußert (vgl. § 5 Abs. 4 i. V. m. § 4 Abs. 5 ROG). Siehe dazu auch Schöler, Die Stellung des für die Raumordnung zuständigen Bundesministers im Rahmen der verfassungsmäßigen Verteilung der Verantwortung gem. Art. 65 GG, Beiträge zum Siedlungs- und Wohnungswesen und zur Raumplanung, Bd. 37 (1976), insbesondere $27 \mathrm{ff}$., 31 ff., $49 \mathrm{ff}$.

$109 \mathrm{Zu}$ der Umweltstelle als fach- und ressortübergreifende koordinierende Stelle der allgemeinen Verwaltung siehe Umweltgutachten 1978 (FN 1) Tz 1127.

${ }^{110}$ Die Umweltverträglichkeitsprüfung, wie sie durch die Grundsätze der Bundesregierung für die Prüfung der Umweltverträglichkeit öffentlicher Maßnahmen des Bundes vom 22. 8. 1975 (GMBl. 1975, 717 ff.), abgedruckt in: Natur + Recht 1979, 23 f., vorgesehen ist, ist nicht zuletzt wegen ihres beschränkten Geltungsbereichs - nicht sonderlich wirksam geworden. Siehe auch den Umweltbericht '76 (FN 11) Tz 077 ff., der auf den Beschluß der Bundesregierung vom 9. August 1972 hinweist, der die Gemeinsame Geschäftsordnung der Bundesministerien - Besonderer Teil - GGO II ergänzt und anordnet, daß bei der Bearbeitung von Gesetzesentwürfen, Rechtsverordnungen und Allgemeinen Verwaltungsvorschriften das Bundesministerium des Innern schon zu den Vorarbeiten zuzuziehen ist, wenn Belange des Umweltschutzes berührt sein können, um die Prüfung der Umweltverträglichkeit (Vermeidung oder Ausgleich von Umweltbeeinträchtigungen) sicherzustellen. In der Begründung zu Gesetzesvorlagen und Rechtsverordnungen ist ferner anzugeben, ob Auswirkungen auf die Umwelt zu erwarten sind. Im übrigen siehe dazu Henneke, Raumplanerische Verfahren (FN 50), $25 \mathrm{ff}$. m. w. N.; Heintze, Die Umweltverträglichkeitsprüfung der Bauleitplanung in Hessen (FN 87); Kölble, Staat und Umwelt (FN 46), 10 f. Kritisch: Rehbinder, Umweltrecht (FN 15), 402 f.: „Diese Umweltverträglichkeitsprüfung: 
Die Verbesserung der Integration von Umweltschutzbelangen in alle Arten anderer Planungen soll hier an drei Feldern untersucht werden:

- der Verbesserung des Vorgangs der Ermittlung von Umweltschutzdaten

- der Verbesserung der Zielsetzung und Gewichtung von Umweltschutzbelangen

- der Verbesserung des Umweltschutzes in den Planungsleitbildern

\section{Die Strukturen der Planung und die Strukturen des Um- weltschutzes}

Strebt man in den genannten Bereichen Verbesserungen des Umweltschutzes an, so müssen allerdings die spezifischen Strukturen der Planung berücksichtigt und die Wirkungszusammenhänge im Umweltschutz beachtet werden.

\section{Die Struktur des Planungsvorgangs}

Die Elemente und Phasen der Planung und die Struktur der Normen des Planungsrechts entsprechend den herkömmlichen

stellt indes keine Rezeption des amerikanischen Vorbilds dar, sie hat mit ihm kaum mehr als den Namen gemein: Sie ist als lediglich behördeninterne Erfolgskontrolle ohne Auswirkung und damit ohne Verfügbarkeit von Sanktionen bei der Verletzung der Prüfungs- und Beteiligungspflicht konzipiert; entgegen den ursprünglichen Absichten des federführenden Bundesinnenministeriums fehlt jede Beteiligung der Offentlichkeit, so daß eine öffentliche Diskussion der Prüfungsergebnisse ausgeschlossen ist; schließlich ist die Umweltverträglichkeitsprüfung gegenüber bestehenden Verfahren, in denen bereits (bestimmte) Umweltauswirkungen behördlicher Entscheidungen geprüft werden, subsidiär, selbst wenn dort die Behörden über erhebliche Entscheidungsspielräume verfügen, aber an keine Prüfungs- und Entscheidungsmethodologie gebunden sind. Es bedarf keiner prophetischen Gaben, vorherzusagen, daß sich die Umweltverträglichkeitsprüfung in der vorliegenden Form als wenig wirksam erweisen wird." Im einzelnen siehe Wegener, Umweltverträglichkeitsprüfung im Rechtssystem, Neue Planungsmittel zur Lösung aktueller Konflikte zwischen Industrieansiedlung und Umweltgüteansprüchen?, DVBl. 1974, $327 \mathrm{ff}$. 
Kategorien allgemeiner Planung bedürfen keiner eingehenden Darstellung, da sie weitgehend bekannt sind ${ }^{111}$.

Es sind nur einige Erinnerungsposten aufzurufen: Der Planungsvorgang wird von Rechtsnormen gesteuert, die überwie-

111 Siehe dazu Badura, Das Planungsermessen und die rechtsstaatliche Funktion des Allgemeinen Verwaltungsrechts, in: Verfassung und Verfassungsrechtsprechung, Festschrift zum 25jährigen Bestehen des BayVerfGH (1972), 157 ff.; Hoppe, in: Ernst-Hoppe, Das öffentliche Bau- und Bodenrecht, Raumplanungsrecht (1978), Rdz. $243 \mathrm{f}$., $256 \mathrm{ff}$., $282 \mathrm{ff}$.; Ders., Bauleitplanung und Eigentumsgarantie, Zum Abwägungsgebot des $\S 1$ Abs. 4 S. 2 BBauG, DVBl. 1964, 165 ff.; Ders., Die Schranken der planerischen Gestaltungsfreiheit ( $\S 1$ Abs. 4 und 5 BBauG); Das Urteil des Bundesverwaltungsgerichts vom 12. Dezember 1969 zum Abwägungsgebot ( $\$ 1$ Abs. 4 S. 2 BBauG) und seine Rechtskontrolle, BauR 1970, $15 \mathrm{ff}$; Ders., Rechtsschutz (FN 80), Rdz. 138 ff.; Ders., Zur Rechtskontrolle von Bebauungsplänen, in: Festschrift für Hans Ulrich Scupin (1973), $121 \mathrm{ff}$; Ders., Zwischengemeindliche planungsrechtliche Gemeindenachbarklagen, in: Festschrift für Hans Julius Wolff (1973), $307 \mathrm{ff}$; Ders., Zur Struktur von Normen des Planungsrechts, Bemerkungen zu rechtsstaatlichen Anforderungen an die Begriffsbildung im Planungsrecht, DVBl. 1974, 641 ff.; Ders., Planung und Pläne in der verfassungsgerichtlichen Kontrolle, in: Bundesverfassungsgericht und Grundgesetz (1976), $663 \mathrm{ff}$.; Ders., Die „Zusammenstellung des Abwägungsmaterials“ (FN 67), 136 ff.; Ders., Gerichtliche Kontrolldichte bei komplexen Verwaltungsentscheidungen - Ein Beitrag zu ,zieldiktierten“ Planungs- und komplexen Prognoseentscheidungen, in: Festgabe aus Anlaß des 25jährigen Bestehens des Bundesverwaltungsgerichts (1978), 295 ff.; Ders., Bauplanungsrechtliche Grundsätze bei der Kollision und zur Ausbalancierung von Belangen, JURA 1979, $133 \mathrm{ff}$; Ders., Planungsrechtliche Grundsätze für die Überplanung gewachsener Strukturen und zur Lösung von Standortkonflikten (FN 30); Ders., Verfahren und gerichtliche Kontrolle bei der straßenrechtlichen Planfeststellung (FN 83); Hoppe-Rengeling-Dahl, Die kommunale Bauleitplanung (1973); Manner, Die rechtsstaatlichen Grundlagen des Planfeststellungsverfahrens, Diss. jur. München (1976); Weyreuther, Die Bedeutung des Eigentums als abwägungserheblicher Belang bei der Planfeststellung nach dem Bundesfernstraßengesetz, DOV 1977, 419 ff.; Ders., Rechtliche Bindung und gerichtliche Kontrolle planender Verwaltung im Bereich des Bodenrechts, BauR 1977, 392 ff.; Wahl, Rechtsfragen der Landesplanung und Landesentwicklung, Bd. 1 (FN 69), 21 ff., 114 ff., 156 ff.; Würtenberger, Staatsrechtliche Probleme politischer Planung (FN 53), 36 ff., 68 ff.; Wolfgang Graf Vitzthum, Parlament und Planung, Zur verfassungsrechtlichen Zuordnung der Funktionen von Bundesregierung und Bundestag bei der politischen Planung (1978); Brünner, Politische Planung im parlamentarischen Regierungssystem, Forschungen aus Staat und Recht, Bd. 41 (1978), 2; Wegener, Das Abwägungsgebot in der Bauleitplanung, BlGBW 1979, 105 ff. 
gend final programmiert sind ${ }^{112} 118$. Sie ermöglichen damit die planerische Gestaltungsfreiheit. Nicht minder geläufig sind in der Planungstheorie die Schritte der Planung: Der Ermittlungsund Feststellungsvorgang mit der Zusammenstellung des Abwägungsmaterials, der Vorgang des Gewichtens der Belange und schließlich der eigentliche Abwägungsvorgang, die planeri-

112 In der steuernden Funktion wird ein Funktionswandel des Rechts gesehen; in Bereichen wie denen des Umweltschutzes und der Planung komme es darauf an, das steuernde Potential des Rechts auszuschöpfen, Wälde, Rechtliche Aspekte von „Technology Assessment", VerwArch. 1976, 1 ff., 2; Henneke, Raumplanerische Verfahren (FN 50), 4; siehe hierzu auch Denninger, Die Herausforderung der Technik an das Recht (FN 72), 1152: „Eine Rechtsordnung, die von der Herbeiführung des Einmalig-Zukünftigen her ordnet, wird ganz andere Rechtsnormen entwickeln als eine Rechtsordnung, die in der Wiederholung des Bewährten ihren Bestand hat." Zur Steuerungsfunktion und zum Begriff der Steuerung siehe Wahl, Rechtsfragen der Landesplanung und Landesentwicklung (FN 69), 45 ff.; siehe auch Herzog, Allgemeine Staatslehre (1971), 328 ff., zum Planungsgesetz.

113 Oberndorfer, Strukturprobleme des Raumordnungsrechts, Die Verwaltung 5 (1972), 257 ff. Ob der Gegensatz zwischen Konditionalund Finalprogrammen kategorial gedacht werden kann oder nicht, so Schmidt-Aßmann, Planung unter dem Grundgesetz (FN 54), 547, macht keinen großen Unterschied aus. Nachdem Schmidt-A $\beta$ mann, Verwaltungsverantwortung und Verwaltungsgerichtsbarkeit, VVDStRL 34 (1976), 221 ff., zunächst der Charakterisierung der Planungsrechtsnormen als final strukturiert zurückhaltend gegenüberstand, erkennt er diesen Charakter jetzt auch an, in: Ernst-ZinkahnBielenberg, Bundesbaugesetz, Kommentar, 3. Auflage, § 1 BBauG, Rdn. 305. Zum finalen Charakter siehe auch Steiger, Zur Entscheidung kollidierender Interessen (FN 50), $416 \mathrm{ff}$., der von Gestaltungsgesetzen spricht; Ders., Probleme des Umweltrechts (FN 50), 59 ff. Siehe jetzt auch das Urteil des Österreichischen Verfassungsgerichtshofs vom 13. März 1978 - V 51/77, Osterreichische Zeitschrift für Wirtschaftsrecht (OZW) 1978, $121 \mathrm{ff}$, der den finalen Charakter der planungsrechtlichen Rechtsnormen bestätigt; siehe dazu Oberndorfer, Zur verfassungsgerichtlichen Kontrolle von Flächenwidmungsplänen, OZW 1978, 97 ff. m. w. N. Bei Hoppe, Planung und Pläne in der verfassungsgerichtlichen Kontrolle (FN 111), $691 \mathrm{ff}$., wird neben den Maßstäben, die Ziele setzen (finale Maßstäbe), noch weiter unterschieden in Maßstäbe, die die Grenzen der Planung bestimmen (determinierende Maßstäbe), die sich auf die Mittel beziehen (instrumentale Maßstäbe) und auf das Verfahren (prozedurale Maßstäbe). $\mathrm{Zu}$ den Funktionen planungsrechtlicher Vorschriften, insbesondere zu Zweckfixierungen und Zielsetzungen, siehe Würtenberger, Staatsrechtliche Probleme politischer Planung (FN 53), 205 ff. 
sche Entscheidung, welche Belange zurückgesetzt und welche vorgezogen werden sollen ${ }^{114}$.

\section{Die Wirkungszusammenhänge im Umweltschutz}

Die Wirkungszusammenhänge und Phasen des Umweltschutzes sind dagegen rechtlich noch nicht so strukturiert wie der Planungsvorgang. Die umweltschutzrechtlichen Normen, die aus der Tradition des Polizei- und Gewerberechts hervorgegangen sind, enthalten zunehmend planerisch-finale, aber auch zuteilungsrechtliche Momente. Umweltschutzrecht nimmt nämlich mehr und mehr verteilende Funktionen - z. B. im Hinblick auf knappe Ressourcen - wahr ${ }^{115}$.

Der Umweltschutz nimmt Einfluß auf einzelne Glieder oder Komplexe einer Kausalkette menschlichen Verhaltens, als die sich Umweltbelastungen und Umweltschädigungen darstellen: Sozio-ökonomische Aktivitäten wie Produktion, Konsum, Rohstoffgewinnung, Energieumwandlung, Verkehr und Siedlung (1. Wirkungsebene) haben Einwirkungen auf die Umwelt durch Abgabe von Schadstoffen an die Umweltmedien (Luft, Wasser, Boden), durch Entnahme von natürlichen Ressourcen (Wasser, mineralische Stoffe), physikalische Einwirkungen (Lärm, Strahlung, Wärme) und technische Eingriffe und Veränderungen (Überbauung, Gewässerbau, Landschaftsbau). Aufgrund der komplexen ökologischen Wirkungszusammenhänge im Naturhaushalt führen die Veränderungen in den direkt betroffenen Umweltbereichen vielfach, wenn nicht gar in der Regel, zu vielfältigen indirekten Folgewirkungen (2. Wirkungsebene). Die

114 Nachweise bei Hoppe, Gerichtliche Kontrolldichte bei komplexen Verwaltungsentscheidungen (FN 111), 302.

115 Storm, Umweltrecht, AgrarR (FN 18), 183 f.; Ders., Umweltrecht (FN 11), 38, kennzeichnet die Umweltschutznormen als instrumental, reaktiv, planend, naturwissenschaftlich-technisch, zentralisierend wirkend, begrifflich weit und eher final als konditional strukturiert sowie „administrativ“. Storm sieht in diesem Recht ein Raster, das die übrigen Teile der Rechtsordnung bedeckt und an den Knotenpunkten zu berücksichtigen ist. Nach Rehbinder, Umweltrecht (FN 15), 367, ist modernes Umweltrecht nicht klassische Substanz des Rechts, sondern Instrument von Umweltpolitik, womit die finale Komponente hervorgehoben wird.

$\mathrm{Zu}$ den zuteilungsrechtlichen Momenten, die in der Verknüpfung von Planung und Restriktion liegen, siehe Bothe, Umweltschutz als Aufgabe der Rechtswissenschaft (FN 12), 487, 501 f. (am Beispiel der Zuteilung knapper natürlicher Hilfsquellen, der Wärmelastpläne, Luftreinhaltepläne); Kloepfer, Zum Grundrecht auf Umweltschutz (FN 17), 15; Ders., Staatsaufgabe Umweltschutz (FN 8). 
direkten und indirekten Wirkungen äußern sich als negative Auswirkungen (Belastungen und Schädigungen) auf Mensch und Natur sowie Kultur- und Wirtschaftsgüter. Das Ausmaß hängt von der Summierung und der gegenseitigen Beeinflussung der Einzelwirkungen ab (Synergismus-Problem) (3. Wirkungsebene) ${ }^{116}$.

Aus diesen Wirkungszusammenhängen ergeben sich für die Planung Konsequenzen:

- Die rechtlichen Instrumente der Umweltsicherung können auf jeder Stufe der Kausalkette - vermeidend, verteilend, sanierend - angesetzt werden. Je früher das Instrument eingesetzt wird, umso mehr entspricht dies dem Vorsorgeprinzip ${ }^{117}$.

- Auf jeder Wirkungsebene sind Planungsinstrumente - neben überwachungsrechtlichen Instrumenten - einsetzbar, die sich aber unterschiedlich auswirken:

$\bigcirc$ Eine planerische Steuerung der zulässigen sozio-ökonomischen Aktivitäten - etwa durch räumliche Planung der Nutzungen - hat Umweltbeeinträchtigungen vermeidenden Charakter.

$\bigcirc$ Eine planerische Steuerung der zulässigen Einwirkungen auf die Umwelt - etwa durch Belastungspläne oder aktiven Lärmschutz - hat im Hinblick auf die Inanspruchnahme der Umwelt verteilenden Charakter.

$\bigcirc$ Eine planerische Steuerung der zulässigen negativen Auswirkungen auf Mensch, Natur, Kultur- und Wirtschaftsgüter - z. B. durch passiven Lärmschutz - hat sanierenden Charakter ${ }^{118}$.

116 Siehe dazu Kölble, Staat und Umwelt (FN 46), 5; Boese-Eckstein-Schier, Voraussetzungen und Nutzen integrierender Umweltschutzpläne (FN 65), $8 \mathrm{ff}$.

117 Kölble, Staat und Umwelt (FN 46), 5.

118 Es wäre zu begrüßen, wenn sich ein Umweltschutzplanungsgrundsatz des Vorrangs der Vermeidung von Umwelteingriffen und -belastungen vor der Verteilung von zulässigen Umwelteingriffen und -belastungen und der Sanierung von unvermeidbaren Umwelteingriffen und -belastungen herausbilden würde. Diese Frage hat bei der Diskussion des Verkehrslärmschutzgesetz-Entwurfs eine große Rolle gespielt. Für diesen Grundsatz im Verkehrslärmschutzgesetz: Hoppe, Stellungnahme (FN 83), $47 \mathrm{ff}$. In die Neufassung des VLärmSchGE (BT-Drucks. 8/3730), die nach der Anhörung von Sachverständigen durch den Ausschuß für Verkehr und für das Post- und Fernmeldewesen des Deutschen Bundestages am 8. und 15. 11. 1978 zustande gekommen ist (siehe dazu Fickert, Quo vadis, Verkehrs- 
- Der Vorgang der Ermittlung von Umweltschutzdaten hat sich auf alle Wirkungsebenen des Umweltschutzes $\mathrm{zu}$ erstrecken und mit allen Fakten und Zusammenhängen zu befassen, die auf der jeweiligen Wirkungsebene umweltschutzrelevant sind.

\section{Die Verbesserung des Vorgangs der Ermittlung von Um- weltschutzdaten}

Damit ist der Vorgang der Ermittlung von Umweltschutzdaten, die diesen Wirkungszusammenhängen besser als bisher Rechnung tragen muß, angesprochen.

\section{Die Bedeutung der Ermittlung von Umweltschutzdaten}

Dem Vorgang der Ermittlung von Umweltschutzdaten ist bisher in der Planung allgemein, aber auch in der Umweltschutzplanung, wenig Beachtung geschenkt worden ${ }^{119}$. Es fehlt inso-

lärmschutzgesetz?, DVBl. 1979, $645 \mathrm{ff}$.), ist dieser Grundsatz in $\S 2$ : „Straßen und Schienenwege sollen nach pflichtgemäßem Ermessen unter Abwägung aller öffentlichen und privaten Belange so geplant werden, daß Einwirkungen des von ihnen ausgehenden Verkehrslärms so weit wie möglich vermieden werden", 3 Abs. 1: "Soweit Lärmeinwirkungen durch Planung im Sinne von $\S 2$ nicht zu vermeiden sind, hat der Träger der Baulast bei dem Bau oder der wesentlichen Änderung von Straßen oder von Schienenwegen durch Maßnahmen am Verkehrsweg sicherzustellen, daß der Mittelungspegel des von dem zu erwartenden Verkehr ausgehenden Lärms einen Immissionsgrenzwert nach $\$ 5$ nicht übersteigt" (aktiver Lärmschutz), \$4 Abs. 1: „Soweit überwiegende öffentliche oder private Belange Lärmschutzmaßnahmen nach $\$ 3$ Abs, 1 entgegenstehen, diese insbesondere unverhältnismäßig hohe Aufwendungen erfordern würden, können diese unterbleiben. In diesem Falle hat der Träger der Baulast dem betroffenen Eigentümer seine Aufwendungen für notwendige Lärmschutzmaßnahmen für Räume, die nicht nur zum vorübergehenden Aufenthalt von Menschen bestimmt sind, $z u$ erstatten" (passiver Lärmschutz), aufgenommen worden.

119 Darauf ist es wohl zurückzuführen, daß der Gedanke des OVG Lüneburg im Beschluß vom 20. 2. 1975 - VII B 60/74 -, Energiewirtschaftliche Tagesfragen 1975, $234 \mathrm{ff}$., daß einer schrankenlosen Industrialisierung des Unterelberaums zu gegebener Zeit im öffentlichen Interesse Einhalt geboten werden müsse, insbesondere, wenn eine Gefährdung des ökologischen Gleichgewichts zu befürchten sei, wofür sich in letzter Zeit die Anzeichen zu mehren schienen; die Forderung nach einem ökologischen Gesamtgutachten sollte deshalb sehr ernstgenommen werden; das Fehlen derartiger Ưberlegungen könnte 
weit an einer hinreichenden Prüfungs- und Entscheidungsmethodologie für die Aufarbeitung der Umweltschutzdaten, mit deren Hilfe die Umweltschutzbelange überhaupt erst erkennbar und berücksichtigungsfähig gemacht werden ${ }^{120}$.

Mit der in der Regel im Mittelpunkt stehenden Problematik der Zielsetzung und Zielgewichtung von Umweltschutzbelangen betrachtet man immer nur einen Teil des Planungs- und Abwägungsprozesses. Deswegen bewirkt die Aufnahme einiger umweltfreundlicher Wendungen in den Belangekatalog des $\S 1$

in künftigen Verfahren das Gericht veranlassen, den einer Industrieansiedlung zugrunde liegenden Planungen die Anerkennung als verbindliche Konkretisierung öffentlicher Interessen zu versagen -, Befremden und Unverständnis ausgelöst hat. Die Forderung nach einem ökologischen Gesamtgutachten ist nichts anderes als die Forderung nach einer umfassenden Ermittlung unter ökologischen Gesichtspunkten. Czajka, Rechtsprobleme bei der Festsetzung von Immissionsgrenzwerten (FN 87), 18, vertritt inzwischen die Auffassung, daß kein Verwaltungsgericht - nicht einmal das OVG Lüneburg gegenwärtig einen Genehmigungsbescheid aufheben werde, weil es noch kein abgeschlossenes ökologisches Gesamtgutachten für den Unterelberaum oder für irgendein anderes Gebiet gebe. Denn nach unserem rechtlichen Verständnis sei dieses Gutachten kein Instrument des Nachbarschutzes, dem die Gerichtsentscheidungen der letzten Jahre vornehmlich dienten, also kein Instrument des Individualrechtsschutzes, sondern ein Instrument, das dem Interesse der Allgemeinheit diene. Mit diesem rechtlichen Hinweis kann hingegen nicht gegen ein eventuelles Ermittlungsdefizit argumentiert werden, wenn dieses die erteilte Genehmigung rechtswidrig machen sollte. Der Betroffene macht nämlich nicht etwa einen Anspruch auf Ermittlung im Wege eines ökologischen Gesamtgutachtens geltend, sondern begehrt die Aufhebung einer rechtswidrigen Genehmigung, die ihn in seinen Rechten beeinträchtigt. $\mathrm{Zu}$ diesem Urteil siehe auch Rehbinder, Umweltrecht (FN 15), 402.

120 Rehbinder, Umweltrecht (FN 15), 400, beklagt zu Recht die mangelnde Festlegung einer solchen Prüfungs- und Entscheidungsmethodologie und stellt fest, daß damit weitgehend ein geordnetes, kontrollierbares Entscheidungsverfahren fehle. Es frage sich, ob eine angemessene Berücksichtigung des Umweltschutzes bei der Planung durch Festlegung einer Prüfungs- und Entscheidungsmethodologie erreicht werden könne, die den Träger der Planung zu systematischer Prüfung aller Umweltauswirkungen, Abwägung der Vor- und Nachteile einer konkreten Planung - insbesondere auch für ökonomisch und sozial Schwächere -, Berücksichtigung umweltverträglicher Alternativen und Prüfung von Maßnahmen zur Minderung von Umweltbelastungen verpflichtet; siehe auch Ders., Grundfragen des Umweltrechts (FN 8), 252; Steiger, Probleme des Umweltrechts (FN 50), 66; Henneke, Raumplanerische Verfahren (FN 50), $40 \mathrm{ff}$. 
Abs. 6 BBauG bei der Novellierung dieses Gesetzes relativ wenig'21.

Gerade bei mangelnder materiell-rechtlicher Determinierbarkeit von Planungsvorgängen könnte eine prozedurale Disziplinierung auch in Form von Ermittlungsregelungen eine kompensatorische Wirkung entfalten ${ }^{122}$.

Vor allem liegt in der unzureichenden Ermittlung von Umweltschutzdaten der eigentliche Mangel und der Ursprung der unzulänglichen Beachtung von Umweltschutzbelangen überhaupt. Das wird bestätigt, wenn man in den in letzter Zeit erstellten Untersuchungen - beispielsweise zum Umweltschutz in der Bauleitplanung und in der Verkehrsplanung - den dort gekennzeichneten Ursachen mangelnden Umweltschutzes nachgeht. Die Notwendigkeit entsprechender Ermittlungen wird bei der Bauleitplanung vielfach überhaupt nicht erkannt und Zielkonflikte werden mangels Informationen gar nicht bewußt' ${ }^{123}$.

In der Verkehrswegeplanung läßt die derzeit angewandte, sehr hochgezüchtete und mathematisierte Planungsmethodik immer noch erhebliche Ermittlungsdefizite erkennen ${ }^{124}$. Das be-

121 Siehe dazu Stich, Sicherung einer menschenwürdigen Umwelt durch städtebauliche Planung, ZfBR 1978, 58 ff.; Schmidt-Aßmann, in: Ernst-Zinkahn-Bielenberg (FN 113), § 1 BBauG, Rdn. $248 \mathrm{ff}$.

122 Ernst, Zur staatlichen Verantwortung (FN 9), 8, 11 (im Hinblick auf die durch Verfahrensverbesserung möglicherweise entfallende Notwendigkeit einer Klagebefugnis für Verbände); Henneke, Raumplanerische Verfahren (FN 50), 6 ff., 10 f.; Steiger, Zur Entscheidung kollidierender Interessen (FN 50), 406; Vorbericht über das Handbuch zur ökologischen Planung (FN 87), 1 f.

${ }^{123}$ So stellt die im Auftrag des Umweltbundesamtes erstellte empirische Untersuchung von Küpper-Reiberg, Umweltschutz in der räumlichen Entwicklungsplanung - Zur organisatorischen und planerischen Verankerung der Umweltpolitik auf der Gemeindeebene (1976), siehe auch Untersuchung „Umweltschutz in der Gemeinde“, Umwelt Nr. 54 (1977), 25 f., ein mangelndes Wissen der gemeindlichen Planungsträger um die schädlichen Auswirkungen planerischer Maßnahmen auf die Umwelt und über natürliche und materielle Wirkungszusammenhänge in Räumen und Naturhaushaltssystemen fest (a. a. O., 176); siehe auch Umweltgutachten 1978 (FN 1) Tz $1041 \mathrm{ff}$., ferner: Karpe-Reuter-Kimmel-Kre $\beta$-Jansen-Werner, Vorschläge zur besseren Einbindung des Umweltschutzes in den kommunalen Planungs- und Politikvollzug, H. 2 der Veröffentlichungen des Instituts für Umweltschutz der Universität Dortmund (1979).

124 Es wird nicht verkannt, daß die Richtlinien für die Planfeststellung nach dem Bundesfernstraßengesetz (Planfeststellungsrichtlinien - PlafeR), AS Straßenbau Nr. 9/76 vom 16. 8. 1976, VKBl. 1976, 564, abgedruckt bei Fickert, Planfeststellung für den Straßenbau (1978), 13 ff., die Berücksichtigung des Umweltschutzes (Nr. 9 PlafeR) 
ginnt bei der Verkehrsanalyse ohne Erfassung der Zahl der gegenwärtig oder zukünftig durch Verkehrslärm Betroffenen ${ }^{125}$, geht über die Bewertung von Planungsvarianten mit unzureichenden ökologischen Gewichtungsfaktoren ${ }^{128}$ und der unzulänglichen Wertstellung des Umweltschutzes im „Koordinierten Investitionsprogramm" (KIP) ${ }^{127}$ bis zu dem Urteil des Umweltgutachtens 1978, der landschaftspflegerische Begleitplan ersetze keine querschnittsorientierte ökologische Untersuchung, er bedeute in der Regel nur eine "Grüngarnierung" des Straßenkörpers $^{128}{ }^{128}$.

anordnen; siehe dazu eingehend Fickert, a. a. O., Nr. 9 PlafeR Tn 41-43.

125 Siehe Umweltgutachten 1978 (FN 1) Tz 1103: „Die überwiegend festzustellende Unzulänglichkeit vergangener Verkehrsplanungen hinsichtlich des Umweltschutzes ist in großem Umfang hierauf zurückzuführen. Wird nicht bereits in der Analyse die Zahl der beispielsweise durch Verkehrslärm gegenwärtig oder zukünftig Betroffenen quantitativ erfaßt, so fehlt damit auch die Basis für eine ,lärmorientierte' Verkehrsplanung. “

128 Siehe Umweltgutachten 1978 (FN 1) Tz $1119 \mathrm{ff}$.

127 Siehe Umweltgutachten 1978 (FN 1) Tz 1126: „Angesichts der Auswirkungen auf die Umwelt... ist der Sachverständigenrat der Ansicht, daß der Umweltschutz im KIP noch unzureichend behandelt und insbesondere beim Bewertungsverfahren für Straßenbaumaßnahmen in gravierender Weise unterbewertet wird. Im Hinblick auf die große Bedeutung des Verkehrswegeinvestitionsprogramms erscheint eine Uberarbeitung des Bewertungsverfahrens aus der Sicht des Rates unerläßlich, zumal die vorgesehene fortlaufende Überprüfung des Investitionsprogramms eine nachträgliche Korrektur gestattet."

128 Umweltgutachten 1978 (FN 1) Tz 1129. Der Sachverständigenrat bezeichnet den derzeitigen Planungs- und Entscheidungsablauf für Bundesstraßen und Autobahnen gem. $\S \S 16$ ff. Bundesfernstraßengesetz und den entsprechenden Regelungen der Länder als umweltund raumordnungspolitisch gleich unbefriedigend. Einer dpa-Meldung zufolge sind bei der Landesregierung des Landes NRW ,berechtigte" Zweifel aufgetaucht, ob die Gutachten über die Autobahnen A 4 (Rothaargebirge) und A 31 ("Ostfriesenspieß"), die vom Emsland in das Ruhrgebiet in Richtung Köln gebaut werden soll, die Umweltverträglichkeit ausreichend berücksichtigt hätten. Diese Erkenntnis ist erst gewonnen worden, nachdem der NRW-Landwirtschaftsminister Deneke wegen der BAB Rothaargebirge zurückgetreten ist. Nicht minder abschreckend ist das Beispiel der Planung der BAB A 45: Odenwald - Neckar - Alb. Siehe auch Henneke, Raumplanerische Verfahren (FN 50), 28; Stich, Normative Anforderungen des demokratischen Rechtsstaats an die städtebauliche Entwicklungsplanung (FN 9), 1674 ff.; Kölble, Reichen die raumbezogenen Instrumente des Umweltrechts aus?, in: Festschrift für Werner Ernst (1980), $263 \mathrm{ff}$. 
Mäding, Infrastrukturplanung im Verkehrs- und Bildungssektor, Schriften zur öffentlichen Verwaltung und öffentlichen Wirtschaft Bd. 41 (1978), 180, hat darauf hingewiesen, daß in den 2. Ausbauplan für Bundesfernstraßen der Umweltschutz nur durch ein Ziel erfaßt und operationalisiert worden sei (Entlastung von Umweltbelastungen in Ortsdurchfahrten). Durch diese Form der Operationalisierung gingen die Umweltschutzziele nicht in ihrer möglichen Breite in die Planung ein, sondern in einer räumlich und sachlich äußerst begrenzten Form. Es wurde außerdem nur von entlastenden, nicht aber belastenden Umweltwirkungen des Straßenbaus ausgegangen. Vielfach werden Beeinträchtigungen wie Bodenerosion, Flächenverbrauch, Trennwirkung, Zerstörung von Lebensgemeinschaften und deren Biotopen, visuelle Beeinträchtigungen mit den zu erwartenden Folgewirkungen auf Nutzungsfunktionen so gut wie nicht berücksichtigt.

Die Stadtverkehrsplanungen bedienen sich des Instruments des "Generalverkehrsplans". Der Plan ist im "Merkblatt Generalverkehrspläne der Gemeinden (M GVP)" verankert, der von der Forschungsgesellschaft für das Straßenwesen aufgestellt und vom Bundesminister für Verkehr durch Rundschreiben vom 22. 10. 1969 eingeführt worden ist. Das Merkblatt genügt ökologischen Kriterien nicht.

120 Die Umweltschutzaspekte in der Landesplanung und ihre Realisierung in den Ballungsgebieten untersucht eine im Auftrag des Bundesministers des Innern vom Umweltbundesamt an das Deutsche Institut für Urbanistik (Berlin) vergebene Studie: „Umweltschutzaspekte in der Landesplanung und ihre Konkretisierung in Ballungsgebieten" von Fiebig-Hinzen-Grzeka-Müller-Witt-Knothe (1977). Die Studie kommt zu dem Ergebnis, daß der Umweltschutz organisatorisch und vom Verfahren her formal in den meisten Bundesländern bei der Raumordnung berücksichtigt werde. Faktisch allerdings fehle in vielen Fällen aber noch die wirksame Durchsetzung des Umweltschutzes gegenüber anderen Ressortinteressen. Die Ursachen für die mangelnde Wirksamkeit umweltschützender Planungen und Maßnahmen sowie die auf allen Ebenen erkennbaren Mängel beim Vollzug seien die instrumentelle Zersplitterung im Planungsrechtskomplex wie im Fachplanungsrecht, die organisatorische Zersplitterung bei der Zuordnung von Aufgaben und die Zersplitterung der Verfahrensarten bei Uberprüfung und Berücksichtigung der Aspekte der Umweltverträglichkeit. Dennoch scheine das Planungssystem der Raumordnung ausreichend dazu geeignet zu sein, Umweltschutzbelangen das nötige Gewicht zu verschaffen. Dazu sei es aber nötig, Umweltschutzfachplanungen in ein ökologisch begründetes und querschnittsorientiertes Gesamtkonzept einzubetten. Dieser wichtige Schritt müsse noch vollzogen werden. Das ist auch eine Frage der Ermittlung. $\mathrm{Zu}$ materiellen und verfahrensmäßigen Defiziten im Bezug auf den Planungsfaktor Umweltschutz in der Landesplanung siehe Karpe-Scholz-Werner-Dubois, Umweltschutz in der Landesplanung, H. 3 der Veröffentlichungen des Instituts für Umweltschutz. der Universität Dortmund (1979). 
Es ist also offensichtlich, daß zunächst einmal diese Ermittlungsvorgänge verbessert werden müssen.

\section{Die Ermittlung als zieldirigierter Informationsgewinnungs- und Informationsverarbeitungsproze $\beta$}

Man gewinnt allerdings keinen Zugang zu dem hochkomplexen Vorgang der Ermittlung, wenn man ihn - wie das Bundesverwaltungsgericht ${ }^{130}$ - als Subsumtion unter die unbestimmten Gesetzesbegriffe der planerischen Belange wertet ${ }^{131}$. Die Ermittlung ist vielmehr ein Vorgang der Informationsgewinnung und der Verarbeitung von Informationen ${ }^{132}$.

Dieser Vorgang wird bestimmt durch die gezielte Auswahl von Informationen, die durch Direktiven gesteuert wird. Die Leitsätze und Leitlinien der jeweiligen Planungsnorm und die Sachgrundsätze des jeweiligen Planungsbereichs übernehmen diese dirigierende Funktion. Daraus resultiert eine Reduktion

130 BVerwG, Urteile vom 5. 7. 1974 - BVerwG IV C 50.72 BVerwGE 45, 309 (für die Bauleitplanung); vom 14. 2. 1975 - BVerwG IV C 21.74 - BVerwGE 48, 56 (für die Fachplanung, insbesondere fernstraßenrechtliche Planung).

131 Eingehende Darstellung und Auseinandersetzung mit dieser Auffassung siehe bei Hoppe, Die „Zusammenstellung des Abwägungsmaterials" (FN 67), 136; Ders., Gerichtliche Kontrolldichte bei komplexen Verwaltungsentscheidungen (FN 111), 303 ff. Zur Gegenposition siehe Weyreuther, Rechtliche Bindung und gerichtliche Kontrolle (FN 111), $301 \mathrm{f}$. Gegenüber Weyreuther ist zu betonen, daß die hier vertretene Auffassung - entgegen seiner Ansicht - weder darauf abzielt, „die mit der bekämpften Auffassung vermeintlich überzogene Inanspruchnahme richterlicher Kontrollbefugnis zurückzudrängen" (a. a. O., 302), noch auf eine Anleihe bei der Rechtsfigur der Koppelungsvorschriften (a. a. O., 303). Die insoweit von mir vorgetragene Argumentation läuft vielmehr darauf hinaus, daß die Sachgegebenheiten des Ermittlungsvorgangs wegen ihrer Komplexität überhaupt nicht als Subsumtion begreifbar sind, also diese rechtliche Charakterisierung nicht der Realanalyse der Planung entspricht und deswegen unrealistisch ist (Hoppe, Die „Zusammenstellung des Abwägungsmaterials" [FN 67], 139 f.), und daß eine solche Subsumtion rechtlich nicht angeordnet ist (Hoppe, Die „Zusammenstellung des Abwägungsmaterials" [FN 67], 140).

132 Hierzu eingehend Hoppe, Die „Zusammenstellung des Abwägungsmaterials" (FN 67), 141 ff.; siehe auch Kilian, Juristische Entscheidung und elektronische Datenverarbeitung, Methodenorientierte Vorstudie (1974), 109 fi., mit Kritik an dem entscheidungstheoretischen Ansatz, $115 \mathrm{ff}$. 
des umfassenden Tatsachenmaterials auf einen verarbeitungsfähigen Umfang ${ }^{138}$.

Außerdem müssen die derart gefilterten Informationen aufgearbeitet, $d . h$. für die Einstellung in den Abwägungsprozeß aussagekräftig und damit berücksichtigungsfähig gemacht werden. Das geschieht durch die systematische Verknüpfung der Informationen zu einem Ermittlungsergebnis. Dieser mit Bewertungen einhergehende Vorgang der Verdichtung und Verarbeitung des Abwägungsmaterials spielt gerade in einem so komplexen und vielschichtigen Bereich wie dem des Umweltschutzes eine entscheidende Rolle, vor allem, wenn die direkten und indirekten Ein- und Auswirkungen sowie die systemaren ökologischen und synergetischen Zusammenhänge berücksichtigt werden sollen ${ }^{134}$.

Richtet sich beispielsweise bei der Standortsuche für ein flächenintensives Großvorhaben die Ermittlung auf die eventuell zu erwartende Gefährdung des Grundwassers, so erstreckt sie sich auf die Nutzwürdigkeit dieser Ressource, ihre Empfindlichkeit, ihre tatsächliche Belastung, ihre Schutzbedürftigkeit und ihre Nutzungseignung, woraus sich das Maß des Zielkonflikts zwischen Belastung und Schutzbedürftigkeit ablesen läßt'1ss.

13 Siehe dazu Hoppe, Die „Zusammenstellung des Abwägungsmaterials“ (FN 67), 141 f. Diese Leitlinien werden, da die Leitsätze und Leitlinien gesetzlicher Art kein geschlossenes Maßstabsystem bilden, durch sachnormative Maßstäbe des jeweiligen Planungsbereichs ergänzt, wenn nicht der gesamte von den gesetzlich geregelten Maßstäben nicht abgedeckte Bereich autonomen Maßstäben der planenden Stelle zufallen soll (Hoppe, a. a. O., 142).

${ }^{134}$ Der Vorbericht für das Handbuch der ökologischen Planung (FN 87), 2, konstatiert das Fehlen geeigneter Methoden und Instrumente, die es erlauben, die verfügbaren Informationen im Hinblick auf die angestrebten Ziele auszuwerten und auf eine für planerische Entscheidungen verwertbare Form „zu verdichten"; siehe auch die Kurzinformation über das Handbuch der ökologischen Planung (FN 87), 1, und Henneke, Raumplanerische Verfahren (FN 50), 44 m. w. N.

${ }^{135}$ Beispiel nach dem Vorbericht für das Handbuch der ökologischen Planung (FN 87), 17 ff. Die Ermittlung der Nutzwürdigkeit beruht auf der Bewertung des aufgrund der natürlichen Ausstattung des Raumes gegebenen nutzbaren Angebots der Ressource (Die Bewertung der Nutzwürdigkeit erfolgt auf der Basis von Angaben über die Speicherfähigkeit des Gesteins. Als weitere Kriterien können z. B. die Höffigkeit oder die Ergiebigkeit vorhandener Brunnen oder Quellfassungen herangezogen werden), die der Empfindlichkeit auf der Bewertung der aufgrund der natürlichen Ausstattung des Raumes gegebenen Empfindlichkeit der Ressource gegenüber Belastungen (Die Aussage zur Empfindlichkeit kann z. B. durch Bewertung 
Es liegt auf der Hand, daß die ermittelnde Stelle - eventuell eine organisatorisch verselbständigte Umweltschutzstelle - sowohl bei der Informationsgewinnung wie auch bei der Informationsverarbeitung nicht nur nach heteronomen Maßstäben verfährt ${ }^{136}$.

\section{Die Verbesserung der Ermittlung durch das Filtern und Aufarbeiten von Umweltschutzdaten}

Es kommt also darauf an, die verfügbaren Umweltschutzdaten auch gesamtökologischer Art unter Einschluß der ökosystemaren Beziehungen und synergetischen Zusammenhänge auf eine für planerische Entscheidungen verwertbare Form zu „verdichten". Ist das der Fall, so sollte nicht ein inhaltlich fixierter mit Verbindlichkeit ausgestatteter Umweltgesamtplan vorgesehen werden, sondern vielmehr formalisierte Verfahren zur In-

von Durchlässigkeit und Filterwirkung der Deckschicht gewonnen werden), die der Belastung auf der Bewertung der vom bestehenden Besatz des Raumes an Siedlung, Verkehr und Industrie ausgehenden Belastung der Ressource (Die Belastung ergibt sich aus einer Einschätzung des Gefährdungspotentials aufgrund dieses vorhandenen Besatzes unter Berücksichtigung von Art und Menge der auftretenden grundwassergefährdenden Stoffe. Ein weiteres Kriterium ist z. B. die Gefährdung durch verschmutzte Oberflächengewässer). Die Schutzbedürftigkeit ergibt sich aus der Aggregation von Nutzwürdigkeit und Empfindlichkeit der Ressource. Sie zeigt an, in welchem Maße zur Erreichung des Schutzziels die Freihaltung der Ressource von Belastungen erforderlich ist (Die Aussage zur Schutzbedürftigkeit kann durch eine Berücksichtigung der ausgewiesenen Schutzund Schongebiete ergänzt oder durch eine Bewertung der Ressource hinsichtlich ihrer Knappheit im Planungsraum modifiziert werden). Die Nutzungseignung einer Ressource ergibt sich aus der Aggregation von Empfindlichkeit und gegebener Belastung der Ressource einerseits und der Nutzwürdigkeit andererseits. Sie zeigt die Bewertung des sich aufgrund dieser Faktoren ergebenden noch nutzbaren Dargebots. Siehe dazu die kartographischen Darstellungen im Vorbericht (a. a. $0 ., 22 \mathrm{ff}$.).

136 Hoppe, Die „Zusammenstellung des Abwägungsmaterials" (FN 67), 143 f. Zur Frage der Prognoseseite, die hier nicht weiter vertieft werden kann, siehe Hoppe, Gerichtliche Kontrolldichte bei komplexen Verwaltungsentscheidungen (FN 111), $306 \mathrm{ff}$. Die Verwendung autonomer Maßstäbe liegt allein darin begründet, daß die relevanten Daten erst aus anderen Daten abgeleitet werden müssen mit Hilfe von Verfahren, die von einfachen nutzwertanalytischen Ansätzen bis zum hochkomplizierten mathematisch-naturwissenschaftlichen Modell reichen, siehe dazu Vorbericht für das Handbuch zur ökologischen Planung (FN 87), 6. 
formationsgewinnung und Informationsverarbeitung, die zu einem flexiblen Informationsmodell führen. Diese Funktion könnte eine für neue Erkenntnisse und Daten aufnahmebereite, durch ständige Korrekturen auf dem laufenden gehaltene „Umweltschutzdatenbank" übernehmen, die den Abruf verarbeiteter, in der jeweiligen Planungsart verwendbarer Informationen gestattet, selbstverständlich unter Wahrung aller berechtigten Individualschutzinteressen ${ }^{137}$.

Wie dies im einzelnen geregelt wird, ist eine sekundäre Frage. Ich nenne nur einige Vorschläge:

Einführung eines systemaren Testverfahrens im Sinne einer umfassenden Umweltverträglichkeitsprüfung ${ }^{138}$; Erstellung eines räumlichen Informationsrasters mit der Beschreibung von Zustand, Nutzung, Belastung, Leistungsfähigkeit, Nutzungseignung und Schutzbedürftigkeit ${ }^{139}$; Aufstellung eines ökologischen Informations- und Bewertungssystems auf der Grundlage ökologischer Kataster ${ }^{140}$; ökologische Bestandsaufnahmen und Bewertungen, gesamtökologische Gutachten und Wir-

137 Das entspricht dem Gedanken von Denninger, Die Herausforderung der Technik an das Recht (FN 72) 1155 f., der sich für kurz-, mittel- und langfristig zu entwerfende Pläne mit feed-back-Steuerung ausspricht, ein Regelkreis-Normensystem mit flexiblen Orientierungsdaten. Er verweist auf den Gedanken des Plans als eines "flexiblen Aktionsmodells“ bei Kaiser, Der Plan, ein Institut des Rechtsstaats und der Marktwirtschaft, Umrisse eines Aktionsmodells, in: Planung II, hrsg. von Kaiser (1966), 11 ff. Auf diese Weise könnte auch ein Teil des Widerstreits von auf Statik angelegten Gesetzen und durch Dynamik gekennzeichneten technischen Regelungsgegenständen abgebaut werden, dazu siehe Ossenbühl, Aktuelle Probleme des Umweltschutzrechts (FN 19), 5. Zu einem solchen Informationssystem siehe Umweltprogramm 71 (FN 8), 10.

198 Bick, Okonomie - Okologie - Umweltpolitik (FN 61), 6; Henneke, Raumplanerische Verfahren (FN 50), 43 ff., 49 ff.

${ }^{139}$ Vorbericht für das Handbuch zur ökologischen Planung (FN 87), $4 \mathrm{ff}$., das weiter Präferenzmuster und „Strategien der Zulässigkeit zusätzlicher Belastungen" vorschlägt. Es werden unterschieden der Erhebungsraster, der Verarbeitungsraster und der Aussageraster (a. a. O., 13).

140 Ellenberg-Fränzle-Müller, Oekosystemforschung (FN 65), 20 ff.: „Dieses System muß einerseits (flächendeckende) ökologische Daten liefern, ihre Verknüpfung mit unterschiedlichen Raumfaktoren sicherstellen und die aus dem Zusammenspiel zwischen Lebewesen (Tier, Pflanze, Mensch) und Faktoren (z. B. Immissionen) resultierenden Wirkungen sichtbar machen (ökologischer Kataster). Andererseits muß es Daten zur Erhellung der Wirkungszusammenhänge in dem für die Bundesrepublik bedeutsamen Okosystem liefern und die wichtigsten Faktoren-Einflüsse auf zukünftige Entwicklungs- und 
kungskataster 141. Die Luftreinhaltepläne nach $\S 47$ BImSchG weisen mit ihrem feststellenden Teil in diese Richtung ${ }^{142}$.

Wie auch immer der Informationsplan oder die Umweltschutzdatenbank ausgestaltet sein wird, ein solches Instrument kann in dem argumentativen Prozeß der Planung seine Wirkung nur entfalten, wenn es verknüpft wird mit der Regelung von

- Pfichten zur Vorhaltung und perpetuierlichen Fortschreibung dieses Informationsinstruments,

- Pfichten zum Datenabruf für die planenden Stellen bei Planaufstellung in einem möglichst frühen Stadium,

- Pfichten zur Einstellung des verarbeiteten Materials in die Abwägung,

- Pflichten zur kontinuierlichen Überprüfung bestehender Pläne anhand der Daten ${ }^{\mathbf{1 4 3}}$,

Nutzungsmöglichkeit von Räumen und lebendigen Systemen interpretierbar machen (Okosystem- und Sukzessionskontrollen). Okologisch-ökonomische Nutzungsmodelle, die sich hieraus ergeben, können nur dann zum verbindlichen Handlungsprinzip werden, wenn ihre ökologischen input-Daten im Rahmen eines ökologischen $\mathrm{Ka}$ tasters durch funktionale Analysen in exemplarischen Räumen der Bundesrepublik standardisiert werden können."

141 Olschowy, Landschaftsökologische Kriterien der Planung (FN 65), 292 ff.; Umweltgutachten 1978 (FN 1) Tz 1252 verlangt Biotop-Kartierungen und ökologische Wirkungsanalysen (Tz $1219 \mathrm{f}$.).

142 Siehe hierzu Feldhaus, Luftreinhaltepläne - rechtliche Möglichkeiten und Grenzen, BauR 1978, 260 ff., 262: „Nach $\$ 47$ S. 3 Nr. 1 und 2 BImSchG sind im Luftreinhalteplan Art und Umfang der festgestellten und zu erwartenden Luftverunreinigungen darzustellen, Feststellungen über deren Ursachen aufzunehmen und eine Bewertung unter dem Gesichtspunkt schädlicher Umwelteinwirkungen vorzunehmen. Konkret sind damit das Emissionskataster und die Ursachenanalyse, das Immissions- und das Wirkungskataster angesprochen. Dieser feststellende Teil des Luftreinhalteplans wird in der Regel Grundlage für den anschließenden Maßnahmenteil sein. Unabhängig davon kommt ihm aber auch eine eigenständige rechtliche Bedeutung zu. Mit der Feststellung, daß in bestimmten Teilen des Belastungsgebietes schädliche Umwelteinwirkungen auftreten oder zu erwarten sind, wird eine Rechtstatsache festgestellt, die über die Anwendung außer-immissionsschutzrechtlicher Vorschriften zu rechtlichen Konsequenzen führen kann."

143 Herzog, Allgemeine Staatslehre (FN 112), 329, weist darauf hin, daß staatliche Gesetzgebung in Zukunft zumindest dort, wo sie in Form des Planungsgesetzes auftritt, ohne ein institutionalisiertes Fortschreibungsverfahren nicht gedacht und betrieben werden könne. Die Ermittlung im Sinne einer perpetuierlichen Informationseinspeisung ist ein derartiges Mittel der Fortschreibung. 
wiederum selbstverständlich unter Beachtung der im Individualschutzinteresse liegenden rechtlichen Grenzen der Erhebung, Speicherung und Utbermittlung von Daten.

Da Umweltschutz eine fachübergreifende Querschnittsaufgabe ist, und die Ermittlung fachübergreifend-querschnittsorientiert durchgeführt werden muß, bietet sich für diese Informations- und Informationsverarbeitungsprozesse eine fachund ressortübergreifende koordinierende Umweltstelle an, die beispielsweise beim Regierungspräsidenten als regional zuständiger Behörde mit Bündelungsfunktion installiert werden könnte ${ }^{144}$.

144 Siehe dazu Umweltgutachten 1978 (FN 1) Tz 1127: „Auf der Verwaltungsebene ist es allerdings weithin üblich, daß öffentliche Maßnahmen mit dem Ziel geplant und ausgeführt werden, bei rein sektoraler Betrachtungsweise einen möglichst großen Effekt mit gegebenem Mittelaufwand zu erreichen, weitgehend unabhängig davon, welche Folgen und Folgelasten in den anderen Bereichen auftreten. Wenn aber Umweltschutz keine selbständige fachlich begrenzte sektorale Aufgabe, sondern eine fachübergreifende Querschnittsaufgabe ist, muß sichergestellt werden, daß die erforderlichen Umweltverträglichkeitsprüfungen auch durch fach- und ressortübergreifende, koordinierende Stellen der allgemeinen Verwaltung durchgeführt werden, um eben diese rein sektorale Betrachtungsweise auszuschließen. Solange in der Regel nur eigene Ressortinteressen abgesichert werden, kann eine langfristig vorausschauende, gesamtheitlich ausgerichtete Planung jedenfalls nicht wirksam werden." Siehe dazu Schmidt-Aßmann, Umweltschutz in der Raumplanung (FN 43), 7, Buchst. d; Henneke, Raumplanerische Verfahren (FN 50), 57, schlägt Umweltschutzfachstellen vor, die nicht weisungsgebunden sind. Boese-Eckstein-Schier, Voraussetzungen und Nutzen integrierender Umweltschutzpläne (FN 65), 64, sprechen sich auf der Gemeindeebene für ein Team aus allen Dezernaten aus in der Form einer Stabsstelle. Für den Umweltschutz allgemein schlägt die Untersuchung von Küpper-Reiberg, Umweltschutz in der Gemeinde (FN 123), an organisatorischen Maßnahmen in der Gemeindeverwaltung Organisationsmodelle für zwei verschiedene Größenklassen von Gemeinden mit entsprechenden Übergangsregelungen vor, wobei der Bereich Umweltschutz in der Planungs- und Ordnungsverwaltung zu installieren ist, seinen Charakter als Querschnittsaufgabe aber behält. Für die Größenklasse 1 (Großstädte und verwaltungsstarke Mittelstädte) soll dies durch den Umweltplaner in der Entwicklungsplanung und durch den Umweltbeauftragten in der Ordnungsverwaltung, für die umfassende Aufgabenkataloge ausgearbeitet sind, geschehen. Für die Größenklasse 2 (kleinere Mittelstädte und ländliche Gemeinden) sollen Funktionen und Aufgaben dieser beiden Dienststellen in einer Dienststelle bzw. Person vereinigt werden. Für alle Gemeinden wird die Einrichtung von Koordinationsgremien empfohlen, deren Zuständigkeit bzw. Aufgaben- 
Die Verbesserung der Qualität der Ermittlung von Umweltschutzdaten in der beschriebenen Art hat Vorteile gegenüber einem eigenständigen, verbindlichen Umweltplan, an den sich andere Planungen in den ohnehin kompletten planerischen Handlungszusammenhängen nur über mehr oder weniger offene Bindungsvorschriften anpassen ließen ${ }^{145}$.

Sieht man Planung hingegen als einen argumentativen, offenen prozeßhaften Vorgang der Abwägung an, als ein phasenweises Herantasten an eine Lösung, so ist das faktische Gewicht "gefilterter" und „aufbereiteter" Umweltinformationen unverkennbar ${ }^{146}$.

Gegenüber einem festgeschriebenen, statischen Umweltschutzplan kann ein für neuere Erkenntnisse und Daten aufnahmebereiter, auf Fortschreibung angelegter Informationsraster überdies eine Gelenkfunktion zwischen den einzelnen Planungen und dem jeweiligen Erkenntnisstand ökologischen Wissens erfüllen. Er überstrapaziert also nicht die Ökologie, wie dies vielfach bei neueren gesetzlichen Regelungen, so bei der Landschaftsplanung, von den Okologen beklagt wird ${ }^{147}$.

bereich durch die Ausführung einer Dienstanweisung näher erläutert wird. Mit beiden Vorschlägen sind aber nicht nur die angesprochenen unabhängigen Umweltfachstellen überlokalen Charakters gemeint.

${ }^{145} \mathrm{Zu}$ den Schwierigkeiten der Abstimmung und des Einbindens von Plänen in gestufte Handlungszusammenhänge komplexer Planungen mit Formulierungen, daß diese Pläne „anzupassen“, „zu beachten“, aus anderen "zu entwickeln" oder "in andere einzufügen" seien oder einen vorgeordneten Plan "vertiefen", "entfalten" oder „zugrunde legen" sollen, siehe Wahl, Rechtsfragen der Landesplanung und Landesentwicklung (FN 69), $157 \mathrm{f}$.

${ }_{146}$ So auch Henneke, Raumplanerische Verfahren (FN 50), 15 f., 29 mit FN 1, 66: Eine Auseinandersetzung mit umweltrelevanten, quantifizierten Planungsdaten im Rahmen der Umweltverträglichkeitsprüfung sei unabhängig von ihrer materiellen Verbindlichkeit sinnvoll und daher vorzuschreiben, da sie auf jeden Fall Bewertungsanhaltspunkte und Interpretationshilfen zur Konkretisierung der Ziele der Raumordnung liefern und daher zur Erhöhung der Problemtransparenz bei der Planung beitragen könnten. So auch Schmitt-Glaeser, Partizipation an Verwaltungsentscheidungen, VVDStRL 31 (1973), 179 ff. m. w. N., unter Hinweis auf die behavioristisch-rationale Entscheidungstheorie. Er spricht von einem mehrphasigen, stufenweisen Herantasten an die Lösung.

147 Olschowy, Landschaftsökologische Kriterien der Planung (FN 65), 291; Ellenberg-Fränzle-Müller, Oekosystemforschung (FN 65), 19. 


\section{Verbesserung der Zielsetzung, der Gewichtung und der Abwägung von Umweltschutzbelangen}

So wenig sich die Bemühungen im Umweltschutz auf die Ermittlung von Umweltschutzdaten erstrecken, so sehr steht die Zielgewichtung und die Forderung nach einer Erhöhung des Gewichts des Umweltschutzes in der planerischen Abwägung ${ }^{148}$ im Vordergrund der Erörterungen.

\section{Die Gleichrangigkeit aller planerischen Ziele}

Der Umweltschutz stellt bei der planerischen Abwägung im gesamten Spektrum der Planungsinteressen nur einen Belang dar, dennoch einen sehr gewichtigen ${ }^{149}$. Selbst die Planungsklausel des $\S 50$ Bundes-Immissionsschutzgesetz, wonach bei raumbedeutsamen Planungen und Maßnahmen die für eine bestimmte Nutzung vorgesehenen Flächen einander so zuzuordnen sind, daß schädliche Umwelteinwirkungen auf die ausschließlich oder überwiegend dem Wohnen dienenden Gebiete sowie auf sonstige schutzbedürftige Gebiete soweit wie möglich

148 Dem Umweltschutz kann eine relative Priorität, ihm kann aber auch ein absoluter Vorrang eingeräumt werden. Es wird viel erörtert, ob dem Umweltschutz in der Planung für den Fall von Gesundheitsgefahren für die Bevölkerung bzw. der Gefahr von funktionsgefährdenden Dauerschäden an den natürlichen Lebensgrundlagen gesetzlich ein absoluter Vorrang vor anderen Planungsinteressen einzuräumen sei, das heißt praktisch, daß kein Abwägungsspielraum verbliebe. So heißt es in der Entschließung der Ministerkonferenz für Raumordnung "Raumordnung und Umweltschutz" vom 15. 6. 1972, 10: „Bei Zielkonflikten muß dem Umweltschutz der Vorrang eingeräumt werden, wenn eine wesentliche Beeinträchtigung der Lebensverhältnisse droht oder die langfristige Sicherung der Lebensgrundlagen der Bevölkerung gefährdet ist." Der Raumordnungsbericht der Bundesregierung von 1974, BT-Drucks. 7/3582, 10, betont, daß Gesundheit und Sicherheit der Bevölkerung wichtiger als Wirtschaftswachstum seien, weil sie Voraussetzung für ein solches langfristiges Wirtschaftswachstum seien. Vorrang für den Umweltschutz fordern auch: Külz, Umweltschutz mit Besinnung, BB 1971, 1017; Feldhaus, Konturen eines modernen Umweltschutzrechts (FN 41), 617; Steiger, Zur Entscheidung kollidierender Interessen (FN 50), 428; Ders., Mensch und Umwelt (FN 17), 24; siehe hierzu Kuhl, Umweltschutz im materiellen Raumordnungsrecht (FN 50), $69 \mathrm{ff}$.

${ }^{149} \mathrm{Kuhl}$, Umweltschutz im materiellen Raumordnungsrecht (FN 50), 35, 64 ff. 
vermieden werden ${ }^{150}$, räumt dem Umweltschutz keine Priorität ein, allenfalls eine relative Priorität $t^{151}$.

Dieser Stellenwert der Umweltschutzbelange bedeutet, daß sie sich zwar durchsetzen können, wenn sie mit anderen Planzielen harmonieren oder ihnen gegenüber neutral sind. Sie werden aber vielfach zurückgestellt, wenn sie mit anderen Planungsinteressen wie etwa Verkehr, Industrieansiedlung, Erholung, seien die Belange privat oder öffentlich ${ }^{152}$, konkurrieren oder gar konfligieren ${ }^{153}$.

Es wird nämlich als geradezu typisch für die planerische $\mathrm{Ab}-$ wägung angesehen, daß sich die planende Stelle - bei Beachtung des Grundsatzes der Verhältnismäßigkeit - in der Kollision zwischen verschiedenen Belangen für die Bevorzugung des einen und damit notwendig für die Zurückstellung des anderen entscheiden kann ${ }^{154}$.

Dieser ohnehin geringe Stellenwert des Umweltschutzes wird dadurch noch weiter relativiert, daß die ungelösten Zielkonflikte oft auf die Exekutive abgeschoben werden ${ }^{155}$. Die nicht ge-

${ }^{150}$ Es handelt sich bei $\S 50$ BImSchG nicht um einen Programmsatz, so Lenz, Ansiedlung von Anlagen der gewerblichen Wirtschaft, BauR 1975, 159 ff., 163, sondern um geltendes Recht; Feldhaus, Zum neuen Bundes-Immissionsschutzgesetz, Landk. 1974, 124; Fickert, Straßenplanung und Straßenbau unter der Rechtsgeltung des Bundes-Immissionsschutzgesetzes und unter Einbeziehung des Entwurfs einer Straßenschallschutzverordnung, BauR 1976, $1 \mathrm{ff.,} 4$.

151 So Feldhaus, Konturen eines modernen Umweltrechts (FN 41), 617; a. A. Fickert, Straßenplanung und Straßenbau unter der Rechtsgeltung des BImSchG (FN 150), 5, unter Berufung auf das Urteil des BVerwG vom 14. 2. 1975 - IV C 21.74 - BVerwGE 48, 56 ff., 62 f.

152 Die öffentlichen Belange genießen keinen Vorrang vor privaten Belangen, Hoppe, Bauleitplanung und Eigentumsgarantie (FN 111), 170; Schmidt-Aßmann, Umweltschutz in der Raumplanung (FN 43), 5; Müller, Umweltschutz und kommunale Bauleitplanung (FN 92), $27 \mathrm{ff}$.

${ }^{153} \mathrm{Zu}$ den Anforderungen an Zielsysteme und zu den harmonischen, neutralen oder konkurrierenden Beziehungen zwischen zwei oder mehr Teilzielen siehe Wilkenloh, Probleme und Bedingungen einer zielorientierten Politik unter besonderer Berücksichtigung des Sektors Verkehr, Die Verwaltung 8 (1977), 434 ff., 438; Würtenberger, Staatsrechtliche Probleme politischer Planung (FN 53), 79 ff.

154 So die ständige Rechtsprechung des BVerwG, die das Abwägungsgebot - in dieser Form - aus dem Wesen einer rechtsstaatlichen Planung ableitet, Nachweise siehe bei Hoppe, in: Ernst-Hoppe, OffBauBoR (FN 111), Rdz. 283, 287.

155 Rehbinder, Umweltrecht (FN 15), 371; Umweltgutachten 1978 (FN 1) Tz 1644: „Die Lösung der Konflikte darf nicht der zur Ausführung der Gesetze berufenen Verwaltung überlassen werden. Ziel- 
ringe Zahl der geregelten Planungsbelange erhöht außerdem nicht nur die Zielkonflikte, sondern auch den ohnehin nur durch sehr weite unbestimmte Gesetzesbegriffe bestimmten Abwägungsspielraum ${ }^{158}$ bei dem Vor- und Zurückstellen von Belangen ${ }^{157}$.

Schließlich wird den Umweltschutzbelangen gewissermaßen von Hause aus eine Durchsetzungsschwäche - vor allem im Vergleich zu sektoralen Fachplanungsinteressen - nachgesagt ${ }^{158}$.

\section{Die Verbesserung der Umweltschutzziele und deren Gewichtung}

Diesen Schwächen der Umweltschutzbelange bei Zielkonflikten in der Planung kann durch verschiedene Mittel entgegengewirkt werden, und zwar

konflikte sind vielmehr in den politischen Lenkungsorganen auszutragen. Die erlassenen Regelungen sollten ferner ein System bilden, das neben klaren Zielhierarchien eine innere Struktur besitzt, die es für die ausführenden Behörden durchschaubar und nachvollziehbar macht. Dabei wird es in Zukunft für die Gestaltung des einzelnen Gesetzes, der einzelnen Verordnung oder Verwaltungsvorschrift mehr als bisher darauf ankommen, Erfahrungen aus der Praxis der Gesetzesanwendung durch die Verwaltung, insbesondere aus ihrem tatsächlichen Verhalten und Handeln, in die Vorschriften einzubringen. Nur so können Normen geschaffen werden, bei denen nicht wegen mangelnder Vollziehbarkeit aufgrund mangelnden Praxisbezuges ein gewisses Vollzugsdefizit von vornherein programmiert ist."

${ }^{156} \mathrm{Zu}$ der Weite der unbestimmten Gesetzesbegriffe $\mathrm{Kuhl}$, Umweltschutz im materiellen Raumordnungsrecht (FN 50), 104 ff.; Ernst, Zur staatlichen Verantwortung (FN 9), 1 f.; Rehbinder, Grundlagen des Umweltrechts (FN 87), 37 f.; Papier, Die Stellung der Verwaltungsgerichtsbarkeit (FN 27), $30 \mathrm{f}$.

157 Zur Vergrößerung des Abwägungsspielraums siehe Scheuner, Staatszielbestimmungen, Festschrift für Ernst Forsthoff (1972), 325 ff., 340, zu den Zielkonflikten des "magischen Vierecks" in § 1 Stabilitätsgesetz und damit des Art. 109 Abs. 4 GG; Oberndorfer, Zur verfassungsgerichtlichen Kontrolle von Flächenwidmungsplänen (FN 113), 97; Ders., Strukturprobleme des Raumordnungsrechts (FN 113), 266 f.

158 Nach Rehbinder, Umweltrecht (FN 15), 364, sind die ,auf Naturverschwendung" angelegten Interessen manifester, meßbarer, kurzfristiger und lassen sich deshalb in weitaus stärkerem Maße artikulieren, organisieren und im Konfliktsfall durchsetzen; Henneke, Raumplanerische Verfahren (FN 50), 16. 
- durch Operationalisierung der Umweltschutzbelange ${ }^{158}$ im Wege der Konkretisierung der Ziele des Umweltschutzes ${ }^{100}$ und durch ihre Quantifizierung, sofern Quantifizierung sinnvoll möglich ist,

- durch die Aufstellung von Präferenzskalen für die Gewichtung,

- durch Aufstellung oder eindeutigere Formulierung von Leitsätzen bei nicht quantifizierbaren Zielsetzungen.

Für solche Quantifizierungen gibt es eine Reihe von Vorschlägen, die Indikatorenkataloge und Grenzwerte, Planungsrichtwerte und Belastungsgrenzen vorsehen, die an Mindeststandards, Flächenimmissionsstandards, Flächenzuordnungsstandards und Eckdaten sowie ähnliche Festlegungen denken. Entscheidend ist, daß solche Richt- und Grenzwerte in die Planung als Maßstäbe integriert werden, woran es bisher fehlt ${ }^{101}$.

150 Die Operationalisierung, für die sich auch das Umweltgutachten 1978 (FN 1) Tz 1929 ausspricht, ist ein allgemeines Problem jeder Planung; Rehbinder, Grundlagen des Umweltrechts (FN 87), 37; Ders., Umweltrecht (FN 15), $371 \mathrm{ff}$., $379 \mathrm{f}$.

160 Dazu siehe Schmidt-Aßmann, Die Grundsätze des Naturschutzes und der Landschaftspflege, Natur + Recht 1979, 1 ff., 6 m. w. N.

161 Nach dem Umweltgutachten 1978 (FN 1) Tz 1934 muß Umweltpolitik auf der Planungsebene schrittweise Qualitätsziele festzulegen versuchen. In Tz 1211 setzt sich der Sachverständigenrat für ökologische Grenz- oder Optimalwerte für das Verhältnis von Flächennutzungen zueinander ein. Eingehend und grundlegend hierzu siehe $K u h l$, Umweltschutz im materiellen Raumordnungsrecht (FN 50), der sich vor allem für Umweltstandards (116 ff. m. w. N., 116 FN 2) einsetzt. Er unterscheidet Standards für die Aufteilung der Gesamtfläche auf die einzelnen Nutzungsformen (120 ff.), Flächenimmissionsstandards (123 ff.), Flächenzuordnungsstandards (125 ff.), Standards für die Ausstattung einer Region mit Ver- und Entsorgungsanlagen (128 f.), Wasserverunreinigungs- bzw. Aufwärmungsstandards (129 ff.). Dort siehe auch zum Verfahren zur Festsetzung der Standards (131 ff.), zu deren rechtlicher Zulässigkeit (135 ff.), zur Rechtsform der Festlegung der Standards (157 ff.). Die Vorteile sieht $\mathrm{Kuhl}$ in folgendem: „Nur mit Hilfe von Standards lassen sich die Ansprüche, die an die natürlichen Lebensgrundlagen zu stellen sind, wirklich operational umschreiben. In den den Belastungsgrenzen zugrunde liegenden Naturwissenschaften wird ausschließlich mit zahlenmäßig ausdrückbaren Kenn- oder Maßgrößen gearbeitet. Nur rechnerische Größen lassen sich miteinander in klare Beziehung setzen, machen die einzelnen Faktoren austauschbar und ermöglichen es, die noch nicht ausgeschöpften Belastungskapazitäten deutlich $\mathrm{zu}$ erkennen. Es findet auf diese Art und Weise auch eine weitgehende Objektivierung statt, die es ermöglicht, etwa zur Errechnung 
Nicht immer sind die Ziele quantifizierbar. Aber auch nicht quantifizierbare Ziele sollten durch eine genauere Fassung in ihrer Schutzwirkung erhöht werden. Vor allem erscheinen sie nur dann wirksam, wenn ihnen eine Rangfolge oder Gewich-

der Belastungsgrenzen oder der noch vorhandenen Kapazitäten technische Hilfsmittel wie Computer einzusetzen. Ebenso wird sich jede einzelne Maßnahme transparenter auf ihre Umweltauswirkung untersuchen lassen, d. h. die Kontrolle der Planung wäre effizienter durchzuführen. Daraus folgt, $\mathrm{daB}$ es der betroffenen Materie nicht angemessen ist, abstrakte oder umschreibende Begriffe zu verwenden. Für die Planung ist aber insbesondere von Bedeutung, daß Standards im Gegensatz zu auf unbestimmten Rechtsbegriffen beruhenden Abwägungs- und Ermessensentscheidungen dazu in der Lage sind, umweltschädlichen Aktivitäten eine absolute Obergrenze zu setzen. Es ist deutlicher erkennbar, ob die Planungsmaßnahmen sich innerhalb der landes- bzw. regionalplanerisch gesetzten Obergrenzen hält oder nicht.“ Backes, Umweltstrafrecht, JZ 1973, 337 ff., 341, spricht sich für Qualitätsnormen zur Immissionsbegrenzung aus; Baltes, Immissionsgrenzwerte und Art. 2 Abs. 2 GG, BB 1978, $130 \mathrm{ff}$., 132, spricht sich für Immissionsgrenzwerte im Interesse der Rechtssicherheit bei der Planung aus; Beirat für Raumordnung, Sicherung der natürlichen Lebensgrundlagen (FN 50), 74 f.: Indikatoren für die Sicherung der natürlichen Lebensgrundlagen, Zielwerte und Belastungshöchstwerte für Umweltindikatoren; Beirat für Raumordnung, Gesellschaftliche Indikatoren für die Raumordnung (FN 50), 29 ff.; Bullinger, Umweltrechtliches Verursacherprinzip und Raumordnung (FN 50), 670, $676 \mathrm{ff.,} \mathrm{für} \mathrm{Immissionsgrenzwerte} \mathrm{und} \mathrm{Güteklassen}$ (im Zusammenhang mit Abgaben); siehe auch das von EllenbergFränzle-Müller, Oekosystemforschung (FN 65), vorgeschlagene ökologische Informations- und Bewertungssystem; Ernst, Zur staatlichen Verantwortung (FN 9), 6, für Indikatoren durch zahlenmäßig fixierte Grenzwerte oder Bandbreiten; Schmidt-Aßmann, Umweltschutz in der Raumplanung (FN 43), 7, verlangt vom Gesetzgeber präzisere Vorgaben. Notwendig seien nicht so sehr Grundsätze, sondern Umweltstandards und Eckwerte, wie sie in den Technischen Anweisungen heute schon existierten; siehe auch Plogmann, Zur Konkretisierung der Raumordnungsziele durch gesellschaftliche Indikatoren (1977); Rehbinder, Grundlagen des Umweltrechts (FN 87), 33, für Einbeziehung der Standards in die Planung; Ders., Umweltrecht (FN 15), 375, für Umweltqualitätsnormen (Immissions- und Wassergütestandards in der Form von Richt- und Grenzwerten), zugleich für Einbeziehung in die Planung $(376,381)$; siehe auch Thoss, Ohne konkrete Ziele geht es nicht!, Gesellschaftliche Meßgrößen zur Bestimmung der Raumordnungspolitik, in: Raumordnung auf neuen Wegen? - Chancen und Bedingungen gleichwertiger Lebensverhältnisse im Bundesgebiet, Schriftenreihe der Bundeszentrale für politische Bildung, Bd. 112 (1975), 59 ff. 
tung zu entnehmen ist, die allerdings nicht auf einen absoluten Vorrang hinauslaufen kann ${ }^{162}$.

Wir haben ein Defizit an Grundsätzen, die - bei angemessener Berücksichtigung anderer Planungsbelange mit dem ihnen zukommenden Gewicht - für den Umweltschutz eine optimale Verwirklichung etwa im Sinne einer relativen Priorität vorsehen ${ }^{163}$. Das wird in der Praxis immer wieder deutlich an

182 Siehe hierzu Feldhaus, Bundesimmissionsschutzgesetz (Loseblatt, Stand März 1978) §50 BImSchG; Ule, Bundes-Immissionsschutzgesetz, Kommentar (Loseblatt, Stand Februar 1979), § 50 BImSchG; Kuhl, Umweltschutz im materiellen Raumordnungsrecht (FN 50), 66, 108 ff.; Schmidt-Aßmann, Umweltschutz in der Raumplanung (FN 43), 3, sieht in \$50 BImSchG einen wichtigen, allerdings nicht sehr griffigen Ansatz; Rehbinder, Umweltrecht (FN 15), 379, erkennt in $\S 50 \mathrm{BImSchG}$ nur den Charakter einer „Tendenzaussage ${ }^{\text {“ }}$ an, deren Bindungswirkung unsicher sei und letztlich vom Umfang der gerichtlichen Nachprüfung abhängig sei. Da das BVerwG inzwischen ausgesprochen habe, bei der Planungsklausel des § $50 \mathrm{BImSchG}$ handle es sich um einen seit jeher anerkannten Planungsgrundsatz (BVerwG vom 5. 7. 1974 - IV C 50.72 - BVerwGE 45, 309 ff., 327; vom 21. 6. 1974 - IV C 14.74 - BauR 1974, 330 ff., 332; vom 1. 1. 1975 - IV C 38.71 - BauR 1975, 35 ff., 37), sieht Rehbinder durch $\S 50$ nichts an der Gleichrangigkeit aller Planungsziele geändert. Als erste Schritte in diese Richtung können die bereits erwähnte Planungsklausel des $\S 50$ BImSchG sowie die beabsichtigte Festsetzung einer Rangfolge: Vermeidung von Verkehrslärm - aktiver Schallschutz - passiver Schallschutz - im Entwurf eines Verkehrslärmschutzgesetzes angesehen werden. Eingehend dazu Hoppe, Stellnungnahme (FN 83), $44 \mathrm{ff}$.; siehe auch Ders., Das Verkehrslärmschutzgesetz als Beitrag zur Lösung des Konflikts zwischen Straße und Umwelt, in: Straße und Umwelt, hrsg. von Blümel, (1979) 17 ff., 28 f.; Fickert, Quo vadis, Verkehrslärmschutzgesetz? (FN 118). Zum Fehlen einer Vorschrift im Fluglärmgesetz, die zur Prüfung verpflichtet, ob der mit der Festsetzung des Lärmschutzbereiches erstrebte Erfolg auf andere Weise nicht oder nicht rechtzeitig oder nur mit unverhältnismäßigen Mitteln erreicht werden kann, siehe Soell, Schutz gegen Fluglärm (FN 70), 74 f. Wenn solche Planungsgrundsätze und Rangfolgen aufgestellt werden, muß zugleich ihr Charakter als Planungsgrundsatz klargestellt werden, vor allem muß die Abgrenzung zur Enteignung deutlich gemacht werden, siehe dazu Hoppe, Stellungnahme (FN 83), $41 \mathrm{ff}$; ; Ders., Das Verkehrslärmschutzgesetz, a. a. O., 21.

${ }^{163}$ Für eine mehrdimensionale Nutzenoptimierung Rehbinder, Grundlagen des Umweltrechts (FN 87), $37 \mathrm{ff}$.: Das bedeutet, daB mehrere Ziele gleichzeitig verfolgt werden, und zwar so, daß alle optimiert werden. Zur relativen Priorität siehe Feldhaus, Konturen eines modernen Umweltschutzrechts (FN 41), 617; Rehbinder, Umweltrecht (FN 15), 379. 
der fehlenden Diskussion von Planungsalternativen unter dem Gesichtspunkt einer besseren Realisierung von Umweltschutz. Diesem Mangel kann man mit einer Reihe von Leitlinien, Prinzipien und Richtpunkten für die Planungsträger abhelfen, die stärker auf den Umweltschutz zuzuschneiden wären, Grundsätze, die Handlungsmaßstäbe für die planende Verwaltung darstellen und den argumentativen ProzeB der Abwägung anreichern ${ }^{164}$.

$\mathrm{Zu}$ nennen ist das Gebot der planerischen Konfiktbewältigung und damit das Verbot, Umweltkonfikte offenzulassen ${ }^{165}$, und als Ausprägung dieses Grundsatzes: Das Gebot der möglichsten Ausschöpfung des im Planungsrecht vorgegebenen Potentials zur Lösung von Umweltkonflikten ${ }^{168}$, das Verbot der

164 Siehe dazu Hoppe, Bauplanungsrechtliche Grundsätze (FN 111), 133 ff.; Ders., Planungsrechtliche Grundsätze für die Uberplanung gewachsener Strukturen und zur Lösung von Standortkonflikten (FN 30). Diese Grundsätze sind an der Bauleitplanung entwickelt, lassen sich aber auf andere Planungen übertragen.

105 Das Gebot stellt eine Grundforderung an die rechtsstaatliche Planung dar und lautet - in der Formulierung von Weyreuther, Das bebauungsrechtliche Gebot der Rücksichtnahme (FN 30), 5 f. -: Von jedem Plan muß verlangt werden, daß er die ihm zuzurechnenden Konflikte bewältigt. Der Plan darf der Plandurchführung nur überlassen, was diese an zusätzlicher Harmonisierung tatsächlich zu leisten vermag. Dieses Gebot bedeutet mithin, daß der planerischen Entscheidung eine Analyse der vorhandenen und der durch die Planung möglicherweise hervorgerufenen alsbald oder in Zukunft auftretenden Konflikte - innerhalb und außerhalb des Plangebietes vorausgehen muß und daß die Verwaltung das ganze Arsenal der planerischen Mittel durchmustern muß, um solche Konflikte zu bereinigen, zu vermeiden oder angemessen zu lösen, jedenfalls nicht offenzulassen, Hoppe, Bauplanungsrechtliche Grundsätze (FN 111), 136.

${ }^{166} \mathrm{Zu}$ dem Konfliktlösungspotential gehören - z. B. für den Bebauungsplan - alle Festsetzungsmöglichkeiten des in $\S 9$ Abs. 1 BBauG vorgegebenen Katalogs mit Freiflächen, Schutzflächen, Regelungen über Vorkehrungen im Bereiche des Umweltschutzes usw. und die Ausnutzung aller Differenzierungsmöglichkeiten, die die BauNVO in ihrer neuen Fassung gestattet, siehe dazu Hoppe, in: Ernst-Hoppe, OffBauBoR (FN 111), Rdz 124; ferner von Holleben, Die Sicherung bestehender gewerblicher Standorte bei der Ubberplanung dicht bebauter Bereiche (FN 30), 42 ff. Zur Ausschöpfung des Konfliktlösungspotentials gehört auch die angemessene Berücksichtigung von sich aus zukünftigen und überschaubaren Entwicklungen ergebenden Konflikten. Wenn hier nicht entsprechende Sicherheitsmargen und Reserven für künftige Schutzbedürfnisse und kommende Entwicklungen rechtlicher oder tatsächlicher Art vorgesehen sind, 
Verlagerung dieses Konflikts auf gewerbe- und immissionsschutzrechtliche Steuerungsmittel repressiver Art ${ }^{107}$.

obgleich das möglich ist - d. h. wenn sich nicht eine andere Planung als notwendig anbietet oder als unumgänglich aufdrängt -, ist die Planung fehlerhaft, Hoppe, Bauplanungsrechtliche Grundsätze (FN 111), 138.

${ }^{167}$ Sich abzeichnende Konflikte hat die Planung, wenn eben möglich, entweder zu vermeiden oder zu lösen, sie darf nicht auf andere rechtliche Möglichkeiten verweisen, wenn sich diese - nach gehöriger Abwägung - konfliktträchtige Planung - gemessen an dem Gewicht der Notwendigkeit, das sie einbringt - nicht aufdrängt, mindestens aber anbietet oder doch nahelegt, so die Formulierung in BVerwG vom 16. 4. 1971 - IV C 66.67 - BRS Bd. 24 Nr. 166, 257 ff. Das ergibt sich aus dem Vorrang der Konfliktlösung durch vorausschauendes und umweltgestaltendes Planungsrecht vor dem Einsatz rechtlicher Mittel repressiver Natur und von Abwehr- und Schutzrecht wie Umweltschutzrecht, zivilrechtliches Nachbarrecht und ähnliche Rechte eingreifenden und Eingriffe abwehrenden Charakters. Diesen Grundsatz hat das BVerwG präzise im Urteil vom 5. 7. 1974 - IV C 50.72 BVerwGE 45, 309 ff., 327 - zum Ausdruck gebracht: „Das Nebeneinander von Wohn- und Industriegebieten ist in seiner prinzipiellen Anfälligkeit für Konflikte kein Phänomen, das es gewerbe- bzw. immissionsschutzrechtlich $\mathrm{zu}$ steuern gilt, sondern es ist ein solches, das - wo nur irgend möglich - planungsrechtlich vermieden werden sollte." - Das aus dem Gebot der Rücksichtnahme in vorbelasteten Gegenden mit unverträglicher Nutzung abgeleitete Mittel der Duldung von reduzierten Richtwerten (Mittelwerte) z. B. nach der TA Lärm (BAnz. Nr. 137/1968) (zum Rechtscharakter der in der TA Lärm festgelegten Immissionswerte siehe BVerwG vom 17. 2. $1978-1 \mathrm{C}$ 102.76 - BauR 1978, $201 \mathrm{ff}$; zu Mittelwerten: BVerwG vom 12. 12. 1975 - IV C 71.73 - BVerwGE 50, $49 \mathrm{ff}$., 54, unter Berufung auf BVerwG vom 16. 4. 1971 - IV C 2.69 - Buchholz 406.11, § 19 BBauG Nr. 26, S. 16 ff., 23; siehe auch OVG Lüneburg vom 21. 8. 1974 - VII OVG A 107/72 - GewArch. 1975, 275) darf nicht als planungsrechtlich zulässiges Mittel zur Konfliktlösung im Rahmen von Neuplanungen gedeutet werden. Dieser Anpassungseffekt kann nicht durch Planung herbeigeführt werden, wie vielfach angenommen wird.

Neben diesem Verbot des Konflikttransfers auf Mittel des repressiven Umweltschutzes gibt es einen planungsinternen Vorrang von planungsrechtlichen Mitteln der Konfliktvermeidung (durch Trennung von unverträglicher Nutzung, Ausweisung von Pufferzonen, durch gestufte, z. B. terrassenförmige Bauweisen, gegliederte Nutzungsregelungen etc.) vor konfliktlösenden Mitteln; z. B. durch Festsetzung von Vorkehrungen zum Schutz vor schädlichen Umwelteinwirkungen oder zur Vermeidung oder Minderung solcher Einwirkungen ( $\$ 5$ Abs. 2 Ziff. 6 BBauG und $\$ 9$ Abs. 1 Ziff. 24 BBauG). Die Verletzung dieses Grundsatzes dient vielfach dazu, das Verbot der Verlagerung des Konflikttransfers auf gewerbe- und immissionsschutzrechtliche Mittel und das Gebot der Trennung unverträglicher 
Einen weiten Bereich des Umweltschutzes in der Planung deckt das Gebot der Rücksichtnahme auf schutzwürdige Individualinteressen $a^{108}$. Es gebietet - auch und gerade unter Umweltschutzgesichtspunkten - Sicherung und Abmilderung von Umweltkonfikten durch abstufende und damit konfliktdämpfende Festsetzungen ${ }^{169}$. Es verlangt die möglichste Trennung

Nutzung zu umgehen, wobei zusätzlich die Mittelwertrechtsprechung des BVerwG in vorhandenen Lagen stimulierend wirkt. Dabei bleibt allerdings unberücksichtigt, daß durch planungsrechtliche Festsetzungen die Richtwerte, die nach $\$ 66$ Abs. 2 BImSchG verbindlich sind, nicht abbedungen werden können, auch nicht unter Rückgriff auf die Mittelwertrechtsprechung (siehe dazu zutreffend den nwRunderlaß vom 8. 12. 1976, MBl. NW 1976, 2712, auf den sich Stich, Sicherung einer menschenwürdigen Umwelt durch städtebauliche Planung (FN 121), 68 f., bezieht. Ebenso VG Düsseldorf, Urteil vom

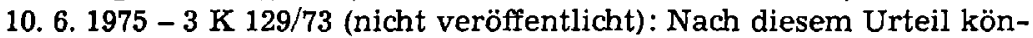
nen immissionsschutzrechtlich festgelegte Immissionsrichtwerte bodenrechtlich nicht abgeändert werden. Zu dem Verbot des Konflikttransfers siehe im einzelnen Hoppe, Bauplanungsrechtliche Grundsätze (FN 111), 139.

${ }^{108}$ In seiner allgemeinen Ausprägung richtet sich das Gebot der Rücksichtnahme auf schutzwürdige Individualinteressen, so gekennzeichnet vom BVerwG vom 25. 2. 1977 - IV C 22.75 - DOV 1977, 752 ff., 753; DVBI. 1977, 722 ff. mit Anm. Schrödter $=$ GewArch. 1977, 307 ff. $=$ BauR 1977, $244 \mathrm{ff} .=$ JuS 1977, $837 \mathrm{ff}$., an den Planer, der Grundstücke verplant, die ohnhin kraft der sie verbindenden "Situation" in einem eigentumsrechtlich-bebauungsrechtlichen Geflecht der Rücksicht aufeinander stehen. Diese Beziehungen werden bei der Planung um- und ausgeformt. Diese Um- und Ausformung ist ein Vorgang der Bewertung dieser Beziehungen durch den Planungsträger. Dieser Vorgang der Bewertung wird durch die Rücksichtnahme gesteuert, so Weyreuther, Das bebauungsrechtliche Gebot der Rücksichtnahme (FN 30), 3. Zu den dogmatischen Grundlagen siehe Hoppe, Bauplanungsrechtliche Grundsätze (FN 111), 142.

${ }_{169}$ Der Grundsatz der Rücksichtnahme - insoweit eine Ausprägung des Verhältnismäßigkeitsgrundsatzes - gestattet nicht nur eine Differenzierung, er fordert sie vielmehr. So genießt tunliche Schonung eines Wohnbereichs durch entsprechende städtebauliche Festsetzung den Vorrang vor der Schadloshaltung für die Aufgabe entwerteten Eigentums, VGH Baden-Württemberg vom 19. 5. 1970 - II 450/66 BRS Bd. $23 \mathrm{Nr}$. 8. Das BVerwG hat in seinem mehrfach erwähnten Urteil vom 16. 4. 1971 eine Differenzierung verlangt, je nachdem, ob die Ausnutzung des vorhandenen Bestands eines betroffenen Grundstücks oder nur die Erweiterungsfähigkeit des vorhandenen Bestands beeinträchtigt wird. Die fehlende Differenzierung kann zum Planungsfehler werden, wenn mangelnde Abstufung und Abmilderung z. B. gegenüber massiven, erdrückenden, Licht und Sonne wegnehmenden Bauvorhaben vorliegen, obgleich die öffentlichen Be- 
unverträglicher Nutzung z. B. von Wohngebieten und umgebungsbelastenden Industriegebieten ${ }^{170}$. Es fordert die Verwirklichung des Vorsorgegedankens in der Planung durch Berücksichtigung von Spielräumen für sich ändernde Umweltschutzanforderungen auch im Hinblick auf nachträgliche Anordnungen nach $\S 17$ BImSchG'171. Dazu gehört schließlich der Grundsatz, daß potentiell konfliktträchtige Emissionen und Immissionen bei der Planung tatsächlich und rechtlich beherrschbar sein müssen ${ }^{172}$.

lange eine so weitgehende Rücksichtnahme zulassen, Hoppe, Bauplanungsrechtliche Grundsätze (FN 111), 143.

${ }^{170}$ Nach dem Urteil des Bundesverwaltungsgerichts vom 5. 7. 1974 IV C 50.72 - BVerwGE 45, 309 ff., 327, gilt der Grundsatz, daß Wohngebiete und die nach ihrem Wesen umgebungsbelastenden Industriegebiete möglichst nicht nebeneinander liegen sollten und daß darin ein wesentliches Element geordneter städtebaulicher Entwicklung (\$ 1 Abs. 1 BBauG) und deshalb ein in der Tat elementarer Grundsatz städtebaulicher Planung gesehen werden muß. Es entspricht der Relativität dieser Gebote, wenn das BVerwG betont, bei dem Gebot der Trennung handle es sich um nicht mehr als um einen ausnahmefähigen Grundsatz. Dasselbe Urteil räumt dem Grundsatz aber eine hohe Rangstufe ein. Dieser Grundsatz entspricht nunmehr § 2 (Planungsgrundsatz) des neuesten Entwurfs des Verkehrslärmschutzgesetzes (FN 118).

${ }^{171}$ Aus dem Gedanken des vorbeugenden und vorsorgenden Umweltschutzes ergibt sich. daß das Immissionsschutzrecht nicht mehr nur als Reaktion auf Störfälle, sondern als Instrument planender Gestaltung eingesetzt werden muß. Das ergibt sich auch aus der Aufnahme der „Belange des Umweltschutzes“ in § 6 Abs. $1 \mathrm{~S}$. 2 BBauG. Der Vorbeugegedanke bei der in die Zukunft weisenden sinnvollen Planung verlangt eine Marge der Dispositionsfreiheit bei - nach neuen wissenschaftlichen Erkenntnissen und einem neuen Stand der Technik - erhöhten Anforderungen an Immissionsrichtwerte. Dies gilt insbesondere im Hinblick auf die Unsicherheit der Durchsetzung von nachträglichen Anordnungen. siehe Hoppe, Wirtschaftliche Vertretbarkeit im Rahmen des BImSchG, Schriftenreihe des BMI H. 8 (1977). 2. Auflage. $36 \mathrm{ff}$ - - vor allem auch im Bereich des vorbeugenden Umweltschutzes, der durchaus - bei neuen wissenschaftlichen Erkenntnissen, etwa im medizinischen Bereich über die Toleranzgrenzen bei Umwelteinflüssen - in schadenabwehrenden Umweltschutz umschlagen kann, Hoppe, Bauplanungsrechtliche Grundsätze (FN 111), $144 \mathrm{f}$.

172 Die Beherrschbarkeit muß durch eine hinreichend konkrete Planung rechtlich abgesichert sein. Die planende Gemeinde muß die Einzelheiten des Immissionsschutzes richtig in den Griff bekommen. Jedenfalls genügt es nicht, auf das Instrumentarium repressiven Umweltschutzes zu vertrauen, insbesondere auch nicht auf die rechtliche Durchsetzbarkeit und tatsächliche Wirksamkeit nachträglicher 
In anderen Bereichen ist an generelle Umweltschutzplanungsklauseln als Auffangtatbestände zu denken, obgleich die Wirkung derartiger Grundsätze umso geringer ist, je weniger konkret und griffig sie sind. Deswegen sollte man sich auch von der Einfügung einer auf Umweltschutz abzielenden Grundsatznorm oder Staatszielbestimmung in der Verfassung zur besseren Gewichtung des Umweltschutzes nicht zuviel versprechen, wenngleich der Stellenwert des Belangs Umweltschutz in der Planung dadurch unterstrichen wird ${ }^{173}$.

Jedenfalls kann sich der Umweltschutz in Planungsprozessen umso besser behaupten und die der Durchsetzung von Umweltbelangen dienliche Kontrolldichte zunehmen, je mehr die bisher relativ offene Abwägung durch Elemente einer stärker zielgerichteten Abwägung mit z.T. quantifizierten Gewichtsvorgaben und konkretisierten Umweltschutzdirektiven bestimmt wird.

\section{Die bessere Vernetzung der Planungen}

Es muß allerdings eine bessere Verzahnung der umweltschutzrelevanten Planungen hinzukommen. Der Umweltschutz ist in den umweltfachspezifischen Plänen wie den Luftreinhalteplänen, den Abfallbeseitigungsplänen, den Landschaftsprogrammen, Landschaftsrahmenplänen und Landschaftsplänen sowie den forstlichen Rahmenplänen unmittelbar Gegenstand und Primärziel dieser Planung. In anderen Gesamt- oder Fachplanungen ist er hingegen restriktive Rahmenbedingung. Utber die Verknüpfung dieser Pläne untereinander, über ihre Verbindlichkeit, ihre Auswirkungen und ihre Einpassung in die Gesamtplanung oder Fachplanungen ist wenig nachgedacht worden ${ }^{174}$.

Als für dieses Regelungsdefizit exemplarisch kann die Landschaftsplanung ${ }^{175}$ nach dem Bundes-Naturschutzgesetz und

Auflagen. Eine Planung, deren Abwägung erst unter Berücksichtigung des Einsatzes dieses Instruments „stimmig“ wird, ist fehlerhaft, Hoppe, Bauplanungsrechtliche Grundsätze (FN 111), 145.

${ }^{173}$ Zur Staatszielbestimmung "Umweltschutz" siehe oben I. 2. Im Hinblick auf die Staatszielbestimmung hat Scheuner, Staatszielbestimmungen (FN 157), 339, darauf hingewiesen, daß der Umfang der Bindung der politischen Funktionen durch Staatszielbestimmungen nicht überschätzt werđen dürfe.

174 So zu Recht Schmidt-Aßmann, Umweltschutz in der Raumplanung (FN 43), 4.

175 Die Landschaftsplanung ist eine der wenigen Planungen, die als eine ökologisch ausgerichtete, querschnittsorientierte Planung angesehen werden kann, siehe Umweltgutachten 1978 (FN 1) Tz $1202 \mathrm{ff}$. 
entsprechenden landesrechtlichen Vorschriften ${ }^{176}$ und deren

(Landschaftspflege und Naturschutz), Tz 1312 ff. (Aufgabe und Ablauf der Landschaftsplanung); siehe dazu Soell, Neuere Entwicklungen des Naturschutz- und Landschaftspflegerechts in der Bundesrepublik Deutschland, Vortrag, gehalten auf dem Symposium der Alexander-von-Humboldt-Stiftung „Neuere Entwicklungen im Offentlichen Recht (Völker-, Staats- und Verwaltungsrecht) in internationaler und rechtsvergleichender Sicht", vom 10. bis 14. Oktober 1978; Schmidt-Aßmann, Die Grundsätze des Naturschutzes und der Landschaftspllege (FN 160), $1 \mathrm{ff}$.

Für die Planung besonders wichtig sind die in $\S 1$ BNatSchG geregelten Ziele des Naturschutzes und der Landschaftspflege mit den in $\S 1$ Abs. 1 BNatSchG geregelten Handlungsaufträgen des Naturschutzes und der Landschaftspflege, dem Abwägungsgebot des $\S 1$ Abs. 2 BNatSchG, der Planungsnorm des $\$ 2$ Abs. 1 BNatSchG mit Grundsätzekatalog (zu der Struktur der Vorschriften siehe SchmidtAßmann, Die Grundsätze des Naturschutzes und der Landschaftspflege, a. a. O., $2 \mathrm{ff}$., $4 \mathrm{f}$., $7 \mathrm{ff}$.), die Vorschriften über die Landschaftsplanung ( $\S \S 5 \mathrm{ff}$. BNatSchG). Für die Fachplanung gilt das Ausgleichsgebot des $\S 8$ Abs. 4 BNatSchG. Dazu, daß $\S 8$ BNatSchG, der Bestimmungen über die Voraussetzungen und die Erforderlichkeit der Ausgleichspflicht, die Ausgeglichenheit eines Eingriffs und die verfahrensmäßige Handhabung enthält, für die Planung und Planfeststellung nach Straßenrecht die wichtigste Vorschrift ist, siehe Fickert, Der Verkehrswegebau im Lichte des neuen Naturschutz- und Landschaftspflegerechts, BayVBl. 1978, 681 ff., 685 ff. - Als Oberziel von Landschaftspflege und Naturschutz wird im BNatSchG die Sicherung und Entwicklung optimaler und nachhaltiger materieller wie immaterieller Leistungen der Naturausstattung von Landschaftsräumen für die Gesellschaft gesehen. Dies umfaßt die folgenden ökologischen und gestalterischen Teilziele, die sich gegenseitig ergänzen und auf verschiedenen Ebenen und unter verschiedenen Aspekten bedingen: Sicherung und Entwicklung einer optimalen ökologischbiologischen und strukturell-visuellen Vielfalt der Landschaftsräume; Sicherung ökologisch wertvoller Räume durch Schaffung eines integrierten Systems von Schutzgebieten (Natur- und Landschaftsschutzgebiete, Naturdenkmale, geschützte Landschaftsbestandteile, Wald- und Wasserschutzgebiete) sowie Schutz der wildwachsenden Pflanzen und wildlebenden Tiere (Artenschutz); Sicherung und Schaffung eines optimalen Nutzungsverbundes unter ökologischen und strukturell-visuellen Gesichtspunkten mit einem Minimum gegenseitiger Beeinträchtigungen der Nutzungen (evtl. unter Einsatz von Störeffekte minimierenden Schutz- und Pflegemaßnahmen) bzw. einem Maximum gegenseitiger Förderungswirkungen (Umweltgutachten 1978 [FN 1] Tz 1206).

176 Gesetz über Naturschutz und Landschaftspflege (Bundes-Naturschutzgesetz - BNatSchG) vom 20. Dezember 1976 (BGBl. I S. 3573); Hessisches Landschaftspflegegesetz vom 4. 4. 1973 (GVBl. S. 126); Schleswig-Holsteinisches Landschaftsgesetz vom 16. 4.1973 
Verknüpfung mit der Bauleitplanung - als Beispiel für die Gesamtplanung - und mit der verkehrswegerechtlichen Planung - als Beispiel für die Fachplanung - angeführt werden $^{177}$. Die Landschaftsplanung vollzieht sich nämlich als querschnittsorientierte Planung, und zwar als Beitrag zur Gesamtplanung (wie Raumordnung von Bund und Ländern, Landesund Regionalplanung, Bauleitplanung der Gemeinden), als Mitwirkung in der Fachplanung (wie Agrar- und Forstplanung, Verkehrsplanung, Wasserwirtschaftsplanung und als sektorale Fachplanung, und zwar als Fachplanung Naturschutz und als Fachplanung freiraumbezogene Erholung ${ }^{178}$.

(GVOBl. SchlH S. 122), geändert durch Gesetz vom 3. 12. 1977 (GVOBl. SchlH S. 507); Rheinland-Pfälzisches Landespflegegesetz vom 14. 6. 1973 (GVBl. S. 147), geändert durch Gesetz vom 12. 11. 1974 (GVBl. S. 521); Bayerisches Naturschutzgesetz vom 27. 7. 1973 (GVBl. S. 437), zuletzt geändert durch Gesetz vom 23. 7. 1976 (GVBI. S. 294); Nordrhein-Westfälisches Landschaftsgesetz vom 18. 2. 1975 (GVNW S. 190); Baden-Württembergisches Naturschutzgesetz vom 21. 10. 1975 (GBl. S. 654), geändert durch Gesetz vom 10. 2. 1976 (GBl. S. 99). Zur Entstehungsgeschichte des BNatSchG siehe Müller-Oldenburg, Das neue Bundes-Naturschutzgesetz, NJW 1977, 925; Stein, Die neue Situation im Naturschutzrecht im Bund und in den Ländern, Jahrbuch für Naturschutz und Landschaftspflege 25 (1976), 21 ff.; früher bereits dazu Stich, Notwendigkeit und Inhalt eines modernen Naturschutzund Landschaftspflegerechts, DVBl. 1972, $201 \mathrm{ff}$;; Kolodziejcok, Das. neue Naturschutzrecht des Bundes, Jahrbuch Naturschutz und Landschaftspflege 25 (1976), $10 \mathrm{ff}$.; Schmidt, Der Standort der Landschaftsplanung und ihr Verhältnis zur Landesplanung, Regional- und Bauleitplanung, Landschaft und Stadt 1975, 173 ff.; Kolodziejcok-Rekken, Naturschutz, Landschaftspflege, Kommentar (Loseblatt, Stand 1978); Emonds und Kolodziejcok, Grundzüge des neuen Bundes-Naturschutzgesetzes, Natur und Landschaft 1977, $35 \mathrm{ff}$.

${ }_{177} \mathrm{Zu}$ der Verknüpfung mit der Verkehrswegeplanung siehe Fikkert, Der Verkehrswegebau im Lichte des neuen Naturschutz- und Landschaftspflegerechts (FN 175), 681 ff. m. w. N.; zur Verknüpfung mit der Bauleitplanung Gerschlauer, Landschaftsplanung der Gemeinde und Bauleitplanung, DVBl. 1979, $601 \mathrm{ff}$.

${ }^{178}$ Olschowy, Die Landschaftsplanung - Methodik und Auswertung, in: Olschowy (Hrsg.), Natur- und Umweltschutz in der Bundesrepublik Deutschland (1978), $818 \mathrm{ff} ., 819 \mathrm{f}$. Zum gegenwärtigen Stand der Landschaftsökologie im Hinblick auf die Leistungen, die sie für die Planung erbringen kann, Olschowy, Landschaftsökologische Kriterien der Planung (FN 65), $291 \mathrm{ff}$.

Zu den verschiedenen Plänen siehe Olschowy, Landschaftsplanung, a. a. O., 818: Landschaftsprogramme: In ihnen werden die überörtlichen Erfordernisse und Maßnahmen zur Verwirklichung der Ziele des Naturschutzes und der Landschaftspflege für den Bereich eines Landes dargestellt (\$5 Abs. 1 BNatSchG); Landschaftsrahmenpläne: In ihnen werden die überörtlichen Erfordernisse und Maßnahmen 
Sowohl von seiten der gemeindlichen Planungsträger als auch aus der Sicht der Verkehrsplaner wird Klage darüber geführt, daß das Verhältnis dieser Planungen zueinander im Gesetz unklar geregelt sei. Es fehlt an der Integration der Landschaftsplanung in die Landesplanung ${ }^{179}$.

zur Verwirklichung der Ziele des Naturschutzes und der Landschaftspflege für Teile des Landes dargestellt ( 5 Abs. 1 BNatSchG); Landschaftspläne: In ihnen werden die örtlichen Erfordernisse und Maßnahmen zur Verwirklichung der Ziele des Naturschutzes und der Landschaftspflege mit Text, Karte und zusätzlicher Begründung dargestellt, sobald und soweit dies aus Gründen des Naturschutzes und der Landschaftspflege erforderlich ist; Landschaftspflegerische $B e$ gleitpläne: In ihnen werden vom Planungsträger einer Fachplanung die zum Ausgleich eines Eingriffs erforderlichen Maßnahmen des Naturschutzes und der Landschaftspflege in Text und Karten dargestellt, soweit dies nicht im einzelnen im Fachplan vorgenommen wird; der Begleitplan ist Bestandteil des Fachplans ( $\S 8$ Abs. 4 BNatSchG); Grünordnungspläne: In ihnen werden die örtlichen Ziele der städtebaulichen Grünordnung, in der Regel im Rahmen der Bauleitplanung (vornehmlich im Zusammenhang mit dem Bebauungsplan), dargestellt oder festgesetzt.

179 Gerschlauer, Landschaftsplanung der Gemeinde und Bauleitplanung (FN 177), 601; Fickert, Der Verkehrswegebau im Lichte des neuen Naturschutz- und Landschaftspflegerechts (FN 175), 684; Soell, Neuere Entwicklungen des Naturschutz- und Landschaftspflegerechts (FN 175), 7; Stein, Die neue Situation im Naturschutzrecht (FN 176), 23; Kölble, Staatsaufgabe Umweltschutz (FN 7), 480; Schulz, Landschaftsplanung und Regionalplanung, in: Olschowy (Hrsg.), Natur- und Umweltschutz in der Bundesrepublik Deutschland (1978), 827 ff., 831. Zur Bedeutung der Landschaftsplanung für Gesamtplanungen und für Fachplanungen siehe Schmidt-Aßmann, Die Grund:sätze des Naturschutzes und der Landschaftspflege (FN 160), 7 f. Zur Einbindung der Landschaftsplanung in die Landesplanung siehe Schmidt, Inhalt und Methodik des Landschaftsplans und seine Einfügung in die Landes-, Fach- und Bauleitplanung; Bauer, Trägerschaft, Verfahren und Wirkung der Landschaftsplanung, beide in: Material aus den Lehrgängen Nr. 114 und Nr. 115 des Deutschen Volksheimstättenwerks, Landesverband Nordrhein-Westfalen 1976; Stich, Die Rechtsgrundlagen einer umweltschutzwirksamen Gemeinde- und Regionalplanung und ihres Vollzugs, Natur und Landschaft 1974, 3 ff.; Niemeier, Die Integration der Landschaftsplanung in die Gesamtplanung, Innere Kolonisation 1974, 64 ff.; Der Landschaftsplan nach dem Nordrhein-Westfälischen Landschaftsgesetz, hrsg. von dem Minister für Ernährung, Landwirtschaft und Forsten des Landes Nordrhein-Westfalen (1977); Schmidt-Aßmann, Umweltschutz in der Raumplanung (FN 43), 1 ff.; Ders., Die Grundsätze des Naturschutzes und der Landschaftspflege (FN 160), $7 \mathrm{ff}$. 
Es ist hier nicht im einzelnen zu erörtern, wie dieser für die Realisierung des Umweltschutzes nachteilige Mangel an Integration und Koordination ${ }^{180}$ behoben werden kann. Grundsätzlich müssen die Utberlegungen darauf abzielen, die rein fachbezogene, sich weitgehend im Binnenraum einer Fachplanung "abschottende" Abwägung von sektoralen Belangen auszuweiten auf die - auch verfahrensmäßig abgesicherte - abwägende Einbeziehung von sogenannten „externen“ Leitsätzen anderer Bereiche, nicht zuletzt des Umweltschutzes ${ }^{181}$. Die -

$180 \mathrm{Zu}$ diesem Mangel siehe auch Rheingutachten (FN 1) Tz 355.

181 Im Anschluß an das Urteil des BVerwG vom 14. Februar 1975 IV C 21.74 - BVerwGE 48, 56 ff., 62 f., das zwischen dem ,eigentlichen Ziel" der sektoralen Fachplanung und den "gewichtigen abwägungserheblichen Belangen" des Immissionsschutzes unterscheidet, wobei die „optimale" Erfüllung der spezifischen Aufgaben gerade des Fachbereichs im Mittelpunkt stehe, die „gewichtigen abwägungserheblichen Belange" des Umweltschutzes hingegen nicht in den Vorgang einer mehrdimensionalen Optimierung einbezogen werden, ist im Hinblick auf diese Belange von "externen Planungsleitsätzen" die Rede, so z. B. bei Korbmacher, Straßenplanung und verwaltungsgerichtliche Planungskontrolle (FN 83), 2, eine Bezeichnung, die die Integration dieser Belange nicht gerade fördert. - Vor allem muß eindeutig geregelt sein, in welchem Verhältnis die Normenkomplexe der verschiedenen Planungen und umweltschutzrelevante Regelungen zueinander stehen. Das völlig offene Verhältnis von $\S 17 \mathrm{Abs} .4$ Bundes-Fernstraßengesetz (Auflagenregelung bei der Fernstraßenplanung) zu \& 41 BImSchG (Lärmschutz beim Straßenbau) ist ein Musterbeispiel für solche Regelungsmängel. Das Verhältnis von $\S 41$ BImSchG zu $\S 17 \mathrm{Abs.} 4$ FStrG ist immer außerordentlich umstritten gewesen. Während einerseits in der Regelung der $\$ \S 41,42$ BImSchG, die nach $\S 17$ Abs. 4 S. 3 FStrG „unberührt" bleiben, eine Spezialregelung zu $\$ 17$ Abs. 4 FStrG gesehen wird mit der Folge, daß im Bereich des Lärmschutzes $\S 17$ Abs. 4 FStrG nur die verfahrensrechtliche Grundlage für den Erlaß von Schutzauflagen abgeben soll, während die materiell-rechtlichen Bestimmungen als durch das BImSchG ausgefüllt angesehen werden (so, zumindest im Ergebnis, Kastner, Straße und Autobahn 1974, 215; Reinhardt, Lärmschutzmaßnahmen bei Planung und Bau von Fernstraßen, NJW 1974, 1226 ff., 1226; Fickert, Straßenplanung und Straßenbau unter der Rechtsgeltung des BImSchG [FN 150], 1; Nedden, Immissionsschutz beim Straßenbau, DVBl. 1977, 265 ff., 267), bewertet Korbmacher, Straßenplanung und verwaltungsgerichtliche Plankontrolle, a. a. O., 7, diese Regelung völlig anders. Sie werde weder durch das angeblich speziellere Immissionsschutzgesetz verdrängt noch im Verhältnis zu §41 BImSchG in den Rang einer bloßen Verfahrensvorschrift ohne eigenen materiellen Gehalt verwiesen. Sie habe vielmehr überhaupt keine konkurrierende Entsprechung in den erörterten planungsrechtlichen Vorschriften des BImSchG, was $\S 17$ Abs. 4 S. 3 FStrG 
wenn auch verbesserungsbedürftigen - Naturschutzklauseln in einer Reihe von Fachplanungsgesetzen geben hierfür ein positives Beispiel ${ }^{182}$.

Schließlich ist $\mathrm{zu}$ untersuchen, ob nicht umfassende Koordinationsverfahren wie das Raumordnungsverfahren, das alle Länder sehr variantenreich - mit Ausnahme von NordrheinWestfalen - eingeführt haben, zur besseren Koordination und Integration von Umweltschutzbelangen als "helfende Planung“ beitragen können ${ }^{188}$. .

übrigens auch voraussetzen müsse, wenn er regle, daß die $\S \S 41$ und 42 BImSchG "unberührt" blieben; siehe dazu Hoppe, Stellungnahme (FN 83), $35 \mathrm{ff}$. In der Neufassung des VLärmSchGE heißt es in \$1 Abs. 2: „Die Lärmvorsorge sowie die Lärmsanierung an Straßen werden ausschließlich durch dieses Gesetz geregelt."

${ }_{182}$ Es gibt eine Reihe solcher Planungsklauseln, in denen ausdrücklich auf die Belange des Naturschutzes und der Landschaftspflege verwiesen wird, so z. B. § 37 Abs. 2 Flurbereinigungsgesetz in der Fassung vom 16. 3. 1976 (BGBl. I S. 546) für die Neugestaltung des Flurbereinigungsgebietes. Gleiches gilt für die Planfeststellung nach dem Abfallbeseitigungsgesetz in der Fassung vom 5. 1. 1976 (BGBl. I S. 31), dessen $\$ 2$ die Belange des Natur- und Landschaftsschutzes in zwei Spezialklauseln und in einer Generalklausel regelt. Siehe hierzu auch die Naturschutzklauseln in $\$ 1$ Abs. 2 des Landbeschaffungsgesetzes vom 23. 2. 1957 (BGBl. I S. 134) und des $\S 1$ Abs. 3 des Schutzbereichsgesetzes vom 7. 12. 1956 (BGBl. I S. 899), die Land beanspruchende Planung zu militärischen $\mathrm{Zwecken}$ betreffen. Schließlich ist hierher $\S 6$ Abs. 2 S. 1 des Luftverkehrsgesetzes in der Fassung vom 20. 12. 1976 (BGBl. I S. 3574) zu rechnen, weil die Genehmigung der Flugplätze ein Vorgang umfassender Planung ist. Siehe dazu Schmidt-Aßmann, Die Grundsätze des Naturschutzes und der Landschaftspflege (FN 160), 8, der bemerkt, daß nicht alle dieser sogenannten Naturschutzklauseln die spezielle Wirkungsweise der in $\S 2$ BNatSchG ausdrücklich benannten Belange des Naturschutzes und der Landschaftspfiege deutlich genug herausstellen.

${ }^{183}$ Siehe dazu Raumordnungsverfahren als Instrument zur Durchsetzung raumordnerischer Ziele, Bundesforschungsanstalt für Landeskunde und Raumordnung / wiss. Red., Einführung zu: Raumordnungsverfahren als Instrument zur Durchsetzung raumordnerischer Ziele, Informationen zur Raumentwicklung 1979, $71 \mathrm{f}$., mit Länderberichten von Scheurer, Das Raumordnungsverfahren nach badenwürttembergischem Landesgesetz, 105 ff.; Buchner, Das Raumordnungsverfahren nach bayerischem Landesplanungsrecht, $115 \mathrm{ff}$.; Frommhold, Das Raumordnungsverfahren nach hessischem Landesplanungsrecht, 127 ff.; Schnitker, Das Raumordnungsverfahren nach dem niedersächsischen Landesplanungsgesetz, 141 ff.; Depenbrock, Landesplanung ohne Raumordnungsverfahren? - Stellungnahme aus nordrhein-westfälischer Sicht, 149 ff.; Schefer, Raumplanerisches Verfahren in Rheinland-Pfalz, 157 ff.; Koch/Menke, Das Raumord- 


\section{Abkoppelung von Einzelgenehmigungen und Umweltschutz- planung}

Aber nicht nur die Vernetzung der Planungen untereinander ist verbesserungsbedürftig. Das Verhältnis von umweltschutzrelevanten Einzelgenehmigungen, beispielsweise nach dem BBauG, dem BImSchG und dem Atomgesetz zur Planung erscheint nicht voll geklärt. Den Anlagegenehmigungsverfahren einerseits und der Planung andererseits sollten nur diejenigen Funktionen zugewiesen werden, die sie nach ihrer Anlage sachgemäß bewältigen können, durch die sie also nicht strukturell überbeansprucht sind ${ }^{184}$.

Dieser Grundgedanke läßt sich in mehreren Forderungen entfalten:

Die erste Forderung gilt der Entkoppelung der Anlagegenehmigungsverfahren von planerischen Fragen der Standortwahl, d. h. die Trennung der Standortplanfeststellung von der Anlagengenehmigung ${ }^{185}$ möglicherweise auf der Basis einer landes-

nungsverfahren nach dem schleswig-holsteinischen Landesplanungsgesetz, $169 \mathrm{ff}$., und kritischen Analysen von Losch, Das Raumordnungsverfahren im Widerstreit der Meinungen, $98 \mathrm{ff}$., und Erbguth, Das Raumordnungsverfahren als förmliches Sicherungsmittel - ein Uberblick, 173 ff. m. w. N., 185; Zoubek, Das Raumordnungsverfahren, Eine rechtsvergleichende Untersuchung des förmlichen landesplanerischen Abstimmungsinstrumentes, Beiträge zum Siedlungsund Wohnungswesen und zur Raumplanung (Bd. 45) (1978); Brenken, Weiterentwicklung des Raumordnungsverfahrens? in: Festschrift für Werner Ernst (1980), 47 ff.; Hesse, Zum Bedeutungsverlust der Raumordnungspolitik (FN 76).

${ }^{184}$ Steiger, Umweltschutz durch planende Gestaltung (FN 8), 135, spricht von einer strukturellen Uberbeanspruchung des Uberwachungsrechts, wenn es in Einzelfallentscheidungen allgemeine Interessen - etwa zwischen Umweltschutz und wirtschaftlicher Entwicklung - ausgleichen soll.

185 Siehe dazu grundlegend und umfassend Blümel, Die Standortvorsorgeplanung (FN 12), $301 \mathrm{ff}$; Friauf, Das Standortplanfeststellungsverfahren als Rechtsproblem, Rechtsfragen des Genehmigungsverfahrens von Kraftwerken, Veröffentlichungen des Instituts für Energierecht an der Universität zu Köln (H. 41/42) (1978), 63 ff.; Lukes-Vollmer-Mahlmann, Grundprobleme zum atomrechtlichen Verwaltungsverfahren - Planfeststellungsverfahren, US-amerikanisches Genehmigungsverfahren, Schriftenreihe Recht und Technik 3 (1974); Ernst, Zur staatlichen Verantwortung (FN 9), 6 f., stellt ebenfalls ein Defizit an Standortplanung bei "sperrigen Vorhaben“ fest und ein Vorherrschen ordnungsrechtlicher Gesichtspunkte; Ossenbühl, Aktuelle Probleme des Umweltschutzrechts (FN 19), 3, kenn- 
planerischen Standortvorsorgeplanung ${ }^{186}$. Auf diese Weise

zeichnet das BImSchG ebenso wie das Atomgesetz in bezug auf die Anlagengenehmigung als ein bloßes Gefahrenabwehrgesetz, das auf planerische Konzeptionen und Ambitionen verzichte. Aus dieser Grundkonzeption des Gesetzes ergäben sich schwerwiegende Konsequenzen und konzeptionell bedingte Mängel. Das Atomgesetz gebe keine Auskunft über die richtige Standortwahl, welche in der Praxis als das „Schlüsselproblem" gelte und als "Schicksalsfrage der Anlagengenehmigung überhaupt" apostrophiert worden sei (so von Friauf, Das Standortplanfeststellungsverfahren als Rechtsproblem, a. a. O., $63 \mathrm{ff}$; Blümel, Die Standortvorsorgeplanung [FN 12], $301 \mathrm{ff}$.). Dies bedeute: Die Standortfrage von Kraftwerken, einschließlich Kernkraftwerken, sei nach noch geitendem Recht eine Entscheidung, die von den interessierten Versorgungsunternehmen getroffen werde, und zwar jeweils ad hoc, ohne übergreifende Koordination und Konzeption, ohne Abstimmung mit anderen Planungen und Vorhaben von allgemeiner Bedeutung. Die Diskussion um die Standortvorsorge des Staates bei der Errichtung von Kraftwerken sei zwar bislang intensiv geführt worden, habe aber noch keine entsprechenden Früchte gezeitigt. Rengeling, Umweltschutz im Verwaltungsverfahrens- und Verwaltungsprozeßrecht, JZ 1978, 457, verlangt, daß die den Einzelgenehmigungen zugrunde liegenden Planungsstrukturen, die sachangemessen nicht durch Planungsnormen mit Finalprogrammen, sondern durch herkömmliche Verwaltungsrechtsnormen mit Konditionalprogrammen eine inadäquate Regelung erfahren hätten, stärkere Berücksichtigung fänden. Rehbinder, Umweltrecht (FN 15), 393, weist darauf hin, daß Einzelgenehmigungen die Gesamtsituation des Umweltmediums nicht erfassen könnten und kein sachadäquates Verteilungsverfahren garantierten. Schmitt-Glaeser, Planende Behörden, protestierende Bürger und überforderte Richter, Rechtliche Aspekte zur Genehmigung von Kernkraftwerken, Landk. 1976, 443 f., nennt das Genehmigungsverfahren nach $\S 7$ Abs. 2 Atomgesetz ein "Verwirrspiel um Koordination und Partizipation“. - Die Mißlichkeiten zeigen sich auch im Rechtsschutz durch die Aufspaltung der sofortigen Vollziehung von atomrechtlichen Teilentscheidungen, bei denen die angeordnete sofortige Vollziehung hinsichtlich der mit der Teilgenehmigung gestatteten Baumaßnahmen bestätigt, die aufschiebende Wirkung jedoch insoweit wiederhergestellt wurde durch gerichtlichen Beschluß, als die Genehmigung die Eignung des gewählten Standortes feststellt und ein positives vorläufiges Gesamturteil über das Kraftwerksvorhaben einschließt, siehe Verwaltungsgericht Karlsruhe, Beschluß vom 18. 8. 1978, Energiewirtschaftliche Tagesfragen 1978, 606; kritisch hierzu Büdenbender-Mutschler, Zur Aufspaltung der sofortigen Vollziehung von atomrechtlichen Teilentscheidungen, Energiewirtschaftliche Tagesfragen 1979, $333 \mathrm{ff}$.

186 Siehe dazu Brocke, Rechtsfragen der landesplanerischen Standortvorsorge für umweltbelastende Großanlagen, Beiträge zum Sied- 
könnte auch die Frage des für den Umweltschutz sehr bedeutsamen Standort-Recyclings adäquat gelöst werden ${ }^{187}$.

Wegen des unzureichenden - auf Einzelfallentscheidungen bezogenen - Normansatzes des BImSchG ist die Forderung erhoben worden: Weg vom einzelfallbezogenen „Windhundverfahren" $z u$ einer mit der Standortentscheidung verbundenen ressourcenverteilenden Planung z. B. in bezug auf die Luft, eventuell durch kooperative Rechtsformen wie regionale „Luftverbände" 188189 .

lungs- und Wohnungswesen und zur Raumplanung (Bd. 53) (1979). Im Entwurf eines Gesetzes über die Planung und Sicherung von Standorten für Kernkraftwerke vom 12. Juli 1978 sieht der Bundesminister für Raumordnung, Bauwesen und Städtebau eine Ergänzung des Raumordnungsgesetzes vor, die eine Verpflichtung der Länder zur landesweiten landesplanerischen Darstellung von Standorten für Kraftwerke enthält. Die Darstellung soll in Form der allgemein in der Landesplanung üblichen Programme oder Pläne erfolgen; dabei sind auch die wesentlichen Gesichtspunkte für die Standortwahl anzugeben.

${ }^{187}$ Siehe dazu Dreyhaupt, Standortvorsorge für Energieanlagen Ein Element zur langfristigen Sicherung der Energieversorgung (Vortrag), Gesellschaft für Reaktorsicherheit (GRS) mbH, GRS-Fachgespräch 1978: Sicherheitsbehälter von Kernkraftwerken (1978) (hektographiert), 15, 21. Standort-Recycling ermöglicht, daß eine echte Uberlappung von Neubau und Abbruch am selben Standort möglich ist. Standort Recycling bedeutet, daß wir nicht immer mehr und neue Standorte für Kraftwerke zu sichern brauchen, sondern daß wir heute Standorte für eine größere spezifische Kapazität sichern müssen, d. h. für etwa 3 bis 5 Blöcke oder 4000 bis 5000 Megawatt (MW), wobei eine Grenze sicherlich durch die Möglichkeit der Abwärmeableitung markiert wird. Die Reservierung größerer Flächen hat aber auch den Vorteil, daß für Kraftwerke vorgesehene Standorte bei schneller oder anders verlaufender technologischer Entwicklung für andere Energieerzeugungsanlagen genutzt werden können, insbesondere etwa zur Kohleumwandlung.

${ }^{188}$ Rohde, Staatsaufgabe Umweltschutz: Probleme der Praxis, DOV 1979, 485, hält den Normansatz des BImSchG wegen seiner Beschränkung auf Einzelfallregelungen für unzureichend; der einzelfallorientierte Regelungsansatz müßte überprüft werden. Globale Regelungszusammenhänge könnten mit dem Normansatz von Einzelfallentscheidungen nicht gelöst werden (a. a. O., 487). Rohde spricht sich für eine mit der industriellen Flächenplanung parallellaufende Angebotsplanung für die Ressource Luft aus (a. a. O., 487). Er sieht vor allem kooperative Regelungsformen als geeignete Sicherungsmittel an, z. B. die Bildung eines regionalen „Luftverbandes“ (a. a. O., $488 \mathrm{f}$.).

189 Ein Mischsystem verwischt - wie in dem Entwurf zum Zweiten Gesetz zur Anderung des BImSchG vorgesehen (BT-Drucks. 8/2751 
Schließlich sollten "sperrige“ Großvorhaben wegen ihrer Umweltrelevanz, die eine Planung mit umfassendem Interessenausgleich unter Einbeziehung der Belange des Umweltschutzes fordert, nicht durch das Planungssurrogat der Einzelgenehmigungstatbestände der $\S \S 34,35$ BBauG „ersatzgeplant" wer$\operatorname{den}^{100}$.

vom 11. 4. 1979) - zwischen - durch Bezugnahme auf Belastungsgebiete nach $\S 44$ Abs. 2 BImSchG - festgesetzten Immissionsrichtwerten mit einer Vermutungsklausel für die Unschädlichkeit von Maßnahmen in Belastungsgebieten und mit einem Verschlechterungsgebot zugunsten besonders empfindlicher Tiere, Pflanzen und anderer Sachgüter in Bereichen außerhalb der Belastungsgebiete einerseits mit speziellen Abwägungsklauseln andererseits, die es den Ländern ermöglichen sollen, außerhalb von Belastungsgebieten Ausnahmen von dem Verschlechterungsgebot zuzulassen, wenn an der Erschließung von Industriestandorten ein überwiegendes öffentliches Interesse besteht, das Verhältnis von immissionsschutzrechtlichen Anlagegenehmigungen und der Raumplanung. Hierzu siehe die Kritik von Breuer, Urteilsanmerkung zum Urteil des BVerwG vom 17. 2. 1978 - 1 C 102.76 -, DVBl. 1978, 598-601" Ders., Die Entwicklung des Umweltschutzrechts seit 1977, NJW 1979, 1868; kritisch auch Dienes, Die Entwürfe zur Novellierung des Immissionsschutzrechts (FN 74), 3 ff.

Ähnlich kompliziert sind die weiteren Regelungen: Eine Sanierungsklausel, die in belasteten Gebieten eine Genehmigungserteilung ermöglichen soll, wenn durch das Vorhaben oder die Maßnahme im Zusammenhang mit dem Vorhaben eine Verbesserung der Luftbeschaffenheit eintritt; sowie eine Luftreinhalteplanklausel, die in belasteten Gebieten eine Genehmigungserteilung ermöglichen soll, wenn an der Durchführung des Vorhabens ein überwiegendes öffentliches Interesse besteht und in einem Luftreinhalteplan gemäß $\S 47$ BImSchG Maßnahmen zur Verbesserung der Luftbeschaffenheit vorgesehen sind (Entwurf neu einzufügender $\$ \S 6 \mathrm{a}-6 \mathrm{c}$ BImSchG). Die Anlage des Gesetzes gestattet, generelle Planungsfestsetzungen, die im Interesse des Umweltschutzes getroffen sind, durch Ausnahmeregelungen zu unterlaufen.

Siehe dazu auch die Entscheidung des OVG Berlin vom 2. 5. 1977 OVG II B 2.77 - DVBl. 1977, 901 ff., wonach die Errichtung einer nach den $\S \S 4 \mathrm{ff}$. BImSch G genehmigungsbedürftigen Anlage, z. B. eines Kraftwerkes, in einem Waldgelände, das durch die Bauleitplanung als Waldgebiet und als Fläche für die Forstwirtschaft ausgewiesen ist, nur im Wege einer förmlichen Änderung der Bauleitplanung, nicht aber durch die Erteilung einer Befreiung nach § 31 Abs. $2 \mathrm{~S} .1$ BBauG ermöglicht werden kann.

${ }^{100}$ Gegen die Genehmigung von Kernkraftwerken und anderen industriellen Anlagen nach $\$ 35$ Abs. $1 \mathrm{Nr} .4$ und 5 BBauG Hoppe, Zur planungsrechtlichen Zulässigkeit von Kraftwerken und sonstigen Großvorhaben im „Außenbereich“, NJW 1978, 1229 ff.; für diese 


\section{Die Verbesserung des Umweltschutzes in den Planungs- leitbildern}

Die Bemühungen um quantifizierte und konkretisierte Unter- und Teilziele des Umweltschutzes machen leicht vergessen, da $B$ Planungsleitbilder der Gesamtplanungen und der Fachplanungen, wie überhaupt Leitziele der verschiedenen Politiken, die als Oberziele diese Planbereiche und Politiken bestimmen, erheblichen Einfluß auf den Umweltschutz haben, auch wenn ihre Operationalisierung vielfach nicht möglich ist. Da sie planerisches Verhalten steuern und sich bei der Gewichtung von Belangen auswirken, beeinflussen sie die Umwelt auf allen Wirkungsebenen.

\section{Wachstumsbegrenzung als Staatsaufgabe?}

Es liegt auf der Hand, daß eine wachstumsorientierte Politik, die auf quantitative Expansion abzielt, sozio-ökonomische Aktivitäten der 1 . Wirkungsebene vermehrt und mit ihren Einund Auswirkungen auf die 2. und 3. Wirkungsebene die Probleme des Umweltschutzes steigert. Deswegen geht die Umweltschutzdiskussion mit der Forderung nach einer Wandlung der sozialen und politischen Zielvorstellungen einher. Sie gipfelt in der Charakterisierung der Wachstumsbegrenzung im Umweltschutzinteresse als Staatsaufgabe - so Saladin - gewissermaßen das Gegenbild zu der Vorstellung von einem Verfassungsauftrag staatlicher Wachstumsvorsorge ${ }^{191}$. Saladin cha-

Genehmigung hingegen Römermann, Zur planungsrechtlichen Zulässigkeit von Kraftwerken im „Außenbereich“, NJW 1978, 2286; Erwiderung von Hoppe, Zur Zulässigkeit von Kraftwerken im „Außenbereich“, NJW 1979, 255. Für die Zulässigkeit dieser Anlagen im Außenbereich Ottmann, Zur planungsrechtlichen Zulässigkeit von Kraftwerken im Außenbereich, BauR 1979, $297 \mathrm{ff}$. Ottmann weicht - was die Anwendung des $\S 35$ Abs. $1 \mathrm{Nr}$. 4 BBauG angeht von der vom Bundesverwaltungsgericht vertretenen Auffassung ab. Die Forderung nach einem Bebauungsplan beruht in meinen Ausführungen nicht auf der Ubberlegung, daß Kraftwerken regelmäßig öffentliche Belange entgegenständen, sondern auf einer Analyse des Tatbestandsmerkmals „soll" in $\S 35$ Abs. 1 Nr. 5 BBauG im Anschluß an die Rechtsprechung des BVerwG. Damit setzt sich Ottmann allerdings nicht auseinander.

191 Siehe dazu Stern-Münch-Hansmeyer, Gesetz zur Förderung der Stabilität und des Wachstums der Wirtschaft, Kommentar, 2. Auflage (1967), 53; Stern, Grundfragen der globalen Wirtschaftssteuerung (FN 96). Saladin, Wachstumsbegrenzung als Staatsaufgabe (FN 12), 549, bemerkt, daß Wachstumsbegrenzung keineswegs mit 
rakterisiert die Begrenzung des Wachstums allerdings - wegen der mit dieser Aufgabe verbundenen umfassenden und tiefgreifenden Interventionen in das Wirtschaftsleben, wegen der Eingriffe in die individuelle Lebensgestaltung und der komplexen Kontrolle als eine "politische Aufgabe von erschrekkenden Dimensionen"182.

\section{Leitbilder der Verkehrspolitik, der Stadtstruktur und der Raumordnung und Landesplanung}

Auch wenn sich gegenüber einer solchen Globalsteuerung ${ }^{183}$, die beängstigende Aspekte auf den nicht nur räumlich und punktuell, sondern im gesamten Wirtschafts- und Infrastrukturbereich umfassend planenden Staat eröffnet, Zurückhaltung empfiehlt, stellen sich in den einzelnen Politiken - wie z. B. im Bereich der Verkehrspolitik - unter dem Gesichtspunkt der Umweltschutzplanung Grundfragen wie die, ob auf die Ver-

\footnotetext{
"Wachstums-Stopp“ oder gar mit „negativem Wachstum" gleichzusetzen sei. Zu unterbinden sei vielmehr ein unbehindertes, exponentielles Wachstum des Kapitals, der Bevölkerung, des Rohstoffkonsums, der Umweltverschmutzung; es gehe um die Herstellung eines Gleichgewichtszustands (equilibrium state").

182 Saladin, Wachstumsbegrenzung als Staatsaufgabe (FN 12), 552. Nach Saladin (a. a. O., 550 f.) wird bei der Verfolgung dieser Staatsaufgabe der Staat einen umfassenden und tiefgreifenden Interventionsauftrag erhalten. Kein Sektor des wirtschaftlich relevanten zwischenmenschlichen Verkehrs werde sich diesem staatlichen Gestaltungsauftrag entziehen können. Der Staat werde in die individuelle Lebensgestaltung auch dort eingreifen müssen, wo sie nur mittelbar ökonomisch relevant sei: Risiken der Umweltverschmutzung und auch Risiken ökonomischer Uber-Expansion würden zur Steuerung, ja zur Unterbindung bestimmter individueller Handlungsweisen führen müssen. Schließlich würden die skizzierten Aufgaben ein komplexes, hochentwickeltes „integriertes“ System staatlicher und zwischen- oder überstaatlicher Strategien und Kontrollen verlangen. Sie bedeuteten "planmäßiges" und langfristig konzipiertes Handeln.

193 Als Globalsteuerung von Saladin, Wachstumsbegrenzung als Staatsaufgabe (FN 12), 552, gewertet, die über den unmittelbaren Bereich der Wirtschaft entschieden hinausgreife: „In einem Staat, der den Gleichgewichts-Auftrag annehmen und ausführen will, hat die Idee einer grundsätzlich unbeschränkten und nur punktuell beschränkbaren individuellen Willkür, wie bemerkt, keinen Raum mehr. Der Staat wird wesentlich mehr Bereiche, gesellschaftlichen" Lebens verantwortlich mit-gestalten müssen als bisher; die Individuen werden sich wesentlich umfassender und enger als heute in die staatliche und überstaatliche Schicksalsgemeinschaft eingebunden sehen" (a. a. O., 559).
} 
kehrserzeugung und damit auf einen Teil der menschlichen Mobilität Einfluß genommen werden soll, ob die Anteile der Verkehrsmittel individuellen und öffentlichen Verkehrs am gesamten Verkehrsaufkommen beeinflußt werden sollen ${ }^{194}$, und ob sich die Gesellschaft unter ökologischen Aspekten einen $\mathrm{Zu}-$ wachs an Verkehr, wie er derzeit prognostiziert wird - man spricht $z$. B. von einem Wachstum des Pkw-Bestandes von heute 22,5 Millionen auf 30 Millionen Stück im Jahr 2000 überhaupt leisten kann ${ }^{196}$.

Dabei setzt sich zunehmend die Erkenntnis durch, daß das Leitbild „Erhöhung der Mobilität" mit der Forderung, daß jeder Punkt der Bundesrepublik nicht mehr als 25 oder $30 \mathrm{~km}$ von einer Autobahnauffahrt entfernt sein soll, nicht mehr allenthalben mit vermehrter Lebensqualität gleichgesetzt werden kann ${ }^{197}$. Das ergibt sich aus den vom Bundesminister für Verkehr für den Fernstraßenbau neuerdings verkündeten „Zielvorgaben": „Lärmschutz vor Kilometer" und "Qualität vor Quantität"198 und der jüngst geführten Diskussion zwischen Bund und Ländern um die Streichung von $6100 \mathrm{~km}$ Autobahnstrecken aus dem Bedarfsplan für den Bundesfernstraßenbau ${ }^{109}$.

${ }^{194}$ Umweltgutachten 1978 (FN 1) Tz 1140.
195 Nach einer Prognose des Deutschen Instituts für Wirtschafts-
forschung, zitiert nach: DER SPIEGEL Nr. 38 vom 17. September
1979, 270: „Klotzig nach vorn.“
186 Umweltgutachten 1978 (FN 1) Tz 1143, 1144.
${ }^{197}$ Siehe auch Umweltgutachten 1978 (FN 1) Tz 1148.
198 Zu den Zielvorgaben siehe Verkehrsblatt vom 31. 5. 1979, 275; siehe auch Gscheidle, Die Zukunft im Fernstraßenbau, FAZ vom 12. 6. 1979. Siehe dazu Fickert, Quo vadis, Verkehrslärmschutzgesetz? (FN 118), 646 f. - Die Beurteilung in der Offentlichkeit ist höchst unterschiedlich. Während DIE ZEIT Nr. 33 vom 19. 8. 1979 (Piehl: „Abschied vom Gigantismus - Weniger neue Autobahnen: Ein Symptom neuer Innenpolitik") die Verkehrspolitik als "Abschied vom Gigantismus" und als "Symptom neuer Innenpolitik" begrüßt, versucht DER SPIEGEL Nr. 33 vom 13. 8. 1979, 30 ff. ("Hohle Sprüche“), den Nachweis zu erbringen, daß die Vorschläge der Reduzierung von neuen Autobahnstrecken erst für das Jahr 2000 vorgesehene Strecken beträfen, deren Realisierung ohnehin fraglich sei. - Zur planerischen Bedeutung der Bedarfsvorausschätzung siehe Mäding, Infrastrukturplanung im Verkehrs- und Bildungssektor (FN 128), $198 \mathrm{ff}$.

${ }_{190}$ Grundlage der Abstimmung zwischen Bund und Ländern ist die Fortschreibung des Bundesverkehrswege-Planes einschließlich des Bedarfsplanes für den Bundesfernstraßenbau für die Dekade zwischen 1981 und 1990. Für diesen Zeitraum, der bereits wegen des erheblichen „Planungsverlaufs" weitgehend disponiert ist, haben Bund und Länder keine Strecken zur Streichung angeboten. Zwischen 1981 und 1990 soll das Autobahnnetz noch einmal um etwa 3000 Kilometer 
Die Ursachen der - unter Umweltschutzgesichtspunkten möglichst gering zu haltenden Mobilität - sind allerdings nicht primär in der Verkehrsplanung $\mathrm{zu}$ suchen, sondern vielfach bei landes-, regional- und stadtplanerischen Entscheidungen der letzten Jahrzehnte, die in Extremfällen Mobilität geradezu erzwungen haben ${ }^{200}$.

Damit kommt man auf die facettenreiche Entwicklung der Leitbilder für die Stadtstruktur zu sprechen, die man als „Dilemma der Stadtplanung" charakterisiert hat ${ }^{201}$. Man denke an die Gartenstadt mit ihren landschaftszersiedelnden Auswirkungen, an die nach der "Charta von Athen" funktional gegliederte Stadt, an der sich die BauNVO orientiert hat, mit ihren monostrukturierten Siedlungsteilen und den daraus resultierenden Verkehrsproblemen, die Wende zur Funktionsmischung mit der sogenannten "geordneten Verdichtung", aus der vielgeschossige, gleichartige Wohnhochhäuser und monostrukturierte Stadtrandsiedlungen hervorgingen ${ }^{202}$. Wohl mehr aus Verlegenheit - und weil die Zweifel an der Tragfähigkeit "endgültiger Konzepte“ wachsen ${ }^{203}$ - propagieren die Stadt-

wachsen. Wegen der zu erwartenden Preissteigerung und möglichen Aktionen von Bürgerinitiativen können nach Auffassung des Bundesministers für Verkehr vielleicht nur 2500 Kilometer gebaut werden. Damit werde das Autobahnnetz etwa 9500 Kilometer Länge im Jahre 1990 haben. In den Gesprächen zwischen Bund und Ländern haben die Autobahnplaner überraschend noch 2800 Kilometer zusätzIiche Strecken gefunden, deren Bau aus heutiger Sicht als illusorisch gilt und die zusammen mit den bereits "abgehakten“ 3300 Autobahnkilometern in der Planungsperiode nach 1990 nicht mehr weiterverfolgt werden sollen (FAZ Nr. 220/38 D vom 21. September 1979, S. 1).

200 Umweltgutachten 1978 (FN 1) $\mathrm{Tz} 1145$, das im Anschluß an Linder-Maurer-Resch, Erzwungene Mobilität (1975), auf das Phänomen aufmerksam macht, daß durch solche Planungen und Leitbilder der Planung in extremen Fällen verkehrsmittelbezogene Mobilität zur Voraussetzung des Zugangs zu wichtigen Funktionen geworden sei, also eine erzwungene Mobilität.

${ }^{201}$ Renate Krysmanski, Historische Entwicklung und Dilemma der Stadtplanung, in: Gesellschaftliche Planung, Materialien zur Planungsdiskussion in der Bundesrepublik Deutschland, hrsg. von Bernhard Schäfers (1973), 283; zu der Entwicklung siehe auch Hoppe, in: Ernst-Hoppe, OffBauBoR (FN 111), Rdz. 130 ff. m. w. N.

${ }^{202}$ Siehe hierzu zusammenfassend Umweltgutachten 1978 (FN 1) Tz 1085 ff.

${ }^{203}$ Siehe dazu Albers und Adrian, in: Städtebauliche Konzepte als Entwicklungsrahmen, Deutsche Akademie für Städtebau und Landesplanung, Mitteilungen Januar 1977, $7 \mathrm{ff}$; ; zur Abneigung gegen normative Theorien der Stadtplanung siehe Umweltgutachten 1978 (FN 1) Tz 1082; Rheingutachten (FN 1) Tz 363. 
planer jetzt das "Stadthaus" und die „erhaltende Erneuerung"204.

Der Sachverständigenrat konstatiert das Fehlen anwendungsbereiter Leitbilder und stellt als „Teilaspekte zu Entwicklungsleitlinien" die stärkere Absonderung der industriellen Produktion von den übrigen städtischen Funktionen - gemäß der Konzeption räumlich-funktionaler Gliederung - und eine Funktionenmischung zwischen Wohnen und dem Dienstleistungsbereich (Tertiärbereich) vor. Das nennt sich räumlichfunktionale Gliederung einer „durchgrünten Verdichtung ${ }^{\text {“205. }}$.

Nicht minder notwendig ist die Frage, ob nicht die Forderung nach „gesunden Lebens- und Arbeitsbedingungen" für die einzelnen Gebiete der Bundesrepublik in den Grundsätzen des Bundesraumordnungsgesetzes ( $\$ 2$ BROG), das raumordnerische Ziel "gleichwertiger Lebensbedingungen" und das Punkt-Axiale-System der Entwicklungsplanung zu einseitig auf die wirtschaftliche und infrastrukturelle Ausstattung einer Region ausgerichtet sind ${ }^{206}$.

204 Hoppe, Rechtliche Aspekte beim Bau in vorgeprägter Umgebung, Gedächtnisschrift für Friedrich Klein (1977), 190 ff.; Haack, Aufgaben des Bundes auf dem Gebiet der Raumordnung und des Städtebaus am Ausgang der siebziger Jahre, Festschrift für Werner Ernst (1980), $157 \mathrm{ff}$.

205 Umweltgutachten 1978 (FN 1) Tz $1091 \mathrm{ff}$.: „Die Funktionsgliederung der, Charta von Athen' in Arbeiten, Wohnen, Verkehr und Erholung entstand zu einer Zeit, in der man den städtischen Arbeitsplatz im wesentlichen am Ort der industriellen Produktion sah. Șeitdem hat der Anteil der Arbeitsplätze im Dienstleistungsbereich stark zugenommen. Will man den Tertiärbereich und die industrielle Produktion aus Umweltschutzgründen räumlich voneinander trennen, so sind diese Möglichkeiten verstärkt“ (Tz 1092). „Den Bereich Wohnen und den Tertiärbereich kann man unter Umweltschutzgesichtspunkten in weiten Bereichen als miteinander verträgliche Nutzungen ansehen. Den Tertiärbereich wird man daher grundsätzlich sehr viel enger als bisher mit dem Boden räumlich verzahnen können. Dies kommt bei einer Funktionsmischung der Verminderung des Verkehrsaufkommens entgegen, indem Arbeitsplätze aus den Kernstädten in die übrigen Stadtgebiete verlagert werden" (Tz 1093). Die zweite Novelle zur BauNVO eröffnet Möglichkeiten in dieser Richtung, siehe dazu Hoppe, in: Ernst-Hoppe, OffBauBoR (FN 111), Rdz 124.

${ }^{206}$ Siehe dazu auch $K u h l$, Umweltschutz im materiellen Raumordnungsrecht (FN 50), 48 ff., 63 f., der sich für die Aufnahme des Kriteriums "Umweltschutz" in die Raumordnungsgrundsätze einsetzt. Für die Landes- und Regionalplanung siehe Niemeier, Die Bedeutung des Umweltschutzes in der Landes- und Regionalplanung, in: Umweltschutz im Bauwesen, hrsg. vom Innenminister des Landes Nordrhein-Westfalen (1974). 
Leitbilder mögen problematisch sein, sie sind aber notwendig, weil die Zusammenhänge zwischen solchen Leitbildern und Umweltqualität unabweisbar sind. Eines der umweltfreundlichsten Ergebnisse seit langer Zeit soll in diesem Zusammenhang nicht unterschlagen werden: Das ist der Umweltschutz durch innerstädtische Verkehrsführung und Verkehrsberuhigung 207 .

\section{Verfassungsrechtliche Grenzen des vorsorgenden Umweltschutzes}

Bei aller Verbesserung des Umweltschutzes, auch vorsorgender Umweltschutz darf nicht zum beherrschenden Planungsbelang werden ${ }^{208}$.

\section{Sicherheitsfaktoren bei dem gesamtökologischen Umwelt- schutz}

Vor allem der gesamtökologisch ausgerichtete Umweltschutz und das langfristig angelegte ökologische Konzept für die Umweltschutzplanung treten - über den medialen Umweltschutz hinausgehend - mit dem Anspruch auf, daß die Umwelt trotz vielfach nur begrenzter Erkenntnisse der Wirkungsforschung, also nur bei mangelhafter Einsicht in den Wahrscheinlichkeitsgrad eines nur vermuteten Schadenseintritts hin zu schützen sei und ökologische Forderungen zu beachten seien, auch wenn

207 Steiner, Aktuelle Rechtsfragen der innerstädtischen Verkehrsführung, in: Straße und Umwelt, hrsg. von Blümel (1979), $71 \mathrm{ff}$. (Schriftenreihe der Hochschule Speyer, Bd. 77); Peine, Rechtsfragen der Einrichtung von Fußgängerstraßen, Ein Beitrag zur rechtlichen Bewältigung eines städtebaulichen Phänomens, Neue Schriften des Deutschen Städtetages, H. 35 (1979), mit umfassenden Literaturnachweisen; Sicherheit für den Fußgänger II, Verkehrsberuhigung, Erfahrungen und Vorschläge für die Verkehrsplanung in Städten und Gemeinden und Schlußfolgerungen aus dem Städtewettbewerb 1977, bearbeitet von Linde-Heuber-Ollefs-Kockelmann-Eichenauer-von Winning-Streichert-Pfundt-Meewes-Steiner-Forst, hrsg. vom Bundesminister für Verkehr und vom ADAC o. J.; Muthesius, Finanzierungsmodelle für die Einrichtung von Fußgängerstraßen, StädteT $1979,324 \mathrm{ff}$.

${ }^{208}$ Siehe auch Kloepfer, Staatsaufgabe Umweltschutz (FN 8), 645. 
ihre sozio-ökonomischen Nachteile nur langfristig erkennbar $\operatorname{sind}^{209}$.

Es ist die Rede davon, daß Entscheidungen des Gesetzgebers im Umweltbereich mehr oder weniger experimentellen Charakter hätten ${ }^{210}$.

Hinzu kommt, daß ein ökologisch ausgerichteter Umweltschutz tendenziell vom medial bestimmten Schutzgut vorverlegt wird auf den Schutz von Ökosystemen und auf die Berücksichtigung langfristig eintretender Folgen und mittelbarer Folgewirkungen.

Wie schwierig sich diese Fragen stellen, sei an zwei Beispielen erläutert:

Unstreitig ist, daß die Form und Intensität der Land- und Forstwirtschaft, die rund $83 \%$ des Bodens in der Bundesrepublik bewirtschaften, bedeutsame Auswirkungen auf den Biotop- und Artenschutz haben ${ }^{211}$. Unbeantwortet ist dagegen die

200 So nachdrücklich Hartkopf, Es ist Zeit für die ökologische Wende (FN 7), 1. Die oben zitierten Wendungen befinden sich allerdings nur in dem vom Bundesminister des Innern herausgegebenen maschinenschriftlichen Redemanuskript vom 21. März 1979, nicht hingegen in dem Abdruck in Umwelt Nr. 69 (1979), 1 ff.

210 Weimar, Zur Funktionalität der Umweltschutzgesetzgebung im industriellen Wachstumsprozeß, Festschrift für Bruno Gleitze (1978), $511 \mathrm{ff}$., 518: Es ist notwendig, die Auswirkungen der bestehenden Gesetze ständig zu beobachten und gleichzeitig das Verfahren offenzuhalten für Korrekturen, die auf neuen Erfahrungen beruhen.

211 Lillotte, Landwirtschaft und Landschaftsgestaltung (FN 14), 16, mit der Forderung, die ökologische Risikoschwelle müsse beweisbar definiert werden, es bestünde eine ökologische Grauzone; siehe auch Bick, Ókonomie - Ókologie - Umweltpolitik (FN 61), 4: Die Landbewirtschaftung ist ein weiterer aktueller Komplex aus dem Bereich ökologisch begründeter Umweltsorge: Problem der Umweltverträglichkeit moderner Landwirtschaft; Umweltgutachten 1978 (FN 1) $\mathrm{Tz}$ 1901: Form und Intensität der Landbewirtschaftung haben bedeutsame Auswirkungen auf den Biotop- und Artenschutz. Die Intensivnutzung führt durch Rationalisierungsmaßnahmen dazu, daß z. B. durch Meliorationen die natürlichen Standortvoraussetzungen zunehmend den Bedürfnissen einer flexiblen Nutzung angepaßt und damit immer stärker nivelliert werden. Das führt zu einer Gefährdung von wildwachsenden Pflanzen und wildlebenden Tierarten und zum teilweise unwiederbringlichen Verlust dieser Arten. Bedenklich ist bei dieser Umwandlung von Biotopen besonders die Trockenlegung von Feuchtbiotopen. Anfälligkeit der Pflanzen gegenüber Krankheiten und Schädlingen und vermehrter Unkrautwuchs mit der Folge des Aufwandes von Pestiziden wird ein durch einseitige Fruchtfolgen, Anbau von empfindlichen Hochleistungssorten, Mono- 
Frage, ob durch eine Verminderung der Arten- und Biotopvielfalt auch die Bodenfruchtbarkeit nachhaltig beeinträchtigt wird ${ }^{212}$.

Die Veränderung des Klimas im Sinne einer globalen Erwärmung durch Spurengase, die infolge menschlicher Aktivitäten in die Atmosphäre emittiert werden, kann in der Zukunft erhebliche Belastungen auslösen. Es ist z. B. an die Kohleverflüssigung zu denken. Eine früher vertretene Theorie, nach der Verschmutzung der Atmosphäre mit Staub zu Temperatursenkungen führe und damit die Erwärmung kompensiere, soll nach neueren wissenschaftlichen Ergebnissen nicht haltbar $\operatorname{sein}^{213}$.

kulturen, Anbau von standortfremden Kulturen, Vergrößerung der Fluren im Rahmen der Flurbereinigung (d. h. Herabsetzen der Diversität) sowie durch verstärkten Düngemitteleinsatz herbeigeführt. Außerdem treten als Gefährdungen auf Massentierhaltung mit Hochleistungszüchtungen mit erhöhtem Aufwand an Antibiotika, Tranquilizer und Hormonen. Zusätzlich treten Abfallbeseitigungsprobleme auf. Ferner können kontaminierte Futtermittel und pharmakologisch wirksame Stoffe über die Nahrungskette zu Lebensmittelkontaminationen führen. Der stets anwachsende Einsatz von ertragsteigernden und -sichernden Mitteln (Pflanzenbehandlungsmittel, Düngemittel) hat aus ökologischer Sicht vielfältige und gravierende Auswirkungen auf die Umwelt: Kontamination der Nahrungsmittel, Belastung der Naturgüter Wasser und Luft, Gefährdung wildwachsender Pflanzen- und wildlebender Tierarten. Siehe dazu auch Weimar, Landwirtschaft als Umweltgestaltung, in: Festschrift für Franz Schad (1978), $473 \mathrm{ff}$., insbesondere $475 \mathrm{f}$.

212 Lillotte, Landwirtschaft und Landschaftsgestaltung (FN 14), 16.

213 Umweltgutachten 1978 (FN 1) Tz 1894. Neuerdings wird gegenüber den Plänen, Kohle zu verflüssigen, vom „Beratungsgremium für Umweltqualität" des US-Präsidenten (CEQ) gewarnt, weil durch die Freisetzung von Kohlendioxid bei massiver Verbrennung fossiler Energieträger die Atmosphäre aufgeheizt werde. Das führe u. U. zur Beeinträchtigung des globalen Wettergeschehens, Verschiebung von Klimazonen um mehrere Breitengrade, Abschmelzen von Polareis und Ansteigen des Meeresspiegels um fünf bis acht Meter. Diese Folge könnte alsbald eintreten: Im Jahre 1978 stieg der Kohlendioxid- $\left(\mathrm{CO}_{2}-\right)$ Gehalt weltweit um 1,5 parts per million (ppm $=$ Teile pro Million Luftteilchen) auf $336 \mathrm{ppm}$, seit 1958 beträgt der globale $\mathrm{CO}_{2}$-Anstieg 6,3 Prozent. Sollte der Verbrauch an fossilen Brennstoffen weiterhin jährlich um 4,3 Prozent ansteigen und der prozentuale Anteil von Kohle, Öl und Gas an der Energieversorgung gleich bleiben, dann würde sich der atmosphärische Kohlendioxid-Anteil bis zum Jahre 2035 verdoppeln. Wenn die USA, die Sowjetunion und die Europäische Gemeinschaft massiv auf Kohleveredelung umschalten und täglich je zwei bis drei Millionen Barrel synthetische Treibstoffe destillieren, dann verdoppelt sich der $\mathrm{CO}_{2}$-Gehalt der Luft in 
Ein Planungsinstrumentarium, das auf einem scharf gefaßten Risikobegriff, einer gesamtökologischen Betrachtungsweise und einem langfristigen Zeitkonzept aufbaut, stößt im Grundrechtsbereich insbesondere der Art. 2 Abs. 1, 12 Abs. 1 und 14 GG auf die Grenzen des Grundsatzes der Verhältnismäßigkeit mit der Frage, wann der Schutz im öffentlichen Interesse unerläßlich ist ${ }^{214}$.

Dabei ist es ein Gutstück politischer, verfassungsrechtlich nicht determinierter Entscheidung, welche Risikomarge tolerabel ist ${ }^{215}$, auch wenn das Gebot zur vorsichtigen Bewertung von Umweltrisiken verfassungsrechtlich ableitbar ist ${ }^{216}$.

Umweltschutzplanung kann jedenfalls Sicherheitsfaktoren im Hinblick auf die Wissenslücken über Schadwirkungen ent-

nur 30 Jahren bis zum Jahre 2010. Ursache des negativen Einflusses der Kohleveredelung ist zum einen die größere potentielle Umweltbelastung durch Kohle gegenüber dem Erdöl und vor allem dem Erdgas. Zum zweiten - und das ist der eigentliche AnlaB der CEQ-Warnung - setzen die Produktion und die Verbrennung von synthetischen Treibstoffen aus Kohle pro Energieeinheit mehr Kohlendioxid frei als die direkte Verfeuerung herkömmlicher fossiler Brennstoffe: $1,4 \mathrm{mal}$ mehr als Kohle, 1,7mal mehr als Ol und 2,3mal mehr als Gas. Experten der Essener Bergbau-Forschung GmbH, des Forschungsinstituts des Deutschen Steinkohlenbergbauvereins, bestätigen diese $\mathrm{CO}_{2}$-Zahlen (Haaf, Nach uns die Sintflut, Die Kohleverflüssigung kann katastrophale Folgen für das Klima auf der Erde haben, DIE ZEIT Nr. 34 vom 17. 8. 1979, S. 17). Nach Feststellungen der $A b$ wärmekommission vom 10. 5. 1979 in Berlin werden sich, bedingt durch Temperaturerhöhungen durch $\mathrm{CO}_{2}$, die Klimazonen, die landwirtschaftlichen Anbaugürtel und die Niederschlagszonen nach Norden verschieben, die Wüsten werden sich ausdehnen.

214 Kölble, Staatsaufgabe Umweltschutz (FN 7), 472, FN 16; siehe BVerfG Beschl. vom 15. 12. 1965 - 1 BvR 513/65 - BVerfGE 342 ff., 349.

215 Weidner, Von der Schadstoffbeseitigung zur Risikoverminderung (FN 65), 37; Albracht, Chemie und Umwelt, in: Industrie und Umwelt 1978, $12 \mathrm{ff}$., 13; Rehbinder, Grundlagen des Umweltrechts (FN 87), 32; siehe dazu allgemein: Schneider, Zur Verhältnismäßigkeitskontrolle insbesondere bei Gesetzen, Bundesverfassungsgericht und Grundgesetz, Bd. II (1976), 390 ff., $397 \mathrm{ff}$.

210 So Götz, Zur Verfassungsmäßigkeit der Dosisgrenzwerte, Viertes Deutsches Atomrechtssymposium, Recht, Technik, Wirtschaft Bd. 8 (1976), 177 ff., 183 ff.: „Für die Gefahrenvorsorge ist Art. 2 Abs. 2 S. 1 GG in seinem Charakter als objektivrechtliche Wertentscheidung relevant. Dem Grundgesetz ist jedoch kein Grundrecht auf Ausschaltung jeglichen Risikos zu entnehmen. Dagegen ist die Notwendigkeit vorsichtiger Bewertung des Strahlenrisikos verfassungsrechtlich ableitbar“ (a. a.O., 185). Dienes, Die Entwürfe zur Novellierung des Immissionsschutzrechts 1979 (FN 74), $6 \mathrm{f}$. 
halten ${ }^{217}$. Umweltschutzplanung hält sich auch bei Berücksichtigung derartiger Sicherheitsfaktoren für solche Ungewißheiten diesseits der verfassungsrechtlichen "Schwelle“ im Sinne der Rechtsprechung des BVerfG zum Restrisiko bei der Genehmigung nach $\S 1 \mathrm{Nr} .2$ und $\S 7 \mathrm{Abs} .2$ Atomgesetz, wenn solche Sicherheitszuschläge auf Abschätzungen anhand praktischer Vernunft beruhen, und die Einschätzungen die potentielle Schadensgröße und den Rang des Rechtsgutes, das durch die Planung tangiert wird, berücksichtigt ${ }^{218}$.

\section{Vorsorge durch Kooperation anstelle von Planung}

Bevor allerdings Umweltschutzplanung aufgrund des Vorsorgeprinzips in diese Grenzbereiche vorstößt, bietet sich Vor-

217 Rehbinder, Umweltrecht (FN 15), $372 \mathrm{f}$.

218 BVerfG, Beschluß des Zweiten Senats vom 8. August 1978 2 BvL 8/77 - BVerfGE 49, 90 ff., 142 f. Das BVerfG hatte sich zu verhalten zu verfassungsrechtlichen Schutzpflichten, die es gebieten, rechtliche Regelungen so auszugestalten, daß auch die Gefahr von Grundrechtsverletzungen eingedämmt bleibt (a. a. O., 142). Hier geht es um die Frage, ob solche - über eventuelle Schutzpflichten hinausgehende - Sicherheitsregelungen zulässig sind. Das Umweltgutachten 1978 (FN 1) Tz 1935 betont sehr nachdrücklich, es sei keine Priorität für den Umweltschutz in den Fällen festgelegt, in denen zukünftige Umweltgefährdungen vermutet werden; eine solche Vorausentscheidung würde auch der von der Bundesregierung formulierten Gleichrangigkeit und Gleichwertigkeit ökologischer und ökonomischer Ziele widersprechen. Es spricht sich dagegen aus, daß versucht werde, vorsorgende Umweltpolitik als Politik mit einem höheren Sicherheitsfaktor zu umschreiben. Das müßte - konsequent zu Ende gedacht nämlich bedeuten, daß im Zweifelsfalle für den Umweltschutz zu entscheiden sei. Das soeben genannte Abwägungsgebot stehe dem aber entgegen. Gerade ökonomische Gesichtspunkte könnten daher offensichtlich auch nach dem Vorsorgegrundsatz zu einer durchaus unterschiedlichen Gewichtung von Restrisiken führen (a.a.O., $\mathrm{Tz}$ 1636).

Zum Restrisiko im Atom- und Immissionsschutzrecht siehe Hanning-Schmieder, Gefahrenabwehr und Risikovorsorge im Atom- und Immissionsschutzrecht (FN 72), 1 ff.; Sellner, Immissionsschutzrecht und Industrieanlagen, NJW-Schriften H. 31 (1978), Rdz. 23 ff. m. w. N.; Breuer, Die Entwicklung des Umweltrechts seit 1977 (FN 23), 1869 f. Rehbinder, Grundlagen des Umweltrechts (FN 87), 32, hält praktisch jede vernünftige Maßnahme des Umweltschutzes, wenn sie nicht zu einer umfassenden $Z$ wangswirtschaft führt, für verfassungsrechtlich legitim. Mit der hier vertretenen Auffassung wird allerdings nicht der Grundsatz „in dubio pro securitate“ übernommen, siehe dazu Rehbinder, Grundfragen (FN 8), 252. Gegen eine zu weite Ausdehnung des Vorsorgeprinzips Bundesverband der Deutschen Industrie (BDI), Umweltschutz (FN 14), 9 f., 13 f. 
sorge durch Zusammenwirken zwischen dem Staat und den gesellschaftlichen Kräften im Interesse der Staatsentlastung und Entbürokratisierung durch Aktivierung der Selbstregulierungskräfte $a^{219}$.

Eine solche Strategie erscheint umso aussichtsreicher, als im Bereich der Wirtschaft der Umweltschutz zu den Zielen jetziger Unternehmensführung zählt ${ }^{220}$.

In der Praxis wird die Effektivität einer solchen positiven Stimulierung der Selbstregulierungskräfte der Wirtschaft durch viele Beispiele belegt: Kaiser betont zu Recht, daß für die Lösung mancher Probleme des Umweltschutzes der Typ hoheitlich inspirierter Verhaltensabreden prädestiniert sei221.

Es ist zu erinnern an die Selbstbeschränkung der Zigarettenindustrie in der Werbung ${ }^{222}$, an die Ubereinkunft des Verbandes der Chemischen Industrie mit dem Bundesinnenminister, vorsorglich und freiwillig bis zu einer europäischen Regelung den Fluorchlorkohlenstoff in Aerosolen bis Ende 1979 auf $25 \%$ der im Jahre 1975 verwendeten Mengen zu verringern ${ }^{223}$, die Mitwirkung der Industrie bei der Standortwahl für „sperrige“ Vorhaben ${ }^{224}$. Bei der Aufstellung des Braunkohlenplanes Hambacher Forst im Rheinischen Braunkohlengebiet ist beispielsweise - ohne jede gesetzliche Anordnung - auf freiwilliger Basis ein umfassendes ökologisches Gutachten eingeholt wor$\operatorname{den}^{225}$.

${ }^{219}$ Kölble, Staatsaufgabe Umweltschutz (FN 7), 484.

220 Heinen, Unternehmerziele IV, in: Gablers Wirtschaftslexikon Bd. 6, 9. Auflage (1976), Sp. 1799; Hinterhuber, Strategische Unternehmensführung (1977), 57 ff., 58 f.; Mellerowicz, Unternehmenspolitik, Bd. I: Grundlagen (1976), 56 ff., 58, 61; Wöhe, Einführung in die Allgemeine Betriebswirtschaftslehre, 13. Auflage (1978), $35 \mathrm{f}$. Hartkopf, Industrie und Umweltschutz - ein Gegensatz? (FN 15), 11; Picht, Umweltschutz und Politik (FN 6), 155 (in bezug auf Umweltforschung); Rohde, Staatsaufgabe Umweltschutz (FN 188), $488 \mathrm{f}$. (Vereinbarung, private „Luftverbände“); Rehbinder, Grundlagen des Umweltrechts (FN 87), 24; Ders., Umweltrecht (FN 15), 404: Kooperation statt Konfrontation; Ders., Grundfragen (FN 8), 254 f.; Kloepfer, Umweltschutz und Recht (FN 24), 1729.

${ }^{221}$ Kaiser, Industrielle Absprachen im öffentlichen Interesse, NJW 1971, 585 ff., 586; Kloepfer, Staatsaufgabe Umweltschutz (FN 8), 640.

222 Kaiser, Industrielle Absprachen (FN 222), 587.

${ }^{223}$ Hartkopf, Es ist Zeit für die ökologische Wende, Manuskript (FN 209), 14.

${ }^{224}$ Blümel, Die Standortvorsorgeplanung (FN 12), 309.

225 Hoppe, Die Planung nach dem Braunkohlengesetz im System der nordrhein-westfälischen Landesplanung, in: Landesplanung und kommunale Selbstverwaltung, Materialien zum Siedlungs- und Wohnungswesen und zur Raumplanung Bd. 19 (1978), 97 ff., 121; siehe auch 
Wirksamer Umweltschutz ist nur möglich durch gemeinsamen Einsatz aller Kräfte des Staates und der Gesellschaft.

Reiners, Landschaft im Wandel, Braunkohlenbergbau im Rheinland, Teil 1: Rechtsgrundlagen des Braunkohlenbergbaus in NordrheinWestfalen, Beiträge der Akademie für Raumforschung und Landesplanung (Bd. 29) (1979), 23 ff. Bedauerlicherweise will die Landesregierung durch Novellierung des Landesplanungsgesetzes die Braunkohlenplanung, die strukturelle Besonderheiten aufweist (siehe Hoppe, a. a. O., $122 \mathrm{ff}$.), in das Landesplanungsgesetz einbeziehen (siehe Gesetzentwurf der Landesregierung vom 28. 6. 1979, LTDrucks. 8/4700). 
Leitsätze des Mitberichterstatters über:

\section{Staatsaufgabe Umweltschutz}

Vorbemerkung:

1. Uber die "traditionellen" Gefahren für die Umwelt hinaus sind alle Prozesse besorgniserregend, die künftige Entwicklungsmöglichkeiten einengen:

- Der Landverbrauch für Verkehrswegebau, Siedlung, Industrie, Landwirtschaft und Erholung am falschen Platz und die ökologisch schädliche Landnutzung - Die weitere Belastung der Naturgüter Wasser, Boden, Luft, Klima, Tier- und Pflanzenwelt und damit die Schädigung von Okosystemen - Eine gesteigerte Naturausbeutung, die eine selbständige Wiedergesundung lebensnotwendiger Ressourcen in Frage stellt - Die Zunahme des gewerblich-industriellen sowie des Verkehrslärms.

2. Wegen dieser Entwicklungen und im Interesse einer dauerhaften Sicherung unserer Lebensgrundlagen gewinnt im Umweltschutz der Aspekt der langfristig vorsorgenden Umweltpolitik und der der planenden Umweltvorsorge zunehmend an Gewicht. Die Bundesregierung will die Periode des reagierenden Umweltschutzes durch eine Politik der Umweltvorsorge und durch eine übergreifende, gesamtökologisch orientierte Umweltschutzplanung ablösen ("ökologische Wende").

3. Umweltschutzvorsorge durch Umweltschutzplanung ist ein zentraler Bereich des Umweltschutzes, für den der Staat schon wegen der zeitlichen Dimensionen existenzsichernder Zukunftsvorsorge eine besondere Verantwortung trägt.

I. Vollzug des Umweltschutzes in der Krise

4. Die kurze und wechselhafte Geschichte des Umweltschutzes und des Umweltschutzbewußtseins wird begleitet von einer Diskussion grundsätzlicher Perspektiven: Grundrecht auf Umweltschutz, verfassungsrechtliche Staatszielbestimmung, Verbandsklage, die vor allem dem „Vollzugsdefizit" entgegenwirken sollen.

5. Die Ursachen der vielfach festgestellten Mängel im Umweltschutz beruhen hingegen in erster Linie auf der Schwäche des für den Umweltschutz zur Verfügung gestellten Instrumen- 
tariums, auch und gerade im Bereich der Umweltschutzplanung. Hinzu tritt die Vielfalt und Unüberschaubarkeit der Regelungen und die besondere Struktur des Umweltschutzrechts (mangelnde Operationalisierbarkeit und Vieldeutigkeit von Zielvorgaben, unzureichende Festlegung von Rangfolgen kollidierender Interessen). Mehr als zwei Drittel der Kommunen sehen sich z. B. durch die umweltpolitische Aufgabenstellung als überfordertan.

6. Unzureichendem Umweltschutz kann nur mit kleinen Schritten abgeholfen werden, „eine modische Globalbetrachtung der Umweltprobleme auf hohem Abstraktionsniveau" kann kaum Entscheidungshilfen bieten (Umweltgutachten 1978).

\section{Planung als Teil der Staatsaufgabe Umweltschutz durch Vorsorge}

7. Die Prinzipien des Umweltschutzes (Vorsorgeprinzip, Verursacherprinzip, Kooperationsprinzip) geben Leitbilder, Grundkonzeptionen und politische Handlungsanweisungen für eine rationale Umweltpolitik ab. Die Umweltschutzplanung ist geeignetes Instrument zur Verwirklichung des Vorsorgeprinzips. Dieses Prinzip begründet aber noch nicht die Umweltschutzplanung als Staatsaufgabe, vor allem noch nicht im Sinne der von der Bundesregierung angestrebten einheitlichen und übergreifenden gesamtökologisch orientierten Planung („umfassendes Umweltgestaltungsinstrumentarium").

8. Für die staatliche Aufgabenwahrnehmung im Bereich der Umweltschutzplanung sprechen allerdings eine Reihe von Momenten:

- Die Bedeutung und der Charakter der prospektiven Interessen koordinierenden und zukünftige Konflikte vermeidenden Funktion einer Umweltschutzplanung, die auf eine weitergreifende zeitliche Perspektive angelegt ist - Die existenzsichernde, freiheitserhaltende und grundrechtsstärkende Bedeutung der vorsorgenden Umweltschutzplanung, ohne die Defizite im Schutz und in der Sicherung der natürlichen Lebensgrundlagen zu erwarten sind - Die räumlich, gegenständlich und zeitlich begrenzte Planungsfähigkeit Privater und die gewerblichindustrieller Unternehmen, auch angesichts der immensen Bedrohung der Umweltgüter - Die längerfristige Verbindlichkeit staatlicher Planung im Unterschied zur Unverbindlichkeit privater Planung.

9. Vor allem Raumordnung und Stadtentwicklung, aber auch Fachplanung (z.B. Verkehrsplanung) und Umweltschutzfachplanung (z.B. Landschaftspläne, Abfallbeseitigungspläne) ha- 
ben eine zentrale Position in der langfristigen Sicherung der natürlichen Ressourcen und zur Verbesserung der Umweltqualität. Ein erheblicher Teil der gegenwärtigen Umweltschäden geht auf die Raum- und Siedlungsentwicklung sowie die Verkehrsplanung zurück, in denen über lange Jahre die Umweltqualität nur eine nachgeordnete Rolle spielte. Selbst Umweltschutzfachplanung kann sich umweltschädigend auswirken.

10. Soweit Umweltschutzvorsorge Staatsaufgabe ist, ist der Staat gehalten, hierfür ein ausreichend geeignetes Planungsinstrumentarium zu schaffen und bereitzuhalten.

11. Umweltschutzplanung mit der Tendenz, ein umfassendes ökologisches Umweltgestaltungsprinzip zu verwirklichen (gesamtökologische Sicht, scharf gefaßter Risikobegriff, weitreichende Gefahrenvorsorge) muß sich der verfassungsrechtlichen Grenzen (Grundrechte, Verhältnismäßigkeitsprinzip) bewußt sein.

12. Der Hinweis auf die verfassungsrechtlichen Grenzen und die Gefahren einer Umweltschutzplanung aus ökologischer Gesamtsicht bedeutet nicht deren Ablehnung: Die ökologische Gesamtbetrachtung ist im kommenden Umweltschutzrecht und in der Umweltschutzplanung der Zukunft unabdingbar.

13. Die ökologische Gesamtsicht wird durch folgende Faktoren bestimmt:

- Abkehr vom sektoralen Schutz einzelner Umweltmedien, einzelner Umweltfaktoren, einzelner Anwendungsgebiete von Stoffen und einzeln erfaßbarer Immissionen - Hinwendung zum Schutz der mehr oder weniger komplexen Systeme, in denen sich Wechselwirkungen zwischen den Organismen und ihrer Umwelt abspielen - Erfassung und Berücksichtigung der weitgehend langfristigen Interaktionen von Schadstoffen sowie ihrer Anreicherung in Nahrungsketten und der Kombinationswirkungen der verschiedensten umweltbelastenden Faktoren, Abhängigkeiten und Querverbindungen (synergetische Zusammenhänge).

14. Eine so verstandene Umweltschutzplanung wirft neue, bisher noch nicht gelöste rechtliche Probleme auf. Sie rühren vor allem aus dem vieldimensionalen Informationsproze $\beta$, der ablaufen mu $\beta$, bevor das „Abwägungsmaterial“ — seine ökosystemaren Querverbindungen und synergetischen Zusammenhängen entsprechend aufbereitet - in den planerischen $A b-$ wägungsproze $\beta$ eingehen kann, gleichgültig, um welche Art von Planung es sich handelt. 


\section{Die Situation des Umweltschutzes und seiner Planung}

15. Vergegenwärtigt man sich den heutigen Stand von Umweltschutz, Planung und Okologie, so laufen die Überlegungen $z u$ Modellen von Umweltschutzplanung, die auf eine wirksamere Durchsetzung von Umweltschutzbelangen in der Planung unter Berücksichtigung einer ökologischen Gesamtkonzeption - abzielen, eher auf zurückhaltende Vorschläge hinaus.

16. Umweltschutz und Umweltschutzplanung haben sich in den letzten Jahren in anderen Planungen nicht hinreichend durchsetzen können. Die Planung selbst - insbesondere die räumliche Planung (Bundesraumordnung, Landes-, Regionalund Bauleitplanung) - weist Mängel auf, die ihre Durchsetzungsfähigkeit in Frage stellt. Ihr wird "Entfeinerung" der Planungsregelungen nahegelegt. "Entfeinerung" ist zur Umweltschutzplanung aus gesamtökologischer Sicht tendentiell gegenläufig. Der Stand der ökologischen Erkenntnisse und Methoden reicht für eine Planung aus gesamtökologischer Sicht noch nicht aus; die Ökologie bleibt sogar hinter dem Stand zurück, den geltendes Recht (z.B. Naturschutz und Landschaftspflege) für den Vollzug von Gesetzen voraussetzt.

\section{Modelle der Umweltschutzplanung}

17. Allein die derzeitige Situation von Umweltschutz, Planung und Ökologie läßt gegenüber globalsteuernden Instrumenten und holistischen Gesamtkonzeptionen des vorsorgenden Umweltschutzes Zurückhaltung geboten erscheinen. Soweit neuere Tendenzen einer einheitlichen und übergreifenden Umweltgesamtplanung in diese Richtung zielen, ist ihr nicht nur die kritische Sonde der Erforderlichkeit als Staatsaufgabe anzulegen, sondern auch zu fragen, ob sie vollziehbar, effektiv und - angesichts des Standes der ökologischen Forschung - realisierbar ist.

18. Ein gangbarer Weg - auch für die Berücksichtigung gesamtökologischer Gesichtspunkte - ist eine Verbesserung der Integration der Umweltschutzbelange in andere Planungen durch verbesserte Ermittlung der Umweltschutzdaten, verbesserte Zielsetzung und Gewichtung von Umweltschutzbelangen und die Aufstellung umweltschutzfreundlicher Planungsleitbilder.

V. Die Strukturen der Planung und die des Umweltschutzes

19. Die Verbesserung muß sich an den Strukturen der Planung (Ermittlung, Abwägung, planerische Entscheidung) und 
an den Wirkungszusammenhängen des Umweltschutzes - (1. Wirkungsebene: sozio-ökonomische Aktivitäten, 2. Wirkungsebene: Einwirkungen auf Umweltbereiche einschließlich mittelbarer Folgewirkungen aufgrund ökologischer Wirkungszusammenhänge, 3. Wirkungsebene: negative Auswirkungen [Belastungen - Schädigungen - synergetische Zusammenhänge]) orientieren unter dem Aspekt der Umweltbeeinträchtigungen vermeidenden Planung, der die Nutzungsmöglichkeiten der Umwelt verteilenden Planung und der zulässige negative Auswirkungen sanierenden Planung.

\section{Die Verbesserung des Vorgangs der Ermittlung von Um- weltschutzdaten}

20. In der unzureichenden Ermittlung von Umweltschutzdaten liegt der eigentliche Mangel und der Ursprung der unzulänglichen Beachtung der Umweltschutzbelange. Die Notwendigkeit entsprechender Ermittlungen wird vielfach nicht erkannt und Zielkonflikte werden mangels Informationen nicht bewußt.

21. Die Ermittlung ist ein Vorgang der Informationsgewinnung und der Verarbeitung von Informationen, nicht ein Vorgang der Subsumtion unter unbestimmte Gesetzesbegriffe. Der Vorgang wird bestimmt durch gezielte Auswahl von Informationen, die durch Direktiven (Leitsätze und Sachgrundsätze der Planung) gesteuert wird. Daraus resultiert eine Reduktion des umfassenden Tatsachenmaterials auf einen verarbeitungsfähigen Umfang. Außerdem müssen die derart gefilterten Informationen aufgearbeitet, d.h. für die Einstellung in den Abwägungsprozeß aussagekräftig und damit berücksichtigungsfähig gemacht werden. Dieser mit Bewertungen einhergehende Vorgang der Verdichtung und Verarbeitung des Abwägungsmaterials spielt gerade in einem so komplexen und vielschichtigen Bereich wie dem des Umweltschutzes eine entscheidende Rolle, vor allem, wenn die direkten und indirekten Ein- und Auswirkungen einschließlich der systemaren ökologischen und der synergetischen Zusammenhänge berücksichtigt werden sollen.

22. Das erfordert formalisierte Verfahren zur Informationsgewinnung und Informationsverarbeitung, die auf einem flexiblen Informationsmodell beruhen sollten, auf einer für neue Erkenntnisse und Daten aufnahmebereiten, durch ständige Korrekturen auf dem laufenden gehaltenen "Umweltschutzdatenbank", die den Abruf verarbeiteter, in der jeweiligen Planungsart verwendbarer Informationen gestattet, selbstverständlich unter Wahrung aller berechtigten Individualschutzinteressen. 
23. Bei der Planung als einem argumentativen, offenen prozeßhaften Vorgang der Abwägung ist das faktische Gewicht "gefilterter" und "aufbereiteter" Umweltinformationen erheblich. Ein auf Fortschreibung angelegter Informationsraster erfüllt eine Gelenkfunktion zwischen den einzelnen Planungen und dem jeweiligen Erkenntnisstand ökologischen Wissens.

VII. Verbesserung der Zielsetzung, der Gewichtung und der Abwägung von Umweltschutzbelangen

24. Der Umweltschutz stellt bei der planerischen Abwägung im gesamten Spektrum der Planungsinteressen nur einen wenngleich sehr gewichtigen Belang dar. Dieser Stellenwert der Umweltschutzbelange bedeutet, daß sie sich zwar durchsetzen können, wenn sie mit anderen Planzielen harmonieren oder ihnen gegenüber neutral sind. Sie werden aber vielfach zurïckgestellt, wenn sie mit anderen Planungsinteressen (Verkehr, Industrieansiedlung, Erholung) konkurrieren oder gar konfligieren. Umweltschutzbelangen eignet von Hause aus eine Durchsetzungsschwäche vor allem gegenüber sektoralen Fachplanungsinteressen.

25. Der mangelnden Berücksichtigung der Umweltschutzbelange bei Zielkonflikten in der Planung kann entgegengewirkt werden durch

- Operationalisierung der Umweltschutzbelange im Wege der Konkretisierung der Ziele des Umweltschutzes und durch eine sinnvolle Quantifizierung (Richtwerte, Grenzwerte, Standards) - Aufstellung von Präferenzskalen für die Gewichtung - Aufstellung oder eindeutigere Formulierung von Leitsätzen bei nicht quantifizierbaren Zielsetzungen.

26. Die rein fachbezogene, sich weitgehend im Binnenraum einer Fachplanung "abschottende" Abwägung von sektoralen Belangen ist auszuweiten auf die - auch verfahrensmäßig abgesicherte - abwägende Einbeziehung von sog. "externen" Leitsätzen anderer Bereiche und damit auch des Umweltschutzes.

27. Anlagegenehmigungsverfahren einerseits und Planung andererseits sollten nur diejenigen Funktionen zugewiesen werden, die sie ihrer Struktur nach sachgemäß bewältigen können (Abkoppelung von Einzelgenehmigung und Umweltschutzplanung). Das bedeutet u. a.: Trennung der Anlagegenehmigungsverfahren von planerischen Fragen der Standortwahl auch im Interesse des Standort-Recyclings; keine „Ersatzplanung" umweltrelevanter Großvorhaben durch Planungssurrogate in Einzelgenehmigungstatbeständen (z. B. $\S \S 34,35$ BBauG). 
VIII. Die Verbesserung des Umweltschutzes in den Planungsleitbildern

28. Planungsleitbilder der Gesamtplanungen und der Fachplanungen haben erheblichen Einfluß auf den Umweltschutz, da sie planerisches Verhalten steuern und sich bei der Gewichtung von Belangen auswirken. Deswegen geht die Umweltschutzdiskussion mit der Forderung nach einer Wandlung solcher Zielvorstellungen einher.

29. Es ist unverkennbar, daßz. B. Leitbilder der Verkehrspolitik ("Erhöhung der Mobilität", "Lärmschutz vor Kilometer") und der Stadtstruktur (Gartenstadt, funktional gegliederte Stadt, "geordnete" Verdichtung, Stadthauskonzeption, „durchgrïnte" Verdichtung) sowie der Raumordnung ("gesunde Lebens- und Arbeitsbedingungen", "gleichwertige Lebensbedingungen", Punkt-Axial-System) erheblichen Einfluß auf die Umweltqualität haben.

IX. Verfassungsrechtliche Grenzen des vorsorgenden Umweltschutzes

30. Bei aller Verbesserung des Umweltschutzes und seiner Planung, vorsorgender Umweltschutz darf nicht zum beherrschenden Planungsbelang werden. Ein Planungsinstrumentarium, das auf einem scharf gefaßten Risikobegriff einer weitgefaßten Vorsorge mit langfristigem Zeitkonzept und einer gesamtökologischen Betrachtungsweise beruht, stößt im Grundrechtsbereich insbesondere der Art. 2 Abs. 2, 12 Abs.1 und 14GG auf die Grenzen des Verhältnismäßigkeitsprinzips mit der Frage, ob der Schutz im öffentlichen Interesse unerläßlich ist. Umweltschutzplanung kann allerdings Sicherheitsfaktoren im Hinblick auf Wissenslücken über Schadwirkungen enthalten. Solche Sicherheitszuschläge müssen aber auf Abschätzungen anhand praktischer Vernunft beruhen und die Größe des gegebenenfalls eintretenden Schadens sowie den Rang des Rechtsgutes, das durch die Planung tangiert wird, berücksichtigen.

31. Bevor Umweltschutzvorsorge in diese Grenzbereiche vorstößt, sollte sie vorrangig durch Zusammenwirken zwischen Staat und gesellschaftlichen Kräften im Interesse der Staatsentlastung und Entbürokratisierung durch Aktivierung der Selbstregulierungskräfte bewerkstelligt werden. Für die Lösung mancher Probleme des Umweltschutzes und der Vorsorge ist der „Typ hoheitlich inspirierter Verhaltensabreden“ (Kaiser) prädestiniert und in der Praxis bewährt. 


\section{Bericht von Professor Dr. Dr. Karl Wenger, Wien}

\section{Staatsaufgabe Umweltschutz in Ơsterreich}

Ähnlich wie in anderen westlichen Industrieländern wurde auch in Österreich der Umweltschutz erst gegen Ende der sechziger Jahre zum politisch relevanten Begriff und damit zum Gegenstand spezieller legislativer und administrativer Maßnahmen. Soweit ich sehe, findet sich der Terminus "Umwelt" i. S. eines besonderen Gegenstandes staatlicher Utberwachung als Gesetzesbegriff erstmals im Strahlenschutzgesetz v. 11. Juni $1969, \mathrm{BGBl} 227$. Sowohl in $\S 1$ als auch in $\S 37$ ist dort von der „behördlichen UUberwachung der Umwelt auf radioaktive Verunreinigung" und von entsprechenden Utberwachungsmaßnahmen die Rede, die sich auf die Luft, die Niederschläge, die Gewässer, den Boden, die Lebensmittel und die landwirtschaftlichen Produkte beziehen. Der Sache nach freilich waren derartige Maßnahmen keineswegs etwas völlig Neues. Immissionsbestimmungen finden sich bereits in $\$ 364$ Abs. 2 des aus dem Jahre 1811 stammenden ABGB, sie sind allerdings ein Ausfluß des privaten Nachbarrechts. Immissionsschutznormen kennt aber auch das offentliche Nachbarrecht bereits im 19. Jahrhundert. Als Beispiele seien nur die Regelungen über kommissionelle Lokalaugenscheinsverhandlungen unter Beiziehung der betroffenen Anrainer in den Bauordnungen der Kronländer und in der Gewerbeordnung bezüglich der Betriebsanlagengenehmigung genannt. $\mathrm{Da} B$ derartige Regelungen, deren $\mathrm{Zahl}$ gar nicht so klein war, nicht zu jenem Umweltbewußtsein führten, für das der vor rund einem Jahrzehnt zum politischen Schlagwort gewordene Begriff "Umweltschutz" heute verbaler Ausdruck ist, lag offenbar daran, daß die damit angesprochenen Gefährdungen noch in relativ engen Grenzen geblieben waren und die darauf Bezug nehmenden nachbarrechtlichen Individualschutzmaßnahmen sich durchaus in das System verwaltungspolizeilicher Gefahrenabwehr einfügen ließen. Erst die Intensivierung und räumliche Ausdehnung der den menschlichen Lebensraum bedrohenden Gefährdungen zur globalen $\mathrm{Be}-$ drohung menschlicher Existenz ließ auch bei uns den Umweltschutz als zentrale Staatsaufgabe erkennen, wobei sicherlich die internationale Diskussion dieser Probleme stimulierend gewirkt hatte. Als Beispiel möchte ich nur die von der Beratenden Versammlung des Europarates am 30. 9. 1969 beschlossene Um- 
weltschutzempfehlung über Maßnahmen hinsichtlich Wohnraum, einwandfreie Beschaffenheit und Reinheit von Lebensmitteln, Verhütung von Luft- und Wasserverschmutzung, Lärmbekämpfung und Abfallbeseitigung sowie das im Mai 1971 beschlossene Arbeitsprogramm der 24. Weltgesundheitskonferenz anführen, worin die Anhebung der hygienischen Grundbedingungen in allen Ländern, die Erarbeitung internationaler Kriterien und Richtlinien über gesundheitsschädliche Umwelteinflüsse, insbes. auf den Gebieten der Luft- und Wasserverunreinigung, der Nahrungsmittel und der Abfallbeseitigung auf nationaler und internationaler Ebene als vordringlich bezeichnet worden war. Osterreich gehört seit 1949 der WHO und seit 1956 dem Europarat als Mitglied an.

Es lag durchaus auf dieser Linie der Anerkennung eines globalen und kollektiven Umweltschutzes als Staatsaufgabe, wenn es in der Regierungserklärung vom 27. April 1970 hieß: „Im Rahmen eines langfristigen Gesundheitsplanes sind Maßnahmen zum Schutz vor gesundheitsschädlichen Umwelteinflüssen durch Sicherung der Erholungsräume, Reinhaltung von Luft und Wasser, hygienische Abfallbeseitigung, Bekämpfung von Lärm- und Geruchsbelästigung und Strahlenschutz zu realisieren". Entsprechend dieser politischen Absichtserklärung wurde noch im selben Jahr durch MinisterratsbeschluB ein Interministerielles Koordinationskommitee für Umwelthygiene unter Vorsitz des Bundeskanzlers eingerichtet, das später als Interministerielles Kommitee für Umweltschutz unter Federführung des BMGuU mit seinen Arbeitskreisen für Luftverunreinigung, Wasser und Boden, Lärm, Abfälle und Müll zur eigentlichen Koordinationsstelle in Umweltschutzfragen wurde, zumal daran außer Vertretern der zuständigen Bundesministerien regelmäßig auch Vertreter der Verbindungsstelle der Bundesländer und des Städte- und Gemeindebundes teilnahmen.

Durch Bundesgesetz v. 21. 1. 1972, BGBl 25, wurde ein eigenes Bundesministerium für Gesundheit und Umweltschutz errichtet. Es übernahm aus dem Wirkungsbereich des BKA die Zuständigkeit zur Wahrung der allen Verwaltungszweigen gemeinsamen Interessen auf dem Gebiete des Umweltschutzes. Diese Koordinationsbefugnis gilt auch im Verhältnis zwischen Bund und Ländern, soweit Bund und Länder an solchen Maßnahmen beteiligt sind. Im übrigen blieb die Zuständigkeit der einzelnen BM auf dem Gebiete des Umweltschutzes, soweit dieser in Sachbereichen mitumfaßt ist, der von den übrigen Ressortministern wahrzunehmen ist, unberührt. Außerdem wurde das BMGuU zur Entwicklung einer zweckentsprechenden Forschungstätigkeit auf dem Gebiete des Umweltschutzes ermäch- 
tigt, wobei zur Koordination dieser Forschungstätigkeit mit Forschungstätigkeiten anderer BM jedoch das BMWuF zuständig ist. In der Kritik wurde vor allem bemängelt, daß ein derart dürftiger Zuständigkeitsbereich die Schaffung eines eigenen Umweltschutzressorts kaum rechtfertige.

Freilich das Fehlen substantieller Kompetenzen in Angelegenheiten des Umweltschutzes hat seine Ursache nicht nur, ja nicht einmal überwiegend. in einem Ressortegoismus der traditionellen Bundesministerien, sondern in erster Linie in der Struktur des Kompetenzkatalogs der Bundesverfassung, zu deren Entstehungszeit die Besonderheiten der Umweltschutzverwaltung noch nicht bekannt waren und folglich auch nicht hatten berücksichtigt werden können. Vor allem die Bundesländer mußten in einer neuen Umweltschutzorganisation des Bundes die Gefahr einer weiteren Aushöhlung ihrer ohnehin schon recht spärlichen Teilhabe an der Ausübung der Staatsfunktionen sehen. Dies zeigte sich deutlich an den von der Verbindungsstelle der Bundesländer herausgegebenen "Leitlinien der Bundesländer für den Umweltschutz", die in einer gemeinsamen Konferenz der Landeshauptleute und Landesfinanzreferenten am 19. 10.1972 in Feldkirch beschlossen worden waren. Die Länder entwickelten nun selbst in verstärktem Maße Umweltschutzaktivitäten. Dies gilt insbesondere für den präventiven Umweltschutz, der in einem engen Konnex steht mit den gemäß einer VfGH-Erkenntnis aus dem Jahre 1954 (Slg 2674) in die Gesetzgebungs- und Vollziehungskompetenz der Länder fallenden Maßnahmen auf dem Gebiete der Raumordnung. Raumordnung und Umweltschutz ist kompetenzrechtlich gemeinsam, daß sie als komplexe Begriffe angesehen werden müssen, die alle Tätigkeiten umfassen, die auf den einzelnen Verwaltungsgebieten der vorsorgenden Planung dienen. Sie müssen als Ausfluß der Zuständigkeit zur Regelung der einzelnen in Betracht kommenden Verwaltungsmaterien angesehen werden und fallen, soweit sie nicht einem speziellen Kompetenzbestand des Bundes zugerechnet werden können, unter die Generalklausel des Art. 15 B-VG zugunsten der Länder. Die Qualifikation des Umweltschutzes durch die Verfassungsrechtslehre als "komplexe flexible Adhäsionsmaterie“ bringt dies sinnfällig zum Ausdruck. Unter Bezugnahme auf die Generalklausel des Art. 15 B-VG erließen die Länder nun, soweit solche Regelungen noch nicht existierten, Luftreinhaltegesetze, Lärmschutzgesetze, Müll- oder Abfallbeseitigungsgesetze, aktualisierte Natur- und Landschaftsschutzvorschriften sowie Novellen zu den Jagd- und Fischereigesetzen. Eine eigene Umweltschutzorganisation mit speziellen Utberwachungsorganen schu- 
fen Kärnten mit dem Gesetz v. 15. 12. 1972 über die Bergwacht, LGB1 1973/25 und Niederösterreich mit dem Umweltschutzorganisationsgesetz v. 25. 1. 1973, LGBl 1973/66 (8050-0 und der Errichtung der „NO Umweltschutzanstalt" als Körperschaft des öffentlichen Rechts gemäß der Novelle zum NÖ Umweltschutzgesetz v. 18. 12. 1975, LGBI 1976/14 (8051-1). Auch die gleichfalls als Körperschaften des öffentlichen Rechts errichteten Organisationen der Steiermärkischen Berg- und Naturwacht (LGBl 1977/49) und der Tiroler Bergwacht (LGBl 1977/6) sowie die Vorarlberger Naturwächter (LGBl 1969/36 und 1970/21) sind zur Wahrnehmung von Umweltschutzaufgaben berufen.

Die Landeshauptstädte und die meisten sonstigen Großgemeinden erließen, gestützt auf das ihnen durch Art. 118 Abs. 6 B-VG zur Beseitigung von das örtliche Gemeinschaftsleben störenden Mißständen und durch die Gemeindeordnungen eingeräumte selbständige Verordnungsrecht, eine Reihe für den Umweltschutz bedeutsamer ortspolizeilicher Verordnungen. Beispiele dafür sind etwa die Eisenstädter Parkordnung 1971, die Klagenfurter Unratsverordnung v, 4. 6. 1975, die Villacher Lärmschutzverordnung v. 29. 4. 1976, die ortspolizeiliche Gesundheitsschutzverordnung St. Pölten v. 30. 10. 1972, die Salzburger Wohnhygiene-Verordnung v. 23. 11. 1973, die Grazer Grünflächen- und Baumschutzverordnung v. 10.6. 1976, die Innsbrucker Lärmbekämpfungsverordnung v. 26. 7. 1973, die Bregenzer ortspolizeiliche Gesundheitsschutzverordnung v. 6. 8. 1971 und die Wiener Verordnungen betreffend die Reinhaltung von Verkehrsflächen und Privatgrundstücken v. 10. 12. 1975 sowie betreffend das Verbot der Verwendung von mit Verbrennungsmotoren betriebenen Rasenmähern am Wochenende v. 26. 9. 1974 .

Diese Hinweise zeigen, daß das zunehmend auch die Öffentlichkeit mobilisierende Umweltbewußtsein - man denke nur an verschiedene Bürgerinitiativen vor allem auf lokaler Ebene - durchaus eine Reihe von Aktivitäten der Gebietskörperschaften auszulösen vermochte. Was jedoch bisher für eine wirkungsvolle Umweltschutzpolitik noch weitgehend nicht gelang, ist eine sinnvolle Koordination der einzelnen Maßnahmen und damit zusammenhängend die Entwicklung eines realisierbaren von allen maßgeblichen politischen Kräften getragenen Umweltschutzkonzepts, an dem sich die für gemeinschaftsbezogene Umweltschutzmaßnahmen verantwortlichen Instanzen bei der Entwicklung zukunftsweisender Strategien wirklich orientieren können. Daß dieser Weg nicht, wie manche vorerst meinten, über die Neuschaffung einer umfassenden Umweltschutzkompetenz des Bundes führen kann, weil eine solche angesichts der 
Komplexität des Umweltschutzes über kurz oder lang zu einer Beseitigung der ohnehin nicht sehr ausgeprägten föderalistischen Struktur unseres Gemeinwesens führen müßte, hat man inzwischen in weiten Kreisen erkannt und angesichts der verfassungsrechtlichen Gegebenheiten und der realen politischen Machtverhältnisse auch überwiegend akzeptiert. Der 1975 vom BMGuU zur Begutachtung versandte Entwurf eines Bundesumweltschutzgesetzes dürfte wegen seiner von den Ländern und von der Opposition nicht akzeptierten Verfassungsbestimmungen auch in der nächsten Zeit kaum Chancen auf eine politische Realisierung haben. Einen brauchbaren Ansatz für die weitere Entwicklung der Umweltschutzpolitik enthält m. E. der Schlußbericht der Abteilung "Grundlagenforschung" des 1976 in Innsbruck abgehaltenen 6. ÖJT, die sich eingehend mit der Problematik "Raumordnung und Umweltschutz" befaßte und etwas verkürzt formuliert zu folgendem Ergebnis kam:

"1) Trotz gewisser Eigenständigkeiten kann weder das Umweltschutzrecht auf die Instrumente der Raumordnung verzichten noch ist die Raumordnung ohne Bedachtnahme auf umweltschutzpolitische Zielvorstellungen realisierbar. Die Aufnahme einer isolierten Staatszielbestimmung „Umweltschutz" in die Verfassung wäre in mehrfacher Hinsicht bedenklich.

2) Weder eine umfassende Umweltschutzkompetenz des Bundes noch die Ablehnung jeder Korrektur des derzeitigen Kompetenzkataloges der Bundesverfassung können als zielführend angesehen werden. Anzustreben wäre vielmehr eine differenzierte, an Sachproblemen orientierte Zuständigkeitsordnung, bei der Kompetenzkorrekturen in beiderlei Richtung nicht von vornherein ausgeschlossen sein sollen.

3) Die Koordination der Umweltschutz- und Raumordnungsmaßnahmen der einzelnen Gebietskörperschaften bedarf einer weiteren Intensivierung. Die zentrale Bedeutung der sowohl im Raumordnungs- wie im Umweltschutzrecht auftretenden Rechtsstaatsprobleme insbesondere des Rechtsschutzes darf nicht außer acht gelassen werden. $\mathrm{Zu}$ prüfen ist $u$. a., inwieweit das in diesem Rechtsbereich feststellbare Vordringen primär zielorientierter Regelungen auch neuartige Formen der Vollzugsdeterminierung und der Kontrolle erfordert.

4) Neben der verfassungs- und verwaltungsrechtlichen Seite des Umweltschutzes und der Raumordnung sind vor allem auch deren finanzrechtliche Aspekte $\mathrm{zu}$ beachten. In einem aufgabenorientierten Finanzausgleich sind auch die finanzrechtlichen Konsequenzen einer Aufgabenübertragung an 
nachgeordnete Gebietskörperschaften zu beachten. Das im F-VG normierte Kostentragungsprinzip ist dabei vom funktionellen Gesichtspunkt aus zu sehen."

Inzwischen haben zur Intensivierung der Koordination von Umweltschutz- und Raumordnungsmaßnahmen mehrere Bundesländer von der durch die B-VG-Novelle 1974 eröffneten Möglichkeit, über Angelegenheiten ihres jeweiligen Wirkungsbereiches Gliedstaatsverträge abzuschließen, Gebrauch gemacht. Dem am 3. Oktober 1978 zwecks gemeinsamer Planung in Sachen Raumordnung und Umweltschutz für das gemeinsame Grenzgebiet zwischen Salzburg und Oberösterreich abgeschlossenen Staatsvertrag folgten heuer solche Verträge zwischen Oberösterreich und Niederösterreich und zwischen Oberösterreich und der Steiermark. Bereits im Vorjahr hat die Landeshauptmännerkonferenz vorgeschlagen, daß hinsichtlich der Vereinheitlichung des Schwefelgehaltes im Heizöl zwischen Bund und Ländern ebenfalls eine umweltschutzrelevante Vereinbarung gemäß Art. 15 a B-VG abgeschlossen wird. Zu einer Verwirklichung dieser Anregung ist es bisher nicht gekommen. Obwohl man die praktischen Auswirkungen der erwähnten Gliedstaatsverträge naturgemäß noch nicht beurteilen kann, so scheint es doch, daß derartige Gliedstaatsverträge einen Ausweg aus der bisher ungelöst gebliebenen Kompetenzproblematik des Umweltschutzes eröffnen könnten.

Abschließend noch ein paar Bemerkungen zu den österreichischen Erfahrungen mit Versuchen, Umweltschutzfragen im Wege direktdemokratischer Entscheidungsfindung bzw. bürgerschaftlicher Partizipation an Verwaltungsentscheidungen zu lösen. Der erste Fall betrifft die Inbetriebnahme des Kernkraftwerkes Zwentendorf.

Am 7. 7. 1978 faßte der Nationalrat einen Gesetzesbeschluß, der die Erlaubnis zur Inbetriebnahme des Kernkraftwerkes Zwentendorf unmittelbar normierte. Gleichzeitig wurde jedoch beschlossen, darüber, ob dieser Gesetzesbeschluß Gesetzeskraft erlangen soll, gemäß Art. 43 B-VG eine Volksabstimmung durchzuführen, die vom Bundespräsidenten gemäß Art. 46 Abs. 3 B-VG für den 5. 11. 1978 angeordnet wurde (BGBl 1978/ 493). Das Ergebnis waren 50,5\% Nein- und 49,5\% Ja-Stimmen (BGB1. 1978/493) bei einer Beteiligung von 64,1\% der Stimmberechtigten. Die vorläufige Folge war das (einfache) Bundesgesetz v. 15. 12. 1978 über das Verbot der Nutzung der Kernspaltung für die Energieversorgung in Österreich („Atomsperrgesetz“, BGBl. 1978/676). Als sich im Zuge des Wahlkampfes für die Nationalratswahl 1979 die Atomdiskussion zu emotionalisieren begann, vereinbarten die beiden Großparteien, das 
Atomsperrgesetz in Verfassungsrang zu erheben und damit eine Abänderung von einer 2/3 Mehrheit abhängig zu machen. Nichtsdestoweniger ist die Atomkraftdiskussion nach der Wahl wieder in Gang gekommen und über die Realisierung des seinerzeitigen Parteienpaktes eine neuerliche politische Auseinandersetzung entbrannt, deren Ausgang durchaus noch offen ist.

Der zweite Punkt betrifft eine Reihe von Bürgerinitiativen hauptsächlich zu Umweltschutzfragen in verschiedenen Großgemeinden. Der Fall mit der weitestgehenden politischen Auswirkung war die 1972 in Graz gestartete Bürgerinitiative gegen die von der Stadtplanung vorgesehene Führung der Pyrhnautobahn quer durch dichtbesiedelte Wohnviertel. Sie führte wegen der ablehnenden Haltung des sozialistischen Bürgermeisters bei der anschließenden Gemeinderatswahl $1973 \mathrm{zu}$ einem Machtwechsel im Grazer Rathaus durch eine Koalition der siegreichen OVP und FPÖ bei erheblichen Verlusten der Sozialisten. Die sozialistischen Mandatsverluste hielten auch bei der Gemeinderatswahl 1978 noch an. Die neue Rathauskoalition verdankte ihre Erfolge nicht zuletzt ihren Umweltschutzaktivitäten und dem Umstand, daß sie ein eigenes städtisches Büro für Bürgerinitiativen errichtet und in zahlreichen Bürgerversammlungen und Bürgerbesprechungen der Bevölkerung die Möglichkeit gegeben hatte, ihre umweltschutzpolitischen Anliegen gegenüber der Stadtplanung zur Geltung zu bringen. 
4. Bericht von Professor Dr. Luzius Wildhaber, Basel:

\section{Staatsaufgabe Umweltschutz in der Schweiz}

Das Thema "Staatsaufgabe Umweltschutz" gibt in der Schweiz zu Reflexionen in verschiedenster Richtung Anlaß. Zunächst geht es um ein Problem der föderalistischen Kompetenzverteilung zwischen Bund und Kantonen. Sodann finden wir uns in der politischen Wirklichkeit mit Argumenten konfrontiert, die sich sehr oft der bundesstaatlichen Fragestellung überlagern, nämlich ob und wieweit irgendeine staatliche Ebene Bund, Kantone oder Gemeinden - überhaupt tätig werden und privates Handeln reglementieren soll. Ferner geht es um den verfassungsrechtlichen Umweltbegriff und seine Beschränkung durch Grundrechte oder allgemeine rechtsstaatliche Grundsätze. Es fragt sich aber auch, wie richtiges Recht für eine neue, als immer bedrängender empfundene Problematik aussehen soll; was heute durch Rechtsnormen ganz allgemein kurzund längerfristig machbar und auszurichten ist; ob punktuelle, präzise Maßnahmen mehr Erfolg versprechen als ambitiöse Gesamtkonzepte; und schließlich, ob eine Rechtssetzungs-Verpflichtung des Staates eher zum Ziele führen kann als eine bescheidenere, klassische Ermächtigungsnorm.

Nach der Grundregel der bundesstaatlichen Aufgaben-Ausscheidung liegt die Rechtssetzungs-Kompetenz bei den Kantonen, solange der Bund nicht ausdrücklich oder konkludent zum Erlaß von Maßnahmen ermächtigt oder dazu verpflichtet wird. Kein Kanton hat jedoch ein eigentliches Umweltschutzgesetz erlassen, und nach wie vor gibt es wenig kantonales Umweltschutzrecht. Erst in den letzten sechs Jahren haben einige Kantone begonnen, die gesetzlichen Grundlagen beispielsweise für eine Verbesserung der Wärmeisolation bei Gebäuden, für eine regelmäßige Kontrolle der Ölheizanlagen oder für eine sparsame Ordnung des Energieverbrauchs bereitzustellen.

$\mathrm{Zu}$ den umweltrelevanten, punktuellen Kompetenzen des Bundes kann man vor allem zählen:

- Fischerei, Jagd und Vogelschutz (Art. 25 BV von 1874);

- Eisenbahnen (Art. 26 BV von 1874);

- Wasserbau- und Forstpolizei (Art. 24 BV von 1897);

- Gesundheitspolizei (Art. 69 bis BV von 1897);

- Zivil- und Strafrecht (Art. 64 und 64 bis BV von 1898); 
- Wasserwirtschaft (Art. 24 bis BV von 1908/1975);

- Schiffahrt (Art. 24 ter BV von 1919);

- Motorfahrzeuge (Art. 37 bis BV von 1921);

- Luftfahrzeuge (Art. 37 ter BV von 1921);

- Arbeitnehmerschutz (Art. 34 ter BV von 1947);

- Gewässerschutz (Art. 24 quater BV von 1953, 24 bis BV von 1975);

- Atomenergie (Art. 24 quinquies BV von 1957);

- Nationalstraßenbau (Art. 36 bis BV von 1958);

- Rohrleitungen (Art. 26 bis BV von 1961);

- Natur- und Heimatschutz (Art. 24 sexies BV von 1962);

- Bodenrecht und Raumplanung (Art. 22 ter und 22 quater BV von 1969);

- Forschung (Art. 27 sexies BV von 1973);

- Elektrische Energie (Art. 24 quater BV von 1975).

Gestützt auf diese verschiedenen Bestimmungen ist ein weitverzweigtes Umweltschutzrecht des Bundes entstanden, das in über hundert Bundesgesetzen und -verordnungen verstreut ist. Diese reichen vom Gewässerschutzgesetz bis zum Straßenverkehrsgesetz, vom Nachbarrecht des Zivilgesetzbuches bis zum Arbeitsgesetz und zum Giftgesetz. Daneben tritt noch das kantonale und kommunale Umweltschutzrecht. Die Verwirklichung aller dieser Normen fällt in den Verantwortungsbereich einer Vielzahl von Behörden, die zudem meist andere primäre Aufgaben wahrzunehmen haben als den Umweltschutz. Man hat den geltenden Rechtszustand als Zersplitterung, ja als Konzeptionslosigkeit kritisiert. Er zeigt jedenfalls, da $B$ man konkret und pragmatisch auf die jeweils dringlichsten Probleme reagiert hat.

Von den verschiedenen Umweltelementen ist das Wasser normativ am besten geschützt. Das Gewässerschutzgesetz des Bundes von 1971 untersagt allgemein, „feste, flüssige oder gasförmige Stoffe jeder Art, die geeignet sind, das Wasser zu verunreinigen, mittelbar oder unmittelbar in die Gewässer einzubringen oder abzulagern". Der Verwirklichungsgrad ist freilich je nach Kanton höchst unterschiedlich. Im Kanton Genf können 99,3\% aller Einwohner an die bestehenden Kläranlagen angeschlossen werden. In 18 der 26 Kantone oder Halbkantone können mehr als zwei Drittel der Einwohner erfaßt werden. Im Kanton Glarus beträgt der Prozentsatz aber nur $24 \%$, in BaselStadt $6 \%$ (weil die jetzige Kläranlage immer noch im Bau ist), im neuen Kanton Jura schließlich ganze $2 \%$. 
Der Boden ist bisher unter Umweltgesichtspunkten kaum geschützt. Immerhin ist dieses Jahr endlich das neue Raumplanungsgesetz des Bundes angenommen worden. Von Flora und Fauna sind einzelne, speziell direkt gefährdete Arten geschützt. Wohl am bedeutsamsten ist das Verbot der Verminderung des Waldareals in der Schweiz, das 1902 durch das Forstpolizeigesetz ausgesprochen worden ist und das vielleicht als die einzige gesetzgeberische Heldentat im Bereich des Umweltschutzes bezeichnet werden darf. Der Qualität der Luft insgesamt hat sich der Gesetzgeber bisher nicht zugewendet. Stattdessen wurden spezifische Vorschriften über einzelne Quellen der Luftverschmutzung erlassen.

Nach ersten Vorstößen von 1956 und einer Motion von Nationalrat Binder von 1964 wurde 1971 mit einer eindrücklichen 12:1-Mehrheit (1 222931 Ja gegen 96359 Nein) der neue Artikel 24 septies BV angenommen. Er lautet:

„Der Bund erläßt Vorschriften über den Schutz des Menschen und seiner natürlichen Umwelt gegen schädliche oder lästige Einwirkungen. Er bekämpft insbesondere die Luftverunreinigung und den Lärm.

Der Vollzug der Vorschriften wird, soweit das Gesetz ihn nicht dem Bund vorbehält, den Kantonen übertragen."

Dieser Artikel ist gewissermaßen als eine die bisherigen Teilbereiche übergreifende Querschnittskompetenz gedacht. Im übrigen soll er nicht nur Kompetenzbegründung sein, sondern auch Programmnorm und Staatszielbestimmung, sowie Verpflichtung $\mathrm{zu}$ wirksamer Rechtssetzung und Gestaltung. Umweltschutz soll nach Art. 24 septies BV in erster Linie Lebensund Gesundheitsschutz sein. Die Verfassung fordert indes ebenso den Schutz der natürlichen Umwelt, nämlich von Wasser, Luft, Boden, Tieren und Pflanzen, sowie der ökologischen Gegebenheiten und der Lebensgemeinschaften von Menschen, Tieren und Pflanzen. Darunter fallen wohl etwa Volumenveränderungen an ober- und unterirdischen Gewässern, die Belastung des Bodens durch thberdüngung, ungenügende oder unzweckmäßige Bewirtschaftung, Vorschriften über die Wärmeisolation im Bauwesen oder baulicher Umweltschutz in dem Sinne, daß die Verhinderung einer ökologisch schädlichen Bauweise indirekt auf Ortsbild- und Landschaftsschutz hinauslaufen könnte. Indessen hat es sich als politisch unmöglich erwiesen, die potentielle Spannweite des Verfassungsartikels auf Gesetzesebene auszuschöpfen.

Nicht unter den Begriff der natürlichen Umwelt gemäß Art. 24 septies BV fällt die soziale oder die künstliche Umwelt, also Häuser, Bauten, Denkmäler. Aufgrund des Werdegangs der 
Verfassungsbestimmung ist auch klar, daß der Bund gestützt darauf weder eine Bevölkerungspolitik betreiben noch ein Nullwachstum anstreben darf. Die Vorschrift bedeutet auch nicht, daß die Verfassung das Verursacherprinzip zwingend festschreiben oder für oder gegen die Kernenergie Stellung beziehen würde.

Die Einfügung des neuen Umweltartikels bietet nicht geringe Auslegungsprobleme. Er muß zunächst mit den schon vorhandenen Kompetenznormen harmonisiert werden, also etwa den Gewässerschutz-, Atomenergie- und Natur- und HeimatschutzArtikeln. Er muß ferner in ein ausgewogenes Verhältnis zu den Grundrechten gerückt werden. Umweltschutzmaßnahmen, die auf einer gesetzlichen Grundlage beruhen, verhältnismäßig und nicht-diskriminatorisch sind, können aufgrund der neueren Rechtsprechung als im öffentlichen Interesse liegend und sozialpolitisch motiviert betrachtet werden. Solange ihr Kerngehalt gewahrt bleibt, stehen weder die Eigentumsgarantie noch die Handels- und Gewerbefreiheit solchen Maßnahmen entgegen.

Ende 1973 wurde ein erster Entwurf zu einem Umweltschutzgesetz des Bundes der Öffentlichkeit vorgestellt. Er war weit gefaßt und bezog sich auf Einwirkungen jeder Art, welche die Gesundheit oder das Wohlbefinden des Menschen oder die ökologischen Gegebenheiten beeinträchtigen. Anschließend sollte das allgemein gehaltene Gesetzeswerk auf Verordnungsebene verfeinert und seine weitgefaßten Generalklauseln der notwendigen Konkretisierung zugeführt werden. Die Kostenzurechnung sollte nach dem Verursacherprinzip erfolgen.

In der beginnenden Rezessionsphase, in der das Vernehmlassungsverfahren 1974 durchgeführt wurde, stie $B$ der Gesetzesentwurf auf heftige Kritik, sowohl bei den Kantonen wie bei Industrie und Gewerbe. Man warf ihm vor, er sei eine perfektionistische Supergesetzgebung, zu wenig präzis in Zielen und Maßnahmen, zu unklar in der Kompetenzausscheidung zwischen Bund und Kantonen, zu wenig abschätzbar in seinen finanziellen Folgen, zu fragwürdig in seinen generalklauselartigen Delegationen.

Der Bundesrat verzichtete deshalb auf die ambitiöse Gesetzeskonzeption und legte 1978 einen zweiten, bescheideneren Vorentwurf vor. Der Verfassungsauftrag des Art. 24 septies BV soll nun durch ein etappenweises gesetzgeberisches Vorgehen erfüllt werden. Im Vordergrund stehen die vier Teilbereiche der Luftreinhaltung, Lärmbekämpfung, Abfälle und umweltbelastende Stoffe. Auf ein eigenes Haftpflichtrecht und Len- 
kungsabgaben soll verzichtet werden, ebenso wie auf Vorschriften über baulichen Umweltschutz.

Man hat dem zweiten Vorentwurf vorgeworfen, es handle sich mehr um halbherzigen Immissionsschutz denn um vollzugswirksamen Umweltschutz unter Beachtung ökologischer Erkenntnisse. Umgekehrt plädierte Nationalrat Akeret folgendermaßen eloquent für den Entwurf: Ein „'Alles oder Nichts' fördert lediglich den Immobilismus und wird zur Folge haben, daß wir uns noch weitere 20 Jahre über Untätigkeit oder Versagen der Behörden aufhalten, uns in Feuerwehrübungen verzehren und uns über luftverpestete Alpentäler ärgern dürfen." (NZZ vom 28. Juli 1978). Dieser letzteren Ansicht schlossen sich im Vernehmlassungsverfahren zwei Drittel der Kantone, Parteien und Verbände an. Es scheint wahrscheinlich, daß das Grundkonzept des Entwurfes zum Gesetz werden wird.

Wo stehen wir also heute? Die Zustimmung zum Umweltschutzartikel von 1971 war überwältigend und geradezu von einer emotionellen Grundwelle getragen. Vielleicht war die Zustimmung aber gerade deswegen so hoch, weil im Grunde der eigentliche politische Sachkonflikt in keiner Weise ausgetragen war. Dem Gesetzgeber war weitestgehende Ermessensfreiheit belassen in der Wahl der Mittel und Verfahren, des Zeitkalenders und allgemein des politisch Machbaren. Daß man in der Lehre den Umweltschutzartikel 24 septies BV als Verpflichtung zur gestaltenden Rechtssetzung und zur Verwirklichung eines Gesamtkonzeptes bezeichnete, änderte daran wenig. Ich glaube, daß es auch nicht geholfen hätte, wenn man ein Grundrecht auf gesunde und saubere Umwelt konzipiert und sich dann in einem Dschungel-Kleinkrieg vor Gerichten verloren hätte.

Man kann nicht sehr stolz sein auf den Stand des jetzigen Umweltschutzrechtes in der Schweiz. Die Auswirkungen der Fluoremissionen der drei Aluminiumwerke im Kanton Wallis führten in den letzten Jahren zu beängstigenden Schäden an den Früchtekulturen und zu einem beschleunigten Absterben von Wäldern, darunter auch des altehrwürdigen und einzigartigen Pfynwaldes oberhalb von Sierre. Der Bundesrat stellte sich 1977 auf den Standpunkt, für die Abgabe von Fluor in die Atmosphäre gebe es noch keine gesetzlichen Vorschriften, und die Grenzwerte für die Abgabe ins Wasser müßten erst ab 1982 eingehalten werden, so $\mathrm{da} B$ keine rechtliche Grundlage zu einem Vorgehen gegen die Aluminiumfabriken bestehe. Wir haben einen Umweltschutzartikel in der Bundesverfassung und ein Waldrodungsverbot im Forstpolizeigesetz, aber im Effekt kann man Wälder ungestraft statt mit der Axt durch Fluoremissionen roden. Nach heftigen Demonstrationen und langwie- 
rigen Verhandlungen erklärten sich die betroffenen Unternehmen bereit, das AusmaB ihrer Emissionen zu vermindern, - somit zu der "hoheitlich inspirierten Verhaltensabrede", von der Herr Hoppe sprach.

Offenbar muß sich auch das Umweltschutzrecht den ehernen Regeln der schweizerischen Konkordanz-Demokratie unterziehen. Politik wird bei uns unter Vermittlung und gelegentlich unter Führung des Staates durch Kompromisse aller Direktbetroffenen mitbestimmt und vollzogen. Für neue Konzepte bedarf es eines breitgestreuten Konsenses. Sie müssen, wie man sagt, „erdauert" werden und unterliegen der Doppelkontrolle der obligatorischen Verfassungsbestimmung mit Volk- und Ständemehr und daran anschließend des fakultativen Gesetzesreferendums mit Volksmehr. Gesetzgebung ist dabei kein reiner Verfassungsvollzug.

Man diskutiert in der Schweiz zur Zeit mehrere Gesamtkonzepte oder Globallösungen, nicht nur das Umweltschutzgesetz, sondern auch Vorschläge für eine Gesamtenergie- und eine Gresamtverkehrskonzeption, von der Totalrevision der Bundesverfassung ganz zu schweigen. Alle diese Versuche zur Gesamtschau müssen den „Erdauerungs-Prozeß“ durchmachen.

Gesamtkonzepte schaffen nicht nur normative, sondern auch kognitive Erwartungshaltungen, nicht nur überdachende rechtliche Ordnungsversuche, sondern auch erzieherisch-aufklärerische Langfristwirkungen. Davon abgesehen gehorchen sie jedoch anscheinend ihren eigenen Gesetzen. Der Umweltschutzartikel präsentiert sich als ein umfassender Gestaltungsauftrag an den Rechtssetzer. Der politische Proze $\beta$ hat ihn aber zu einer beschränkten, vorsichtigen, auf den Stand der Technik und die wirtschaftliche Zumutbarkeit abstellenden Vorschrift werden lassen. Die unumschränkte Verfassungsnorm findet sich auf Gesetzesebene mit einer Vielzahl von Beschränkungen wieder.

Das künftige Bundesumweltschutzgesetz widerlegt diese Beurteilung nicht, sondern bestätigt sie vielmehr. Kantons-, Verbands- und Rezessionseinflüsse bremsten den Höhenflug des Verfassungsanspruches und erinnern daran, daß die schweizerische Demokratie offenbar ausgeprägter als früher gegenüber neuen Staatsaufgaben eine Staatsform der großen Geduld und der kleinen Schritte ist. 


\section{Aussprache und Schlußworte \\ Staatsaufgabe Umweltschutz}

Vorsitzender (Scholz): Meine sehr verehrten Herren Kollegen! Ich darf hiermit die Aussprache zum zweiten Beratungsgegenstand eröffnen.

In Übereinstimmung mit den Referenten möchte ich Ihnen zur Konzentration unserer Aussprache einen Dispositionsvorschlag unterbreiten, demzufolge wir uns zunächst in einem ersten Diskussionskomplex den allgemeineren Grundsatzfragen einer Staatsaufgabe Umweltschutz zuwenden wollen, $d . h$. vor allem den tatsächlichen und rechtlichen Voraussetzungen sowie Dimensionen einer solchen Staatsaufgabe - angefangen von Problemen der Realanalyse über die Dimensionen eines aktualisierten Umweltschutzes vom „ökologischen Existenzminimum“ bis hin zur umfassenderen Umweltvorsorge, über Fragen eines Staatsziels Umweltschutz bis zu konkreteren Zielkonflikten. Im folgenden Diskussionskomplex sollten wir die näheren verfassungsrechtlichen Grundlagen des Umweltschutzes besprechen; im anschließenden dritten Diskussionskomplex soll es um die Instrumentarien und Maßstäbe eines effizienten Umweltschutzes gehen. Die abschließenden Komplexe sollen zunächst Detailfragen legislatorischer und exekutivischer Umweltschutzverantwortung und ihrer Kontrolle sowie den Poblemen des Rechtsschutzes im Umweltschutzbereich gewidmet sein.

Indem ich Ihr freundliches Einverständnis mit diesem Dispositionsvorschlag voraussetzen darf, bitte ich zunächst Herrn Dürig, das Wort zu nehmen.

Dürig: Wenn ich von einem Thema viel verstehe, das war gestern, halte ich in der Diskussion den Mund. Sie können also auf die Qualität meines heutigen Diskussionsbeitrags schließen. Die "Ökologische Vernetzung" als "Ökologische Wende" kann einem ja im bösen Traum kommen. Tröstlich ist nur, daß so etwas menschenunmöglich ist. Das schafft auch kein Staat, nicht einmal als Diktatur. In der Sicht der beiden Referate mag es fast ketzerisch klingen, aber wir sollten uns zunächst und primär mit dem harten Geschäft der eigentlichen repressiven und präventiven Gefahrenabwehr begnügen. Bei der Staatsaufgabe Umweltschutz stehen wir doch vor einem ganz verquollenen Okologiebegriff. Man hat ihn vor allem durch folgende drei 
Erweiterungen aufgepumpt. Erstens ist da die Einbeziehung der Ästhetik; es muß in Stadt und Land alles "schön“ sein, auch wenn es sich für den Polizeirechtler um bloße Geschmacklosigkeiten und Belästigungen handelt. $\mathrm{Da}$ ist ferner jener "grandiose" Gesundheitsbegriff der WHO, wonach Gesundheit nicht bloß die Abwesenheit von Krankheit und Schwäche ist, sondern völliges körperliches, geistig-seelisches und soziales "Wohlbefinden". Dies als Staatsaufgabe muß man erst einmal auf der Zunge zergehen lassen. Aber m. E. sind "Aktiv- und Passivrauchen“, „Margarine oder Butter" usw. nun einmal keine abendfüllenden Themen für ausgewachsene Staatsrechtler. Und da ist drittens das Ausufern in Sentimentalität und Romantik. Jeder Baum, der dazu gehörende Rehbock sowieso, jeder Tümpel (der Lurche wegen) ist dann allemal gut für eine Bürgerinitiative und einen Verwaltungsprozeß. Manche Ökologiegruppen spüren nicht einmal, wie sollten sie auch, daß ihr Vokabular jedenfalls Leute meiner Generation verdammt an die gehabte "Blut- und Boden"-Terminologie erinnert. Wenn man dies und noch mehr über den Ökologiebegriff alles zur Staatsaufgabe Umweltschutz macht, dann $m u \beta$ ja, wie im frischen Hamburger Giftmüll-Skandal, die simple und nüchterne Gefahrenabwehr notleidend werden. Ich habe es nie sehr lustig gefunden, wenn man Industrien, die rund um die Uhr drei Schichten fahren, durch Gewerbeaufsichtsbehörden mit 40Stunden-Woche (und Gründonnerstag frei ab $12 \mathrm{Uhr}$ ) beikommen will. In der Tat besteht im Umweltschutz ein „Vollzugsdefizit", nämlich bei der Gefahrenabwehr. Frido Wageners Diagnose von der letzten Tagung stimmt hier ganz besonders. Man macht mit starken ökologischen Vokabeln Pläne, Erlasse, Richtlinien usw., aber man hält nicht viel vom konkreten Verwaltungsvollzug. In Hamburg hätte sich ja dabei jemand die Hände und Stiefel dreckig machen müssen. Ein weiteres fällt mir bei der Staatsaufgabe Umweltschutz auf. Es ist das Springen in der Dimension Zeit auf Kosten des Hier und Heute. Ökologen sehen sich gern als Futurologen, und die "kommenden Generationen“ gehören zum Standard der Argumentation. Mit dieser Futurologie ist ganz merkwürdig jedoch oft Nostalgie verknüpft. Die ganz Progressiven wollen mit dem Rousseau in der Tasche zurück, möglichst in die vorindustrielle Epoche. Dieses Changieren mit der Dimension Zeit $m u \beta$ ja geradezu bewirken, daß man hic et nunc nicht einmal mehr mit mittleren Katastrophen fertig wird; "mittlere" deshalb, weil im letzten Winter nur die Hälfte der Republik von Eis und Schnee katastrophal zugedeckt wurde. Es ist doch auch nicht so, daß die Beschränkung auf die Gefahrenabwehr im Umweltschutz von uns und unserem „Job“ 
- von Bau-, Gewässer-, Gewerbepolizei udgl. verstehen wir doch etwas - zu wenig abverlangt. Was ist mit dem Verhältnis von Gefahr und "Restrisiko"? Was ist, da es in der Naturwissenschaft keine Nullwerte gibt, mit Gefahren, die erst durch Summierung entstehen, obwohl aber auch jeder "nur" tut, was per se polizeilich erlaubt ist, weil es technisch besser (noch) gar nicht geht. Veranschaulicht am „Umkippen“ eines Gewässers, obwohl jeder Haushalt, jeder Betrieb, jede Gemeinde das Abwasser klären, „so gut es geht", hat man mir schon dreimal dieses Summierungsproblem als Doktorarbeit zurückgegeben. Ich meine also: Wir kümmern uns in der Staatsaufgabe Umweltschutz erst einmal um die Gefahrenabwehr und dann machen wir meinetwegen "Ökologische Wende" und "Ökologische Vernetzung".

Vorsitzender: Vielen Dank, Herr Dürig, für Ihren kritischen Auftakt.

Ipsen: Ich spreche zu Thesen 24, 25 von Herrn Hoppe - Zielkonflikte. Er hat darauf hingewiesen, bei Konkurrenz von Zielen spiele der Umweltschutz mit seinem Stellenwert oft eine schwächere Rolle gegenüber anderen relevanten öffentlichen Interessen. Er hat darauf hingewiesen, die Entscheidung über den Zielkonflikt liege oft in den Händen der Exekutive, oft nach den Maßstäben unbestimmter Rechtsbegriffe, was er auch als nicht sonderlich hilfreich empfunden hat. Ich würde meinen, es gibt auch Hilfen für die Entscheidungen dieses Zielkonflikts aus vorhandener Gesetzgebung, die man überhaupt insgesamt einmal durchforsten sollte, systematisch nach der Qualifizierung bestimmter öffentlicher Interessen und ihrer Zuordnung zueinander. Ich nehme als Beispiel auf der einen Seite gewichtige außenpolitische Interessen, Verteidigungsinteressen, Sicherheitsinteressen, auf der anderen Seite Umweltschutzinteressen teils solcher Art, wie Herr Dürig sie etwas sentimental gekennzeichnet hat, die mir aber unter dem Stichwort öffentliche Gesundheit, Naturschutz, Landschaftspflege doch relevant zu sein scheinen. Es geht im Bundesleistungsgesetz, im Landbeschaffungsgesetz, in der Naturschutzgesetzgebung um die Frage, was bei Konfliktsituationen zwischen diesen außenpolitisch-militärischen Interessen auf der einen Seite und den anderen, die ich nannte, den Vorrang hat. Da gilt die Regel: Normalerweise, in Nicht-Spannungszeiten dürfen in Naturschutzgebieten militärische Utbungen nicht stattfinden. Es dürfen zwar Naturschutzgebiete enteignet werden für Truppenübungsplätze, aber als Ersatzland für den Betroffenen darf nun nicht wiederum irgendein 
anderes Naturschutzland genommen werden. Da sind also Konfliktlösungen legislatorischer Art gegeben. Ich halte diese Hilfen für wesentlich, denn sie geben die Auskunft des Gesetzgebers über die Zuordnung dieser Stellenwerte, wobei man dann noch berücksichtigen sollte, um welche Art öffentlicher Interessen im Sinne der Rechtsprechung des Verfassungsgerichts es sich handelt, um absolute oder solche, die kraft Qualifikation durch den Gesetzgeber zu öffentlichen Interessen gemacht und ausgewiesen werden. Diese Interessen finden zur Zeit keine Berücksichtigung in dem Raum, in dem ich zuhause bin. Zwischen Soltau und Lüneburg leben 30000 Menschen in Naherholungsgebieten, in Gebieten, die durch die Landesplanung als bevorzugte, befriedete Gebiete ausgewiesen sind, als Naherholungsräume und eben auch Naturschutzgebiet. Dort finden seit - sage und schreibe - 35 Jahren Tag und Nacht, wenn auch mit Unterbrechungen, militärische Ưbungen statt.

Vorsitzender: Vielen Dank, Herr Ipsen! Ich hoffe und bin sicher, daß uns auch die weitere Diskussion noch viel wirksame Munition für die ,Schlacht von Raven' liefern wird. Als nächstes darf ich Herrn Bach of bitten!

Bachof: Herr Rauschning fordert in seiner These 22, daß die Entscheidung über die Schutzintensität im Bereich der Risikovorsorge von der Gerichtsbarkeit auf die politisch verantwortlichen Gewalten zurückverlagert werden müsse. In der Tat, es handelt sich um ein „Zurückverlagern"! Es ist heute wirklich so, daß die eigentliche Entscheidung über umfangreiche Planungen von den Gerichten getroffen wird. Damit sind die Entscheidungen nicht nur politisch falsch verortet, sondern sie übersteigen auch das Vermögen der Gerichte. Ich war viele Jahre Mitglied eines VGH-Senats, der mit Bauplanungsfragen zu tun hatte. In allen größeren Bauleitverfahren ging es auch - und sogar vorzugsweise - um Fragen des Umweltschutzes: um Lärmbelästigung, Luftverunreinigung, Kleinklimaverschiebung u. dgl. mehr. Der Kampf gegen einen solchen Plan wird regelmäßig auf zwei Ebenen geführt: auf der ersten Ebene wird die Einhaltung der Richtwerte, auf der zweiten die Richtigkeit dieser Richtwerte bestritten. Diese Richtwerte sind ihrerseits nicht durch Rechtsvorschriften festgelegt, sondern sie beruhen auf Verwaltungsanweisungen (TA Luft, TA Lärm usw.), z. T. sogar auf privaten „Normen“; denn die Verwaltungsanweisungen verweisen ihrerseits oft auf DIN-Normen, auf TUV-Normen und auf ähnliche Regelungen, die oft in schwer zugänglichen Katalogen enthalten sind und die sich überdies häufig ändern. Zunächst wird also geltend gemacht, die Richtwerte 
seien nicht eingehalten. Der Streit darum wird mit Gutachten und Gegengutachten geführt, das Gericht muß oft ein Obergutachten einholen. Schon hier ist die Arbeit für die Gerichte sehr schwer, sie sind fast überfordert. Jedoch handelt es sich dabei um eine Aufgabe, der sie sich nicht entziehen können. Fast unlösbar wird die Aufgabe aber, wenn der Kampf auf der zweiten Ebene geführt und nunmehr geltend gemacht wird, die Richtwerte selbst seien falsch, sie entsprächen nicht den durch unbestimmte Rechtsbegriffe - Sicherheit, Gefährdung, Vermeidbarkeit, Stand von Wissenschaft und Technik usw. - geprägten gesetzlichen Vorschriften. Die Gerichte müssen also auch noch feststellen, ob die Richtwerte „richtig“ sind, d. h. jenen Vorschriften entsprechen. Dazu werden oft Gutachten über Gutachten beigebracht, die Prozesse ziehen sich endlos hin, und es ist ausgeschlossen, daß zwei oder gar alle Gerichte in der Bundesrepublik zu den gleichen Ergebnissen gelangen. Deshalb ist es unerläßlich, daß die Richtwerte autoritativ - d. h.: rechtsnormativ - festgesetzt werden. Im Augenblick fühlen sich die Gerichte zwar ein wenig erleichtert, weil das Bundesverwaltungsgericht die einschlägigen Verwaltungsanweisungen als vorweggenommene Gutachten besonders sachverständiger Gremien bezeichnet hat, so daß man praktisch zu einer Umkehr der Beweislast gekommen ist. Denn es ist in der Tat sehr schwer für jemanden, der die Pläne angreift, zu beweisen, daß die "gutachtlichen" Richtwerte falsch sind. Aber auf Dauer sind die Gerichte dadurch natürlich nicht entlastet; denn nach wie vor kann geltend gemacht werden, daß nicht die rechtsnormativ festgesetzten Richtwerte falsch seien. Wenn jene Rechtsprechung im Augenblick offenbar weitgehend akzeptiert wird, so wohl deshalb, weil die Angreifer noch unter einer Art Schockwirkung stehen. Ich glaube, es wird nicht mehr lange dauern, bis sie auch solche „vorweggenommenen Gutachten" angreifen werden. Als weiterer Mangel der derzeitigen Regelungen kommt hinzu, daß ihnen Zuverlässigkeit und Publizität fehlt. Denn manche Verwaltungsanweisungen sind nicht veröffentlicht, jedenfalls nicht amtlich; erst recht gilt das für DIN-, TỦVund ähnliche Normen. Oft müssen die Gerichte sie sich bei den Ministerien erst beschaffen; nicht selten erhalten sie sie mit dem Hinweis, daß auch das Ministerium nicht genau wisse, ob die vorgelegten Regelungen noch dem letzten Stande entsprächen. Also, solche Regelungen sind nicht zuverlässig, sie sind nicht hinreichend publiziert, das alles ist rechtsstaatlich unerträglich.

Ich habe anläßlich des Wyhl-Prozesses und der an ihm geübten Kritik des damaligen Regierungschefs von Baden-Würt- 
temberg diesen in einem Brief auf obige Mängel hingewiesen; der Brief wurde allen beteiligten Ministerien zur Stellungnahme gegeben. Der dadurch bewirkte umfangreiche Schriftwechsel hat letzten Endes zu nichts geführt. Gegen eine gesetzliche Festlegung der Richtwerte wurden Bedenken wegen der mangelnden Flexibilität der Gesetzgebung erhoben; eine Festlegung durch Rechtsverordnung wurde zwar überwiegend als wünschenswert erachtet, teilweise aber auch als ungenügend angesehen; jedenfalls meinte man, zunächst einmal weiter abwarten zu sollen. Demgegenüber meine ich, der Gesetzgeber müsse durch möglichst konkrete Zielbestimmungen die Verwaltung $\mathrm{zu}$ einer Regelung durch Rechtsverordnung ermächtigen. Dabei kann man in die Verordnungen natürlich nicht die ganzen technischen Details hineinbringen; aber die Richtwerte selbst müssen unbedingt gesetzlich oder durch Rechtsverordnung festgesetzt werden. Die Gerichte jedenfalls sind mit der Ermittlung der „richtigen" Richtwerte schlechthin überfordert. Da hilft auch der elektronische Taschenrechner nichts, ohne den ein Richter heute kaum noch in eine Planverhandlung gehen kann. („Judex non calculat“? Und wie der Richter heute rechnen muß!)

Vorsitzender: Vielen Dank, Herr Bachof! Als nächsten Diskussionsredner darf ich Herrn Vogel bitten und mit ihm gleichzeitig die Diskussionsrunde zum ersten Komplex, den Grundsatzfragen, abschließen.

Vogel: Anknüpfend an den ideologiekritischen Beitrag von Herrn Dürig würde ich gern an den Anfang ganz naiv noch einmal die Frage stellen: Was ist das eigentlich „Umweltschutz"? Wir haben gehört: Umweltschutz reicht vom Rasenmäher bis zum Atomkraftwerk und bis zur Verteilung des "knappen Gutes Luft" (eine kafkaeske Vorstellung!), er umfaßt also, um hier in Berlin auch einmal Fontane zu seinem Recht kommen zu lassen, ein außerordentlich „weites Feld“. Vielleicht kann man versuchsweise dieses Feld in drei Ebenen aufteilen: Die erste wäre in meiner Sicht die Abwehr von Beeinträchtigungen, von Immissionen, Umweltschutz also als polizeiliche Aufgabe, wobei aber eine Tendenz zu erkennen ist, sowohl das Schutzgut zu erweitern (schon etwa seit der Jahrhundertwende sind ja mit der Verunstaltungsgesetzgebung zum klassischen Polizeirecht andere, ästhetische Maßstäbe hinzugekommen) als auch die Eingriffsschwelle zu senken, von der klassischen "Gefahr hin zu dem, was wir früher "Belästigung“ nannten. Der zweite Bereich wäre der der Erhaltung und Pflege der natür- 
lichen und kulturellen Umwelt, etwas modischer gesprochen der Planung, gegebenenfalls sogar der Neugestaltung der Umwelt, wenn etwa Bäume gepflanzt und Parks angelegt werden. Und erst an dritter Stelle würde ich den Bereich sehen, für den sich das Fremdwort „Verteilung von Ressourcen“ eingebürgert hat, einfacher ausgedrückt: die Verteilung von knappen Gütern.

Ich möchte nun vorschlagen, auf diese drei Tätigkeitsbereiche des Staates im Umweltschutz - auch da knüpfe ich an Herrn Dürig an - den Gedanken der Verhältnismäßigkeit im Sinne einer "Stufentheorie“ anzuwenden: derart, daß eine Regelung jeweils/zunächst auf der niedrigeren Stufe geboten ist und der Staat zu einer Regelung auf der nächsthöheren Stufe erst übergehen darf, wenn ein Vorgehen auf der niedrigeren Stufe nicht mehr ausreicht. Wo also Gefahrenabwehr genügt, ist eine Gesamtplanung nicht erforderlich und damit auch unzulässig wenn ich Sie recht verstanden habe, Herr Hoppe, bin ich da mit Ihnen durchaus einer Meinung -, und wo jedenfalls beide gemeinsam ausreichen, besteht kein Anlaß und damit kein Recht zu einer staatlichen Ressourcenbewirtschaftung. Wir wissen ja doch alle, daß der Staat im allgemeinen überfordert ist, wenn er knappe Güter bewirtschaften soll; wir wissen das aus der Kriegswirtschaft, wir sehen es beim Numerus clausus und wir sehen es, wenn wir von hier aus dem Reichstagsgebäude einen Blick über die Mauer werfen. Natürlich gibt es Situationen, in denen der Mangel so groß ist, daß um der Gerechtigkeit willen der Staat den "Mangel verteilen“ muß, das steht außer Zweifel. - Auf der Basis der skizzierten Dreiteilung samt „Stufentheorie“ könnte man dann auf jeden der Bereiche die klassischen Institute des Verwaltungsrechts anwenden, gegebenenfalls sie vorsichtig fortentwickeln; so ließen sich Probleme wie Vertrauensschutz, Haftung des Verursachers für die Kosten einer Maßnahme usw. in Entfaltung der herkömmlichen freiheitssichernden Funktion dieser Rechtsinstitute lösen.

Ich möchte noch kurz etwas anderes anreißen: Wenn Sie auf dem Weg nach Berlin die Bahn oder das Auto benutzt haben, werden Sie gemerkt haben, daß der Umweltschutz, die Verhinderung von Emissionen, in unserem deutschen Bruder- oder Schwesternstaat offenbar noch viel weiter zurück ist als gegenwärtig bei uns. Es scheint, daß eine reine Staatswirtschaft damit größere Probleme hat als eine gemischte Wirtschaft, wie wir sie in der Bundesrepublik haben. Wenn wir uns daraufhin aber einmal anschauen, wo eigentlich in der Bundesrepublik die politisch brisanten Probleme des Umweltschutzes liegen, dann, meine ich, können wir feststellen, daß auch das gerade nicht die Bereiche der reinen Privatwirtschaft sind, sondern 
überwiegend solche der öffentlichen Wirtschaft. Die Energieversorgungsunternehmen sind ja keine Bilderbuchkapitalisten, sondern sind durchweg Unternehmungen in öffentlicher Hand. Würde man hier die eigenwirtschaftlichen Interessen solcher Unternehmungen wieder stärker von den klassischen staatlichen Aufgaben, besonders der Gefahrenabwehr trennen, dann wäre möglicherweise auch das Vertrauen gegenüber den staatlichen Organen größer, daß sie nicht wirtschaftliche Erwägungen über solche des notwendigen Rechtsgüterschutzes stellen. So frage ich mich rückblickend etwa, ob man nicht vielleicht klüger getan hätte, wenn man sich im Bereich der Atomenergiewirtschaft auf die staatlichen Aufgaben der Wachstumsvorsorge und im übrigen der Gefahrenabwehr beschränkt und sich nicht auch auf die Wachstumsbewirkung eingelassen hätte. Ich will damit nicht für eine Privatisierung plädieren, das ist ja auch nicht unser Thema, aber doch dafür, institutionell stärker zu trennen und verantwortliche Stellen zu schaffen, die unabhängig von den eigenwirtschaftlichen Interessen solcher öffentlich-wirtschaftlicher Unternehmungen für die Interessen des Umweltschutzes zu sorgen haben.

Pernthaler: Meine Diskussionsbemerkung wird sich sicher die Zensur „modische Globalbetrachtung" einhandeln. Dennoch: Viele haben ein tiefsitzendes Gefühl des Unbehagens und Mißtrauens, wenn sie die Themenformulierung „Staatsaufgabe Umweltschutz" lesen und diese in der Erfahrung bisheriger staatlicher Umweltpolitik begründeten irrationalen Ängste und Zweifel sind durch die Referate nicht ganz ausgeräumt worden. Beobachtet man die kurze Geschichte des Umweltschutzes, so spielt der Staat hier offensichtlich keine rühmliche Rolle. Er hat diese Aufgabe nicht von sich aus erkannt, sondern wurde durch eine breite Bürgerbewegung förmlich in diese Richtung gestoßen und auch heute sind die Defizite des Umweltschutzes im Grunde viel tiefer greifend als nur sektorales Ungenügen oder Versagen; die Prognosen für die nähere Zukunft stimmen eher noch pessimistischer. Ich sehe im Umweltschutz primär ein demokratietheoretisches Problem: Umweltschutz steht in einem unmittelbaren Bezug zu einer vorstaatlichen, alle Partei- und Verbandsstrukturen gleichfalls sprengenden Kategorie der Allgemeinheit der Bevölkerung und der Gesamtheit von Raumund Umweltbeziehungen (Ökosystem). Diese Dimensionen der "Gesamtheit" bewirken ein Übersteigen der pluralistischen Ordnungsstrukturen der repräsentativen Demokratie und ihrer Organe auf allen Ebenen. Daraus resultiert wiederum das bekannte Gefühl der Ohnmacht und des Unmutes des Bürgers 
im Umweltschutz. Diese Gefühle sind nun nicht unberechtigt, wenn man bedenkt, welch mächtiges Kartell von Interessen und technokratischer Potenz hinter jeder schwerwiegenden Umweltbedrohung steht. Es ist für mich von hohem symptomatischen Wert, daß die erste Thematik des wiederbelebten Gespräches zwischen Arbeitgebervereinigungen und Gewerkschaftsbund die Frage einer besseren Ausnützung der Atomkraft war. Ich bin daher nicht allzu optimistisch über die Wirksamkeit von Absprachen zwischen den gesellschaftlich-ökonomischen Machtträgern und den von ihnen vielfach gesteuerten oder abhängigen Verwaltungsorganen. Dazu kommen die primär ökonomisch und technokratisch orientierten Leitbilder gewisser Fachplanungen - vor allem der Verkehrsplanung - die jederzeit in der Lage sind, ihre Wertungen datenmäßig zu immunisieren und alle Alternativplanungen auf diese Weise zu entkräften. Gewiß spielen aber auch die in den Referaten aufgezeigten staatsrechtlichen und verwaltungswissenschaftlich-planerischen Unzulänglichkeiten und Defizite der ausreichenden Informationsbeschaffung, Koordination und des Verfahrens eine überragende Rolle für die Schwäche des Umweltschutzes gegenüber den technokratisch perfektionierten, zugleich aber auch immer schwerer faßbar werdenden Umweltbedrohungen. Gegenüber diesen Defiziten der rechtlich- und planungswissenschaftlichen Unzulänglichkeiten des Umweltschutzes kann man Verbesserungen finden. Nur: Grundsätzliche Änderungen wird man auf diese Weise nicht erzielen können! Diese können nur aus einer Besinnung auf die eminent politische Dimension des Umweltschutzes auf allen Ebenen - und nicht nur bei Gesetzgebung und den "großen Planungen" - erwachsen. Diese politische Dimension bedingt, daß die hinter jeder UmweltschutzEntscheidung stehenden Wertungen in einem politischen Verfahren offengelegt und entschieden werden müssen. Die Bürgerbeteiligung hat hierbei ihre Funktionen genauso wie die Entscheidungstechniken der repräsentativen und plebiszitären Demokratie. Die Verwaltung und Planung wird diese Wertentscheidungen jedenfalls nicht autonom oder in Verbindung mit organisierten Interessen treffen können. Verfassungsrechtlich ist diese politische Dimension des Umweltschutzes und die daraus folgenden Ansprüche - ohne daß ich dies im einzelnen jetzt begründen könnte - im Demokratiesystem und den sogenannten politischen Grundrechten der Staatsbürger begründet. Ein anders organisierter Umweltschutz verfehlt nicht nur die Sachlösungen, sondern vor allem auch das Ziel einer evolutionären Weiterentwicklung unseres politischen Systems. Beängstigend sind in Wahrheit nicht die angesprochenen "politischen Gesamt- 
entscheidungen" über den Umweltschutz, sondern ein rein ökonomisch-technologisches Verständnis dieses im Kern politischen Vorganges als eines Prozesse der reinen Datenvermittlung und Datenverarbeitung.

Häberle: Mir geht es um die Verknüpfung der anthropologischen und sozialen Dimensionen des - notwendigen - Schutzes der „Um-Welt" für unsere „Nachwelt", für die wir ein Minimum des Status quo an "guter" Umwelt aufrecht erhalten müssen, also um die Zeitdimension im Blick auf spätere Generationen. Zwei Sätze der beiden Referenten haben mich „elektrisiert": Erstens die wohl eher nebensächliche Aussage von Herrn Rauschning zum „ökonomischen" bzw. jetzt zum „ökologischen Existenzminimum" zweitens die Passage von Herrn Hoppe, Umweltschutz sei nicht nur Staatsaufgabe.

Erstens zu Herrn Rauschning: Das Bundesverwaltungsgericht hat schon im 1. Band von 1954 den Anspruch auf das wirtschaftliche Existenzminimum aus Art. 1, 2 und 20 GG begründet. Heute haben wir eine andere Herausforderung für das 30-jährige Grundgesetz im Sinne von Herrn Zachers gestrigem Votum. Damals ging es um die Bekämpfung wirtschaftlicher Existenznot, heute, d. h. etwa seit den 70er Jahren, haben wir den Parallelvorgang: ein Mindestmaß an guter Umweltqualität beginnt knapp zu werden, wir brauchen jetzt die Art. 1 und 20 GG, um ein Mindestmaß des Status quo an "guter" Umwelt zu erhalten. Welches ist die verfassungstheoretische Verknüpfung zwischen I Ihrer Gliederung, Herr Vorsitzender (,Vorfragen“) und II (zum „positiven Verfassungsrecht")? Sie liegt in dem Versuch, eine Verfassungs- und Verwaltungstheorie des - sozial erfüllten - Raumes zu entwickeln. "Mensch und Raum" meint anthropologisch: Der Mensch braucht ein Mindestmaß an gesunder Umwelt: Ich muß spazieren gehen und einen Fluß anschauen können, ich brauche Wälder; wenigstens das Vorhandene an Baumkulturen, Fluß- und Kulturlandschaften soll im Interesse von Leben und Gesundheit geschützt werden. Ähnlich wie in der kommunalen Selbstverwaltung muß der Mensch eine "gute" Umwelt erfahren können. Der Bürger sucht nach einer neuen personalen Nähe im knappen Raum. Der Status quo einer menschlichen Umwelt, die Kulturgut ist, soll bleiben. -

Verehrter Herr Dürig: Wie von keinem anderen haben wir von Ihnen die Ausstrahlungswirkungen und -ebenen der Art. 1, 2 GG gelernt. Heute müssen wir sie im Umweltschutz entsprechend wirksam machen. Und da reicht das überkommene Polizeirecht eben nicht voll aus, auch wenn wir es vielleicht noch besser durchsetzen müssen. 
Zweitens ein Wort der Zustimmung zu Herrn Hoppe: Es genügt nicht, vom Umweltschutz als „Staatsaufgabe“ zu sprechen, wir hätten sonst - in der Tat, Herr Dürig - zu viel Staat, zu viel "totale" Vernetzung. Das Ganze des Umweltschutzes erfassen wir erst dann, wenn wir ihn teils als Staatsaufgabe, teils als öffentliche Aufgabe, teils als private Aufgabe begreifen: öffentliche Aufgabe hier verstanden als Aufgabe im gesellschaftlich-öffentlichen Bereich, auch der Umweltverbände usw. Der für die öffentliche und private Verantwortung nötige Wandel im allgemeinen Umwelt-Bewußtsein ist ja sozialethisch schon im Gange: im Sinne einer tagtäglichen Aufgabe jedes einzelnen von uns, frei nach Goethe vor der „eigenen Haustür zu kehren", im Interesse der Erhaltung des Umwelterbes für die späteren Generationen.

Püttner: Ich möchte an Herrn Häberle anknüpfen. Seine Bemerkungen bekräftigen in mir den Wunsch, die Frage von Herrn Vogel noch einmal zu stellen: Was ist denn eigentlich Umweltschutz? Als Kommunalwissenschaftler bin ich geneigt, hierin nur ein neues Wort für eine alte Sache zu sehen; denn wir haben uns mit Abfallbeseitigung und dergleichen schon Hunderte von Jahren oder vielleicht Tausende von Jahren beschäftigt, aber anscheinend geht es - das zeigen die Bemerkungen von Herrn Häberle - doch um etwas anderes. Er hat das Wort „Erhaltung“ gebraucht (das auch die Referenten gerne gebraucht haben), und das Wort "Umweltschutz" deutet in der Tat darauf hin, daß eine schöne Umwelt vorgegeben ist, die es zu erhalten gilt. Aber darin liegt doch wohl eine Irreführung: Die Umwelt, wie wir sie haben ist nicht nur erhaltenswert, sondern z. T. auch schlecht; und wir wollen doch gerade dem, was schlecht ist, entgegenwirken. Da wir aber das, was schädlich ist, nicht beseitigen können oder wollen - nämlich die Industrie und die Autos -, geht es nicht um Erhaltung, sondern um Gestaltung oder allenfalls um Wiederherstellung günstigerer $\mathrm{Zu}$ stände, meistens aber um eine konstruktive Neugestaltung, indem wir nicht den Urzustand des Paradieses wiederherstellen, sondern einen ganz neuen Zustand schaffen wollen, ein neues Gleichgewicht. Und wenn wir die Dinge so betrachten, dann ist in der Tat eine umfassende Aufgabe gegeben!

Wenn man damit ernst machen will, müßte der Gedanke noch weiter ausgedehnt werden: Geht es wirklich nur um die Erhaltung von Leben und Gesundheit, gibt es nicht von der Umwelt her auch psychische Einwirkungen auf den Menschen - ich erinnere an monotonen Städtebau und dergleichen -, kann also nur eine auf Leben und äußere Gesundheit gerichtete „funk- 
tionale" Politik Platz greifen, oder müßte man nicht noch einen Schritt weitergehen und sich überhaupt die gesamte Umwelt einmal als Ideal (als Leitbild, wie es genannt wurde) an die Wand werfen; aber wie soll das Ideal aussehen? Aber dann, Herr Hoppe, kommt das Problem, ob wir einem solchen Ideal mit dem Stichwort Planung gerecht werden können. Ihre Anmerkungen, in denen auch das Wort Datenbank vorkam, haben bei mir einen kleinen Schrecken hervorgerufen, denn (Sie haben Schulz zur Wiesch übrigens selbst zitiert) die bisherigen Gesamtplanungen haben noch nicht derartige Erfolge gezeitigt, daß wir allzu optimistisch sein dürften. Entweder war die Wirkung gering; oder man bekommt die Dinge nicht in den Griff, weil Informationen und Abwägungen dieses Ausmaßes uns einfach im Moment noch überfordern. In der Stadtentwicklungsplanung, bei der man sich ja auch bemüht hat, Gesamtplanung für alle Bereiche zu betreiben, ist man bekanntlich nicht ans Ziel gekommen; und man ist heute schon sehr zufrieden, wenn man sektorale Pläne (für Schulen oder Jugendheime) einigermaßen sinnvoll erstellen kann. Hier sind Sie also m. E. etwas zu optimistisch gewesen (oder Sie korrigieren mich nachher in der Antwort). Im übrigen möchte ich noch darauf hinweisen, daß leider der Umweltschutz wie so viele moderne Vokabeln die Tendenz in sich trägt, unser System von Föderalismus und Selbstverwaltung $\mathrm{zu}$ bedrohen. Immer, wenn so eine große, "globale" Aufgabe (wie auch die Konjunkturpolitik, damals war es ähnlich) vor uns hingestellt wird, dann kann es nur einen großen Plan geben zu deren Bewältigung - so klingt es jedenfalls durch. Es ist für mich interessant, daß die Stichworte Föderalismus und Selbstverwaltung, also die Entscheidung auf den unteren Ebenen, in den Referaten so gut wie nie vorkam, außer in den Mitberichten aus Österreich und der Schweiz. Vielleicht ist hier noch etwas nachzutragen.

Mayer-Tasch: Herr Vorsitzender, meine Damen und Herren! Ich möchte gerne einige Anmerkungen zu dem ersten Referat, dem Referat von Herrn Rauschning, machen, das mich in seiner hermetischen Geschlossenheit sehr beeindruckt hat. Ich würde gerne einige methodische Bemerkungen machen und würde diese methodischen Bemerkungen gerne einleiten, indem ich ein Forsthoff-Zitat zurechtrücke. Forsthoff hat nicht etwa auf normativer Ebene argumentiert, als er von einem Gegensatz der Staatsaufgabe Umweltschutz zum Allgemeininteresse gesprochen hat, sondern Forsthoff hat empirisch argumentiert. Forsthoff hat davon gesprochen, daß die Durchsetzbarkeit eines Interesses mit dem Grad seiner Allgemeinheit schwinde. Das 
war eine empirische Aussage; Forsthoff hat damit eine ganz wesentliche Qualität bewiesen: Einen Blick für politische Realitäten. Das ist in der Tat der Auftakt zu meinen Bemerkungen: Unsere Disziplin steht ja immer in einer doppelten Gefahr: Erstens in der Gefahr, ihre Abhängigkeit von politischen Gegebenheiten zu verkennen, zum zweiten aber auch, faktische Wertungen stillschweigend normativen Aussagen zu unterlegen. Ich glaube, daß das erste Referat - und ich beziehe mich nur auf dieses - gerade dieser doppelten Gefahr in erheblicher Weise erlegen ist. Zur Begründung des ersten, - die Abhängigkeit von politischen Gegebenheiten zu verkennen, -: Auch für ein normativ angelegtes Referat muß ich sagen: Ganz ohne Empirie geht die Chose nicht, und wenn man über die Staatsaufgabe Umweltschutz redet, dann sollte man doch zumindest auch fragen, inwieweit der Staat überhaupt in der Lage ist, Umweltschutz zu betreiben. Ich darf auf Untersuchungen hinweisen, die erwiesen haben, daß unsere Umweltpolitik überhaupt nur in dem Sektor des technologischen Umweltschutzes Leistungen erbracht hat, daß er aber weitgehend unfähig ist, strukturelle Veränderungen, also strukturelle Umweltschutzmaßnahmen, durchzuführen. Den ganzen Horizont, der etwa durch Begriffe wie Dezentralisation und dergleichen angeschnitten wird, habe ich vermißt in dem Referat. Zum zweiten, was die Unterstellung von faktischen Wertungen, die stillschweigende Unterstellung betrifft: Hier muß ich sagen, daß der ganze Bereich, über den wir uns hier unterhalten, in hohem Maße im Spannungsfeld a) naturwissenschaftlicher und b) politischrechtlicher Wertung steht, in erster Linie naturwissenschaftlicher. Aber genau diese Ambivalenzen habe ich in dem Referat vermißt, und zwar vermißt in mehrfacher Hinsicht: Erstens beim Umgang mit Begriffen; es war die Rede von ökologischem Existenzminimum und von Restrisiko. Was ist das, ein ökologisches Existenzminimum? Was ist Restrisiko? Für mich ist ein Restrisiko entweder ein apologetischer oder ein polemischer Begriff, aber auf jeden Fall kein Begriff, der in einem juristischen Diskurs irgendeine Berechtigung hat. Dasselbe gilt für den Umgang mit normativen Wertungen, z. B. mit der Aussage, daß Menschenwürde ein zu erhabener Wert sei, um im Zusammenhang mit Umweltbelästigungen bemüht zu werden. Dasselbe gilt für die Frage, ob man die Sozialstaatsklausel in diesen Zusammenhang bringen kann; dasselbe gilt etwa für das Urteil über die Verhältnismäßigkeit; es gilt aber erst recht etwa für Aussagen über den Erfolg der Umweltpolitik. Ein letzter Satz noch, Herr Vorsitzender: Ich habe eine direkte Frage an Sie, Herr Rauschning. Sie sagten, unser Ziel sei oder müsse sein, 
- das war eine apodiktische Aussage - , die Umweltnutzung, nicht aber ihre Minimalisierung. Ich sehe da einen enormen Widerspruch, erstens zu Art. 14, zu der Relativierung von Art. 14, und zweitens zu dem Akkord, den Sie angeschlagen haben, indem Sie die Ambivalenz der biblischen Aussagen angesprochen haben. Sie haben nämlich nicht nur die Genesis-Fassung, sondern auch die jahwistische -1 . Moses 2, Vers $15-$ zitiert und damit einen Akkord angeschlagen, der in den Bereich der ökologischen Ethik gehört. Das scheint mir überhaupt nicht zu dieser apodiktischen Aussage zu passen. Dankeschön!

Vorsitzender: Vielen Dank Herr Mayer-Tasch! Ihre kritischen Bemerkungen geben mir das Signal, beiden Referenten Gelegenheit zu einem $\mathrm{Zwischenresümee} \mathrm{zu} \mathrm{geben.} \mathrm{Wenn} \mathrm{ich} \mathrm{zu}-$ nächst Sie, Herr Rauschning, bitten darf zu beginnen.

Rauschning: Ich darf mich zunächst ganz herzlich bedanken bei Herrn Bachof, für die Erläuterungen meines Ansatzes, auch des Ansatzes, daß die Entscheidung konkret im Bereich unterhalb der Gefahr auf die politisch verantwortlichen Instanzen zurückverlagert werden muß. Ich bin für die Bekräftigung dankbar, daß die Scheidung der Bereiche eben auch und wesentlich durch Verordnung geschehen kann. Es freut mich, daß die Grenze, wie ich sie zu ziehen versucht habe, von Herrn Dürig unterstützt wird. Wir sollten uns auch um den Schutz gegen Allgemeingefahren kümmern, lassen Sie uns dann durchaus auch dem Bürger einen Bereich der Risikovorsorge zuordnen, aber begrenzt, weil die Entscheidung über eine weitergehende Vorsorge unterhalb der Gefahrenschwelle eben dezentralisiert durch die Gerichte nicht möglich ist.

Ich bin weiterhin sehr dankbar für die Möglichkeit, die mir Herr Vogel gegeben hat, doch auf die Frage der Staatswirtschaft und der Trennung von Betreiber - oder Tätigwerdendem - und Uberwacher einzugehen. Es ist ja gerade von den zentralen Verwaltungswirtschaften sozialistischer Prägung gesagt worden, das ganze Umweltproblem liege nur an der Ausbeutermentalität. Die Erfahrung - auch bei Reisen können Sie sie alle machen - ist die, daß das Umweltschutzproblem und das Umweltschmutzproblem dort wesentlich stärker ist, und das beruht im wesentlichen darauf, $\mathrm{da} \beta$ Utberwacher und Betreiber jeweils identisch sind. Wenn Sie also sehen, daß Sie im Ruhrgebiet bei ungefähr 40000 Hektar Fichtenwald Zuschüsse haben zahlen müssen, um stattdessen Laubwald anzusiedeln, dann müssen Sie eben gleichzeitig berichten, daß 160000 Hektar von Komotau bis hinüber in die CSSR einfach abgestorbener 
Wald sind. Allerdings, Herr Vogel, in der konkreten Beurteilung würde ich Ihnen ein wenig widersprechen, schon auch wegen unserer bundesstaatlichen Situation. Die Hamburger Elektrizitätswerke beantragen das Kernkraftwerk Brokdorf, und der Bund und Schleswig-Holstein müssen es genehmigen; und dabei ist besonders makaber, da $B$ dann der Aufsichtsrat der Hamburger Elektrizitätswerke die Schleswig-Holsteiner deshalb politisch angreift, weil sie es genehmigen -, aber das spielt ja hier vielleicht keine Rolle.

Herr Pernthaler, ich meine, Sie haben in Ihrer Bemerkung deutlich gemacht, daß es eine lange Geschichte des Umweltschutzes gibt: Die Grundsatzregelung in $\$ 5$ BImSchG stammt fast wörtlich aus $\S 16$ der Gewerbeordnung von 1869 , der wieder $\S 26$ der Preußischen Gewerbeordnung entnommen ist. Die Umweltlage mag im industriellen Bereich schlechter geworden sein, aber ich darf sagen, daß auch der Prager Fenstersturz nur deshalb überlebt worden ist, weil eben so viel Unrat vor den Fenstern der Burg lag, daß man noch von 15 Metern aus dort weich landete. Wenn Sie die alten Stadtrechte durchsehen, dann können Sie etwas erstaunt feststellen, wogegen man mit Rechtsnormen hat angehen müssen. Die Weltgesundheitsorganisation, die Herr Wenger zitiert hat, kümmert sich jetzt darum, solche Zustände in der ferneren Welt einzuschränken.

Ich möchte auch auf Herrn Püttner noch kurz eingehen: Es geht um menschengestaltete Umwelt, und auch die historisch überkommene Umwelt ist menschengestaltet; und es geht um eine bessere Gestaltung, auch unter dem Tenor Umweltschutz, da würde ich Ihnen ganz zustimmen. Herr Häberle, ich bin nicht so weit gegangen in der Frage des ökologischen Existenzminimums, ich habe mich an Herrn Scholz angeschlossen, der sagte - und das auch zur verfassungsrechtlichen Begründung -: Praktisch ist selbst das eingeschlossen in Art. 2 II GG - der Schutz vor existenziellen Gesundheitsgefährdungen, das ist das Existenzminimum. Darein würde ich nicht einschließen die Möglichkeit, in Wälder und an Flüsse zu gehen, so sehr ich mit Ihnen dort gerne gehe oder so sehr ich das gleichermaßen schätze; ich meine nicht, daß das in Art. 2 II GG eingeschlossen ist.

Ich glaube nicht, daß ich Forsthoff mißverstanden habe. Er meinte, daß es ernste Interessengegensätze im Umweltbereich zwischen Staat und Industriegesellschaft gebe, und daB der Staat nicht im Stande sei, gegenüber der mächtigen Industriegesellschaft das Allgemeininteresse durchzusetzen. Ich meine, gerade hier gibt es einen Interesseneinklang. 
Hoppe: Gegenüber den Bemerkungen von Herrn Dürig, der den Umweltschutz auf die Gefahrenabwehr beschränken will und vor einer Ausdehnung des Umweltschutzgutes, etwa im Sinne des Gesundheitsbegriffes der Weltgesundheitsorganisation, warnt, möchte ich zunächst darauf hinweisen, daß ich mich nicht für die „ökologische Wende“ ausgesprochen, daß ich im Gegenteil zur Zurückhaltung gegenüber dieser von Herrn Staatssekretär Hartkopf gegebenen Empfehlung geraten habe.

Ich teile zwar die Sorge von Herrn Dürig im Bezug auf die ökologische Betrachtungsweise, ich kann ihm aber in den daraus abgeleiteten Konsequenzen nicht folgen. Ich habe erhebliche Zweifel daran, ob wir im Umweltschutzrecht zurückgehen können auf die Gefahrenabwehr im polizeirechtlichen Sinne. Ich meine vielmehr, daß eine angemessene und sachgerechte Berücksichtigung der Langzeitwirkungen, der unterschiedlichsten Folgewirkungen und der Kombinationswirkungen von Umwelteingriffen mit diesem Gefahrenbegriff nicht mehr möglich ist. Ich darf ein Beispiel erwähnen: Die Kohleverflüssigung und die damit zusammenhängenden $\mathrm{CO}_{2}$-Auswirkungen auf die Atmosphäre, ihre Erwärmung und damit eine erhebliche Veränderung der klimatischen Verhältnisse. Das sind Auswirkungen von anderer Qualität als wir sie bisher kennen.

Herr Ipsen hat dankenswerterweise auf einige positivrechtliche Regelungen, die in einem planerischen Abwägungsproze $\beta$ die Berücksichtigung von Umweltschutzbelangen anordnen, hingewiesen. In meinem Mitbericht hatte ich bereits erwähnt, $\mathrm{daB}$ es solche verbesserungsbedürftigen „Planungsklauseln", insbesondere "Naturschutzklauseln“, in einer Reihe von Fachplanungsgesetzen gäbe. Das ist z. B. im Flurbereinigungsgesetz, im Abfallbeseitigungsgesetz, im Landbeschaffungsgesetz, im Schutzbereichsgesetz und im Luftverkehrsgesetz der Fall. In der Tat muß man diese Planungsklauseln hinzuziehen, um die Zielkonflikte richtig bewerten zu können. Allerdings sind diese Planungsklauseln durchaus nicht ausreichend. Sie sind vielmehr noch verbesserungsbedürftig.

Herr Vogel hat hingewiesen auf eine Art "Stufentheorie" (Abwehr von Beeinträchtigungen - Erhaltung und Pflege von Umweltschutzgütern durch Planung - Verteilung von knappen Gütern). Ich glaube, daß wir - zumindest im Ansatz - derselben Auffassung sind, Herr Vogel, ich würde nur meinen, daß - zumindest unter dem Aspekt der Planung - der Vermeidung von Beeinträchtigungen vor ihrer Abwehr ein Vorrang eingeräumt werden sollte. Sie hatten das Verhältnis, wenn ich Sie recht verstanden habe, etwas anders gesehen. Mir ist dieses Problem begegnet beim Verkehrslärmschutzgesetz: Ich habe 
mich bei einer Anhörung im Bundestag dafür eingesetzt, daß zunächst der Vermeidungsgrundsatz herausgestellt wird, Vermeidung von Lärm -, daß dann die Rangfolge geregelt wird: Aktiver Lärmschutz - passiver Lärmschutz. Das ist auch eine Stufentheorie oder Stufenfolge. Ich glaube, daß wir uns darin einig sind.

Herr Pernthaler, zwei kurze Anmerkungen zu dem, was Sie sagten: Ich glaube nicht, daß man diese Absprachen, die ich am Schluß meines Berichtes erwähnt habe, so gering einschätzen sollte. Das sind doch ganz erhebliche und weitreichende Regelungen, wenn Sie z.B. daran denken, daß die Braunkohlenplanung bei der Aufstellung des Braunkohlenplans nach dem nordrhein-westfälischen Braunkohlengesetz im Hambacher Forst ein gesamtökologisches Gutachten von sehr großer Reichweite hat erstatten lassen, obgleich das nach dem Braunkohlengesetz nicht vorgesehen ist. $\mathrm{Da}$ es etwa zu einer Absprache zwischen der Chemischen Industrie und dem Bundesministerium des Innern gekommen ist, nach der Fluorkohlenstoffe in Aerosolen in der nächsten Zeit nur noch zu einem bestimmten Prozentsatz in die Luft abgegeben werden. Das sind meines Erachtens durchaus wirksame Instrumente, die voll eingesetzt werden sollten. Ich darf Ihnen gegenüber allerdings noch eines richtigstellen: Es geht mir nicht darum, daß nur Datenermittlung erfolgen soll. Ich sehe aber eine verbesserte Ermittlung von Belangen als einen ganz entscheidenden Beitrag zur Erhöhung der Effektivität des Umweltschutzes an.

Mit Herrn Häberle - dazu brauche ich nichts zu sagen stimme ich überein.

Herr Püttner, ich bedaure es außerordentlich, daß Sie mich mißverstanden haben: Ich setze mich gerade nicht für eine Gesamtplanung mit Hilfe einer solchen Informationsdatenbank ein, - im Gegenteil: Ich meine, daß die vorhandenen, bestehenden Planungsverfahren, die ja hinsichtlich der Berücksichtigung von Belangen des Umweltschutzes wenig effektiv sind, - das hatte ich in meinem Bericht sehr deutlich hervorgehoben -, verbessert werden können, wenn die Umweltschutzinformationen und die Ermittlungen von Umweltschutzbelangen verbessert werden. Es ist $\mathrm{z}$. B. in der heutigen Bauleitplanung ein Faktum, daß etwa ein Kinderspielplatz ausgerechnet an eine Stelle gelegt wird, an der sich erhebliche Emissionen und Immissionen auswirken. Das liegt an einem Informationsdefizit bei der Planaufstellung und deswegen müssen diese - so meine ich - Ermittlungen verbessert werden. Das heißt aber nicht etwa, - das darf ich Ihnen gegenüber noch einmal beto- 
nen - daß ich mich für ein Gesamtplanungsmodell ausspreche, im Gegenteil: Ein solches Gesamtplanungsmodell scheitert meines Erachtens z. Zt. schon daran, daß der ökologische Wissensstand und der Stand der Wirkungsforschung noch nicht weit genug vorangeschritten sind.

Vorsitzender: Vielen Dank, Herr Hoppe! Vielen Dank Herr Rauschning!

Meine Herren, ich darf damit zugleich unseren dritten Diskussionskomplex, die Fragen um Maßstäbe und Instrumentarien des Umweltschutzes, aufrufen. Als ersten darf ich Herrn Zacher bitten!

Zacher: Ich möchte die Referenten fragen, warum in den beiden Referaten so wenig vom Gleichheitssatz die Rede war. Was ich dazu zu sagen habe, geht im Ansatz parallel zu dem, was Herr Vogel schon gesagt hat. Ich habe mir auch Rechenschaft gegeben, worin das Thema eigentlich besteht. Ich kam dann zunächst zum Schutz gegen Umweltbelastungen im Interesse Privater - das sagte uns Herr Rauschning - Thesen 9-13, 17. Herr Hoppe ging dann - These 8 - weiter, indem er sagte, im Interesse Privater kann sogar Planung nötig sein. Dann ist der Schutz gegen Umweltbelastungen im Interesse der Allgemeinheit notwendig. Das ist nun das, was in beiden Referaten stark herausgestellt wird - Thesen 13, 14 von Herrn Rauschning bei Herrn Hoppe von These 4 an, wenn ich recht sehe. Ferner besteht das Thema in den Grenzen dieses Schutzes. Und hier zieht man institutionell-allgemein normative Grenzen - die Thesen Rauschning $16 \mathrm{ff}$. und Hoppe 30 -, desgleichen individualrechtliche Grenzen, weil man auf den Widerstand der Grundrechte des einzelnen stößt, - Hoppe These 30, wenn ich richtig sehe.

Nun aber zurück zu dem eigentlichen Ansatzpunkt. Es wird also Schutz vor Umweltbelastungen verlangt. Und die ergriffenen Schutzmaßnahmen und -regulative verdichten sich nun. Da gibt es einen Weg, daß sie sich durch Häufung ungewollt, ungeordnet verdichten. Und dann gibt es den anderen Weg von dem Herr Hoppe ja vor allem gesprochen hat -, daß diese Verdichtung des Schutzes vor Umweltbelastungen geplant wird. Und hier kommen wir nun in die Sphäre, daß ein Umschlag eintritt, sozusagen von der ungemachten Welt zur staatlich gemachten Welt, von der nicht gewillkürten Welt zur staatlich gewillkürten Welt - ein Umschlag, wo die Verantwortung des Staates zur Regel wird, wo der Staat sich nicht mehr aus der Verantwortung für seine Eingriffe zurückziehen kann, sondern 
eine Verantwortung für die Verteilung trägt, wo er sich nicht mehr auf die Verantwortung für die Veränderung beschränken kann, sondern eine Verantwortung für den Zustand trägt. Hier gerät man unausweichlich in die Nachfrage nach Maßstäben, wie der Staat nun diese Verteilung vornimmt.

Dabei gibt es zwei Verteilungsprobleme: nämlich erstens die Verteilung von Chancen der Umweltbelastung, von dem Herr Vogel, glaube ich, in erster Linie auch gesprochen hat, - daß die Industrie noch mehr Rauch ablassen darf usw.; und zweitens die Verteilung der Chancen der Teilhabe an der noch heilen Umwelt. Wir leben noch in einer Welt, in der letzteres als die Verteilungsproblematik eines noch unbegrenzt gedachten Vorrates an Umwelt angenommen wird, und in der die Verteilung dem Regulativ der Freiheitsrechte anvertraut ist, die den Zugriff ermöglichen. Jeder betätigt sich und nimmt damit an dieser Chance teil. Nach jenem Umschlag aber wird die Verteilung der Teilhabe an der heilen Welt als Verteilung eines begrenzt gedachten Vorrats an Umwelt zu denken sein. Dann fragt sich: Nach welchen Regulativen nimmt man nun diese Verteilung vor? Hier bleibt dann wahrscheinlich nichts als der Gleichheitssatz übrig! Der Gleichheitssatz hat aber noch ein anderes einschlägiges Anwendungsfeld, nämlich: Wenn diese Verdichtung eintritt, dann werden möglicherweise die Besitzstände, die vorhandenen Besitzstände, ob das Grundstück am Waldesrand liegt, ob noch frische Luft da ist usw., umgewertet. Auch hier muß ja der Gleichheitssatz irgendwann einmal für diese Umverteilung der Umweltnutzung herangezogen werden.

Nun wollte ich damit nicht sagen, daß der Gleichheitssatz eine wirkliche Lösung ist. Nach allen Erfahrungen, die wir so mit dem Gleichheitssatz als unmittelbares Regulativ von Verteilung haben, würde ich vielmehr sagen, daß die Ansicht, daß wir dann auf den Gleichheitssatz geworfen sind, uns so abschrecken sollte, daß wir versuchen sollten, an dem Verdichtungsgrad, der uns in diese Lage bringt, möglichst vorbeizukommen. Und damit treffe ich wieder auf Herrn Vogel.

Badura: Herr Vorsitzender, meine verehrten Kollegen! In dem Streit zwischen Herrn Dürig und anderen und Herrn Hoppe möchte ich für Herrn Hoppe Partei ergreifen. Herr Hoppe hat in seinem Vortrag, glaube ich, eine umfassende Deutung, auch ein Programm für eine sachgemäße Handhabung des Umweltschutzes durch vorsorgende Planung gegeben; ich denke dabei vor allem an seine Thesen 18, 24, 25, 26, 27 und 30. Da unausgesetzt Vorhaben durchgeführt, Straßen gebaut, Häuser gebaut werden, schädliche Quellen entstehen, kann man sich nicht auf den Standpunkt zurückziehen, daß von Fall zu Fall 
eben nach Grundsätzen der Gefahrenabwehr zu entscheiden sei. Der knappe Raum der Bundesrepublik macht es in meinen Augen unausweichlich, einen Weg zu gehen, wie er von Herrn Hoppe und anderen bereits mehrfach vorgezeichnet worden ist. Dabei kann dann die Frage schließlich nur sein - das betrifft die Punkte 2 und 3 der Diskussionsgliederung -, in welchem Umfange das eine Sache des Gesetzes oder aber der Verwaltung ist und darin sehe ich die Kernfrage. Ich denke dabei jetzt weniger an ökologische Spezialplanungen wie im Rahmen des Naturschutzrechtes, sondern an die Integration des ökologischen Gesichtspunktes in die Gesamtplanungen und in die einzelnen Fachplanungen; an die Frage also, wie der Belang Umweltschutz bei den dort notwendigen Abwägungen einzubringen und zu gewichten ist.

Man könnte sich vorstellen, daß in jeder gesetzlichen Ermächtigung für Gesamtplanungen oder für Fachplanungen eine Art „ökologische Klausel“ enthalten wäre - so wie es Raumordnungsklauseln in Fachplanungsgesetzen gibt -, die gewissermaßen die Erfordernisse des Umweltschutzes fixieren würde. Ich fürchte nur, man wird nicht so weit gehen können, daß die ökologische Klausel eine Art absolute Vetoposition schafft, so daß dann, wenn Erfordernisse des Umweltschutzes gegeben sind und dem Vorhaben entgegenstehen, damit das Vorhaben erledigt wäre. Und das führt $\mathrm{zu}$ der Schwierigkeit, daß durch eine gesetzgeberische Entscheidung jedenfalls nicht alle in Betracht kommenden Fälle mit einer Gewichtungsentscheidung vorentschieden werden können, sondern daß insoweit die Vollmacht der Verwaltung als eine planerische Vollmacht bestehen bleiben muß und es nur auf die korrekte Handhabung der gegebenen Richtlinien und Abwägungsgrundsätze ankommen kann. Das Gesetz muß allerdings die Planungsaufgabe und die Planungsrichtlinien regeln, entsprechend dem Kalkar-Beschluß (BVerfGE 49, 89) die "wesentlichen" Entscheidungen treffen, auch soweit Rechtsbeeinträchtigungen in Betracht kommen, die Maßstäbe dafür angeben; auch, was eben Herr Zacher sagte, soweit durch ökologische Entscheidungen oder durch damit zusammenhängende Fragen das Verteilungsproblem und der Gleichheitssatz berührt, soweit das möglich ist, ist politisch, durch Gesetz zu entscheiden. Auch - und dabei knüpfe ich an das an, was Herr Wenger heute vormittag sagte - soweit Kostenwirkungen für den öffentlichen Haushalt damit verbunden sind, müßte das durch den Gesetzgeber entschieden werden.

In den Gesetzen, die den Gesamtplanungen und den Fachplanungen zugrunde liegen, ist normalerweise die ökologische Frage lediglich als ein Belang vorgesehen. Eine letzte Frage 
nun, die sich hier stellen könnte, ist die, ob nicht wenigstens eine Konzentration so möglich wäre, daß diese ökologische Entscheidung oder die Beurteilung der ökologischen Erfordernisse für Vorhaben oder für überörtliche oder örtliche Gesamtplanungen in der Landesplanung konzentriert werden; ob es also nicht denkbar wäre, daß jedenfalls alle irgendwie größerflächigen oder weiträumigeren oder langfristigeren Auswirkungen von Vorhaben oder von städtebaulichen oder von überörtlichen Gesamtplanungen durch eine bestimmte - höherstufige - landesplanerische Entscheidung vorfixiert werden könnten und damit dann in der Tat eine Bindungswirkung eintreten würde für die von der landesplanerischen Entscheidung abhängigen örtlichen Gesamtplanungen und für die Fachplanungen. Ich frage also, Herr Hoppe, ob es sich vielleicht in das von Ihnen vorgeführte System einfügen könnte, daß man die ökologische Klausel in die Landesplanung integrieren und dort mit einer gewissen Anpassungspflicht für die davon abhängigen anderen Planungen ausstatten könnte, also mit verfahrensrechtlicher, organisatorischer Konsequenz und mit materiellrechtlicher Konsequenz.

Suhr: Herr Vorsitzender, meine Herren! - Eine Bemerkung und ein dogmatisches Problem. Die Bemerkung betrifft Herrn Dürig: Ich kann es nicht als ein beruhigendes Zeichen werten, wenn Herr Dürig sich hier seine ironisierende Heiterkeit bewahrt hat angesichts der Tatsachen, die auf uns zukommen. Wir haben es heute nicht mit einem Müll zu tun, der sich innerhalb von 25 Stunden zersetzt, sondern z. B. mit Plutonium, der eine Haltbarkeit von 25000 Jahren hat und von dem wenige parts per million schon tödlich sind.

Mein dogmatisches Problem betrifft These 13 von Herrn Rauschning, in der es um die Belastungen Dritter geht: ein Privater belastet einen anderen. Ich durchschaue das dogmatisch noch nicht ganz, obwohl Herr Rauschning sich da wohl weitgehend an die herrschende Lehre gehalten hat. Also: Bürger A belastet seine Umwelt, in der Bürger B lebt; A fügt B Nachteile zu. Nun kommt der Staat und sagt: $\mathrm{Du}, \mathrm{A}$, darfst dem $B$ Nachteile mit der Intensität I zufügen, und $\mathrm{Du}, \mathrm{B}$, mußt das gefälligst hinnehmen! Dann kommt Herr Rauschning und sagt, wenn durch diese normative Grenzwertfestsetzung dem A gesagt werde, was er dem $B$ an Nachteilen zufügen dürfe, so sei das zwar ein Eingriff in die Freiheit des A, aber nicht ein Eingriff in die Freiheit des B, den sich der Staat, wie Sie formulieren, "sozusagen zurechnen" lassen müsse. Dies, obwohl gerade dem $B$ letztlich die Nachteile zugefügt werden. Da, meine ich, 
setzen Sie eine Freiheit des einen Privaten gegenüber dem anderen Privaten voraus, diesem anderen Nachteile zuzufügen. Was ist das für eine Freiheit des A, dem B Nachteile zuzufügen: Ist das eine privatrechtliche Freiheit? Ist das ein Grundrecht? - ein Grundrecht auf Belästigung des Nächsten, etwa wie beim Rauchen? Und was ist das für eine Pflicht des B, der diese Nachteile dulden muß? Ist das eine Pflicht des Privatrechts? - oder eine vorstaatliche Pflicht des Naturrechts? Ist das etwas Grundrechtliches, Verfassungsrechtliches? Irgendeine Pflicht muß doch da sein. Oder ist das ein rechtsleerer Raum, in dem eben gilt, daß der eine dem anderen Nachteile zufügen darf? - so daß es auch wieder kein rechtsleerer Raum ist! Sie nannten das Eigentum als Beispiel: Da wird immer $\S 906$ BGB zitiert, wonach nur wesentliche Beeinträchtigungen ausgeschlossen sind. $\mathrm{Daß}$ der BGB-Gesetzgeber dabei im Prinzip aber anders angesetzt hat, wird dabei nicht erwähnt. In $\S 903$ heißt es nämlich, daß der Eigentümer zunächst einmal prinzipiell andere „von jeder Einwirkung ausschließen" könne: von jeder Einwirkung! Und dann erst muß der, der einwirkt, nach \$906 BGB darlegen und beweisen, daß er das Eigentum des anderen nicht wesentlich beeinträchtigt. Damit die Auslegung des §906 BGB dem verfassungsrechtlichen Utbermaßverbot entspricht, muß er heute so gelesen werde: Vermeidbare oder unnötige Belästigungen in diesem Bereich sind unzulässig. Wo nämlich kein Grund ist, überhaupt jemanden zu belästigen, dort braucht der die Belästigung auch nicht zu dulden.

Vorsitzender: Vielen Dank, Herr Suhr! Meine sehr verehrten Herren, ich darf Ihr Einverständnis voraussetzen, wenn ich jetzt Herrn Dürig die Gelegenheit zur Erwiderung gebe.

Dürig: Meine sehr geehrten Herren, ich glaube ich bin mißverstanden worden. Selbstverständlich bestreite ich nicht die Befugnis des Staates, ökologisch auch zu planen und an die $\mathrm{Zu}-$ kunft zu denken. Nur: das ist nicht ein „sowohl als auch“, etwa im Sinne der Arbeitsteilung von Behörden. Sie kriegen nämlich erst dann und nur dann Vertrauen und Konsens auf dem Gebiet ökologischer Vorsorge, wenn die Primärfunktion des öffentlichen Rechts - und das ist die Gefahrenabwehr - wieder funktioniert. Gegenwärtig funktioniert sie nicht. Und wegen dieses Defizits fehlen Vertrauen und Konsens bei der ökologischen Vorsorge und zerflattert insoweit alles in verschiedensten, widersprüchlichen radikaldemokratischen Strömungen. Ich wollte vorhin auch nicht ironisieren und bagatellisieren. Dagegen halte ich in der Tat daran fest, meine Herren Kollegen, daß der Oko- 
logiebegriff, wie er durch den Gesundheitsbegriff der WHO aufgepumpt ist, durchaus eine juristische Glosse verträgt. Was da an Glücksbelehrung und Glücksbekehrung für alle Leute drinsteckt, kann (und darf) kein Staat leisten, es sei denn mit der Allzuständigkeit eines Totalstaates.

Steiger: Ich möchte zu zwei Punkten etwas sagen, nämlich einmal zur Grundrechtsfrage und dann doch noch einmal zu dem Problem, das auch Herr Bachof vorhin schon angesprochen hat und auf das Herr Rauschning dann noch einmal eingegangen ist, die Vergesetzlichung der Grenzwerte.

Herr Vorsitzender, Sie erlauben, - das greift zwar zum Teil III über - daß ich das zusammen mache. Zunächst zur Grundrechtsfrage; ich möchte hier nicht meine vor einigen Jahren schriftlich niedergelegten Gründe für eine sorgsame - glaube ich jedenfalls - und vorsichtige Ausdehnung des Art. 2 Abs. 2 des Grundgesetzes im Hinblick auf das heute - und gestern auch im übrigen von Herrn Achterberg - vielzitierte ökologische Existenzminimum noch einmal vortragen, sondern ich möchte zwei weiterführende Bemerkungen machen. Herr Rauschning, Sie haben gemeint, die Diskussion sei mehr oder weniger am Ende, jedenfalls bei uns in der Bundesrepublik habe ich Sie recht verstanden? - , es wäre jedenfalls im Augenblick nicht aktuell. Vielleicht für uns in der Bundesrepublik nicht, aber seit unseren Gesprächen, die wir vor einigen Jahren - 1975 - in Bonn geführt haben, hat sich doch in Europa etwas getan, - und wir sind ja in Europa. Es hat sich einmal in der portugiesischen Verfassung etwas getan, im Art. 10, nach dem jeder das Recht auf eine gesunde und ausbalancierte Umwelt hat - ich zitiere das jetzt aus dem kürzeren Text -, und es hat sich in der spanischen Verfassung im Art. 45 einiges getan, wo steht, daß alle das Recht haben sollen auf eine angemessene Umwelt und ihre individuelle Entwicklung in derselben. Es ist allerdings hinzufügen, meine Herren, daß es sich dabei nicht um Grundrechte im Sinne des subjektiv-öffentlichen Rechtes handelt, wie wir sie bei uns in der Bundesrepublik im Grundgesetz vorfinden, wohl aber doch um individuell bezogene Rechtspositionen. Aber wir befinden uns, glaube ich, hier in Europa - denn was ich hier für zwei westeuropäische Länder zitiert habe, gilt im übrigen auch auf der institutionell-europäischen Ebene, nämlich des Europarats und der Europäischen Gemeinschaften - doch in einer Entwicklung, die keineswegs abgeschlossen ist, die durchaus noch offen ist und diskutiert wird; zu Anfang dieses Jahres hat in Straßburg auf Einladung des Instituts für Menschenrechte ein westeuropäischer Kongreß, 
leider nur mit einem osteuropäischen Einsprengsel stattgefunden, der diese Fragen sehr ausführlich behandelt hat. Es bestand immerhin ein so großes Interesse europäischer Staaten, daß etwa aus Osterreich die Frau Gesundheitsministerin erschien und auch aus anderen europäischen Ländern Staatssekretäre dort diskutiert haben. Es scheint also in Europa doch ein Interesse an dieser grundrechtlichen Lösung $\mathbf{z u}$ bestehen und da wir ja - wie gesagt - zu Europa gehören, glaube ich müssen wir das mitbedenken. Es könnte sein, daß sich hier ein gemeineuropäisches Recht entwickelt und Grundrechte - und Menschenrechte sind ja in Europa immer gemeineuropäisch, ganz abgesehen von den institutionellen Bindungen, die wir haben, von dem wir uns nicht abkoppeln und isolieren dürfen. Unsere enge Verbindung von subjektiv-öffentlichem Recht und Grundrecht ist sicher notwendig, aber sie birgt auch die Gefahr der Verengung des Grundrechtsbegriffs. - Eine zweite Bemerkung ganz kurz dazu: Ich halte die damals - 1975 - vertretene Auffassung einer strikten Trennung zwischen Grundrecht und Staatszielbestimmung, die ich damals meinen Untersuchungen zugrundegelegt habe, aufgrund dieser europäischen Entwicklung nicht mehr ganz so aufrecht. Die Utbergänge sind anscheinend, wenn auch nicht in Deutschland, in der Bundesrepublik, so doch außerhalb fließend. - Nun zum Punkt 2: die Frage der Vergesetzlichung oder Normierung. Ich möchte dazu doch noch einiges ganz kurz sagen dürfen: Herr Bachof, ich teile Ihre Sorge und ich teile die Nöte der Richter, aber - ich fürchte was Sie sich erhoffen von einer Normativierung der Grenzwerte, wird nicht gelingen; aus folgenden Gründen. Erstens einmal: Bekannte Grenzwerte, die wir haben in der TA-Luft, die ja dann übernommen werden müßten, sind nach Auffassung der Naturwissenschaftler nicht gesichert - erinnern Sie sich bitte auch an die Ereignisse von Boehringer in Hamburg, dort sind die Grenzwerte eingehalten worden, trotzdem hat es diese erheblichen Nachteile und Schäden gegeben. Zum zweiten: für die Mehrheit der Stoffe gibt es überhaupt noch keine Grenzwerte, etwa für die gesamten Kohlenwasserstoffe, also das heißt für die gesamte Chemie. Zum dritten müßten die Meßverfahren mit normativiert werden, auch die Beurteilungsflächen und andere Faktoren. Die gemessenen Werte sind davon abhängig und können je nach Verfahren sehr stark variieren, nach oben wie nach unten. Viertens, wie sollen die Anreicherungen und Wiedergaben über den Boden erfaßt werden. Und zum letzten: Ich glaube nicht, daß, wenn wir Werte haben, die normativiert sind, wir noch das sichern können, was Sie die allgemeine Vorsorge nennen, Herr Rauschning. Wir kriegen dann wahrschein- 
lich - und die Tendenz zeigt sich nämlich heute schon, auch in der Rechtsprechung - die festgelegten Werte als die maßgeblichen und hinzunehmenden Umweltstandards der Qualität unserer Umwelt und dann ist mit normativer Vorsorge nichts mehr, sondern dann haben wir unter Umständen eines Tages einen Anspruch auf diese Werte, im Guten wie im Bösen.

Sicherheit und Gewißheit lassen sich m. E. nicht über den Ausbau und die Verdichtung der substantiellen Regelungen erreichen, sondern nur über Verfahrensregelungen und eine größere eigene Zurückhaltung der Gerichte, z. B. durch Anerkennung eines Beurteilungsspielraumes. - Vielen Dank!

Soell: Ich möchte zunächst eine Bemerkung noch zum Themenkreis I machen, und zwar aufgrund zweier Hinweise von Herrn Vogel und Herrn Püttner.

Meine Herren, ich halte es für wenig sinnvoll, einen amorphen Umweltschutzbegriff in die Diskussion einzuführen, wie das etwa die Kommission der Europäischen Gemeinschaften getan hat, wenn zum Umweltschutz auch die Verbesserung der kulturellen und sozialen Umwelt gezählt wird; denn dann verkennt man allzu leicht die politischen Prioritäten, um die es auch beim Umweltschutz geht, und dann kann man sich auch erklären, weshalb es auf der Stockholmer Umweltkonferenz zu dem Schisma zwischen den Industriestaaten und der Dritten Welt gekommen ist. Das zuvor - und nun zum Themenkreis II: Herr Rauschning, zu Ihren Thesen 4, 8 und insbesondere 14. Ich meine doch, daß man aus dem Sozialstaatsprinzip die Umweltschutzaufgabe des Staates begründen kann. Herr Bachof hat schon 1954 als den legitimierenden Grundzweck des Sozialstaatsprinzips die Existenzsicherung des Individuums bezeichnet, und wenn es um die Sicherung der natürlichen Lebensgrundlagen - und das ist eigentlich ein schärfer konturierter Umweltbegriff — geht, dann geht es eben auch um solche ökologischen Existenzgrundlagen, deren Sicherung der Staat zu leisten hat, soweit private und gesellschaftliche Initiative dazu nicht in der Lage ist. Und, meine Herren, das Sozialstaatsprinzip steht ja in einem Wechselbezug zum Demokratieprinzip; das Sozialstaatsprinzip effektuiert sich und wird wirksam überhaupt erst - das wissen wir seit Schaumann - in und über die Gesetzgebung. Nur der Gesetzgeber ist der Demokratisch-Legitimierte zur Setzung der notwendigen Prioritäten zur Lösung von Grundrechtskollisionsfragen. Herr Suhr, das ist eine Antwort auch auf Ihren Beitrag; hier geht es nämlich, wenn ich Sie recht verstanden habe, um eine Frage der Grundrechtsgüterkollision zwischen mehreren Grundrechtsträgern. Auch dafür 
ist der Gesetzgeber der eigentlich Demokratisch-Legitimierte, und er hat diese Aufgabe zu leisten; das gibt ihm das Sozialstaatsprinzip mit auf. Drittens: Herr Rauschning, Sie haben von der Schutzpflicht des Staates gesprochen und haben das teilweise aus Art. 2 Abs. 2 in Verbindung mit Art. 1 abgeleitet, haben aber diese Schutzpflicht beschränkt auf erhebliche Gesundheitsbeschädigungen - ich zitiere wörtlich aus Ihren Leitsätzen. Ich frage Sie, ob das bewußt so getan worden ist von Ihnen, um etwa teilweise den amorphen Gesundheitsbegriff der Weitgesundheitsorganisation zu eliminieren. Ich stimme Herrn Dürig zu, daß wir mit diesem Begriff im Umweltschutzrecht nichts anfangen können, sondern daß wir einen wesentlich schärfer konturierten Begriff bei der Gefahrenabwehr benötigen. Ein Drittes: Nun komme ich zu dem, was Herr Hoppe gesagt hat; es zieht sich als ein wesentlicher Grundgedanke durch die Ausführungen von Herrn Hoppe hindurch, findet sich aber auch in der These 21 von Herrn Rauschning: Die Frage der Umweltvorsorge und damit zusammenhängend auch die Frage des Drittschutzes im Umweltrecht. Man muß scharf unterscheiden nach meiner Meinung zwischen Gefahrenabwehr - hier haben wir regelmäßig drittschützende Normen, hier haben wir regelmäßig nur noch einen engen Ermessensspielraum der Umweltschutzbehörden - und dem Umweltvorsorgeprinzip. Das Umweltvorsorgeprinzip des $\$ 5$ BImSchG ist dagegen ein Planungsprinzip. Es geht hier einmal um staatliche Planung, nämlich eine Verwaltung der Umweltbelastungspotentiale, die unterhalb der Schwelle der Gefahrenabwehr und der Abwehr von Nachteilen und erheblichen Belästigungen liegt. Es geht ferner um eine Abwägung wie bei jeder Planungsentscheidung mit konkurrierenden öffentlichen und privaten Interessen, und es geht, meine Herren, aber auch um eine Planungsentscheidung auf seiten der Unternehmen, nämlich um die Berücksichtigung des neuesten Standes der Technik bei Investitionsentscheidungen und etwa um die Aufstellung eines Zeitplans, auch des Aushandelns dieses Zeitplans mit den staatlichen Behörden. Die Konsequenz davon ist, daß wir sowohl einen größeren Ermessensspielraum beim Vorsorgeprinzip konstatieren können - das wirkt sich auch im Rahmen des §17 BImSchG bei der nachträglichen Anordnung aus und - hier widerspreche ich dem OVG Münster daß das Vorsorgeprinzip keinen drittschützenden Charakter haben kann. - Vielen Dank!

Saladin: Eine Bemerkung und eine Frage zu Herrn Rauschning. Sie haben, wenn ich richtig gehört habe, gesagt, daß das Leben des einzelnen ebenso schützenswert ist von der Verfas- 
sung her wie das Leben vieler, - sicher richtig, unbestreitbar, unbestritten! Ich frage mich nur, ob die These in dieser Form für unseren Zusammenhang wirklich bestimmend ist. Wenn wir davon ausgehen, daß ein wesentlicher Teil des Umweltschutzes - ich denke besonders an das Atomenergierecht - der Risikoverminderung dient, dann heißt das doch, daß es hier darum geht, Risiken für die Grundrechtsgüter Leben und Gesundheit zu vermindern. Der Gesetzgeber hat von der Verfassung her den Auftrag, solche Risiken zu vermindern; und in dieser Optik kann es - nach meiner Auffassung - eben durchaus verfassungsrelevant sein, is t es verfassungsrelevant, ob zum Beispiel ein Kernkraftwerk in einem dicht- oder in einem dünnbesiedelten Gebiet errichtet wird. Das Risiko wird zwar nicht schlimmer im dicht-besiedelten Gebiet, aber es wird größer.

Also: Ich glaube, die Frage der Standortwahl, der Standortplanung darf nicht dem Gesetzgeber oder einer Exekutive oder auch irgendwelchen Privaten zur völligen Disposition überlassen werden. Kleine Anmerkung: Jedes Kernkraftwerk - und das kam vielleicht etwas wenig zum Ausdruck bei Ihnen - ist Träger eines potentiellen Katastrophenrisikos, auch wenn dieses Risiko nach herrschender Auffassung als sehr unwahrscheinlich betrachtet wird.

Und die Frage: Wenn das Leben das erste Grundrechtsgut, das erste Verfassungsgut ist und falls - ich sage ausdrücklich: falls - statistisch erwiesen oder wenigstens plausibel gemacht werden könnte, daß durch Geschwindigkeitsbegrenzungen auf Straßen die Unfallquote gesenkt wird, ist dann nicht der Gesetzgeber von der Verfassung her verpflichtet, Geschwindigkeitsbegrenzungen einzuführen?

Vorsitzender: Vielen Dank, Herr Saladin! Als nächstem darf ich Herrn Breuer das Wort geben, der bereits zum Fragenkomplex der Einzelfragen des Umweltschutzes als legislativer und exekutivischer Aufgabe überleiten wird. Zum gleichen Komplex noch eine kurze Bemerkung von Herrn Blümel.

Breuer: Ich kann es mir nach dem letzten Diskussionsbeitrag von Herrn Dürig ersparen, noch einmal darauf hinzuweisen, weshalb der Umweltschutz über die Gefahrenabwehr hinausgeht. Ich möchte indessen Stellung nehmen zu der Frage, auf welcher Entscheidungsstufe eigentlich der Staat die Aufgabe des Umweltschutzes aufgreifen sollte, damit sie glaubhaft wahrgenommen wird, und zwar sowohl im Hinblick auf die Gefahrenabwehr als auch im Hinblick auf die Risikovorsorge. Die erste Entscheidungsstufe bildet die Verfassung. Im Gegensatz 
zu Herrn Rauschning bin ich der Meinung, daß das Sozialstaatsprinzip sehr wohl fruchtbar gemacht werden kann für einen Verfassungsauftrag, das vielbeschworene ökologische Existenzminimum zu schützen. Dies ist nur ein Minimalstandard. Ich gehe nicht so weit, einen Optimalstandard des Umweltschutzes aus der Verfassung herzuleiten; dies würde viel zu weit gehen. Vielmehr verbleibt stets ein weiter Gestaltungsspielraum des Gesetzgebers. Daß dies keine reine Theorie ist, zeigt meines $\mathrm{Er}$ achtens der Kalkar-Beschluß des Bundesverfassungsgerichts, wo im Zusammenhang mit dem Sozialstaatsprinzip die grundrechtlichen Schutzpflichten hervorgehoben worden sind. In diesem Zusammenhang darf ich besonders darauf hinweisen, daß das Bundesverfassungsgericht den Gesetzgeber auch für verpflichtet hält, bei einem Wandel der Situation und bei neuen Erkenntnissen „nachzufassen“, also seine Gesetze zu überprüfen und gegebenenfalls zu ändern. Auf der zweiten Stufe geht es um die gesetzliche Regelung und um die ergänzende Regelung durch Rechtsverordnungen. In diesem Punkte stimme ich Herrn $B a c h o f$ voll zu: Es bedarf in der Tat einer stärkeren Konkretisierung der maßgeblichen Standards des Umweltschutzes durch Gesetz und Rechtsverordnung. Das Bundesverwaltungsgericht hat zwar Verwaltungsvorschriften wie die TA Luft und technische Regeln als sogenannte antizipierte Sachverständigengutachten anerkannt, die man bei der Auslegung dieser Begriffe fruchtbar machen kann. Ich habe die Begründung dieser Entscheidung selbst mitgetragen und will mich nicht davon distanzieren. Trotzdem gebe ich $\mathrm{zu}, \mathrm{da}$ es sich hierbei um eine Notlösung handelt. Der rechtsstaatlich klarere Weg und die größere Rechtssicherheit würden durch eine normative Regelung erzielt, soweit diese möglich ist. Die letztere Einschränkung muß man machen; aber sicherlich gibt es eine ganze Reihe von Grenzwerten, die - wie die Naturwissenschaftler und Techniker sagen - „auf der sicheren Seite liegen“. Wenn dies so ist, könnte man solche Werte auch durch Gesetz oder Rechtsverordnung festschreiben. Zum dritten: Ich stimme Herrn Hoppe voll zu, wenn er betont, daß es auf der Stufe zwischen dem Gesetz und der Rechtsverordnung einerseits und der Einzelfallentscheidung - insbesondere der Anlagengenehmigung - andererseits eine effektive, den Umweltschutz berücksichtigende Planung geben müßte. Es hat sich in der Praxis gezeigt, daß es nicht möglich ist, erst bei einer einzelnen Anlagengenehmigung die Standortfrage vernünftig $\mathrm{zu}$ erfassen und $\mathrm{zu}$ entscheiden. Wenn etwa alternative Standorte zur Debatte stehen, ermöglicht der Antrag auf Erteilung der Anlagengenehmigung nicht mehr in hinreichendem Maße die Erörterung dieser Alternativen. Die 
Frage der Standortalternativen muß vielmehr im Wege der Planung vorweg entschieden werden. Ich darf nur zwei kritische Akzente zu dieser dritten Entscheidungsstufe setzen: Einmal meine ich - wenn ich richtig verstanden habe, in Utbereinstimmung mit Herrn Hoppe -, daß es untunlich wäre, eine weitere Fachplanung einzuführen. Zum anderen meine ich, daß die kommunale Bauleitplanung wahrscheinlich überfordert ist, wenn nicht bereits auf der Stufe der Landes- und Regionalplanung entscheidende Daten für die Standortwahl und den Umweltschutz gesetzt werden. Auf der vierten Entscheidungsstufe, bei der Anlagengenehmigung im Einzelfall, würde meines Erachtens eine erhebliche Entlastung eintreten, wenn durch normative Konkretisierung und durch effektive Planungen die notwendigen Grundentscheidungen vorweg getroffen werden.

Blümel: Ich habe mich eigentlich nur gemeldet, weil Herr Badura: an Herrn Hoppe die wichtige Frage gestellt hat, ob der Umweltschutz in der Landesplanung zu verantworten sei. Wir müssen diese Frage in der Tat diskutieren. Wir haben allerdings schon Beispiele, etwa in dem nordrhein-westfälischen Landesentwicklungsplan IV (Schutz vor Fluglärm). Dort ist diesem Anliegen bereits Rechnung getragen. Nur, ich würde weiter gehen, ich würde sagen, daB der Umweltschutz auf allen Ebenen und auf allen Stufen der Gesamtplanungen und der Fachplanungen zu verorten ist, daß wir uns also hier nicht auf die Landesplanung beschränken können. Für die Bauleitplanung haben wir jetzt die Umweltschutzklausel in dem Katalog des $\S 1$ Abs. 6 BBauG. Nur ein Problem bleibt zu bedenken - und das steckt bei Ihnen vielleicht im Hinterkopf, Herr Badura, wir kennen uns ja -: Wenn Sie den Umweltschutz in der Landesplanung verorten, dann hat das natürlich gleich wieder die Bedeutung, $\mathrm{da} B$ auch die Wirkungen der Ziele der Raumordnung und Landesplanung eintreten und daß damit eine weitere Einbindung etwa der kommunalen Selbstverwaltungsträger erfolgt.

Steinberg: Herr Vorsitzender, meine Herren! Es sind eine ganze Reihe von Problemen in den Referaten und im Laufe der Diskussion zur Sprache gebracht worden; ich möchte mich einem speziellen Aspekt widmen und zwar dem Problem der Administration des Umweltschutzes, ich möchte das Wort Vollzug vermeiden, weil damit doch vielleicht falsche Vorstellungen verbunden sind. Mir scheinen die Probleme der Administration des Umweltschutzes in der Tat besondere zu sein, und ich möchte das kurz erläutern. Die besonderen Schwierigkeiten sind teilweise bereits von Herrn Hoppe in seinem Referat erwähnt wor- 
den; ich weise auf den Leitsatz 5 hin - die Vielfalt und Unüberschaubarkeit der Regelungen, die besondere Struktur des Umweltschutzrechts. Ich möchte weitere Gründe erwähnen das ist in der Diskussion bereits einmal angesprochen worden und zwar die Tatsache, daß es sich hier um technisches Recht handelt, wobei die Probleme und Schwierigkeiten der Technik auch in die Rechtsmaterie eindringen. Als weiteren Grund und hier kann ich mich auch auf Herrn Mayer-Tasch mit seinem Forsthoff-Zitat berufen - die Weite der Umweltschutzaufgaben. Mehrere Diskussionsredner haben versucht, hier eine Definition, zumindestens eine gewisse Klärung vorzunehmen; ich glaube, das wird auf sehr große Schwierigkeiten stoßen. Umweltschutz als Aufgabe kann nicht scharf abgegrenzt werden wie andere staatliche Aufgaben; diese Aufgabe überlagert sich vielfältig mit anderen primären Staatsaufgaben, deswegen ist die Aufgabe des Umweltschutzes meiner Ansicht nach richtig als Querschnittsaufgabe bezeichnet worden. Und schließlich - auch das scheint mir wichtig zu sein für die Schwierigkeiten der Administration dieses Problems - die Interessenintensität und Konfliktträchtigkeit der Materie; es kommen hier verschiedene gesellschaftliche Interessen, vielfach entgegengesetzte Interessen, sehr weite Interessen, zum Zuge, die sich teilweise, allerdigs in unterschiedlicher Weise dann auch auf der Verwaltungsebene widerspiegeln. $\mathrm{Ob}$ einem das paßt oder nicht, aber etwa die Tatsache der Existenz von Bürgerinitiativen, die andere Interessen und andere Vorstellungen von diesen Fragen haben als etwa die Betreiber bestimmter Anlagen, sind nicht aus der Welt zu schaffen. Damit befindet sich die Verwaltung des Umweltschutzes in einem Dilemma; der Durchsetzungsschwäche der Umweltschutzbelange - wie Herr Hoppe gesagt hat - kann vielleicht in dem einen oder anderen Punkte begegnet werden, die Durchsetzungsschwäche kann gemildert werden, aber sie ist meiner Ansicht nach nicht aufzuheben. Dessen muß man sich eben auch bei der administrativen $\mathrm{Zu}-$ wendung dieses Problems bewußt sein.

Es sind eine Reihe von Faktoren bereits genannt worden, die wirksam werden für das Verwaltungshandeln und Auswirkungen haben auf das Ergebnis dieses Verwaltungshandelns in diesem Bereich: Da ist einmal die Ebene der Programmierung - dazu haben die Referenten und eine Reihe von Diskussionsrednern bereits das Nötige bemerkt - zum anderen die Frage der Ausgestaltung des Verwaltungsverfahrens dieser Frage hat sich vor allem der Co-Referent, Herr Hoppe, zugewandt und eben - meiner Meinung nach völlig zutreffend - Umweltschutz als Planungsproblem dargestellt. Ich 
möchte ganz kurz noch einen weiteren Faktor des Umweltschutzes nennen und zwar das Problem der Organisation des Umweltschutzes in der Verwaltung; auch hier sind bereits Hinweise in der Diskussion erfolgt. Herr Badura etwa hat einen ganz konkreten Organisationsvorschlag gemacht, Herr Vogel hat auf das Problem des Verhältnisses von Betreiber und Uberwacher in einer Hand hingewiesen. Mir erscheint es erforderlich zu sein, daß die Belange und die Bedeutung von Organisation stärker in das Bewußtsein gerade auch in diesem Fragenbereich einbezogen werden, gerade deswegen, weil materielle inhaltliche Kriterien viel weniger das Verwaltungshandeln bestimmen, weil das Ausmaß an konkreter Normierung viel geringer ist als in anderen Rechtsbereichen. Dabei bedarf die Frage der Organisation, die Wahl der Organisationsstruktur durchaus unterschiedlicher Antworten - je nach Aufgabentypus der Verwaltung: Etwa für Koordination wird es anderer organisatorischer Lösungen bedürfen als für operative Aufgaben. Wiederum andere organisatorische Formen dürften zur Einrichtung der Beratung, der Informationssammlung und -vermittlung, - etwa das Beispiel der Datensammelbank würde da dazugehören - auf dem Sektor des Umweltschutzes angebracht sein. - Vielen Dank!

Salzwedel: Ich möchte zu dem Leitsatz 22 von Herrn Rauschning Stellung nehmen. Ich bin der Meinung, daß seine Aussagen zu den Grenzwerten einer stärkeren Differenzierung und Präzisierung bedürfen. Zunächst muß man zwischen Emissionsgrenzwerten und Immissionsgrenzwerten unterscheiden. Bei der Festlegung von Emissionsgrenzwerten kommt es überhaupt nicht darauf an, wo die Schwelle für eine wirkliche Gefährdung von Nachbarn verläuft. Dementsprechend ist die Einräumung eines Rechtsanspruchs auf Einhaltung dieser Emissionsgrenzwerte stets systemwidrig. Es besteht auch kaum die Gefahr, daß die Bäume in den Himmel wachsen und mit der Verbesserung der technischen Möglichkeiten ständig Umweltressourcen verschenkt würden. Für das Wasser besteht die Gefahr nicht, weil $\S 1$ Abs. 2 WHG grundsätzlich durch die speziellere Regelung des $\S 7$ a WHG ausgeschlossen wird. Die Mindestanforderungen an die Behandlung von Abwasser sind aber an allgemein anerkannten Regeln der Technik orientiert, womit ein recht bescheidener Reinigungsaufwand umschrieben ist. Nach den Gewässerschutzrichtlinien der EG sind die Reinigungsanforderungen für Stoffe der Schwarzen Liste zwar strenger. Aber der Maßstab der best available means wird unzweifelhaft von einer sehr starken wirtschaftlichen Kompo- 
nente mitbestimmt. Die jetzt im Entwurf vorliegenden Folgerichtlinien für die Einleitung von Aldrin und Dieldrin sowie für Quecksilber aus der Alkali-Elektrolyse belegen dies hinlänglich. Entsprechendes gilt auch letztlich nach $\$ 5$ Ziff. 2 BImSchG für die Behandlung der Abluft; der Begriff des Standes der Technik unterliegt auch von der wirtschaftlichen Seite immanenten Beschränkungen. Entgegen Ihren Ausführungen würde kein Mensch auf die Idee kommen, das exponentielle Wachsen der Kosten für Reinigungsanstrengungen oberhalb eines Wirkungsgrades von $90 \%$ bei der Festsetzung des Standes der Technik außer Betracht zu lassen.

Ihre Ausführungen könnten hintergründig eine gewisse Distanziertheit zum Vorsorgeprinzip erkennen lassen, das das neuere Umweltrecht beherrscht. Es läuft auf die Preisgabe aller Emissionsgrenzwerte hinaus, die sich erfreulicherweise auf dem Kontinent - anders als im Vereinigten Königreich - durchgesetzt haben. Emissionsgrenzwerte dürfen nicht danach beurteilt werden, ob im Einzelfall noch mit meßbaren Schädigungen des Gewässers oder der Umwelt gerechnet werden muß. Emissionsstandards dürfen auch nicht auf dem Umweg über das Verhältnismäßigkeitsprinzip unterlaufen werden, indem man ihre Durchsetzung im Einzelfall davon abhängig macht, $\mathrm{da} B$ meßbare Verbesserungen der Umweltsituation nachgewiesen werden. Wenn z. B. feststeht, daß Emissionsgrenzwerte etwa für die Einleitung von Schadstoffen der Schwarzen Liste mit dem Abwasser wirklich auf zugleich toxische und persistente und bioakkumulative Verbindungen beschränkt sind, darf die Durchsetzung von Behandlungsauflagen im Einzelfall nicht davon abhängig gemacht werden, daß dies aus der Sicht des aufnehmenden Gewässers notwendig ist, um irgend jemanden zu schützen.

Rechtsansprüche Dritter auf die Einhaltung solcher vom Vorsorgeprinzip getragenen Emissionsgrenzwerte kann es vernünftigerweise nicht geben. Für das Wasserrecht ist es nahezu unbestritten, daß weder die Mindestanforderungen nach $\S 7$ a WHG noch die Grenzwerte für Stoffe der Schwarzen Liste, die in Landesrecht umgesetzt werden müssen, nachbarschützenden Charakter haben. Das gleiche sollte für $\$ 5$ Ziff. 2 BImSchG gelten, obwohl es in diesem Bereich bereits bedauerliche Fehlentscheidungen gibt. Das Vorsorgeprinzip dient allein Interessen des allgemeinen Wohls, nicht der Gewährleistung angenehmer Lebensverhältnisse für die Nachbarn.

Obwohl es demgegenüber richtig ist, daß Immissionsgrenzwerte grundsätzlich darauf angelegt sind, die Lebensverhältnisse in der Nachbarschaft zu schützen, erscheint es verfehlt, 
hier grundsätzlich Nachbarklagen einzuräumen. Das gilt insbesondere nach der Entwicklung, die das Voerde-Urteil des OVG Münster ausgelöst hat. Seit dem sogenannten Berliner Hearing von 1978 ist das Bundesimmissionsschutzrecht ohne förmliche Gesetzesänderung in eine unglückliche Entwicklung hineingeraten, weil die ursprünglich nicht beabsichtigte Gleichschaltung des Gesundheitsschutzes für den Menschen und des Schutzes von Tier und Pflanze unkalkulierbare Genehmigungshindernisse produzierrt hat, die eigentlich von niemandem zu keinem Zeitpunkt politisch wirklich gewollt waren. Hier scheint eine Entkopplung unerläßlich zu sein: der Gesundheitsschutz für den Menschen einerseits und der Schutz von Tier oder Pflanze oder Ökosystemen andererseits müssen verschieden behandelt werden. Die Bundesregierung dürfte bereits mit einem Scheitern ihrer Novelle zum Bundesimmissionsschutzgesetz rechnen. Die dort vorherrschende Meinung, mit einer raffinierten Auslegung des Begriffs der erheblichen Nachteile im BImSchG schon von Fall zu Fall vernünftige und wirtschaftliche Ergebnisse hinschaukeln zu können, teile ich allerdings nicht.

Wenn wir danach aber Immissionsgrenzwerte festlegen, die dem Schutz von Tier und Pflanze oder von Ökosystemen dienen, dann dürfen auch diese nicht nachbarschützend interpretiert werden. Es geht nicht darum, die Ertragserwartung von Landwirten oder Baumschulen zu optimieren. Wie bei den Emissionsgrenzwerten handelt es sich um Anforderungen, die im Interesse des Wohls der Allgemeinheit und nicht einzelner Eigentümer verbindlich gemacht werden.

Lassen Sie mich also zusammenfassen: Ohne eine deutliche Unterscheidung zwischen Emissionsgrenzwerten und Immissionsgrenzwerten kommen wir nicht aus. Auch für die Immissionsgrenzwerte dürfen keine einheitlichen Rechtsfolgen postuliert werden; je mehr sie verschärft werden, desto stärker ist zu differenzieren. - Vielen Dank!

Götz: Das Problem der Entscheidungsfindung im Umweltrecht tritt in der Tat mit besonderer Deutlichkeit an der von Herrn Rauschning in den Thesen 17 und 22 behandelten Frage hervor, wie die erforderliche Vorsorge abzugrenzen ist von dem hinnehmbaren, tolerablen oder unvermeidlichen Risiko. Mir scheint, daß wir als Juristen und Offentlichrechtler im besonderen sehr stark fixiert darauf sind, zur Beantwortung der Frage, wer hier entscheidet und wonach entschieden wird, unseren Blick auf die verschiedenen Funktionsbereiche des Staates zu lenken, uns also die Frage zu stellen, welchen Anteil Ge- 
setzgebung, Verwaltung und Rechtsprechung an dieser Entscheidung haben. Darin sehe ich die Gefahr, daß wir sozusagen in juristischer Selbstbespiegelung die Rolle der Naturwissenschaft und Technik an diesem Punkte vernachlässigen und zu gering einschätzen. Naturwissenschaft und Technik - der Wissenschaftler und der Ingenieur - sie sind für uns unter anderem Lieferanten der Fakten und Erkenntnisse, aber wir würden ihre Rolle falsch einschätzen, wenn wir sie nur so sähen. Lassen Sie mich das bitte am Beispiel des $\S 7$ des Atomgesetzes erläutern: Dieser $\S 7$ macht es zur Voraussetzung der Genehmigung eines Atomkraftwerkes, da $B$ die nach Wissenschaft und Technik erforderliche Vorsorge gegen Gefahren getroffen ist. In die Erforderlichkeit dieser Vorsorge geht nun auch die Frage - und die Entscheidung - darüber ein, welche Restrisiken unvermeidlich sind und toleriert werden können. Wohlgemerkt: Diese Entscheidung wird vom positiven Gesetz, von $\S 7$, nicht als eine politische Entscheidung verstanden, auch nicht als Wertung eines Richters normiert, sondern wird in die Hand der Wissenschaft - d. h. der Naturwissenschaft - und Technik gegeben. Der Einwand, es sei die Bestimmung jenes Grenzpunktes doch eigentlich keine Frage der Naturwissenschaft und Technik zieht nicht. Denn das Entscheidungsmodell des positiven Gesetzes geht davon aus, daß die in Rede stehende Entscheidung sozusagen aus dem Schoße von Naturwissenschaft lund Technik heraus am besten getroffen werden kann. Ich glaube, wenn man sich das verdeutlicht, muß man Konsequenzen ziehen, die ich nur andeuten kann. Natürlich ist der naturwissenschaftliche und technische Sachverstand zu organisieren, und es werden sich auch Folgerungen für die Kontrolle der so getroffenen Entscheidung durch die Gerichte ergeben.

Vorsitzender: Vielen Dank, Herr Götz! Als nächsten darf ich Herrn Fleiner speziell zum Problem des Umweltschutzes als Gesetzgebungsaufgabe bitten; wie vielen von Ihnen bekannt sein wird, ist Herr Fleiner maßgebend an der schweizerischen Umweltschutzgesetzgebung beteiligt gewesen.

Fleiner: Lassen Sie mich kurz über die Erfahrung sprechen, welche wir bei der Erarbeitung des Gesetzes für das Umweltschutzrecht in der Schweiz gemacht haben, das zum Teil - wie Sie von Herrn Wildhaber gehört haben - kritisiert wird, und darlegen, welche Probleme sich dem Gesetzgeber konkret stellen. Ich darf gleich vorwegnehmen, daß mich beide Referate außerordentlich beeindruckt haben, weil man von der Praxis der Gesetzgebung her grundsätzlich beiden Referaten voll zu- 
stimmen kann. Doch vorerst noch ganz kurz eine Bemerkung wenn Sie gestatten - zu Herrn Saladin, von einem Professor eines finanzschwachen Kantons, zur Frage der Risikoverteilung bei Kernkraftwerken. Ich halte mich hier an den ganz einfachen Grundsatz: Wer profitiert, riskiert.

Nun zur Frage der Gesetzgebung: Ich darf auch hier vorwegnehmen: Der CH-Entwurf für ein Umweltschutzgesetz hat sich seit einem Jahr, d.h. seit dem Abschluß der Vernehmlassung wesentlich erweitert, wir haben den Vernehmlassungen Rechnung getragen, wir haben z. B. die Verbandsklage eingebaut, wir haben im neuen Entwurf auch die Lebensgemeinschaften geschützt, wir verpflichten die Behörden auf eine ganzheitliche, d. h. ökologische Betrachtung.

Das Umweltschutzgesetz der Schweiz beschränkt sich auf das Realisierbare und politisch Mögliche. Wenn es von den Räten genehmigt wird und den Prüfstein des Referendums besteht, wird es aber das erste Umweltschutzgesetz sein, das derart umfassend und auf eine Gesamtkonzeption des Umweltschutzes ausgerichtet ist. Die Vorlage wird in den nächsten Wochen vom Bundesrat verabschiedet werden und dann dem Parlament mit einer Botschaft des Bundesrates zugestellt werden. Die Erarbeitung des Entwurfes war tatsächlich, wie Herr Hoppe das meines Erachtens sehr eindrücklich dargelegt hat, außerordentlich schwierig.

Ich will versuchen, Ihnen zu zeigen, wie wir mit der Tatsache, daß man im Bereich des Umweltschutzrechts mit Generalklauseln arbeiten muß und eben deshalb die Rechtssicherheit immer wieder in Frage gestellt wird, fertig zu werden trachteten, obwohl ich mir im klaren bin: Wir haben manche Mängel noch nicht überwunden. Das erste: Wir bauen auf dem Grundsatz der Subsidiarität auf und verpflichten die Behörden, die Bevölkerung im Bereich des Umweltschutzes umfassend zu informieren, um jedermann zu einem freiwilligen Einsatz im Interesse des Umweltschutzes zu bringen. Die erste Aufgabe der staatlichen Behörde ist meines Erachtens eine gute und umfassende Information über die Umweltbelastung und über Möglichkeiten jedes einzelnen, zur Beeinträchtigung der Einwirkungen beizutragen. Die zweite Möglichkeit: Empfehlungen: Das Umweltschutzamt hat die Aufgabe, Empfehlungen auszuarbeiten, weil es sich ja sehr oft um quantitative Probleme handelt; also: Wenn $80 \%$ der Bevölkerung die leeren Flaschen am richtigen Ort abgeben, dann ist das Problem einer selektiven Behandlung der Abfälle weitgehend gelöst, wir müssen nicht $100 \%$ haben. Derartige Ziele lassen sich sehr oft mit Empfehlungen erreichen. Die dritte und entscheidende Möglichkeit, die 
wir gefunden haben, liegt darin, daß wir mit dem neuen Umweltschutzgesetz Grundsätze, z. B. Immissionsstandards und Emissionsgrenzwerte festlegen, aber diese Werte nicht für neue Bewilligungsverfahren vorsehen, sondern die Behörden verpflichten, sich im Rahmen bestehender Bewilligungsverfahren an diese Werte zu halten; z. B. die Motorfahrzeugüberprüfung muß gleichzeitig auch sicherstellen, daß der Emissionsgrenzwert bei den Motorfahrzeugtypen eingehalten wird. Die Luftfahrtbehörde hat die Aufgabe, sich an den Immissionsgrenzwerten des Umweltschutzgesetzes auszurichten und entsprechende Lärmvorschriften in der Umgebung von Flugplätzen vorzusehen, und die Landwirtschaftsbehörde hat die Aufgabe, im Bereiche der Kontrolle der Pestizide auch die langfristigen ökologischen Auswirkungen der Stoffe zu prüfen, genau gleich die Gesundheitsbehörde im Rahmen des Giftgesetzes. Und dort, wo noch Lücken bestehen, haben wir die bestehenden Vorschriften ergänzt. thberdies enthält das Gesetz eine Grundlage über die vertragliche Zusammenarbeit zwischen Behörden und Privaten im Bereiche des Vollzugs von Umweltschutzvorschriften. Also: Wir wollen versuchen, ohne neue Personalaufstokkungen und ohne neue wesentliche Verfahren Grundsätze für die bestehenden kantonalen, Gemeinde- und Bundesbewilligungen einzubauen, um auf diese Weise einigermaßen dem Problem Rechnung zu tragen und auch das Problem Rechtssicherheit zu lösen.

Vorsitzender: Herzlichen Dank, Herr Fleiner, für Ihren instruktiven Einblick in Ihre Schweizer Arbeit! - Bevor ich Herrn Papier das Wort gebe, darf ich Herrn Bachof Gelegenheit zu einem Zwischenruf - bitte möglichst nur zwei Sätze zum Beitrag von Herrn Götz geben!

Bachof: Vier oder fünf Sätze mögen es schon werden! Herr Götz, Sie sagen, das Atomgesetz selbst habe in $\S 7$ die Entscheidung dem Richter sozusagen genommen und dem Naturwissenschaftler gegeben. Das hat es eben nicht getan, denn dann hätte es auch sagen müssen, welche Naturwissenschaftler oder welches Gremium von Naturwissenschaftlern entscheide. Solange das Gesetz das nicht tut, steht der Richter vor der Situation, daß er 4, 6, 8, ja auch 10 Gutachten vorliegen haben kann, und da $B$ diese $4,6,8$ oder 10 Gutachten auch $4,6,8$ oder 10 verschiedene Meinungen von Naturwissenschaftlern enthalten! Es bleibt dem Richter also nichts übrig, als selbst zu entscheiden: das Gesetz bestimmt zwar, welcher Richter entscheidet; es bestimmt aber nicht, welcher Naturwissenschaftler „entscheidet"! 
Papier: Es sind nun mehrere Jahre verstrichen, seitdem der erste massive Ruf nach mehr Staat im Umweltschutz laut geworden ist, deshalb scheint es mir jetzt an der Zeit zu sein, einmal in Ruhe nachzudenken, ob die Verantwortlichkeiten und Zuständigkeiten zwischen dem Staat einerseits und der Gesellschaft und den Trägern der Privatautonomie andererseits überall angemessen gegeneinander abgegrenzt sind. Ich kann hier nur zwei Fragenkomplexe anführen: Der eine Punkt ist der, $\mathrm{da} ß$ wir - und das ist hier schon des öfteren angeklungen einerseits in zunehmendem Maße von einem breiten Normennetz überzogen werden, andererseits diese Normen doch - es ist bereits das Stichwort "technische Regelwerke“ oder "technische Normen" gefallen - immer wieder ausdrücklich oder stillschweigend, nämlich durch Verwendung teilweise unbestimmter Rechtsbegriffe, auf technische Regelwerke, also auf technisch-wissenschaftliche Standards privater Gruppierungen verweisen. Man muß sich allerdings auch fragen, weshalb in der staatlichen Gesetzgebung diese Bezugnahme auf - wie man häufig untertreibend sagt - technische Regelwerke erfolgt. Sehr häufig stecken in diesen technischen Regelwerken hochbrisante politische Wertungen und Entscheidungen. Es liegt häufig daran - und ich erinnere hier insbesondere an den Verkehrslärmschutz -, daß der staatliche Gesetz- oder Verordnungsgeber sich aus politisch-taktischen Gründen nicht in der Lage sieht, die notwendigen Wertungen, Abwägungen und Prioritätsentscheidungen $\mathrm{zu}$ treffen. Das ist ein Hinschieben der Verantwortung auf private Gruppierungen. Davon abgesehen stellt uns die staatliche Verweisungsübung gerade auch in der richterlichen Praxis vor die Frage: Wie müssen die zur Normbildung berufenen Gremien zusammengesetzt sein? Wie muß das Verfahren der Normaufstellung und der Normakzep$\operatorname{tanz}$ ablaufen, damit im Sinne des Bundesverwaltungsgerichts überhaupt von einem ,antizipierten Sachverständigengutachten" gesprochen werden kann? Auch diese Fragen des Verfahrens 'und der Zusammensetzung der Gremien sind derzeit gesetzlich nicht geregelt.

Wir haben also einerseits ein Defizit an verwaltungsrechtlicher Normierung in der Sache; andererseits - und dies ist der zweite Punkt - muß man sich fragen, ob wir in Teilbereichen nicht zu stark auf den Verwaltungsrechtssatz setzen. Der heutige Gesetzgeber überzieht viele Rechtsverhältnisse, die an sich durchaus dem Privatrecht, der Privatautonomie und der privatautonomen Durchsetzung überantwortet werden könnten, mit einem verwaltungsrechtlichen Regelungssystem. Betroffene wehren sich heute - und ich darf das auch aufgrund meiner 
richterlichen Praxis sagen - in zunehmendem Maße gegen Beeinträchtigungen Dritter nicht nur mit dem privatrechtlichen Abwehr-, Entschädigungs- und Schadensersatzinstrumentarium, sondern greifen zum öffentlich-rechtlichen Abwehrsystem, das ihnen geboten wird mittels der sogenannten öffentlich-rechtlichen Nachbarklage und durch das Institut der nachbarschützenden Verwaltungsrechtsnorm. Damit schalten sie häufig ein viel aufwendiger arbeitendes administratives Verfahren ein, meist sogar ein mehrstufiges Verwaltungsverfahren. Die Verwaltung - dies ist mein Eindruck - verzettelt sich in vielen Fällen auf diese Weise in einem punktuellen, weil nämlich privat initiierten Reagieren, anstatt die großen gemeinwohlbezogenen und nur öffentlich-rechtlich durchsetzbaren Aufgaben wahrzunehmen.

Vorsitzender: Vielen Dank, Herr Papier! - Bevor ich Herrn Bartlsperger das Wort gebe, noch eine $Z$ wischenbemerkung von Herrn Vogel zur Kontroverse zwischen Herrn Götz und Herrn Bachof.

Vogel: Zunächst noch ein Satz zu Herrn Soell: Umweltschutz muß, meine ich, wenn er sinnvoll sein soll, gewisse Kulturgüter mitumfassen; unsere Landschaft selber ist ein Kulturprodukt, und zu der Umwelt, in der wir leben, gehört auch deren Bebauung - um mit Herrn Häberle zu sprechen: wir müssen gelegentlich auch einmal in einem alten Dorf spazieren gehen können!

Jetzt aber zu dem Thema, das Herr Götz, Herr Bachof und auch Herr Papier angesprochen haben. Die Regelungsdichte der Normenwerke, die hier einschlägig sind, ist ja sehr unterschiedlich (Herr Breuer hat dies in einem Aufsatz im AOR. Bd.101, S. $46 \mathrm{ff}$.) sehr anschaulich dargestellt. Am weitesten geht die Verweisung auf außerrechtliche Maßstäbe in $\S 7$ Atomgesetz; er verweist, wie dies hier auch schon gesagt worden ist, nicht nur auf den Erkenntnisstand der Naturwissenschaften, sondern darüber hinaus auf Wertungen; geboten ist die Vorsorge, die "nach dem Stand von Wissenschaft und Technik", was immer das sein mag, erforderlich ist. Das Bundesverfassungsgericht hat gesagt, in diesem Sonderfall sei das zulässig (BVerfGE Bd. 49 , S. 89), und ich glaube, man muß ihm darin recht geben. Aber hier knüpft sich eine Frage an, die wir bisher nicht besprochen haben: wer trägt eigentlich das Risiko, wenn sich jene außerrechtlichen Maßstäbe, auf die verwiesen wird, ändern sei es der Erkenntnisstand oder seien es gar die Wertungen? Also etwa eine Teilgenehmigung wird erteilt, es wird fröhlich 
drauflos gebaut, aber plötzlich ändern sich die Auffassungen darüber, welche Restgefahr noch erträglich ist. Ist das ein Risiko des bauenden Unternehmers - „der Unternehmer", das sind hier nicht selten viele Kleinaktionäre -, oder müssen wir sagen: wenn hier aus öffentlichem Interesse eine ganz ungewöhnlich unbestimmte gesetzliche Regelung verfassungsrechtlich ausnahmsweise zulässig ist, dann müssen zumindest die Folgen, die sich aus der Unbestimmtheit dieser Regelung ergeben, von der Öffentlichkeit, der Allgemeinheit, getragen werden? Kann man hier die Grundsätze der Entschädigungsrechtsprechung über den Vertrauensschutz fortentwickeln? Gibt es eine öffentlichrechtliche Entschädigung dafür, daß der staatliche Gesetzgeber eine Frage zulässigerweise nicht selber geregelt hat - einen "Anspruch aus (und für) Normenmangel"?

Bartelsperger: Ich habe ein paar ganz konkrete Fragen zu den Ausführungen, die Herr Hoppe zum planerischen Vorsorgeprinzip, gemacht hat: Herr Hoppe hat ein planerisches Instrumentarium angesprochen, das er "Institutionalisierung der Informationsgewinnung" und "Informationsverarbeitung in formalisierten Verfahren" genannt hat. Er hat damit die Gewinnung von Planungsleitsätzen gemeint, wenn ich das richtig verstanden habe, und die Möglichkeit von Standortvorentscheidungen. Insgesamt steht dahinter wohl das Anliegen, die umweltspezifische Fachplanung stärker einzubinden. Dazu bestehen nun einige Fragen. Die erste betrifft die Möglichkeiten der rechtlichen Ausgestaltung im Raumordnungsverfahren nach dem Landesplanungsrecht oder in gleichliegenden Verfahren. Erstaunlicherweise hat das Herr Badura bereits bei den verfassungsrechtlichen Fragen angesprochen. Jedoch sind hier zwei ganz konkrete Aspekte wesentlich. Wie können diese querschnittsmäßigen Raumordnungsverfahren ausgestaltet werden im Hinblick auf ihre externe Verbindlichkeit gegenüber Betroffenen? Herr Blümel hat hierzu darauf hingewiesen, daß insofern eine prinzipielle Veränderung unseres Raumordnungsund Landesplanungsrechts eintreten würde. Es würden dann bereits durch solche Verfahren subjektive Rechtspositionen unmittelbar betroffen mit den entsprechenden Konsequenzen für den notwendigen Rechtsschutz. Zum zweiten: Inwiefern sollen dann diese Raumordnungsverfahren und rechtsähnlichen Verfahren landesplanerische Zielbestimmungen im Sinne von $\S 5$ Abs. 4 Raumordnungsgesetz sein mit der Folge, daB alle Hoheitsträger und Behörden daran gebunden sind? Ich glaube, es spricht einiges für die Beibehaltung der Unverbindlichkeit dieser Raumordnungsbeschlüsse. Damit hängen Rechtsschutz- 
fragen zusammen; es würde wahrscheinlich zu einer praktischen Verminderung des Rechtsschutzes führen, wenn Teilentscheidungen zeitlich sehr weit vorverlagert würden. Zum zweiten ist zu beachten, was eben Herr Vogel angesprochen hat und als zeitliche Dimension bezeichnet werden kann. Für die Unverbindlichkeit der betreffenden Verfahren spricht wohl auch, daß in zeitlicher Hinsicht die Flexibilität der Planung erhalten werden muß, und zwar nicht nur wegen der möglichen technischen und sonstigen tatsächlichen Veränderungen, sondern auch wegen des immer vorkommenden Wandels in der Einschätzung der Umweltbelange.

Die nächste Frage betrifft die These 27 von Herrn Hoppe, in der von den Standortentscheidungen die Rede ist. Hier wäre noch eine Klarstellung nötig, ob eine Standortgenehmigung oder eine Standortvorsorgeplanung im Rahmen der Raumordnung und Landesplanung gemeint ist. Auch insofern sind Rechtschutzprobleme eingeschlossen.

Eine dritte Frage bezieht sich auf These 24 von Herrn Hoppe. Diese geht nach meiner Ansicht zutreffend davon aus, daß die Umweltschutzbelange keinen absoluten Vorrang innerhalb der planerischen Abwägung beanspruchen können, sondern gleichen Rang mit den übrigen Belangen haben. Was bedeutet das in institutionell-organisatorischer Hinsicht für das Verhältnis von Staatsverwaltung und gemeindlicher Planungshoheit? Wenn es richtig ist, daß Umweltbelange nur gleichen Rang mit anderen planerischen Belangen haben, dann muß eine danach erfolgende gemeindliche Bauleitplanung in der Rechtsform von Bebauungsplänen Geltung auch gegenüber speziellen Entscheidungen der Staatsverwaltung beanspruchen, die nur der Durchsetzung eines bestimmten Verwaltungszweckes dienen, etwa des Landschaftsschutzes oder des Denkmalschutzes, und damit im Ergebnis einen Vorrang dieser besonderen Umweltbelange durchsetzen wollen. In der Verwaltungspraxis versuchen Staatsbehörden auf diese Weise ständig, über die kommunale Fachaufsicht die Bebauungspläne zu unterlaufen. Daß dies unzulässig sein muß, wäre nach meiner Ansicht die institutionellorganisatorische Konsequenz aus der These 24 von Herrn Hoppe für das Verhältnis von Staatsverwaltung und gemeindlicher Planungshoheit.

Eine vierte, recht diffizile Frage, würde mich zur These 21 von Herrn Hoppe interessieren. Sie betrifft die Reduktion des umfassenden Tatsachenmaterials bei der planerischen Abwägung. Herr Hoppe hat in diesem Punkt vor einiger Zeit im DVBl. die Rechtsprechung des BVerwG kritisiert, indem er sich dafür einsetzt, insofern dem - gemeindlichen - Planungsträ- 
ger eine sogenannte autonome Determinante zuzugestehen. Würden Sie, Herr Hoppe, in dem Zusammenhang so weit gehen, daß dadurch den Gemeinden bei der Auswahl des Abwägungsmaterials in stärkerem Maße Selbstverwaltung eingeräumt wird? Soweit eine staatliche Planung erfolgt, würde sich hier die Frage stellen, ob insofern und in diesem speziellen Bereich wieder eine Art Beurteilungsspielraum oder Beurteilungsfreiheit der Verwaltung eingeführt würde.

Eine kurze Frage noch zu These 22 von Herrn Rauschning. Dort heißt es in der zweiten Hälfte: Auf die Einhaltung dieser Grenzen ist dem Bürger ein Rechtsanspruch ausdrücklich einzuräumen. Hierzu wäre ich für eine Klarstellung dankbar, ob damit wieder die Dispositionsmöglichkeit des Gesetzgebers anerkannt werden sollte, $\mathrm{zu}$ bestimmen, ob eine Norm einen Rechtsanspruch einräumt oder nicht. Möglicherweise ist mit der These nur gemeint, die gesetzliche Formulierung sollte so prägnant sein, daß mittels einer objektiven Interpretation evident festgestellt werden kann, ob ein Rechtsatz nachbarschützend ist oder nicht.

Kloepfer: Neben der Gefahr eines Vollzugsdefizits kann man im Umweltbereich möglicherweise bisweilen auch ein Differenzierungsdefizit feststellen - z. B. bei der Frage, ob Umweltschutz eine Staatsaufgabe ist. Hier bin ich insbesondere dem Herrn Zweitberichterstatter dankbar, daß er diese Differenzierung in Angriff genommen hat. Ich will mich, da wir im Diskussionsbereich IV sind, nur mit seiner These 31 befassen, nämlich mit den hoheitlich inspirierten Verhaltensabreden, wie sie von Herrn Kaiser genannt worden sind. Es geht ja hier letztlich um eine Unterfrage der Problematik: Ist Umweltschutz eine Staatsaufgabe, und welche anderen Möglichkeiten gibt es? Wir haben sehr viel in den Referaten gehört von den Integrationsmöglichkeiten zwischen den verschiedenen Umweltschutzpolitiken, und dann taucht immer wieder die Frage auf, ob es sinnvoll ist, von einem einheitlichen Begriff des Umweltschutzes zu sprechen. Mindestens genau so wichtig ist es aber, sich Gedanken zu machen, wie weit man die Umweltschutzpolitik, wie immer man sie auch in sich differenzieren muB, verbinden kann mit anderen Politikbereichen. Dazu ist diese Diskussion um die hoheitlich inspirierten Verhaltensabreden — die ja auch unter dem Stichwort der Selbstbeschränkungsabkommen diskutiert werden - ein gutes Beispiel.

Es wird sich zeigen, daß die nur positive Sicht der hoheitlich inspirierten Verhaltensabreden im Umweltschutz doch vielleicht schon deshalb ein wenig relativiert werden muß, weil 
derartige Abreden auch einen anderen Politikbereich berühren, nämlich den der Wettbewerbssicherung. Und im Kartellrecht etwa wird ja diese Problematik folgerichtig auch eher als Gefährdung des Wettbewerbs diskutiert. Um nun den Ansatzpunkt zu sehen, muß man sich deutlich machen, daß Umweltschutz ja auch ein Faktor des Wettbewerbs oder aber auch ein wettbewerbsbehindernder Faktor sein kann. So gibt es etwa die Möglichkeit, daß Betriebe mit jeweils weniger Umweltschutz, d. h. mit der hieraus folgenden Kostenersparnis, Wettbewerb treiben; und hier zeigt sich nun, daB mindestens staatlich gebotener Umweltschutz eine Wettbewerbsbehinderung herbeiführen kann: Der Wettbewerb mit weniger Umweltschutz oder um weniger Umweltschutz wird dann verhindert, wenn der Gesetzgeber etwa umweltrechtliche Standards - z. B. Emissionsgrenzen - vorschreibt. Diese Homogenisierung der Wettbewerbsbedingungen führt zu einer Wettbewerbsbegrenzung, wenngleich auf der anderen Seite auch die Ausgangspositionen für den Wettbewerb geklärt und - unter Umweltschutzgesichtspunkten - chancengleich werden. Zum anderen - darauf hat ja Herr Bullinger an anderer Stelle sehr eindrücklich hingewiesen - gibt es auch eine Form der Wettbewerbsbehinderung durch staatliche Genehmigungsverfahren oder durch Informationszwänge in diesen Genehmigungsverfahren, und auch dies muß man im Auge behalten, wenn man das Gesamtproblem der Einbeziehung des Umweltschutzes in andere Politikbereiche diskutieren will.

Die konkrete Politikintegration folgt in dem Bereich der Wettbewerbssicherung und des Umweltschutzes im wesentlichen durch Rechtsanwendung, d. h. durch die Anwendung entweder des Kartellrechts oder des Umweltrechts. Ich halte hier wenig von gesetzgeberischen Formelkompromissen, z. B. bei der Forderung nach einem magischen Fünfeck als Zielkatalog der Globalsteuerung etwa dadurch, daß man das „gesamtwirtschaftliche Gleichgewicht" in $\S 1$ Stabilitätsgesetz aufpumpt, indem man dort noch hineinschreibt „bei einer gesunden Umwelt". Vielmehr bieten die Anwendungsmöglichkeiten beider Rechtsgebiete - des Wettbewerbsrechts und des Umweltrechts schon in ihrer bisherigen Form genügend Möglichkeiten, zu einer Verbindung beider Politikbereiche zu kommen. Wenig gesehen wird etwa bisher die Möglichkeit - weil der Umweltschutz sich sozusagen immer aus sich selbst heraus legitimiert -, auch mit umweltrechtlichen Mitteln die Politikziele anderer Bereiche $\mathrm{zu}$ verfolgen. $\mathrm{Z}$. B. scheint es mir eine wichtige Frage zu sein, ob man nicht auch bei der "wirtschaftlichen Vertretbarkeit" gesamtwirtschaftliche Gesichtspunkte mitbe- 
rücksichtigen kann. Ich meine, die Antwort wird dabei sein, daß man differenzieren muß, wie dieser Begriff verwandt wird; im Abfallrecht etwa können bei der Konkretisierung des Begriffs "wirtschaftliche Vertretbarkeit" auch gesamtwirtschaftliche Gesichtspunkte und damit auch die möglichen Wettbewerbsbeschränkungen durch konkrete staatliche Umweltschutzmaßnahmen mitberücksichtigt werden. In der bisherigen Diskussion steht genau der umgekehrte Punkt im Vordergrund, nämlich inwieweit das Kartellrecht auch ein Mittel sein kann, den Umweltschutz zu ermöglichen. Hier gibt es ja Beispiele aus den Vereinigten Staaten, und dies alles ist ausführlichst im Arbeitskreis Kartellrecht beim Bundeskartellamt diskutiert worden. Ich will hier auf die einzelnen kartellrechtlichen Konstruktionsmöglichkeiten im einzelnen gar nicht eingehen. Die Güterabwägungstheorie im Kartellrecht spielt ebenso eine Rolle wie die Frage danach, ob die "hoheitliche Inspiration" bei Wettbewerbsbeschränkungen eine Möglichkeit ist, vom Kartellverbot Abstand zu nehmen oder ob man zur Ministererlaubnis kommen kann, was dann wieder zu der Frage führt: „Wie ist eigentlich die Kompetenzkonkurrenz zwischen Kartellbehörden und Umweltbehörden zu regeln? Ich würde den Begriff „hoheitliche Inspiration" für sehr euphemistisch halten, denn es geht doch praktisch möglicherweise auch - überspitzt gesagt um eine feinere Form von Nötigung. Der Staat sagt zu den Produzenten: Wir planen ein eingreifendes Umweltgesetz, wir werden z. B. eine Abgasbestimmung erlassen oder wir werden Euch verpflichten, weniger Benzin verbrauchende Autos herzustellen; wenn Ihr Euch aber zu einem entsprechenden Selbstbeschränkungsabkommen „inspirieren“ laßt, dann ist die Möglichkeit da, von diesen staatlichen Maßnahmen Abstand zu nehmen. - Ich würde sagen, dies zeigt im Grunde, daß von einer einseitig positiven Sicht der Selbstbeschränkungsabkommen Abstand genommen werden muß. Ich glaube, man verliert dabei auch ein bißchen die rechtsstaatliche, insbesondere für den Rechtsschutz wichtige Garantiefunktion des Eingriffs, was nicht heißt, daß dies - da würde ich dem Herrn Zweitberichterstatter völlig recht geben - eine sehr effektive Form des Umweltschutzes ist. $\mathrm{Ob}$ es immer eine rechtsstaatlich begrüBenswerte Form des Umweltschutzes ist, daß weiß ich nicht.

Vorsitzender: Vielen Dank, Herr Kloepfer, auch dafür, daß Sie die zusätzlichen Problemaspekte des Kartellrechts mit in die Debatte eingebracht haben. Denn in diesem Bereich liegt bekanntlich eine Fülle weiterer Probleme begründet. Als nächsten, ebenfalls noch zum Komplex der Einzelfragen, bitte ich Herrn Krause! 
Krause: Lassen Sie mich ein paar Fragen anreißen, die nicht nur Einzelfragen sind, sondern in das Allgemeine ausstrahlen.

Es geht um das bislang noch nicht angesprochene Problem des Entscheidungsverfahrens. Beim Umweltschutz werden Entscheidungen höchster Komplexität notwendig. Herr Vogel hat dieses Problem uns allen ausgemalt. Herr Dürig hat die Vertrauenskrise und die Konsensprobleme und die radikaldemokratischen Strömungen aufgewiesen, die sich hier ansiedeln.

Herr Breuer hat das Problem, wie man solche Entscheidungen für die Öffentlichkeit überhaupt glaubhaft machen kann, vertieft. Wir haben es nicht nur mit einer Krise der Glaubhaftigkeit, sondern schon mit einer Glaubenskrise zu tun. Die Komplexität wird noch erhöht, weil die übrigen Staatszielbestimmungen sich eindrängen, - Herr Kloepfer hat eben vom magischen Fünfeck gesprochen -, man kann das beliebig erweitern und noch mehr Eckpunkte einbeziehen, und alle diese Eckpunkte müssen eigentlich bei Umweltentscheidungen mitbedacht werden. Das drängt doch die Frage auf, ob die Entscheidungsverfahren, die wir besitzen, es ermöglichen, derartig komplexe Entscheidungen wirklich glaubhaft $\mathrm{zu}$ treffen oder ob wir dazu ein neues Verfahren entwickeln müssen. Ich gehe dabei davon aus, daß die erforderlichen Daten erhoben und erfaßt sind, wobei ich allerdings gewisse Bedenken unterdrücke, denn die Vertrauenskrise gegenüber Expertenwissen liegt doch am Tage, und so ganz klar ist mir nicht, ob die Datenbänke, die Herr Hoppe hier schaffen will, diese Vertrauenskrise beheben oder noch zusätzlich nähren werden. Die Frage, die ich stellen will, ist indessen, ob wir uns ein Verfahren vorstellen können, in dem derart komplexe Entscheidungen sachgerecht, rational - auch in der Zeit, denn wir haben es heute mit viel zu lange dauernden Entscheidungsprozessen zu tun - und sozial befriedend getroffen werden können. Wenn ich die Entscheidungswege durchmustere, die wir bislang zu bieten pflegen, dann sehe ich nirgends etwas Überzeugendes. Der demokratische Weg der gesetzgeberischen Mehrheitsentscheidung ist offenbar wie er im Moment beschritten wird - problematisch. Herr Papier hat darauf hingewiesen, da $\beta$ der Gesetzgeber wenigstens im Augenblick die Entscheidungen nicht zu treffen bereit ist, sondern daß er sie sehr schnell auf irgendeine andere Instanz verweist. Die Entscheidung durch Richterspruch erscheint mir in höchstem Maße ungeeignet, weil der Prozeß diese Komplexität mit einer Vielzahl von Beteiligten und Aspekten, die oft gar nicht in das Verfahren eingebracht werden können, nicht verarbeiten kann. Keineswegs kann die individuelle Verantwortung - auch darauf wurde heute angespielt - die Sachgerech- 
tigkeit und die Legitimität verbürgen, auch nicht, wenn sie nachträglich dann noch einmal polizeilich kontrolliert wird. Um nun nicht mißverstanden zu werden: Ich halte auch nichts von den radikal-demokratischen Prozessen, die meistens dazu führen, daß man das Ubbel an den Nachbarn verschiebt, jedenfalls die Interessen einseitig und nicht in ihrer Komplexität verarbeitet. Volksabstimmungen haben auch ganz merkwürdige Ergebnisse - wir haben das hier schon gesehen und gehört. Auch die Delegation an Techniker und Experten und deren Wertungen erscheint mir problematisch. Ich meine, daß wir uns hier etwas überlegen müßten, vielleicht ein ganz neuartiges Verfahren, vielleicht aber auch nur eine Neubesinnung auf die Aufgabe des Parlaments, um diese Probleme zu verarbeiten, wenn wir ein Mindestmaß an sozialem Frieden erhalten und nicht der Gefahr eines neuen, diesmal ökologischen Glaubenskrieges der nicht ausgeschlossen ist, wo friedliche Verfahren versagen - ins Auge sehen wollen.

Vorsitzender: Vielen Dank, Herr Krause! Ich schließe damit die Aussprache auch zum vierten Diskussionskomplex, den ausgewählten Einzelfragen, und darf nunmehr den letzten Diskussionskomplex, die Probleme des Rechtsschutzes im Umweltschutzrecht, aufrufen. Als ersten darf ich Herrn Barbey bitten!

Barbey: Zu Leitsatz 22 von Herrn Rauschning: Ich habe Zweifel, ob durch die unbestimmten Rechtsbegriffen beigefügte Klarstellung, daß damit der Schutz vor Gefahren im Rechtssinne gefordert werde, die Dezision über die Schutzintensität von der Gerichtsbarkeit auf die politisch verantwortlichen Gewalten zurückverlagert wird. Die Schwierigkeiten richterlicher Erkenntnis liegen insofern nicht in der rechtlichen Würdigung festgestellter Tatsachen, sondern in der Frage, ob die naturwissenschaftlichen, technischen, medizinischen Vorgaben, die man auf diesem Felde vorfindet, der rechtlichen Würdigung zugrundegelegt werden dürfen. Diese Schwierigkeit ist nicht behebbar, weil der Richter auf den jeweiligen Erkenntnisstand angewiesen ist. Auch wenn dieser nicht hinreichend fortgeschritten und ungesichert ist, kann ihn der Richter nicht in einem salto mortale hinter sich lassen, sondern ist an ihn "gebunden".

In dieser Hinsicht ist im Voerde-Verfahren aufschlußreich gewesen, daß das Berufungsgericht bei der Auslegung und Anwendung unbestimmter Rechtsbegriffe (DVBl. 1976, 794) einerseits seine "Bandbreitentheorie" zu den Grenzwerten der TA Luft damit begründet hat, daß der Sachverhalt naturwissen- 
schaftlich-technisch nicht aufgeklärt werden könne (a.a.O. S. 795 letzter Abs., S. 796 li. Abs. 4).

Ich schließe aus alledem, daß es in derartigen Lagen darauf ankommt, die Organisation und das Verfahren, mit denen die den zu überprüfenden behördlichen Entscheidungen zugrundeliegenden technisch-wissenschaftlichen Erkenntnisse gewonnen worden sind, daraufhin zu überprüfen, ob sie auf Aufklärung und Feststellung des nach dem Gesetz rechtserheblichen Tatsachenstoffs gerichtet sind, und sich dann damit zu bescheiden, wenn Organisation und Verfahren in Ordnung sind, also die gegenwärtig mögliche Erkenntnis gewährleisten. Dahin tendiert auch das Voerde-Urteil des Bundesverwaltungsgerichts, wenn es darauf hinweist, daß ein zentralisiertes Verfahren, wie es dem Erlaß der TA Luft vorausgegangen ist, bessere Ergebnisse liefere als ad hoc veranlaßte Sachverständigenerhebungen im Einzelfall, weil es in viel breiterem Umfang naturwissenschaftliche Erkenntnisse in sich aufnehmen könne als diese (BVerwGE $55,250,256 f$.).

Ich stimme Herrn Breuer darin $z u$, daß die maßgeblichen Grenzwerte durch verfassungsmäßig ermächtigte Rechtsverordnung festgesetzt werden sollten. Hinsichtlich der Intensität der gerichtlichen Nachprüfung von Verwaltungsentscheidungen - zu der allein ich mich hier äußere - ist es freilich gleichgültig, ob der Richter eine in die überprüfte Verwaltungsentscheidung eingegangene Sachverständigenexpertise auf die Sachgerechtigkeit von Organisation und Verfahren überprüft, oder ob eine Rechtsverordnung, die nur der Konkretisierung einer vorgegebenen Norm dient und nicht auf eine darüber hinausgehende Regelungskompetenz zurückgeführt werden kann, daraufhin überprüft wird, ob sie das Gesetz zutreffend konkretisiert hat.

Eine letzte Bemerkung: Leitsatz 22 verlangt, in rechtlich verbindlichen Normen Grenzwerte festzulegen, unterhalb derer eine Gefahr im Rechtssinne gewiß nicht mehr besteht. Werden derartige Grenzwerte durch förmliches Gesetz festgelegt, so verschiebt sich die Rechtsqualität dieser Grenzwerte aus dem Bereich der Gefahrenabwehr in den Bereich der Vorsorge, weil der Gesetzgeber anders als der Setzer etwa einer Polizeiverordnung weder zur Bekämpfung von Gefahren angewiesen noch hierauf beschränkt ist.

Blümel: Herr Rauschning sagt im letzten Satz seiner These 21: „Als Bestandteil der Staatswillensbildung zu Großprojekten ist ein Entscheidungsgang in zwei Instanzen um die sofortige Vollziehbarkeit und weiteren drei Instanzen in der Hauptsache zu 
lang“. Das kann so sicher nicht stehenbleiben, denn für den vorläufigen Rechtsschutz ist nach Aussetzungsbeschlüssen die Möglichkeit einer neuen, die sofortige Vollziehung wiederherstellenden gerichtlichen Entscheidung nach $\S 80$ Abs. 6 VwGO übersehen - und davon wird in zunehmendem Maße Gebrauch gemacht. Zum verwaltungsgerichtlichen Rechtsschutz im übrigen möchte ich die Augsburger Verhandlungen hier nicht wieder aufgreifen. Auf einen wesentlichen Aspekt unseres heutigen Themas, der im Referat von Herrn Rauschning zu kurz kam, muß jedoch hingewiesen werden, nämlich den planungsverfahrens- bzw. verwaltungsverfahrensrechtlichen Aspekt. Ich nenne insoweit zwei hochaktuelle Stichworte, die der weiteren Diskussion bedürfen: Einmal die neuesten sogar vom Bundesverkehrsminister für die Verkehrsplanung - Straßenplanung, Bundesbahnplanung - propagierte und gegenwärtig versuchsweise durchgeführte frühzeitigere Bürgerbeteiligung. Das geltende Recht kennt diese frühzeitige Bürgerbeteiligung bisher nur in $\S 2$ a BBauG. Zum anderen die Auslegung und die praktische Anwendung der in den Verwaltungsverfahrensgesetzen und in den Fachplanungsgesetzen enthaltenen Regelungen über die Massenverfahren. Ich will es mir hier verkneifen, näher auf die verfahrensverzögernde Wirkung der $\S \S 17 \mathrm{ff}$. VwVfG einzugehen; dazu ist in den Kommentaren zum Verwaltungsverfahrensgesetz einiges gesagt. Nichts Brauchbares finden Sie allerdings in den Kommentaren zu den wichtigen Vorschriften über die Zustellung durch öffentliche Bekanntmachung, die ich 1974 in der Werner Weber-Festschrift als verfassungsrechtlich bedenklich bezeichnet habe. Obwohl diese Bedenken im Schrifttum vielfach als nicht stichhaltig angesehen wurden, hat mich die bisherige praktische Anwendung - ich sage: die praktische Anwendung - dieser Vorschriften in meinen rechtsstaatlichen Bedenken bestärkt. Nehmen Sie etwa die Ihnen bekannte Vorschrift des $\S 17$ Abs. 1 und 3 der atomrechtlichen Verfahrensordnung; danach ist in solchen Fällen in der Bekanntmachung der verfügende Teil des Bescheids abzudrucken, und der Betroffene kann diesen Bescheid nebst Begründung dann später anfordern. Ähnliches gilt nach den Fachplanungsgesetzen für Planfeststellungsbeschlüsse. Wie werden nun diese Vorschriften in der Praxis angewendet, etwa bei der Planung von StraBen und Flughäfen? Nehmen Sie etwa den Planfeststellungsbeschluß für den Großflughafen München II, der 12 Bände umfaßt; Band 1 mit über 600 Seiten enthält neben der Begründung einen verfügenden Teil von über 90 Seiten. Diesen verfügenden Teil finden Sie natürlich nicht in der örtlichen Bekanntmachung. Entspricht das nun der gesetzlichen Vorschrift (hier des Ver- 
waltungsverfahrensgesetzes)? Und was bekommen die Betroffenen bzw. die Einwender, wenn sie den Planfeststellungsbeschluß anfordern? Mitnichten den Planfeststellungsbeschluß in seiner Gänze - also die 12 Bände -; sie bekommen nur den Band 1. Ich frage mich natürlich, ob eine solche Praxis - und diese Praxis ist ja nicht unbeachtlich - den gesetzlichen Vorschriften entspricht, ob sie mit rechtsstaatlichen Grundsätzen vereinbar ist. Aber ich frage mich auch, wie eine sachgerechte Regelung eigentlich aussehen müßte. Der ganze Fragenkomplex ist von eminenter Bedeutung für die Planung oder für die Genehmigung von Großvorhaben, etwa von Atomkraftwerken, denn Rechtsverstöße in diesem Bereich - darüber sollten wir nicht zweifeln - können natürlich nicht sanktionslos bleiben.

Mayer-Tasch: Ich habe zwei Bemerkungen noch: Die erste zur Frage der Normativierung der Grenzwerte, die zweite zur t'berforderung der Gerichte. Was die Normativierung der Grenzwerte betrifft, die nun schon mehrfach angesprochen wurde, bin ich in der Tat der Meinung, daß dies wirklich die schönste und sauberste Lösung wäre, aber die Forderung danach ist eben leider aus dem Stoff, aus dem die Träume sind! Der Staat kann meines Erachtens seine Aufgabe Umweltschutz nicht wahrnehmen, wenn er die Grenzwerte normativiert; ich glaube, daß Herr Steiger das vorher mit guten Gründen belegt hat. Auch hier fördert übrigens ein Blick auf die soziale und politische Wirklichkeit, wenn nicht die Rechtskenntnis, dann die rechtspolitische Raison. Die Forderung nach der Normativierung der Grenzwerte ist vor allem durch die Industrieverbände vorgetragen worden.

Die zweite Bemerkung - Utberforderung der Gerichte: Das mag in der Tat sein. Was diese Aussage allerdings relativiert, ist, daB die Verwaltung und zum Teil auch der Gesetzgeber in noch stärkerem Maße überfordert zu sein scheinen bei der Lösung ökologischer Probleme, was ja nicht zuletzt die inflationäre Entwicklung umweltrechtlicher Prozesse indiziert. Wer sich genauer über die Ursachsen informieren will - hier sind sie immer nur pauschal angesprochen worden - der möge doch bitte das Gutachten von Mayntz-Trier, das im Auftrag des Sachverständigenrates für Umweltfragen erstattet wurde, nachlesen; das Vollzugsdefizit ist erschütternd! Herausgekommen ist bei dieser breitangelegten Untersuchung, da $\beta$ die Behörden nicht einmal den Stand der Technik kannten, den sie dann nachher kraft Gesetzes zu implementieren hatten. - Aber das nur am Rande. Ich komme gleich zum Ende. Ich möchte in diesem $\mathrm{Zu}$ sammenhang nur eben davor warnen, daß man mit prozeß- 
rechtlichen oder anderen Korrekturen hantiert; die Wortwahl ist bewußt, ich sage ,hantiert' deswegen, weil die Schwierigkeit, mit der ökologischen Problematik fertigzuwerden, eine Schwierigkeit ist, die unser ganzes politisches System und die ganze Gewaltentrias betrifft, sowohl die Gesetzgebung als auch die Verwaltung und die Rechtsprechung. $\mathrm{DaB}$ diese Schwierigkeiten vorhanden sind, liegt nicht zuletzt daran, daß wir uns meines Erachtens in einer Epoche des fundamentalen kulturellen Umbruchs befinden, in einem Prozeß des Wertewandels. Daß dieser Wertewandel eben zu weitgehenden Polarisierungen geführt hat in der Gesellschaft, das kann ja jeder, der aufmerksam ist und nicht mit einem Brett vor dem Kopf herumläuft, beobachten. Und wir müssen sehr, sehr vorsichtig sein, daß der Vertrauensverlust, der eingetreten ist gegenüber den staatlichen Instanzen, sich nicht gerade durch ein voreiliges Hantieren mit Normkorrekturen noch weiter vertieft. In diesem Sinne möchte ich davor warnen, sozusagen den mobilen Rechtsstaat einzuführen. Ansätze dazu gibt es leider, ich verweise lediglich als pars pro toto - auf die Versuche, die Standortgenehmigungen für Kernkraftwerke an die energiepolitisch noch zuverlässigen Parlamente zu verweisen. - Dankeschön!

Häberle: Aus Zeitgründen beschränke ich mich auf eine kurze Frage zum Rechtsschutz, die sich, freilich funktionellrechtlich modifiziert, auch für Gesetzgebung und Verwaltung im Umweltrecht stellt. Ich möchte das Problem zuspitzen, das hinter der spannenden Kontroverse von soeben u. a. zwischen den Herren Bachof, Götz, Vogel steckt: Die durch präambelartige, in (konfliktträchtigen) Programmen, Betroffenenzahl und Folgen "unbestimmten Rechtsbegriffe" bzw. durch ihre spezifische Symbiose mit den technischen und Naturwissenschaften gekennzeichnete hochkomplexe Eigenart des Umweltschutzrechts zwingt uns zu der Frage: Wie verträgt sich die Eigenart dieses Administrativrechts mit dem verfassungsrechtlichen Prinzip des umfassenden Rechtsschutzes durch unabhängige staatliche Richter, werden doch diese (überforderten?) Richter oft durch Sachverständige aus nichtjuristischen Wissenschaften präjudiziert bzw. durch ihre widersprüchlichen Gutachten irritiert?

Vorsitzender: Ich darf damit die Diskussion schließen und beiden Referenten das Schlußwort geben; zunächst bitte, Herr Hoppe!

Hoppe: Herr Vorsitzender, meine Herren! Ich möchte mein Schlußwort mit der Stellungnahme zu dem einen oder anderen 
Beitrag verbinden. Ich bitte um Nachsicht, wenn ich nach dieser eingehenden Diskussion nicht allen Beiträgen so gerecht werde, wie sie es verdient haben.

Zunächst einmal darf ich bemerken, Herr Dürig, ich finde die Klarstellung sehr erfreulich, daß wir uns mißverstanden haben. Wenn ich Ihren zweiten Beitrag recht interpretiere, dann sehen Sie die Gefahrenabwehr als Grundlage und als Voraussetzung dafür an, daß Umweltschutz überhaupt betrieben werden kann, nicht aber in dem Sinne, wie ich Sie zunächst verstanden hatte, daß nämlich nach Ihrer Auffassung Umweltschutz auf die Gefahrenabwehr reduziert und zurückgeführt werden sollte. Ich glaube, daß wir uns nunmehr einig sind.

Herr Zacher hat auf den Gleichheitsgrundsatz hingewiesen und zugleich bemerkt, daß der Gleichheitsgrundsatz wenig effektiv sei. Ich kann das nur unterstreichen aus der Sicht der Planung. Ich hatte deswegen auf Erörterungen des Gleichheitssatzes, die nicht weitergeführt hätten, verzichtet und vielmehr eine Rangfolge zwischen dem vermeidenden, zuteilenden und sanierenden Umweltschut $z$ aufgestellt unter Betonung der Tatsache, daß dem Umweltschutz, insbesondere der Umweltschutzplanung immer stärker zuteilende Funktionen zuwachsen. Ich meine aber, daß man deswegen in besonderer Weise auf die Rangfolge von der vermeidenden zur zuteilenden und zur sanierenden Funktion achten und in allen Planungen in erster Linie die Umwelteingriffe vermeidende Funktion betonen sollte. Ich hoffe, daß man damit die Schwierigkeiten, die sich aus der Anwendung des Gleichheitssatzes gerade bei der Planung ergeben, ausgleichen kann.

$\mathrm{Zu}$ den Anregungen von Herrn Badura und Herrn Blümel und $\mathrm{zu}$ der Frage, in welcher Planungsart Umweltschutz vornehmlich betrieben werden soll, würde ich sagen, daß Umweltschutz in allen Planungsarten berücksichtigt werden muß, daß es aber sicherlich auch insoweit zu einer Verstärkung der Regionalplanung kommen wird. Ich sehe die Lösung der Probleme in der Tat vor allem in der Region liegen. Ich würde mich deswegen für eine Verbesserung der regionalen Umweltschutzplanung aussprechen. Das endgültige Ergebnis sollte aber von empirischen Untersuchungen zur Effektivigtät der Regionalplanung abhängig gemacht werden.

Herr Bartelsperger, nun zu Ihren Fragen: Ich hoffe, daß ich sie in der mir zur Verfügung stehenden Zeit beantworten kann. Zunächst einmal zu der Frage der externen Verbindlichkeit von Umweltschutzplanung: Ich war in meiner Vorstellung nicht von einer Änderung der externen Verbindlichkeit gegenüber dem Bürger im Hinblick auf Umweltschutzplanung ausgegangen, 
sondern wollte es insoweit bei einer Nichtverbindlichkeit belassen, als Planung auch bisher eine Bürgerverbindlichkeit nicht aufweist. Ich halte es für viel entscheidender, wenn Fakten, Daten und Informationen zum Umweltschutz in die Planung eingebracht werden. Das ist wirksamer, als wenn irgendwelche Verbindlichkeitsregelungen vorgesehen werden. Allein die Tatsache eines solchen Informationsprozesses - und da sollte man sich auch nicht an dem Ausdruck "Umweltschutzdatenbank" stoßen - allein die Tatsache, da $B$ Informationen eingespeist werden, bedeutet für den Umweltschutz mehr als irgendwelche Verbindlichkeitsregelungen. - Die zweite Frage: Bei der Vorsorgeplanung bzw. der Planung von Standorten insbesondere von industriellen Großvorhaben spreche ich mich - in Utbereinstimmung mit Herrn Breuer - für ein kombiniertes System aus: Zunächst für eine Vorsorgeplanung landesplanungsrechtlicher Art wie etwa in Nordrhein-Westfalen im Landesentwicklungsplan VI; dann dafür, daß die eigentliche Standortplanung in der Bauleitplanung, und zwar in der Weise erfolgen soll, daß den $\S \S 34$ und 35 Bundesbaugesetz diese Planungsfunktion abgesprochen wird und daß solche Vorhaben nicht mehr im Wege von Einzelgenehmigungen "geplant" werden, sondern daß für Großvorhaben eine eigene Planungsentscheidung getroffen wird, und zwar in Bebauungsplänen auf der Grundlage von Flächennutzungsplänen. Es bedarf der Uberlegung, ob eine solche Planung vielleicht in fachplanerischen Verfahren vorgenommen werden könnte. Ich neige aber wegen der gemeindlichen Planungshoheit stärker zur Lösung durch Bauleitpläne.

- Die dritte Frage des Gleichrangs und Vorrangs von Belangen in Verbindung mit der Utberlegung, ob die Belange der Bauleitplanung generell Vorrang haben sollten oder könnten vor Belangen etwa des Landschaftsschutzes und des Naturschutzes: Ich habe mich allgemein dafür ausgesprochen, daß alle Belange abstrakt gleichrangig sind und daß ihr Stellenwert jeweils in der konkreten Planungssituation festgestellt werden muß. Das gilt meines Erachtens auch bei der Bauleitplanung im Verhältnis zur Landschaftsplanung und zum Naturschutz. Ich würde also auch hier einen Vorrang der Belange der Bauleitplanung der — wie ich es genannt habe - "autonomen Determinanten“ abstrakt nicht annehmen. - Die vierte und letzte Frage: Die für die Planungsträger bei der Ermittlung. Ich sehe darin ebenso wie Sie einen Zuwachs an planerischer Gestaltungsfreiheit, aber nicht nur für den gemeindlichen Planungsträger, sondern für jeden Planungsträger. Ich möchte aber gerne Begriffe wie "Beurteilungsspielraum“ u. ä. vermeiden, weil sie dahin führen, Begriffsinhalte zu übernehmen, die im Planungsprozeß, 
insbesondere im Hinblick auf die Selektionsvorgänge bei der Ermittlung, fehl am Platze sind. Deswegen habe ich ganz bewußt von „autonomen Determinanten“ gesprochen. Diese „autonomen Determinanten" haben selbstverständlich eine Beschränkung der Überprüfbarkeit zur Folge.

Soviel zu den einzelnen Beiträgen.

Ich darf mich im übrigen sehr herzlich bedanken - und darf dabei einen Terminus aus dem Bundesbaugesetz benutzen für die vielen "Anregungen und Bedenken“ zu meinem Mitbericht. Zugleich danke ich aber auch für die Zustimmung, die ich nicht in dem Maße erwartet hatte, wie ich sie erfahren habe.

Rauschning: Meine verehrten Kollegen! Ich darf zunächst einmal sagen, daß in einer Vorabsprache mit Herrn Hoppe wir uns darüber einig waren, daß wir Ihnen das Lückenerlebnis lassen müssen, und ich darf Sie weiterhin daran erinnern, daß 60 Minuten ein hartes Korsett sind; andererseits bin ich nicht der Meinung, daß wir in unserer Vereinigung diese Zeitbeschränkung aufgeben sollten, sie ist durchaus erzieherisch. Trotzdem ist dabei natürlich manches, was hätte gesagt werden müssen, zu kurz gekommen.

Wenn ich zunächst etwas zum Sozialstaatsprinzip sage, dann darf ich mich an Sie, Herr Breuer, wenden: Ich habe im KalkarBeschluß keinen Hinweis darauf finden können, und es ist jedenfalls auch nicht im Schlagwortregister dieses Bandes genannt! Ich glaube nicht, daß das Bundesverfassungsgericht das Sozialstaatsprinzip für seinen Gedankengang braucht. Ich bin nicht dagegen, es anzuwenden, ich kann nur sagen: Wir brauchen es nicht; auch nicht für das ökologische Existenzminimum, das wir als Existenzminimum aus Art. 2 II GG als hinreichenden Gesundheitsschutz ableiten können. Aber das ist eine Auffassungsfrage. - Für Herrn Soell noch ganz kurz die Frage der Schutzpflicht und die Frage, ob in Leitsatz 12 richtig nur auf erhebliche Gesundheitsbeschränkungen abgestellt wird. Bisher hat das Bundesverfassungsgericht die Schutzpflicht immer nur für das Leben - bei § 218, im Schleyer-Fall usw. - bemüht, und ich meine gefahrlos sagen zu können: für erhebliche Gesundheitsbeschränkungen. Ob es weiter geht und ob auch für Belästigungen die Schutzpflicht aus Art. 2 II GG herzuleiten ist, war mir doch zweifelhaft; deshalb war ich etwas zurückhaltend.

Herrn Götz bin ich sehr dankbar für den Hinweis, wie sehr wir vielleicht doch hier einen autonomen Bereich erkämpfen können, wenn auch Herr Bachof Wasser in den Wein meiner Hoffnungen auch als Prozeßvertreter gegossen hat. - Ich stimme Herrn Papier darin zu, daß die Verwaltung eben durch die 
bürgerinitiierten Einzelpunkte sehr oft sich verzettelt und nicht dazu kommt, die eigentlichen, größeren Aufgaben anzugehen. Herr Häberle, das ist ein Grundsatzproblem überhaupt, ob die Gerichte nicht praktisch über alles entscheiden - das teilen die Juristen mit anderen Disziplinen, die gegebenenfalls auch selber darüber entscheiden und nicht wie wir Sachverständige hören; aber wir sind ja in die Notwendigkeit gebracht, über Verwaltungsakte $\mathrm{zu}$ entscheiden und die Kompetenz kann nicht zweifelhaft sein.

Herr Blümel, die 90 Seiten und die 12 Bände bewegen mich doch noch zu einer Bemerkung, die sicherlich nicht auf die Planungsentscheidungen in diesen 12 Bänden geht, sondern auch auf die Genehmigungen: Auch die Genehmigungen haben diesen Umfang, und ich meine, sie sind einfach zu weit. Es wird viel zu vieles in die Genehmigungen hineingeschrieben, was da schlicht nicht hineingehört. Es ist nicht erforderlich, gesetzliche Verpflichtungen jeweiliger Genehmigungsinhaber auch noch alle zu wiederholen: das ist deren Sache. Es werden die Ziele hineingeschrieben in Form von Auflagen, und wie die Genehmigungsinhaber die erfüllen, das mögen sie gegebenenfalls nachweisen im Betriebshandbuch oder sonstwie, aber das gehört nicht alles in die Genehmigungen. Die Praxis führt dazu, da $B$ man, wenn man von einer Hundebude in einer Anlage ein Dach auswechselt, das ohne Genehmigung nicht mehr darf, und wenn man es doch tut, macht man sich strafbar.

Ich muß an diesem Punkt nun Herrn Suhrs Frage aufgreifen und weiß, daß das eine sehr empfindliche Stelle ist. Herr Suhr: Dennoch, es geht darum, ob eine auch in einer Genehmigung nicht verbotene Einwirkung dem Staat als Eingriff zugerechnet wird. Sie drehen es etwas um, aber ich darf Sie in drei Stufen doch zu meinem Verständnis führen. Wenn wir eine gesetzliche Beschränkung etwa des Auswurfes von Rauchgasen aus Ihrer oder meiner Heizölanlage haben, dann macht sich der Staat nicht den Rest des Auswurfes zu eigen als Begriff — das bleibt trotzdem mein Eingriff! Zweitens: Wenn der Staat lediglich nach Polizeirecht eine Aufsicht führt und nur eingreift, wo ihm das notwendig erscheint, dann sind alle die Fälle, in denen er nicht eingreift, gegenüber denjenigen, zu deren Gunsten er eingreifen würde, auch kein Eingriff. Wenn Sie nun das Aufsichtsmittel umkehren und es liegt ein Verbot mit Erlaubnisvorbehalt vor: Der Staat genehmigt Ihr Kraftfahrzeug, Sie dürfen ohne eine Genehmigung nicht Auto fahren; in dem Augenblick, in dem Sie die Genehmigung erhalten, wird aber der Schaden, den Sie vielleicht mit Ihrem Fahrzeug anrichten, nicht zu einem staatlichen Eingriff. Auch der Schaden aus einer ge- 
nehmigten Tätigkeit kann nicht dem Staat als Schädiger zugerechnet werden.

Die Frage des Gleichheitssatzes, Herr Zacher, ist nicht so einfach von mir aus angefaßt. Ich meine, daß wir nicht die einzelnen Eingriffe derart vergleichen können, weil wir bisher einen Zustand haben, der keineswegs befriedigend ist. Wir können auch kaum sagen: Weil ein anderer das noch darf, darf man gegen den einen nicht einschreiten. Dann würden wir überhaupt zu keiner Verbesserung der Umweltlagen kommen können. Der Gleichheitssatz wird wirklich erst interessant in dem Punkt, wo wir einem befriedigenden Zustand nahe sind. Ich habe da nur ein Beispiel gebracht der ganz engen Vergleichbarkeit: Zwei Kraftwerke mit 900 Megawatt Leistung, - das eine ein Kohlekraftwerk, das andere ein Kernkraftwerk: Wenn man sagt: Das macht nichts, daß das Kohlekraftwerk im laufenden Betrieb mit der Abluft radioaktive Stoffe emittiert, die nach dem Rechenverfahren zu einer hundertfachen Strahlenbelastung führen, dann kann man von dem Kernkraftwerk eine weitere Reduzierung der Abgaben nicht mehr verlangen. In Extremfällen, wenn Evidenz vorliegt, ist hier der Gleichheitssatz verletzt. Sonst würde ich damit vorläufig noch vorsichtig sein.

Ich bin - zum Schluß - sehr dankbar, Herr Salzwedel, für die Frage und den ganzen Komplex der Diskussion, die eben von Herrn Saladin bis zu Herrn Barbey zu den Leitsätzen 21, 22 geführt ist. Ich darf zunächst Herrn Salzwedel bitten, mir zuzugeben, daß meine These 22 nur zu verstehen ist im Sinne dessen, was Herr Bachof auch gesagt hat: Die Entscheidung über Vorsorgemaßnahmen jenseits der individuellen Gefahrenschwelle soll von den Gerichten auf die politisch verantwortli-chen Gewalten zurückverlagert werden. Damit wird nicht in Frage gestellt, daß im Allgemeininteresse eine weitergehende Vorsorge und auch eine Emissionsbeschränkung von dem $\mathrm{Ge}-$ nehmigungs- und Aufsichtsbehörden zu fordern ist. - $\mathrm{Zu}$ Ihrem zweiten Punkt kann ich nur sagen: Ihr Wort ... in der Gerichte Ohr. Sie sagen: Kein Mensch wird den Emissionswerten nachbarschützenden Charakter beilegen, doch z. B. das OVG Lüneburg tut das: In einem Urteil vom 5. 7.1978 begründet es die Zulässigkeit einer Klage eines Fischers wegen einer Wassererwärmung von $1,7^{\circ} \mathrm{K}$ auf dem Wege über $\S 4 \mathrm{WHG}$ - und das Bundesverwaltungsgericht hat mit Beschluß vom 8. 3. 1979 die Revision des Fischers zugelassen, weil die $1,7^{\circ}$ nicht sorgfältig genug errechnet sein mögen. Im übrigen bin ich ganz Ihrer Auffassung. Herrn Saladin und Herrn Steiger möchte ich noch das sagen: Es muß der Raum dafür da sein, daß wir den Um- 
weltstandard jenseits der Gefahrenschwelle für den einzelnen Bürger verbessern - das im Allgemeininteresse. Aber angesichts der Gefahr - die gerade die Länder befürchten -, daß neue Werte in die Hand der gerichtlichen Auslegung fallen und sich dann im Ergebnis wieder auf ein Hundertstel oder Fünfzigstel ungefähr der gesetzten Werte einspielen, bewegt sich nichts. Erst wenn man sagt: Die festgesetzten Werte gelten dann wirklich - nämlich im Allgemeniinteresse - und es kann natürlich dann der betroffene Adressat sich dagegen wehren, erst dann würden wir wieder eine Verbesserung in der wirklichen Risikovorsorge voranbringen können. Damit bin ich mit meinen Sachgesprächen zu Ende.

Ich darf mich gleichermaßen wie Herr Hoppe herzlich bedanken, mich ihm voll anschließen. Ich darf zwei Ergänzungen vorbringen: Zunächst danke ich all denen, die mich unterstützt haben, all denen, die mir geschrieben haben und mir ihre Sonderdrucke entsprechend zugesandt haben. Ich darf auch noch einmal dem Vorstand sehr danken! Wir sind zuweilen in der Gefahr, uns von den Alltagsaufgaben und den kleinen wichtigen Geschäftigkeiten gefangennehmen zu lassen und uns irgendwo zu zerreiben. $\mathrm{Daß}$ man einmal so richtig gezwungen wird, Schularbeiten zu machen, das ist doch auch wiederum ein sehr beglückendes Gefühl - und dafür insbesondere möchte ich mich beim Vorstand bedanken!

Vorsitzender: Meine Herren, ich darf damit die wissenschaftliche Aussprache des heutigen Tages schließen. Namens des Vorstandes möchte ich vor allem beiden Referenten, Herrn Rauschning und Herrn Hoppe, noch einmal sehr herzlich für ihre eindrucksvollen Referate danken. Mein Dank gilt des weiteren den Herren Kollegen Wenger und Wildhaber für ihre informativen Berichte zur Situation in Österreich und in der Schweiz. Mein Dank gilt schließlich Ihnen allen für diese so außerordentlich anregende und, wie ich meine, in vielfältiger Weise weiterführende Diskussion. 
